\title{
Protecting across borders
}

Citation for published version (APA):

Serra Mingot, E. (2018). Protecting across borders: Sudanese families across the Netherlands, the UK and Sudan. [Doctoral Thesis, Maastricht University, Aix-Marseille University]. Datawyse / Universitaire Pers Maastricht. https://doi.org/10.26481/dis.20181217em

Document status and date:

Published: 01/01/2018

DOI:

10.26481/dis.20181217em

Document Version:

Publisher's PDF, also known as Version of record

\section{Please check the document version of this publication:}

- A submitted manuscript is the version of the article upon submission and before peer-review. There can be important differences between the submitted version and the official published version of record.

People interested in the research are advised to contact the author for the final version of the publication, or visit the DOI to the publisher's website.

- The final author version and the galley proof are versions of the publication after peer review.

- The final published version features the final layout of the paper including the volume, issue and page numbers.

Link to publication

\footnotetext{
General rights rights.

- You may freely distribute the URL identifying the publication in the public portal. please follow below link for the End User Agreement:

www.umlib.nl/taverne-license

Take down policy

If you believe that this document breaches copyright please contact us at:

repository@maastrichtuniversity.nl

providing details and we will investigate your claim.
}

Copyright and moral rights for the publications made accessible in the public portal are retained by the authors and/or other copyright owners and it is a condition of accessing publications that users recognise and abide by the legal requirements associated with these

- Users may download and print one copy of any publication from the public portal for the purpose of private study or research.

- You may not further distribute the material or use it for any profit-making activity or commercial gain

If the publication is distributed under the terms of Article $25 \mathrm{fa}$ of the Dutch Copyright Act, indicated by the "Taverne" license above, 


\section{Protecting across Borders}

Sudanese Families across the Netherlands, the UK and Sudan 
(C) copyright Ester Serra Mingot, Maastricht 2018

Printing: Datawyse | Universitaire Pers Maastricht

Cover design and layout: Ester Serra Mingot and Marwin Schmitt

ISBN 978-94-6380-129-4

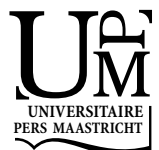

All rights reserved. No part of this publication may be reproduced, stored in a retrieval system or transmitted, in any form or by any means, electronic, mechanical, photocopying, recording or otherwise, without prior permission of the author or the copyright-owning journals for previous published chapters. 


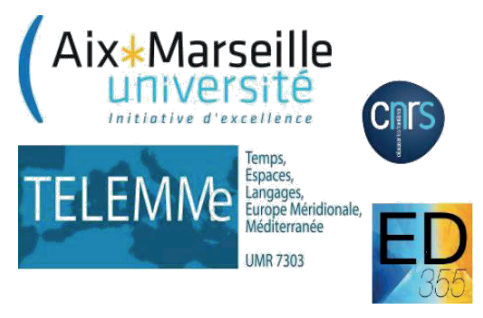

Aix-Marseille Université

Ecole Doctorale 355 «Espaces, cultures, Sociétés»

Laboratoire TELEMMe - UMR7303

\section{Maastricht University}

Maastricht University

Faculty of Arts and Social Sciences

Department of Society Studies

\section{Protecting across Borders}

\section{Sudanese Families across the Netherlands, the UK and Sudan}

\section{DISSERTATION/THÈSE DE DOCTORAT}

to obtain the degree of Doctor

at Maastricht University, on the authority of the Rector Magnificus, Prof. dr.

Rianne Letschert, in accordance with the decision of the Board of Deans, and

pour obtenir le diplôme de Doctorat en Géographie de l'Université d'Aix Marseille at Aix-Marseille University, on the authority of the President Prof. dr. Yvon

Berland,

to be defended in public

on Monday, 17 December 2018 at 12:00h

by

Ester SERRA MINGOT 


\section{Assessment Committee:}

Prof. dr. Maarten Vink (Chair), Professor of Political Sociology (Maastricht University)

Prof. dr. Anna Amelina, Professor of Intercultural Studies (Brandenburg University of Technology)

Dr. Myriam Catusse, Chargée de recherches au CNRS (IREMAM, Aix Marseille University).

Prof. dr. Hildegard Schneider, Professor of European Union Law (Maastricht University) Prof. dr. Wolfgang Schröer, Professor of Social and Organisational Education (Hildesheim University)

\section{Supervisors:}

Prof. dr. Valentina Mazzucato, Professor of Globalisation and Development (Maastricht University)

Prof. dr. Virginie Baby-Collin, Professor of Geography (Aix Marseille University)

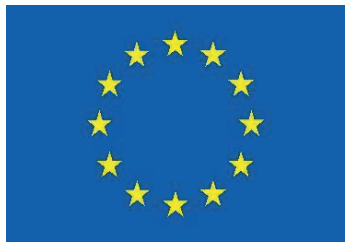

The research conducted for this dissertation is part of the 'Transnational Migration, Citizenship and the Circulation of Rights and Responsibilities' (TRANSMIC) project, funded by the European Union under the FP7-PEOPLE-2013-ITN call and is part of the Marie Curie Actions-Initial Training Networks funding scheme (Project Number 60847). For more details, please visit the project's website: https://law.maastrichtuniversity.nl/transmic/ 


\section{ACKNOWLEDGEMENTS}

Back in 2010, after three years of recurring unemployment spells, a myriad of short term contracts, informal jobs and unpaid internships, I decided to go back to university and do a Masters. Which master it was, I didn't care so much. My goal back then was far from ending up doing a $\mathrm{PhD}$, but to be part of 'The System' again. With all my family unemployed and not being entitled to receive unemployment benefits or social assistance, my plan was clear: go back to university, become a student again, and gain access to a substantial scholarship that would cover for my yearly living expenses. To obtain the scholarship, however, I needed to provide a 'formal' rent contract, which I didn't have. Fortunately, a friend offered to draft this contract for me, even though I never actually lived there. Although 'in paper' I was

paying a rent, 'in reality' I had enrolled in a social programme whereby, I ended up living free of charge with Carmen, a 91-year-old lady, who faced some difficulties living alone. In return, I kept her company every evening and helped her with the house chores. It was, indeed, a perfect symbioses, which not only benefitted Carmen and me, but also my little brother, who, for some sort of bureaucratic issue, that year had been denied his scholarship. Thus, part of the 'formal' scholarship money that I had saved by 'informally' living with Carmen went to pay for part of my brother's studies that year. Throughout different stages of my life I have found myself in situations in which, only thanks to the invaluable help of family and friends, I was able to navigate a system that was not always able to protect. To all of them, thank you.

In fact, I don't think I would be here today were it not for my family; my big and small family, as my respondents would say. Nada de esto hubiera sido posible sin vuestra ayuda, Joan, mama, papa y yayos (aunque ya no estén, también jugaron un papel muy importante y ahora estarían orgullosos). Joan, mama y papa, siempre habéis estado ahí en todas y cada una de las crisis de mi vida (y ha habido unas cuantas...). A pesar de mis cabreos y la mala leche, siempre me habéis ayudado a seguir adelante y me habéis enseñado con palabras y obras una de las cosas más importantes de la vida: "¡No hay que rendirse nunca! A luchar, y pa alante, como los de Alicante!" Nadie podría haberme enseñado mejor lo que significa ser familia, para lo bueno y para lo malo. Mama y papa, nunca hubiera podido tener mejores profesores. Mama, gràcies per tots els matins que t'alçaves amb mi a repassar la lliçó del cole, per fer-me repetir les coses fins que estigueren perfectes, per apoyar-me a viatjar i estudiar fora, i per sempre voler lo millor per a mi i Joan. Papa, gracias por haberme enseñado lo que no se aprende en colegio (imagínate qué hubiera sido de mí de no haber sabido ir en bici en Holanda), por tu trabajo, y por haberme empujado (por alguna extraña razón) a estudiar árabe. Y por supuesto, Joan (Joancito), gracias por ser como eres, por conocerme tan bien, por ser tan buena persona (y hacerme ser mejor persona a mí también), por las mejores postales de Navidad de la historia, por 
las inigualables sesiones de maquillaje y fotografía, y por todos los momentos que hemos compartido juntos; nunca hubiese imaginado poder tener un hermano como tú.

Probably, I would have never thought of doing a $\mathrm{PhD}$ were it not for Marwin. Despite my being difficult, you've always been there in every single step. Thank you for patiently listening to every fuzzy idea for a new paper, for always giving me your feedback, and for your amazing photo-shopping skills that led to this super cool book cover! But most of all, thank you for always being there to support me, for waiting for me at home after a long and lousy day with a delicious meal and a glass of wine, and for always making me feel better when I'm restless and mad at the whole wide world. Thank you for sticking by me all these years.

I will be forever grateful to my supervisor, Valentina Mazzucato, not only for her guidance, advice and support during the whole $\mathrm{PhD}$, but also for trusting me from the beginning, for seeing in me the researcher I didn't even know it existed. You have been the supervisor everyone would want, a supervisor with whom I could discuss and talk openly about the different issues that emerged during this $\mathrm{PhD}$. Thank you for your expertise and for making me the researcher I am now. I also want to express my gratitude to my second supervisor, Viginie Baby-Collin, for her feedback and support throughout the way, not only in the academic issues but also in the complicated bureaucracy of doing a joint PhD! Thank you for always being ready to help.

This research was only possible thanks to my respondents. I cannot even start to express my gratitude to all the Sudanese people who agreed to do my never-ending interviews, who opened me the door to their homes, to their families, to their whole lives, asking nothing in return. Throughout my life I have travelled to many different places, met diverse people, but never have I ever encountered peoples as nice, warm, caring, humble and generous as the Sudanese. I will always be indebted with all my families. Besides my respondents, I want to thank Sarah and Selma, my host-sisters in Sudan, you were really like sisters, and Sarah, I'd always be thankful for your saving me from the muasalat experience so many mornings! Thank you to your dad, Dr. Musa, for sharing his knowledge with me, and also to your lovely mum, Najwa, for being so caring and lovely and always asking me to come and share meals with you. A big thank you to you, my cute, sweet and strong Amal; you barely knew me and you offered me your friendship without questions. And of course, thank you, Amin, for your valuable thoughts, your proofreading skills, and your friendship over, how many, 6 years?

I don't think I could have managed to cope so well during this whole journey without one of the best persons I know and also my paranympth today, Karlijn. During these years, you've been much more than a roommate. You've been a true and generous friend, always there to listen, to give advice, to help, to vent all sort of tensions in 'the box' and to chill over a glass of wine and a good series (I really miss that now...). Karlijn, you've been key in all this. To Clotilde, my other paranymph, 
I also want to say how grateful I am that we met and became such good friends, always being there to discuss and give advice on work, family and men! I was great to go through this whole $\mathrm{PhD}$ experience together.

I would like to thank the European Commission for funding my research through the TRANSMIC project. Thank you also to the whole 'TRANSMIC family', especially Polina, with whom I shared quite some stressful moments.

In Maastricht University, I want to express my gratitude to my colleagues Joan, Marloes, Karlien, Maria Vivas, Lauren, Bilisuma, Onalia, Sarah, Laura and Simone, both for their feedback and their friendship. Thank you also to Valentina and Floris, my office mates with whom I have shared quite a lot of good and bad days. I would especially like to thank Sabine and Cindy, for always looking for our best, for being willing to help and doing an amazing job in every imaginable way.

I also want to thank the members of the assessment committee: Prof. $\mathrm{dr}$ Maarten Vink, Prof. dr Anna Amelina, Dr Myriam Catusse, Prof. dr Hildegard Schneider, Prof. dr Wolfgang Schröer, and Dr Alice Franck, for reading my dissertation and providing their valuable feedback.

Besides Maastricht and Aix-Marseille University, other institutions were part of this research. I would like to express my gratitude to the CEDEJ-Khartoum, and especially to Alice Franck, for their support in conducting my fieldwork in Sudan. Thank you also to Mai, Mohamed, and Mohamed 'the driver', for your endless kindness and support. I also have to thank Birmingham University, in particular Jenny Phillimore, for offering me a place to set my basis during my fieldwork in the $\mathrm{UK}$, and also for putting me in contact with so many people who helped me in this research. In the UK, I would also like to thank some wonderful people working to help others in different charities: Helena, Fahira, and Phil; and in the Netherlands, I would like to thank Christa and Pieter for your support and willingness to help.

I am a very fortunate person for having amazing friends all over the world. We may not see each other much, but you've always been there, caring and listening. Dear Tony, Diana, Beth, Vicenta, Tina and the Angells, thank you for being part of my life and always being there for me. Tony, Beth and Glenn, thank you for agreeing to be the best editing team one could have. I owe you! I want to thank Sonia for your unexpected friendship, and of course, I really want to say a big thank you to my Irish Dancing team! Celestine, thank you for being such a good teacher and for making me such a good dancer! Thank you Noor, Miri and Laura for all the fun times together, all the dancing, and laughing (and crying), and especially for convincing me to take part in competitions! These were some of the few moments in the last four years that made me forget about the $\mathrm{PhD}$. 


\section{TABLE OF CONTENTS}

Acknowledgements .................................................................... I

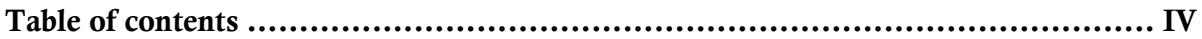

CHAPTER 1 - Introduction............................................................ 1

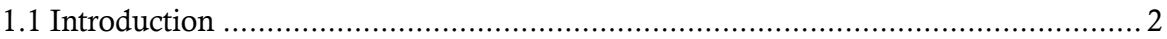

1.2 Navigating the social protections of transnational families ................................. 6

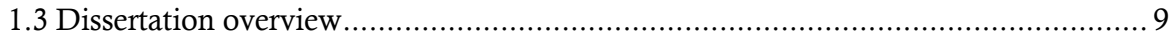

CHAPTER 2 - Literature review: Migration and transnational social protection .......13

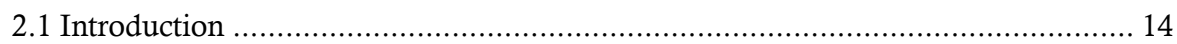

2.2 Migration and social protection: An overview of concepts and previous studies ..... 14

2.2.1 Migration and social protection .................................................................. 17

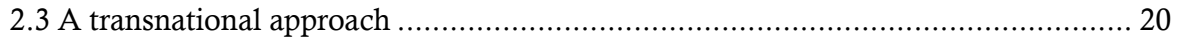

2.4 Transnational social protection: Assemblages and resource environments.............. 22

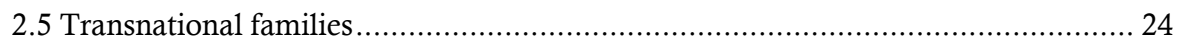

2.5.1 Transnational social protection arrangements within extended family networks 25

2.5.1.1 Caring in transnational social protection arrangements ............................ 26

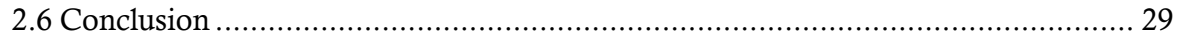

CHAPTER 3 - Data and methodology ..................................................33

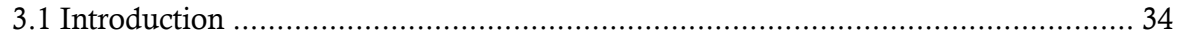

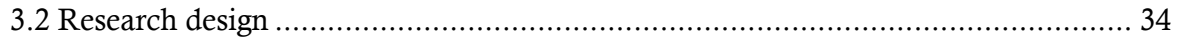

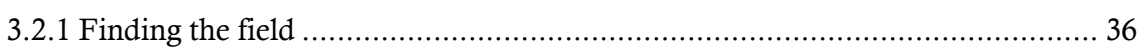

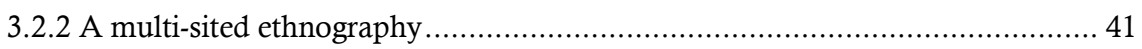

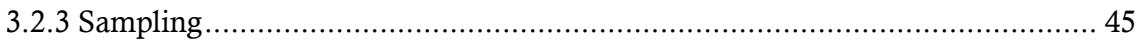

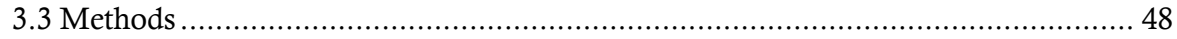

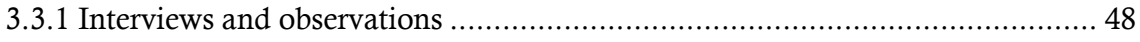

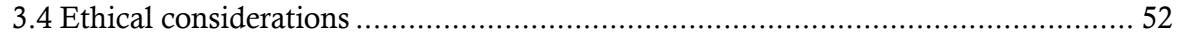

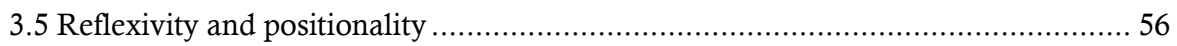

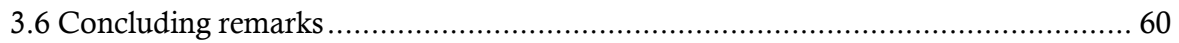

CHAPTER 4 - Migration and social protection in Sudan ............................63

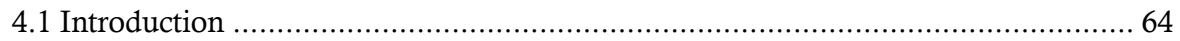

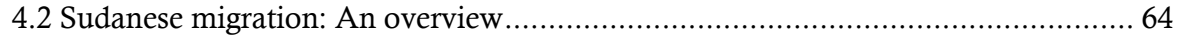

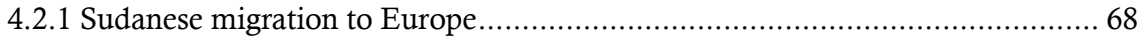

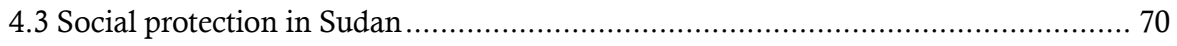

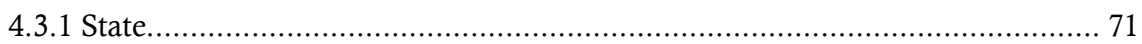

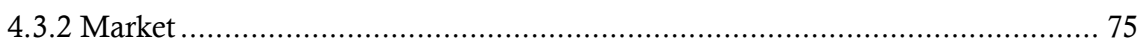

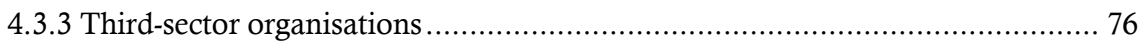




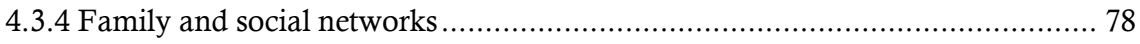

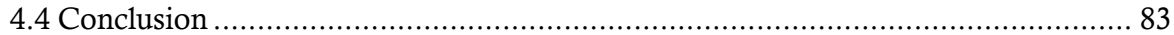

CHAPTER 5 - Migration and social security in the Netherlands and the UK............85

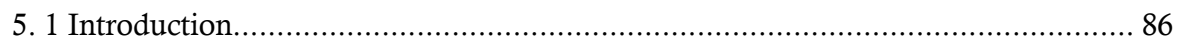

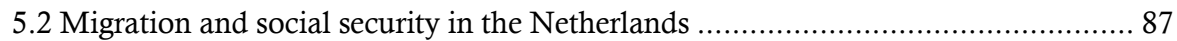

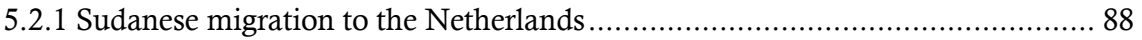

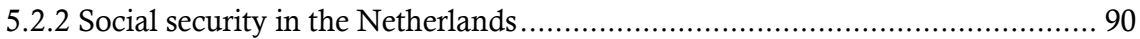

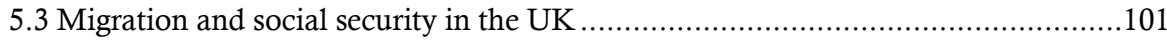

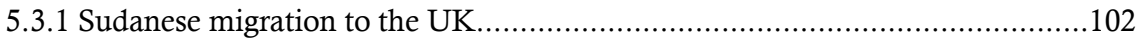

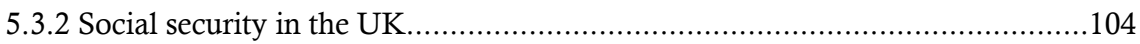

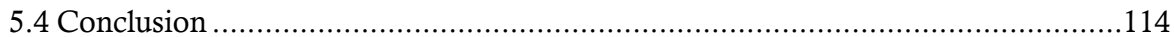

CHAPTER 6 - Mobile populations in immobile welfare systems: A typology of institutions providing social welfare and protection within a mobility framework .... 115

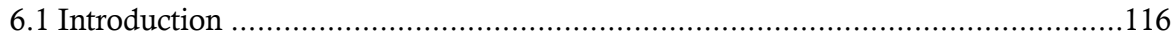

6.2 Social protection across borders: Between formality and informality....................118

6.2.1 Formal social protection across borders ….............................................119

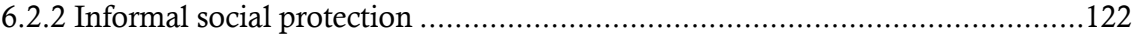

6.2.3 Either formal or informal? Moving beyond the dichotomy .........................123

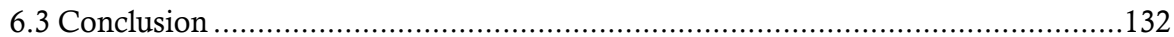

CHAPTER 7 - Providing social protection to mobile populations: Symbiotic relationships between migrants and welfare institutions............................ 135

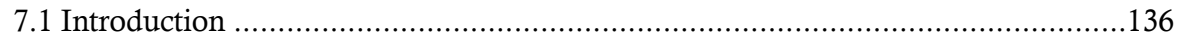

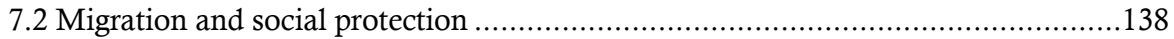

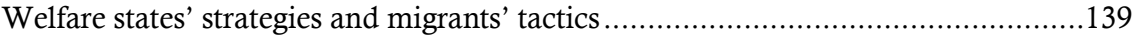

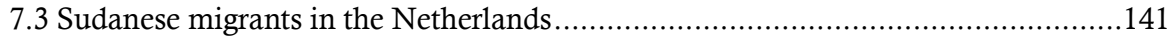

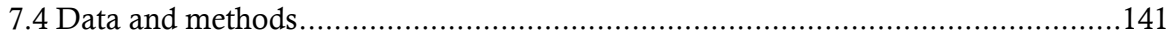

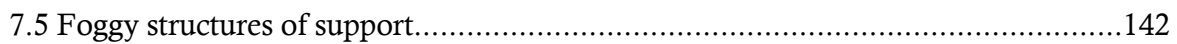

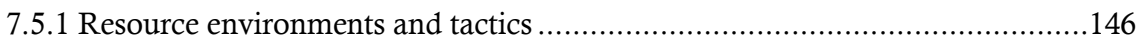

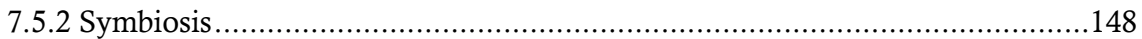

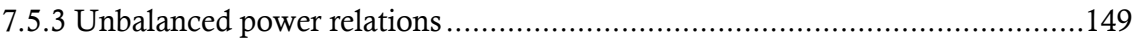

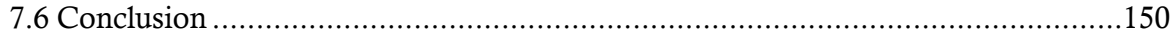

CHAPTER 8 - Moving for a 'better welfare'? The case of transnational Sudanese

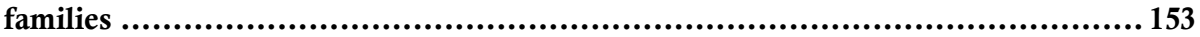

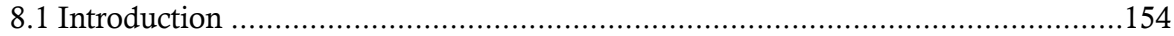

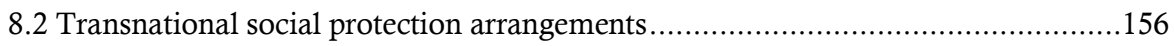

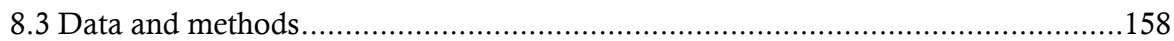

8.4 A transnational family's resource environment ...................................................159

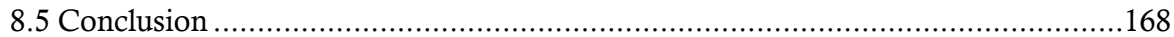


CHAPTER 9 - The gendered burden of care-receiving in transnational social protection arrangements. The case of Sudanese families ........................................... 173

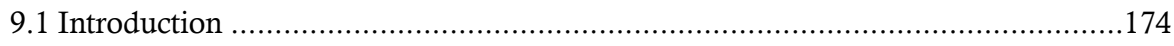

9.2 Care-receiving in transnational social protection arrangements..........................176

9.2.1 Care as a culturally embedded practice: Women's bodies and social protection in

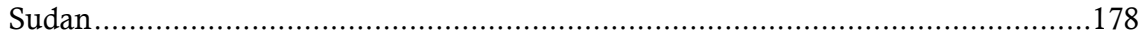

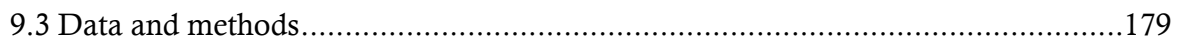

9.4 Protective care-receiving in a transnational context..............................................180

9.4.1 Perceiving care across different social protection contexts ...........................183

9.4.2 Circumventing burdensome care and avoiding conflict .............................185

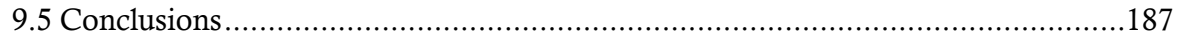

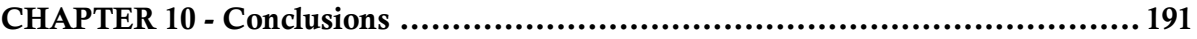

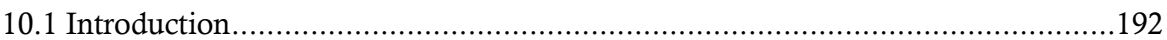

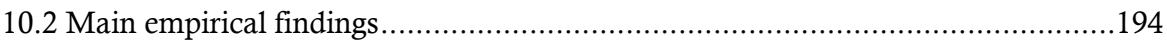

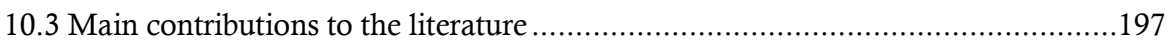

10.4 Limitations of this research and avenues for further research. .........................204

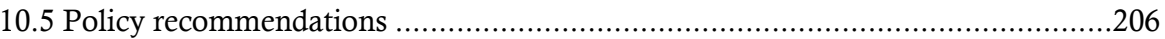

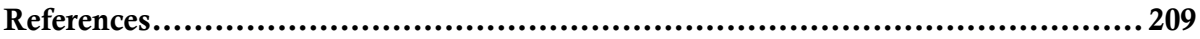

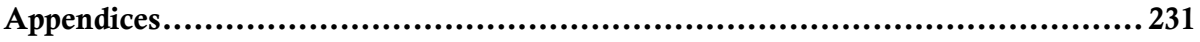

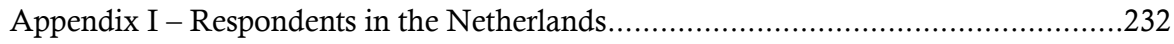

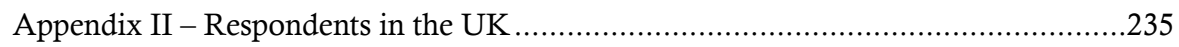

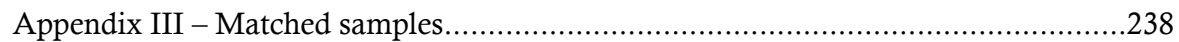

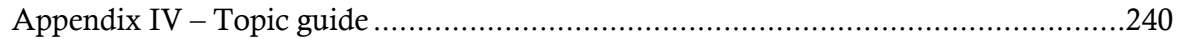

Appendix V - Information brochure for participants (English).................................247

Information brochure for participants (Arabic version) ….................................250

Summary in English ............................................................ 253

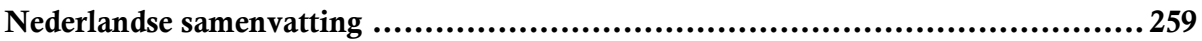

Résumé de la thèse de doctorat en français ......................................... 267

Valorisation addendum ...................................................................... 275

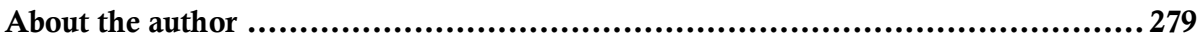




\section{Map of Sudan}

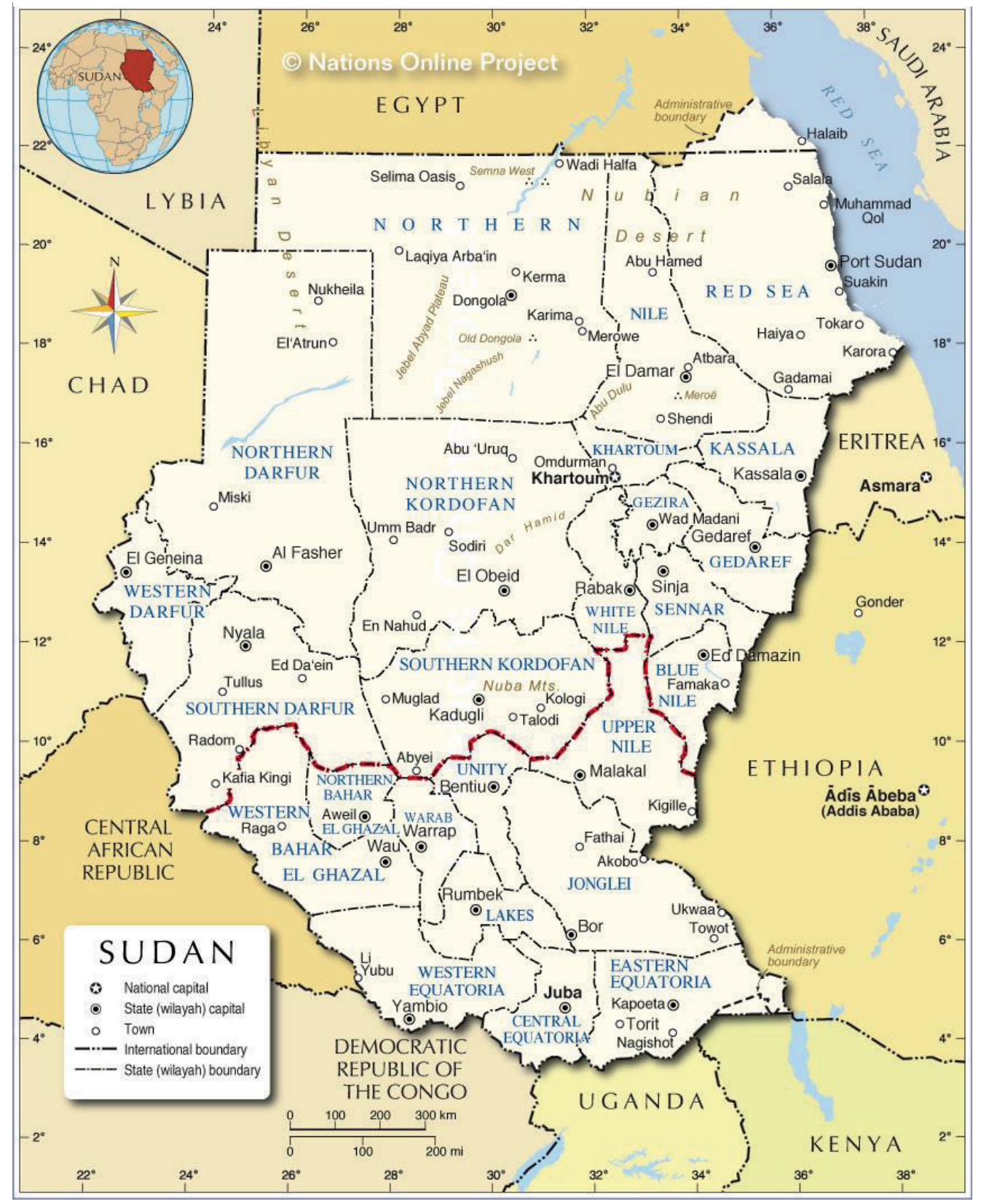

Source: Nations Online Project 2018 

CHAPTER 1

INTRODUCTION 


\subsection{Introduction}

I met Hind in Birmingham in the summer of 2016. She was a 40-year-old Dutch-Sudanese woman, mother of three, with an undergraduate degree in veterinary science and working at the time, as a volunteer teaching assistant in a British primary school. Like her older brother and many other Sudanese, Hind had arrived in the Netherlands as an asylum seeker in the late 1990s alone and in search of a better life. Soon after arriving and coping with the harassment from her male counterparts in the asylum-seeker's camp, Hind met and quickly married her current husband, Zanoon, also a Sudanese asylum seeker. After one year, they both obtained their refugee status and moved together to a small Dutch city, where they had two children. In 2005, however, Zanoon's mother became seriously ill in Sudan. Facing the restrictive migration regulations at the time and the resulting impossibility of bringing his mother to the Netherlands, the whole family moved to Sudan to take care of her. Despite the hardships of moving and settling in Sudan with two little children and an old sick woman, Hind was happy she had brought her children along. For Hind, it was important that they saw how she and her husband took care of their grandmother, because she hoped that would teach them to take care of their own parents, Hind and Zanoon, when they grew old and needed care. Nevertheless, after spending two years in Sudan, where Zanoon was the main breadwinner and Hind the main caregiver, Hind realised her children were struggling too much both in terms of adaptation and educational achievements. Concerned with her children's future, Hind, Zanoon and their children moved back to Europe.

Yet, instead of returning to the Netherlands, they moved to the UK. As it happened, the British regulations at the time allowed Zanoon to bring over his mother to receive the healthcare she needed, which had not been possible in the Netherlands. At the same time, Hind's brother had also left the Netherlands and moved to the UK, and for Hind, being close to her family was very important. Moreover, like her brother and other Dutch-Sudanese, Hind felt that the educational opportunities for her children in the UK were better than in the Netherlands. Although Hind held warm memories of her life in the Netherlands and she cherished many of the values of the country, she was concerned that the Dutch educational system would not give her children the same educational opportunities - and therefore a good professional future - as in the UK.

\section{$\cos 80$}

The story of Hind and her family is not unique. In fact, the multiple social protection challenges they face throughout their lives relate to those of many other families whose members live in more than one nation state. Migration often presents migrants, especially those moving from the Global South to the Global North, with particular dilemmas. In our current globalised world, with new and increasingly frequent flows of people, goods and information, more and more people choose or are pushed to live across national borders, developing thus attachments and responsibilities in more than one nation-state-for example, by earning their livelihoods, making housing investments, caring for family members, or saving for their old-age in different countries (Levitt, Lloyd, Mueller, \& Viterna, 2017). Yet, the traditional formal social protection systems have been envisaged to cater for sedentary populations, tied to one single 
nation-state. This becomes problematic for people with increasingly mobile lifestyles and responsibilities that span nation-state borders (Bilecen \& Barglowski, 2015; Faist, 2013; Levitt et al., 2017). For instance, when moving to another country, any contributions made to the formal social protection systems in the migrant's country of origin might cease to exist (and vice versa). At the same time, newly arrived migrants often have to wait several years before having access, if at all, to formal social protection in the host country (Avato, Koettl, \& Sabates-Wheeler, 2009). Restrictive legislations, administrative regulations or the lack of coordination between countries are some of the hurdles that limit migrants' access to social protection in either their country of residence or origin (ILO, 2017).

Like Hind and her family, many Sudanese arrive in Europe in search of a better life. Many arrive as asylum seekers, while a few of them do so as students or highlyskilled labour migrants. Throughout the years, some return to Sudan, others become undocumented, while some others obtain refugee status and become European citizens. Among the latter, many settle and remain in the host countries of which they are citizens, but others decide to move onwards to other EU countries or elsewhere as European labour migrants. As the migrants' legal statuses change during all these different stages, so do their entitlements to formal social protection provisions. Yet, despite the shifting migration statuses and the different rights and obligations attached to them, most of these people are bound to their families 'back home' through a series of mutual duties. In fact, international migration does not necessarily sever the obligations and responsibilities between family members living apart (Baldassar, Baldock, \& Wilding, 2007; Bryceson \& Vuorela, 2002). On the contrary, rather than an individual project of income maximization in response to emergencies, migration is often considered a family livelihood strategy or social protection mechanism to diversify income sources, face socioeconomic constraints, and guarantee the wellbeing of the different family members, now and in the future (Baldassar et al., 2007; Mazzucato \& Schans, 2011; Sabates-Wheeler \& Waite, 2003; Stark \& Levhari, 1982; Stark \& Lucas, 1988).

Nevertheless, migrants who want to ensure their own and their families' social protection might face different challenges. As Hind's story shows, even when migrants enjoy full access to formal social protection provisions in the receiving country, migrants are often responsible for providing for the needs of their families 'back home', who might not be covered by the social protection system (if any) in their origin countries. At the global level, legal provisions regarding social protection rights for international migrants and their families remain scarce (Sabates-Wheeler \& Feldman, 2011). In the past decades, bilateral social-security agreements between migrant-sending and migrantreceiving countries have become an important instrument to guarantee the portability of social security benefits-such as healthcare or pensions-for internationally mobile workers. Yet, very few developing countries are part of these agreements and only about $23 \%$ of international migrants profit from them (Holzmann, 2016). At the time of conducting this research, Sudan, which is the focus of this dissertation, was not part of 
any of these agreements with EU (van Panhuys, Kazi-Aoul, \& Binette, 2017). Therefore, the current context of restrictive migration regimes and geographically-fixed national welfare ${ }^{1}$ systems often hinders the transnational character of migrants' lives.

Against this backdrop, migrants must then develop a series of strategies that encompass formal and informal elements from different institutions (e.g. the state, the markets, third-sector organisations or informal social networks) to cover for their own and/or their families' needs, which are often related to the provision and reception of care. As the vignette shows, the social protection needs of different family members frequently overlap and change over time. Under these circumstances, a myriad of factors (e.g. capacity to move, financial resources, social networks, gender or norms of intergenerational reciprocity, to name a few) shape the mechanisms guiding the access, circulation and coordination of different resources to cover for different but intertwined social protection needs, especially the provision of care. Indeed, as Hind's case illustrates, the care circulated within transnational family networks is a crucial element in transnational social protection (TSP) arrangements, based on a system of reciprocity between migrants and their families 'back home'. As a socio-culturally embedded practice, the care work circulating within families-including caregiving and carereceiving-highly depends on cultural notions of gender roles in the sending society, which not only determine who should provide care, but also how such care should be received. In fact, care may feel differently depending on the perspective of either the provider or the receiver. Despite the caregiver's good intentions, care might be experienced as a burden by the receiver, since the definition of 'need' might not equally satisfy both parties (Bondi, 2008; Locke, 2017). Indeed, agreeing on what 'need' means becomes more difficult in relationships with bigger differences in power (such as gender relations), particularly when such relationships take place across culturally and geographically distant places (Tronto, 1993).

Understanding how transnational families navigate different forms of social protection, locally and transnationally, is at the core of this dissertation. To do so, I chose to focus on the specific case of Sudanese migrants in the Netherlands and the UK, and their families back home. The Sudanese case is relevant for the study of TSP for two main reasons. First, the Sudanese constitute a relatively recent migrant group in Europe. In the Netherlands, for instance, while much research has been conducted on 'old migrant groups', such as the Moroccans (see Grillo and Mazzucato, 2008), only a few studies have focused on recent migrants from sub-Saharan Africa in Europe. This is an important gap in the literature, since new groups face different migration and receiving contexts, which might impact the manner in which they engage in different

\footnotetext{
${ }^{1}$ Social security and welfare are two concepts highly related to the support provided by the state. Social protection is a broader concept as it includes different mechanisms of social risk management provided not only at a public, but also at a private, community, and market level (Avato et al., 2009), in order to cope with the social risks, such as lack of employment, healthcare or education, which might hamper the realisation of life opportunities (Faist et al., 2014). I elaborate on these distinctions in Chapter 2.
} 
TSP practices (Chelpi-den Hamer \& Mazzucato, 2010; Grillo \& Mazzucato, 2008). Second, in terms of legal (e.g. documented labour migrants, refugees, asylum seekers or undocumented migrants) and socio-economic status, the Sudanese are a highly heterogeneous group (see Chapters 4 and 5 for further details), which allows for diversification in the sample, to better understand how social protection mechanisms are accessed by migrants of different legal and socio-economic statuses.

The selection of the UK and the Netherlands is based on three main reasons. First, as Hind's case illustrates, both countries have different welfare and migration policy systems, which helps to understand the role that policies have in the social protection arrangements that migrants devise. Second, the Sudanese community in the UK is bigger and older than in the Netherlands, which was expected to cast some light on the role of personal social networks. Finally, like in Hind's case, many Sudanese in the Netherlands have relatives and friends living in the UK, some of whom moved to the UK after living in the Netherlands for some time. This allowed me to address the social protection mechanisms across the borders of three nation states (i.e. Sudan, the Netherlands and the UK), and also to investigate the motivations triggering onward movements from the Netherlands to the UK.

Within this backdrop, this dissertation addresses the following research question: How do Sudanese migrants in the Netherlands and the UK and their families back home navigate their social protection, locally and across borders? To do so, this broader question is broken down into the following sub-questions, which are addressed in the three empirical chapters of this dissertation (Chapters 7-9):

1. How do migrants navigate formal state-bounded social protection provisions to informally provide for themselves or their families back home? And, in doing so, in which manners do both welfare-state institutions and migrants work together at the interstices of the formal and informal to cater to national and transnational social protection needs? (Chapter 7)

2. What kinds of considerations underlie the decisions of migrants and their families when moving to certain places to address social protection needs? Which are the mechanisms guiding the access, circulation and coordination of resources to cover for different but related social protection domains? (Chapter 8)

3. How do female care-receivers in transnational social protection arrangements circumvent the unwanted consequences of unsolicited care provided by their male relatives abroad? (Chapter 9)

To answer these questions, I conducted 14 months of multi-sited and partly matched-sample ethnography across the three contexts where the migrants and their families lived - the Netherlands, the UK and Sudan. Multi-sited research was conducted using semi-structured interviews, informal conversations and observations with 21 respondents in the Netherlands, 22 respondents in the UK and 19 of their family members in Sudan (see Chapter 3 for further details). This allowed me to understand the roles and guiding mechanisms of two key institutions in the provision of social 
protection: welfare and family. By conducting research with different family members across multiple locations, I could unpack the complexities of providing social protection across diverse contexts when resources are limited.

The following section elaborates on the previous research sub-questions, highlighting the scientific relevance of this thesis.

\subsection{Navigating the social protections of transnational families}

As the vignette above has shown, migrants might face different challenges to address their own and their families' social protection needs. To date, such challenges have been mostly addressed by three different bodies of literature: migration and social protection, TSP and transnational care. Traditionally scholars on migration and social protection have tended to focus on the individual migrant's access to formal social protection or welfare in the receiving countries in the Global North and its implications for the migrants' well-being (Avato, Koettl, \& Sabates-Wheeler, 2010; Baldwin-Edwards, 2004; Cuadra, 2012; Engbersen \& Broeders, 2011; Sainsbury, 2006). Although these studies acknowledge the importance of informal mechanisms of support, these are mainly conceived in terms of filling the gaps of the formal system (Amuedo-Dorantes \& Pozo, 2006; Avato et al., 2010). Social protection thus is usually defined in terms of either formal or informal support mechanisms for individual migrants in the receiving country, largely neglecting the role of the migrants' families and the sending context (Avato et al., 2010; Oduro, 2010).

Recently, transnational migration scholars have problematized such clear-cut distinction between the formal and informal dimensions of social protection, looking at the 'assemblages' or interrelations between formal and informal resources, where social actors constantly negotiate and combine the use of both provisions (Bilecen \& Barglowski, 2015). Moreover, TSP studies include both migrants and their nonmigrants families 'back home' (Levitt \& Jaworsky, 2007; Poeze, Dankyi, \& Mazzucato, 2017). As the New Economics of Labour Migration (NELM) studies have pointed out, migration is a social protection strategy orchestrated at a family level. Yet, the NELM's focus on economic remittances from the migrant to the family has obscured the myriad of relationships, inequalities and conflicts of interest related to aspects like gender, generation or age (de Haas and Fokkema, 2010), as well as the role of non-migrants as remittance senders to the migrant (see Mazzucato, 2011). Transnational approaches to migration and social protection have addressed these gaps by analysing the multiple family arrangements undertaken across national borders, (Baldassar \& Merla, 2014; Mazzucato, 2008c; Poeze et al., 2017), emphasising the previously neglected services that people 'back home' provide for migrants, especially when migrants do not have access formal social protection (Mazzucato, 2011).

Many social protection arrangements within transnational families are often related to the provision of care (Baldassar et al., 2007; Boccagni, 2013; Mazzucato, 2008c; Poeze et al., 2017). Yet, literature on social protection and migration has rarely 
incorporated the care-work involved in transnational families. Care has mainly been theorised within the field of 'transnational family studies' (e.g. Baldassar \& Merla, 2014), highlighting the circular character of care from the perspective of intra-familial duties and solidarities, which fluctuate over the life course within transnational family networks (Baldassar \& Merla, 2014; Hochschild, 2000; Hondagneu-Sotelo \& Avila, 1997; Mazzucato, 2008c; Parreñas, 2001; Poeze et al., 2017). Whereas the exchange of face-to-face care is not always possible in families whose members are dispersed across multiple locations, care work continues to be at the core of transnational families (Baldassar et al., 2007; Boccagni, 2015; Coe, 2011; Poeze et al., 2017).

Since the early 2000s, these bodies of literature have made invaluable contributions that help us understand the underpinnings of social protection for mobile populations from different perspectives. Yet, some gaps still remain. The following paragraphs point out to these gaps and the ways in which this dissertation aims to address them and contribute to the current literature on migration and TSP. First, although transnational scholars have analysed different aspects related to the care and social protection arrangements that families undertake across national borders from the perspective of intra-familial duties and solidarities (Baldassar \& Merla, 2014; Mazzucato, 2008c; Poeze et al., 2017), most of these studies gravitate around the nuclear family and more specifically around the parent-child dyad. In this study, however, the units of analysis are migrants and their extended families 'back home'. Understanding how social protection arrangements work beyond nuclear families is important because in many countries around the world, especially in those with weak welfare systems, such as Sudan, extended families continue to play a crucial role in the social protection and sustenance of individuals (see Chapter 4). Looking at migrants within their extended family networks allows me to contribute to the current literature by analysing how responsibilities and obligations span beyond parents and children, to include other extended family members like siblings, uncles or aunts. Chapters 8 and 9 look into this aspect in depth.

Second, rather than focusing on labour and/or undocumented migrants, who have often been the main focus of research on migration and social protection (Bilecen, 2013; Boccagni, 2015; Cuadra, 2012; Dankyi, Mazzucato, \& Manuh, 2017; Engbersen \& Broeders, 2011; Sienkiewicz, Sadovskaya, \& Amelina, 2015; Vivas-Romero, 2017), in this dissertation I include migrants with different legal statuses, encompassing: labour migrants, refugees, asylum seekers, or undocumented migrants. As illustrated in the opening vignette, migrants' social protection needs and legal statuses change over time. Asylum seekers might eventually obtain the refugee status, but also become undocumented migrants. If they become refugees, many of them obtain the citizenship of the receiving country after some years, and some might become labour migrants if they decide to move somewhere else. In all these different stages, people's access to social protection varies. As the empirical chapters of this thesis show, by including migrants with different legal statuses I could observe common aspects in the social protection needs and the strategies to address them, which expand beyond migration 
labels and are strongly based on the principle of reciprocity. Therefore, throughout this dissertation I use the term migrant to refer to people who left their country of origin and are now living somewhere else. Only when the migration status is crucial to understand certain arguments - e.g. the lack of access to some form of social protection-do I make use of the specific word that determines the legal status of the individuals involved.

Third, the transnational approach and the multi-sited matched-sample design of this research, allowed me to incorporate data from the migrants and their non-migrant families, across sending and receiving countries. By investigating one sending (Sudan) and two different receiving contexts (the Netherlands and the UK), this thesis allows for a comprehensive understanding of the ways in which contexts shape social protection arrangements, locally and transnationally. In doing so, this thesis questions the meaning of social protection, as understood in the different contexts; in Sudan-were the role of the state is almost non-existent-and in Europe-where the state is the main provider of social protection for its citizens. Unlike the traditional Western clear-cut compartmentalisation of social protection domains (e.g. old-age, survivors, incapacity, health, family, active labour market programmes, unemployment, housing and education), in contexts with weak welfare states, informal social protection systems result in highly intertwined domains. In the case of transnational families, where elements of the formal welfare system in the receiving country combine with traditional informal systems of support and reciprocity from their country of origin, it is important to understand how such intertwinedness takes places across different contexts and social protection domains. Chapter 8 delves specifically into this issue.

In addition to this, while currently many studies adopt a transnational lens, very little research is conducted in a multi-sited manner with matched samples, particularly in the field of social protection (with some notable exceptions, see McDonald and Valenzuela, 2012; Osili, 2007; Poeze et al., 2017). Matched-sample studies are crucial because, in collecting information from both from the migrants in the receiving country and their family members back home, '(they) can best investigate questions about the inner workings of transnational flows and link migrants' actions with those of people back home' (Mazzucato, 2009: 73). By using a multi-sited matched-sample methodology, this dissertation has contributed to the understanding of the socioculturally embedded web of obligations and responsibilities that bind family members together and shape social protection arrangements. As the empirical chapters show, the needs of the migrants' families 'back home' and the adequate ways to address themin conformity with deeply-rooted sociocultural norms on how and by whom support should be provided - might impact on whether and how specific resources are accessed or not. Moreover, some of the matched-samples in this research spanned across the three contexts. That is, some of the Sudanese respondents in the Netherlands had relatives in the UK, or moved to the UK as EU citizens, after having acquired the Dutch nationality. This allowed me not only to explore the transnational dimension beyond the traditional dichotomy of sending and receiving countries, but also to problematize the idea of receiving country. 
Fourth, although the care practices conducted within transnational families is an integral part of their social protection (Dankyi et al., 2017), the care work involved in transnational families has been mainly theorised within the field of family studies and transnational caregiving (see Baldassar and Merla, 2014). The empirical chapters (7-9) show that care is, indeed, a crucial part of social protection, and one of the main drivers of TSP arrangements. Moreover, studies on transnational caregiving have mostly focused on the caregivers, disregarding the role of care-receivers and the actual consequences of care. As a gendered and socio-culturally embedded process, the provision and reception of care might be problematic in a transnational context, where perceptions on who should provide care, how and for whom might differ across contexts. Chapter 9 addresses this issue in detail, focusing in particular on the ways in which female care-receivers circumvent the consequences of unsolicited care provided by their male relatives abroad.

Fifth, in this thesis I investigate TSP by drawing on and connecting different bodies of literature, namely: migration and social protection, transnational families, welfare-regime theories and care literature. All these disciplines have made important contributions to different aspects of migration and the family, but very rarely have they built on each other. To better understand how transnational families navigate different social protection provisions across borders, it is necessary to bring together diverse bodies of literature, since the family is a complex institution shaped by overlapping and shifting socioeconomic, cultural and political aspects. Current migration regimes have an impact on who is entitled to move where, or to access certain social protection provisions. At the same time, sociocultural norms of intergenerational and generalised reciprocity within families also play a role in establishing who should care and provide for whom, and how. In bringing together these different bodies of literature, this thesis analyses how different elements intersect in the social protection arrangements that transnational families engage into.

\subsection{Dissertation overview}

This dissertation is article-based, whereby the conceptual chapter (6) and the three empirical chapters $(7,8$, and 9$)$ are articles that have been either published or submitted to international peer-reviewed journals. They follow the structure of academic articleseach of them with their own introduction, theoretical, methodological analytical sections and conclusion. This creates some inevitable overlap in the theoretical and methodological sections. At the time of writing this dissertation, Chapters 6 and 7 were published in international peer-reviewed journals (see the footnote at the beginning of each empirical chapter), Chapter 8 was accepted for publication, and Chapter 9 had been submitted to a journal and is pending decision. The title of each of these chapters is the same as that in the published articles.

The four empirical chapters are preceded by five chapters. After this Introduction, Chapter 2 provides an overview of the theoretical underpinnings of this 
thesis. In Chapter 3 I elaborate on the data and methods. Chapter 4 provides a thorough background on the migration and social protection contexts in Sudan, while Chapter 5 focuses on the Dutch and British contexts.

Chapter 6 is a conceptual paper that presents a detailed review of the literature on social protection and migration from a transnational lens. It problematizes the clearcut dichotomy between formal and informal social protection, arguing that the boundaries between these two categories are blurred when looking at the combinations of institutional arrangements that migrants devise to ensure their own and their families' social protection in a transnational manner. The chapter offers a comprehensive typology of the current formal (i.e. state, market and international organisations) and informal institutions providing social-protection to migrants and their families back home, introducing a third category of institutions, namely, the semi-formal, which combines informal elements migrants know from their origin countries, with other formal social protection schemes. Through several examples of semi-formal organisations (e.g. hometown associations, transnational healthcare insurances or rotating credit associations, to name a few) this chapter highlights the importance of these institutions due to the high degree of flexibility to support their members in a broad range of contingencies. To better understand the social protection strategies of migrants and their families back home, this chapter highlights the need to obtain deeper insights into the intertwined mechanisms and linkages between formal, semi-formal and informal social protection schemes, not only in the receiving but also in the sending countries.

Chapter 7 problematizes the clear-cut division between formal and informal social protection systems, which ignores the manners in which both welfare-state institutions and migrants work together at the interstices of the formal and informal to cater to national and transnational social protection needs. Based on data collected in the Netherlands, this chapter investigates how migrants sometimes enter into symbiotic relationships with different welfare-state institutions, such as municipal offices, nongovernmental organisations and other immigration institutions, which in turn rely on the support of these migrants to provide social protection to people who would otherwise escape their purview. While these interplays allow migrants, who are sometimes undocumented, to informally participate in the formal social protection system, such practices are embedded within power relationships that are at times risky, especially for migrants.

Chapter 8 aims to disentangle what kinds of considerations underlie the decisions of migrants and their families to move to certain places for their social protection needs. Drawing on the life-stories of members of a Sudanese transnational extended family based in the Netherlands, the UK and Sudan and whose members are scattered across multiple countries, this chapter contributes to the current debates on TSP, expanding on the concept of 'resource environment' (Levitt et al., 2017). Through a transnational approach, this paper analyses the mechanisms guiding the access, circulation and coordination of resources to cover for different but related social protection domains. 
Chapter 9 focuses on the concept of care as a key element in social protection arrangements within family networks, based on a system of reciprocity between migrants and their families 'back home'. In particular, the chapter explores the agency of female care-receivers-both as migrants and as non-migrants or 'left behind'-to navigate the care provided by different family members abroad, while protecting themselves and their children's wellbeing. I examine the strategies of three women to manoeuvre the reception of unwanted care while avoiding conflict with their relatives and gaining control of their own and their children's bodies. In doing so, the chapter elucidates how, just like care-giving, care-receiving is a highly gendered process, in which men and women have different roles to play. Like in the previous chapter, this chapter moves beyond the caregiving practices between parents and children, addressing instead the care dynamics within extended families across the Netherlands, the UK and Sudan. In exploring the intricacies of care-receiving in transnational family networks, I analyse how geographical distance may exacerbate the perception of different care needs, while at the same time, it gives the care-receivers more space to navigate the reception of unsolicited care.

This dissertation ends with the conclusions (Chapter 10), which summarize the main research findings, discussing the implications for the theoretical development of TSP. In this chapter I also discuss the limitations of this research, provide suggestions for further research in the area of TSP and make some policy recommendations. 

CHAPTER 2

LITERATURE REVIEW: MIGRATION AND TRANSNATIONAL SOCIAL PROTECTION 


\subsection{Introduction}

This chapter presents an overview of the research conducted to date on migration and social protection, with a particular focus on transnational families and their social protection arrangements across borders. A range of studies have shed light on different aspects of social protection for mobile populations, such as, the lack of access to formal provisions in the receiving countries, the circulation of informal resources, or the provision of care, but they have often remained unconnected (see Sabates-Wheeler and Waite 2003; Baldassar, Baldock, and Wilding 2007; Faist et al. 2014). In the following sections, I explain how in this study I bring together these different bodies of literature, highlighting their contributions to our understanding on migration and transnational social protection (TSP) for transnational families.

This chapter starts by elaborating on a series of important areas of research in the field of migration and social protection. I start by addressing and delimiting the concept of social protection, as it is used in this research, reasoning why it has been chosen over social security. I then proceed to examine the theoretical underpinnings of household theories on migration, paying special attention to the NELM and its contributions to analysing migration as a family strategy rather than an individual project. I provide an overview of the literature on migration and social protection, highlighting some of its main contributions to the field, but also pointing out some of the limitations of this body of literature, whose focus is often on the receiving nationstates and the welfare entitlements for individual migrants.

In Section 2.3, I concentrate on the transnational approach used in this study. Only recently, migration and social protection studies have taken a 'transnational turn', moving their focus away from the nation-state that characterised previous approaches. In this section I present a brief overview this transnational turn, highlighting the main benefits of using a transnational lens to investigate how migrants and their families navigate different forms of social protection across borders.

Finally, in Section 2.4 I address aspects of transnational families and care, relevant for this thesis. On the one hand, I briefly review the literature on transnational families and how, despite the geographical distance, these families continue to be units of protection and reproduction. On the other hand, I elaborate on caregiving practices within transnational families, emphasising the role of care as a crucial but highly neglected element in the study of social protection for mobile populations.

\subsection{Migration and social protection: An overview of concepts and previous studies}

Before elaborating on the existing literature on migration and social protection, it is important to clarify what social protection means and how the concept is used in this 
study. Social protection does not have a universally accepted definition. In fact, over the years, it has often been used interchangeably with the concept of social security, which was also preferred in most academic literature, official documents and international conventions (Midgley, 2012). Social security, as defined by the International Labour Organisation, refers to:

the protection which society provides for its members through a series of public measures: to offset the absence or substantial reduction of income from work resulting from various contingencies (notably sickness, maternity, employment injury, unemployment, invalidity, old age and death of the breadwinner); to provide people with healthcare; and to provide benefits for families with children' (ILO 2000: 29).

Social security, thus, is the formal assistance provided by the state to its citizens, based on formal employment, and including different social insurance and assistance measures, to make sure that citizens meet their basic needs, such as education, housing and health (Raithelhuber, Sharma, \& Schröer, 2018; SabatesWheeler, 2009; Shepherd, Marcus, \& Barrientos, 2004; Vonk \& Tollenaar, 2009).

For the purposes of this research, however, this concept presents two main limitations. On the one hand, as a social system of support based on formal employment, extending the coverage of formal social security system to developing countries, where large numbers of self-employed operate in the informal sector, seems problematic (Shepherd et al., 2004). Indeed, systems of socio-economic security were introduced in Europe in the late 19th century and consolidated over the years as a means of improving the well-being of the poor, reduce social inequality and conciliate different social demands (Justino, 2003). Whereas these objectives should also be addressed in developing countries, such as Sudan, the structural characteristics of these states impede the implementation of some of the usual mechanisms of assistance of typical Western welfare states, such as: pension systems, unemployment benefits, or maternity subsidies (ibid.). In this study, I do not only focus on the migrants and the available social security provisions in the receiving country. Instead, I also include the migrants' families in Sudan, with a practically non-existent social security system. Therefore, a broader concept is needed that can encompass the social support systems in the Netherlands, the UK and Sudan.

On the other hand, social security encompasses the support provided by the state to its citizens, leaving out the role of other actors in the provision of support, such as family, NGOs, private health insurance or religious groups. Families, charity organisations and other social networks play a crucial role in the support of migrants, especially the undocumented and the newly-arrived, who are not citizens in the receiving state, and therefore have limited (if any) welfare rights. Moreover, in countries with weak social welfare systems, like Sudan, a patchwork of resources provided by different actors becomes crucial for the sustenance of families and individuals. Since, the aim of this thesis is to understand how transnational Sudanese 
families cover their needs by accessing and circulating resources across countries (namely, the Netherlands, the UK and Sudan), with different degrees of formality and informality in their welfare systems, a broader and more holistic concept than social security is necessary.

Social protection is, indeed, a much wider concept than social security. Yet, as a broader term, definitions vary among practitioners and researchers, and discrepancies around what is provided, by whom and to whom abound. Some definitions are rather narrow, reducing social protection to the traditional social welfare provided to the 'deserving poor'; others equate it with social safety nets to protect the poor against production and consumption shocks mainly in subsistenceoriented communities; and some others adopt very broad approaches, including education and health subsidies, or job creation (for a detailed review, see Devereux and Sabates-Wheeler, 2004; Norton, Conway, and Foster 2002). Despite the discrepancies, all definitions agree that the main goals of social protection are: reducing poverty, managing vulnerability and enhancing economic growth and human development (Avato et al., 2010; Sabates-Wheeler \& Waite, 2003; Shepherd et al., 2004).

Moreover, most make an explicit distinction between formal and informal mechanisms (Avato et al., 2009; Mendola, 2010; Oduro, 2010; Verpoorten \& Verschraegen, 2008). Formal social protection is usually considered to involve publicly funded state regulations, reinforced by laws or statutes, institutionalised in policy and legislation, and conveyed in the form of eligibility criteria (SabatesWheeler \& Waite, 2003). Services provided by international organisations and private markets also fall within the category of formal social protection, although they have received much less attention in the literature on migration and social protection. Informal social protection is provided by social networks based on collective norms such as solidarity, reciprocity, or obligation (Devereux \& SabatesWheeler, 2004; Oduro, 2010). From this perspective, social security is often understood as the formal state-provided part of social protection (Sabates-Wheeler, 2009).

For the purpose of this research, I draw on the concept of social protection, understood as 'all interventions from public, private and voluntary organisations and informal networks to support communities, households and individuals in their efforts to prevent, manage and overcome risks and vulnerabilities' (Shepherd et al., 2004: 8). Regarding the domains covered, I rely on Peggy Levitt and colleagues' (2017) scope of social protection, who-based on the Organisation for Economic Cooperation and Development (OECD 2007)-identify nine domains of social protection, including: old age, survivors, incapacity-related benefits, health, family, active labour market programmes, unemployment, housing and education (Levitt et al. 2017). 


\subsubsection{Migration and social protection}

The complexities of migration and social protection have increasingly caught the attention of researchers, policy makers and international organisations. The first body of literature to address migration as an insurance or social protection mechanism for households is the NELM. The NELM theory argues that, rather than an individual project of income maximization, migration is often considered a family or household livelihood strategy to diversify income sources, face socioeconomic constraints, and guarantee the wellbeing and social protection of the different family members, now and in the future (Lucas \& Stark, 1985; McDowell \& de Haan, 1997; Stark \& Levhari, 1982). In situations of uncertainty and hardship, people organise their livelihoods not individually but in a wider social context, whereby households send their best-suited individuals abroad to gain an income, so that the money that migrants remit can be used to spread income risks and to increase income, and improve living conditions and investment capacity (de Haas \& Fokkema, 2010; Taylor, 1999). It should be mentioned that the NELM has many conceptual similitudes with the livelihood approaches that developed from the late 1970s as a result of micro-research conducted among anthropologists, geographers and sociologists in developing countries (de Haas 2007b). The livelihood approaches emphasise the fundamental role of human agency, arguing that poor people are not mere passive victims of global capitalism, but active actors striving to improve their livelihoods within the constraining conditions they live in (Lieten \& Nieuwenhuys, 1989). This approach looks at migration as a key strategy to diversify, secure and improve livelihoods (de Haas 2007b). Thus, both NELM and the livelihood approaches conceptualise migration as a household livelihood strategy to diversify income sources and overcome socio-economic constraints in places of origin (ibid.).

Remittances are thus explained as the outcome of a self-enforcing and mutually beneficial contract between migrants and their families, including the provision of income to one another (Stark \& Lucas, 1988; Taylor, 1999). In fact, the NELM literature has investigated the motives leading the migrants to stick to this contract, rather than cutting ties with their families and keeping their earnings for themselves (Mazzucato, 2009b). The three main motives are: altruistic feelings or the duty to support those left behind, self-interest or the desire to be eligible for family inheritance, and co-insurance, that is, that the migrant is also insured by the informal family contract (Lucas \& Stark, 1985; Taylor, 1999).

Despite the important contributions in explaining migration-especially in developing countries or highly disadvantaged social groups - this body of literature has received some criticism. First, in focusing on the poor or highly disadvantaged population, these studies do not seem to explain the migration of the highly-skilled or the relatively well-off (Castles, de Haas, \& Miller, 2014). Similarly, the NELM has also been criticised for being unable to account for the cause of migration when it comes to forced migration (Lindley, 2010). Second, it neglects the intra-household 
relationships, inequalities and conflicts of interest related to aspects such as gender, generation or age (de Haas \& Fokkema 2010). Third, in these studies, economic remittances from the migrant to the family are one of the main motives for migrating (de Haas, 2010). Research, however, has shown that remittances might not always be the purpose of migration at the beginning and that migrants might not always send remittances (ibid.).

As a family-based livelihood strategy, migration has also been referred to as a social protection mechanism to reduce the probability of crises before they happen, or as a means to cope with such crises once they have occurred (Sabates-Wheeler and Waite 2003; Brown, Connell, and Jimenez-Soto 2014; de Haas 2007b). In the last years, migrants' lack of access to formal social protection in the Global North has received increasing attention from scholars from different disciplines (Cuadra \& Staaf, 2014; Holzmann \& Koettl, 2011; Sabates-Wheeler \& Waite, 2003; Sainsbury, 2006; van Ginneken, 2013). In one of the most comprehensive overviews of social protection for international migrants, Rachel Sabates-Wheeler (2009) identifies four main components of social protection: (i) access to formal protection (e.g. social security and social services) in sending and receiving countries; (ii) portability of vested social security rights (e.g. pensions and healthcare) between host and origin countries, (iii) labour market conditions for migrants in receiving countries and the recruitment process in the origin country, and (iv) access to informal networks to support migrants and their family members. Migrants' lack of access to and portability of formal social protection as well as the lack of regulated market conditions, might result in higher levels of vulnerability, financial loss or exploitation, all of which have an impact on the migrants' well-being (Avato et al., 2009; Taha, Messkoub \& Siegmann, 2013; van Ginneken, 2013). At the same time, informal social protection also plays a crucial role, be it in the form of family or social networks supporting the migrants in the host countries-especially when access to formal support is not possible - or the migrants' remittances to their families back home to help them cover basic social protection needs (e.g., housing, schooling or hospitalisation) (Amuedo-Dorantes \& Pozo, 2006; Azam \& Gubert, 2006; SabatesWheeler \& Koettl, 2010). Social protection, thus, tends to be defined in terms of either formal or informal support for migrants, mostly in the host country; the former referring to protection provided by public and private entities and the latter to the support provided by families and other social networks, when formal mechanisms fail (Avato et al., 2010).

Addressing social protection for migrants from the perspective of the either formal or informal mechanisms of support in the receiving country poses two main limitations. On the one hand, this approach neglects the role of the migrants' families back home, who are often seen as net receivers of the migrants' remittances (Boccagni, 2015). Besides the initial family financial investment to send a migrant abroad, seldom are migrants conceived to be receivers of support from their families 'back home', which is, in fact, a recurring phenomenon coined as 'reverse 
remittances' (Mazzucato, 2009b). For example, migrants are the receivers of different types of services from people back home, who often take care of the migrants' children while they are working abroad, or help migrants resolve paperwork issues needed for their status regularisation in the receiving countries. Yet, such services have remained largely unexplored due to the tendency of this body of literature to focus on individual migrants rather than their extended families in the origin country (ibid.). On the other hand, in the current global context where people move from countries with different social protection systems, making clear-cut distinctions between the formal and informal hinders the understanding of new emerging social protection arrangements, where formal and informal mechanisms become blurry. Chapter 6 presents a detailed discussion on the main institutions providing social protection to migrants and their families back home, introducing a semi-formal category of institutions, in which formal and informal elements become closely intertwined.

Recently, a growing body of literature has also looked into the interactions between welfare-states and migration regimes, particularly regarding the policies of control and exclusion and the counterstrategies that they trigger in migrants, especially the undocumented (Broeders \& Engbersen, 2007; Vasta, 2011). Such counterstrategies, also described as the 'weapons of the weak' (Scott, 1985) or 'tactics' (de Certeau, 1984), refer to the strategies of powerless groups to resist and undermine the power that the state, public authorities and elites have over them. Although national and European policies aim at preventing irregular migration, local authorities must deal with the presence of undocumented migrants through different means, and appeals are made to their compassion when they use their discretion to navigate a static welfare system. These situations lead to inclusive, but ambiguous, mechanisms (Ambrosini, 2017; Barberis and Boccagni, 2014; Gendera, 2011; Verloo, 2017) or 'foggy social structures' (Bommes \& Kolb, 2002), in which migrants appear as sneaking their way into the formal system, while street-level bureaucrats help them out of compassion. Yet, as Chapter 7 shows, there are clear symbiotic elements in such interactions, where both parties can benefit from each other.

Whereas the bulk of this literature focuses on undocumented migrants as tactical actors, documented migrants and refugees can also be described as tactical actors in that 'they are systematically excluded from accessing the strategic possibilities of official systems' (Williams, 2006). In fact, these categories of migrants often encounter situations-lack of family and strong social networks to provide childcare while parents work, or the lack of access to certain social benefits-in which they also must devise tactics between the formal and informal to achieve their social protection aims (Serra Mingot \& Mazzucato 2018 [Chapter 7 of this thesis]). It is precisely the use of a transnational lens (see below) that allows us to add to this body of literature by looking beyond the migrants' tactics to meet their own individual needs in the receiving country. Indeed, even when their own needs are covered, in Chapter 7 we discuss how documented migrants sometimes informally interact with 
official institutions to cater to their social protection obligations for their families back home.

\subsection{A transnational approach}

By and large, the main focus of both migration researchers and policy makers during the 1970s and 1980s was either on aspects related to the assimilation and integration of migrants in the receiving countries, or on the impact of migration on sending countries (Basch, Glick Schiller, \& Szanton Blanc, 1994; Guarnizo, Portes, \& Haller, 2003; Mazzucato, 2008a). This body of literature addressed migration from the perspective of the nation-state, splitting migrants' lives between here and there, and overshadowing the myriad of processes that take place beyond the boundaries of the nation-state. Such assumption that nation-states are 'the natural social and political form of the modern world' has been described as 'methodological nationalism' (Wimmer \& Glick Schiller 2002: 302).

As a response to these studies, a transnational turn in migration studies emerged during the 1990s. Basch, Glick Schiller, and Szanton-Blanc defined transnationalism as 'the process by which immigrants forge and sustain multistranded social relations that link together their societies of origin and settlement' (1994: 6). Transnational scholars argue that, in order to understand migrants' realities, it is crucial to consider multiple familial, socioeconomic, religious, political, and cultural linkages and interactions between people and institutions that migrants keep and sustain across the borders of nation-states (Faist, 2000; Kivisto, 2001; Levitt \& Jaworsky, 2007; Mazzucato, 2008a; Vertovec, 1999; Wimmer \& Glick Schiller, 2003). Such linkages across nation-states produce flows of people, money, and ideas that shape both the sending and receiving societies (Al-Ali, Black, \& Koser, 2001; Levitt, 2005; Portes, Guarnizo, \& Landolt, 1999). From a transnational perspective, thus, the individual migrant is 'a member of a larger whole that extends beyond geographical boundaries' (Mazzucato 2009: 71).

The conceptualisation of migration as transnational received some criticism over the years. First, several scholars have criticised the concept for being too broad. Some have argued for narrowing it down to describe sustained economic and political activities, while others have discussed the different types of transnational activities-including political, economic and sociocultural-as well as varying degrees of institutionalisation and the frequency of such activities (e.g. Portes, et al., 1999; Itzigsohn et al. 1999; Levitt 2001). These conceptualisations acknowledge the heterogeneity of transnational practices through which migrants maintain and develop linkages across national borders. A second critique has been the fact that transnationalism is nothing new, in that linkages across borders are intrinsic in all migration processes (e.g. Kivisto 2001). Although the links that migrants maintain between sending and receiving societies are, indeed, not new, the current times with more, better, cheaper and faster technological developments, have multiplied the 
intensity and frequency of the cross-border flows of people, goods, money, or ideas, allowing migrants to effectively maintain their social, financial, political or cultural relationships and interests, here and there, that is, beyond the geographical boundaries of a single nation-state (Levitt \& Jaworsky, 2007; Mazzucato, 2004, 2008b; Vertovec, 2001). Finally, transnational scholars have often been criticised for questioning the role of the nation-state. Such critiques have argued that migrants should only be studied at the level of the nation-state (Waldinger \& Fitzgerald, 2004). Transnationalism scholars, however, have not rejected the importance of the nationstate in migrants' lives. On the contrary, transnational studies do acknowledge the role of states in shaping migrants' transnational activities, but they also point out to a series of cultural, social or religious practices that migrants engage in, which do transcend the nation-state (Levitt \& Glick Schiller, 2004; Mazzucato, 2004).

In the study of social protection for international migrants and their families, a transnational approach is particularly useful for two reasons. First, in moving between countries, migrants also move between differently regulated labour markets and social protection systems, with different institutionalised levels of formality and informality (SASPEN, 2014). This has implications that span a single nation-state. As Chapters 3, 4 and 5 show, whereas both the Netherlands and the UK have relatively strong welfare states that cater for most of their citizens' basic needs, in Sudan a very weak welfare system leaves most of its citizens dependent on family and community support. Migrants, thus, must navigate the rules governing these different social protection systems in order to cover for their own and their families' needs here and there.

Second, a transnational approach allows the researcher to consider both migrants and non-migrants, and multiple levels of engagements across national borders (Levitt \& Jaworsky, 2007). This is especially important to understand the social protection arrangements between migrants and their families back home. Indeed, social protection for mobile populations is not only about individual migrants, but also about their families. Although transnational families have existed across the world for centuries, they have been largely neglected by migration and social protection scholars, who have mostly used the individual migrant in the receiving country as the main unit of analysis (Mazzucato \& Schans, 2011). Moreover, when the family has been taken into consideration in migration studies, the main focus has been on the nuclear family or the household, largely neglecting other family constellations (Bryceson \& Vuorela, 2002). As the different cases presented in this thesis show, even when the migrant's needs are covered in the receiving country, the needs of their relatives back home play an important role in the migrant's wellbeing. A transnational lens on the social protection of migrants and their families is therefore particularly useful to understand how these families navigate the different resources accessible across borders to cover their needs at particular moments in time. In the following section I discuss social protection from 
a transnational lens. Afterwards, section 2.5 addresses the issue of transnational families, paying special attention to the TSP arrangements with which they engage.

\subsection{Transnational social protection: Assemblages and resource environments}

Moving away from these dichotomies, transnational migration scholars have analysed migration and social protection through a transnational lens, including both migrants and their families back home, as well as considering the multiple levels of engagement across sending or receiving countries (Levitt and Jaworsky 2007). Instead of splitting migrants' lives into disconnected areas, a transnational approach allows for a comprehensive understanding of the different social situations and relationships that migrants must confront and reconcile, both here and there (Grillo \& Mazzucato, 2008). As some of these studies have shown, TSP is a truly two-way coinsurance mechanism, where both migrants and non-migrants, as well as the different institutions involved in the sending and receiving country, play an important role (Boccagni, 2011; Dankyi et al., 2017; Mazzucato 2009b).

Transnational migration scholars have problematized the clear-cut distinction between formal and informal social protection, advancing the existence of a semiformal category, in which the formal and informal merge (Serra Mingot \& Mazzucato 2018 [Chapter 7 of this thesis]). Indeed, rather than being independent and mutually exclusive mechanisms of support, formal and informal elements of social protection present different interrelations or 'assemblages', whereby social actors constantly negotiate and combine the use of formal and informal provisions (Bilecen \& Barglowski, 2015). As opposed to previous studies focusing on the receiving countries, what these studies have shown is that sometimes informal mechanisms are not only filling the gap in formal social protection schemes, but they are perceived as more viable for covering specific needs (ibid.; see also Chapter 8 of this thesis).

To operationalize social protection and understand which institutions are used to satisfy certain needs and to take care of risks, Levitt and colleagues (2017) introduced the heuristic tool of 'resource environment', which they define as 'a combination of all the possible protections available to them from our four potential sources (states, markets, third sector, and social networks)' (ibid.: 6). States provide different degrees of social security through a range of institutions, and operating at different levels. Markets provide social protection usually linked to health insurance or paid child-care. Third sector organizations generally provide low-cost support to specific groups, including healthcare, employment training, education, or housing, amongst others. Finally, individual social networks might provide a wide variety of support, including housing, childcare, cash transfers, or employment opportunities (ibid.). The protection which is ultimately available, though, depends upon several factors, such as: the nature of the market, the strength of sending and receiving states, 
the traits of the third sector organizations and the characteristics of individual migrants (e.g. nation of origin and residence, social networks, gender, race, ethnicity, religion, class and education) (ibid.).

Levitt's 'resource environment' is closely related to the 'Welfare Pentagon' model developed by de Neubourg (2002). The Welfare Pentagon represents the five core institutions-family, markets, social networks, membership institutions and public authorities - that households can access to meet their current and future needs in a specific society. Yet, for the purpose of this research, the Welfare Pentagon presents two main limitations, namely: its focus on households in a specific society. Even though 'household' and 'family' have often been used interchangeably, in the context of migration, family units are more fluid and may be divided among several households (Young \& Ansell, 2003). The focus of this research, is not households, but families, whose members might live spread across distant geographical locations. Therefore, the household - as the main analytical unit in the Welfare Pentagon model -is too limiting. At the same time, de Neubourg's model is based on a specific society, linked to a particular nation-state. Whereas understanding the resources available in a particular country is important, this study aims to understand how transnational families, whose members are spread across different countries, navigate their social protection across two or more national contexts. To do so, a more comprehensive and versatile term is needed. The concept of 'resource environment' allows for a more flexible understanding of how migrants navigate the different resources available to receive and provide support locally and across borders.

I approach this research with an open and broad working definition of TSP, which refers to the combination of provisions provided by the state, the market, the third sector (i.e. NGOs, churches, international organisations) as well as, family and social networks to protect individuals and families against declining living standards arising from a number of basic risks and needs-associated with old-age, survivors, incapacity, health, family, active labour market programmes, unemployment, housing and education - in a transnational manner (de Neubourg \& Weigand, 2000; Devereux \& Sabates-Wheeler, 2004; Levitt et al., 2017).

The relevance of using this approach lies in two main aspects. First, only by understanding what is available where and to whom, can we understand and reflect on what migrants actually decide to or are able to access across the different locations in which resources are available to them. Second, whereas the UK and the Netherlands have relatively strong welfare systems, in the case of Sudan, the weak and almost non-existent welfare support leads people to resort to highly institutionalised forms of informal social protection, such as: family networks, community support, and migration itself. Looking at the three contexts allowed me to investigate not only which forms of social protection individual migrants resort to when different needs arise in different contexts, but also how such needs are dealt with at a family level when the different members are split across two or more nation-states. Indeed, rather than looking at the resource environment of a single individual migrant, as done by 
Levitt and colleagues (2017), I look at the resource environment of families where individual migrants are embedded. Thus, within the scope of a family, individuals are both providers and receivers of different social protections.

\subsection{Transnational families}

Currently, many families choose or are pushed to live with their members spread across national borders. Yet, despite the growing recognition that family formations are becoming more diverse and complex, both methodologically and theoretically, families are usually conceived of as nuclear, composed by two married adults and their children living together, and bounded by the nation-state, whereby geographical proximity becomes a prerequisite for interaction and exchange (Mazzucato \& Schans, 2011; Zontini, 2010). Moreover, families with one or more members living abroad have often been considered as a temporary phenomenon, with family reunification as the preferred outcome for everyone (ibid.).

In the early 2000s, transnational migration scholars became increasingly interested in the intricacies of transnational families, challenging the assumption that maintaining family relationships across national borders was unfeasible (Mazzucato $\&$ Schans, 2011). These studies recognised the impact of international migration in family and kinship ties and highlighted the importance of theorising mobility and absence as common aspects of family life, bearing in mind the role of both: those who leave and those who are 'left behind' (Baldassar, 2007; Baldassar \& Merla, 2014; Bryceson \& Vuorela, 2002; Dankyi et al., 2017; Mazzucato \& Schans, 2011; Razy \& Baby-Collin, 2011). Bryceson and Vuorela defined transnational families as those that 'live some or most of the time separated from each other, yet hold together and create something that can be seen as a feeling of collective welfare and unity, namely "familyhood", even across national borders' (2002: 3).

Whereas the meaning of 'family' is often reduced to the nuclear family household, there is considerable evidence showing that relationships with the wider kinship group remain an important part in most people's lives (Finch \& Mason, 1993). For the purposes of this study, I draw on the 'modified extended family' definition, understood as 'a social unit in which parents, children, and other relatives do not necessarily live under one roof' (Medora, 2007: 164). Despite the geographical distance, family members keep in constant contact with each other and exchange practical assistance in a variety of tasks, such as: visits, financial support, childrearing support, or attendance at life-cycle events such as births, marriages, or deaths, which continue to be obligations and integral components of the modified extended family (Litwak, 1959; Medora, 2007). These families may be split among multiple households, with membership constantly changing (Young \& Ansell, 2003). Indeed, as empirical and anthropological studies have shown, families are not clear-cut entities. On the contrary, they are rather fluid and changing over time and space (Young \& Ansell, 2003; Zontini, 2006), whereby, "who is thought to be a "family" 
and what that implies varies -between groups, individuals and contexts' (Bjeren 1997: 236). To address this issue, the participants of this research were given the freedom to describe 'family' according to their own views and experiences (see Chapter 3 for further details).

\subsubsection{Transnational social protection arrangements within extended family networks}

The empirical Chapters 7, 8 and 9 of this thesis illustrate how the members of transnational families make use of multiple formal and informal mechanisms of social protection, which are intertwined in a web of generalised reciprocity and norms of social exchange. Despite the availability of formal social protection institutions for individual migrants in the receiving countries, families back home often lack access to any form of formal social support. At the same time, formal welfare systems in the receiving countries are not devised to support people outside the nation state. Migrants must then engage in a combination of formal and informal practices to cover for the needs of their families, which often answers to the practice of reciprocity and norms of social exchange. This is especially the case when the needs involved are related to the provision and reception of care. Reciprocal relations, however, are not uniform and involve different types of exchanges, where the relationship between the actors involved, the value and the type of expected returns, and the degree of conditionality varies (Mau, 2004; Sahlins, 1974).

Welfare regimes can, in fact, be described as a sort of social contract, that is, people support welfare state arrangements because they benefit from welfare income flows and because they approve of the moral purpose of such welfare programmes (Mau, 2004). Reciprocity is an important element to understand under which conditions people support and engage with formal welfare arrangements, in that 'those contributing to the welfare schemes expect some material, or symbolic, reward for their efforts' (Mau 2004: 68). In the case of transnational families, such expectations become more unclear. Even when migrants have full access to the welfare of the host country, what happens when some family members back home (e.g. aging parents or sick dependants) do not fall within the protective arm of the host welfare state? What happens when sociocultural norms around the provision of care, for instance, make people favour certain informal arrangements over formal ones, even when the latter are available? Or how do migrants envisage their old-age when the built-up pension in the host country cannot be transferred to their origin country, where many of them wish to spend their last years?

Indeed, the relationship between migrants and the welfare system in the receiving country might not always be reciprocal and people might prefer to resort to informal practices. Therefore, to understand how transnational families access and circulate resources to cover for certain social protection needs, it is important to look beyond the Western welfare state models (e.g. pensions, unemployment benefits, etc.), bearing also in mind the context of the sending country and its social protection 
institutions. For instance, whereas pensions are one of the main and more resilient pillars of most Western welfare systems (see Chapter 5), for most of my respondents, pensions - as a welfare-state benefit - did not seem to be a priority. As explained in Chapter 4 and further discussed in the empirical chapters (7-9), pensions in Sudan are rarely understood as a state-provided benefit. Instead, pensions are mostly envisaged in terms of working hard in one's adult life, building a house and giving your children the best education so that they can provide for you in the future. Providing children - not only one's own biological children, but also other children in the family, such as cousins, nieces, or nephews-with the best possible formal education can be understood as a long-term strategy of 'generalized reciprocity', intended to result in reciprocal support in one's old-age pension (Alber, van Der Geest, \& Whyte, 2008; Mazzucato, 2008c; Nyambedha, 2008). At the same time, many refugees spend years waiting in the asylum process to obtain refugee status, during which time, they cannot work or study. Once the status is given, they must go through integration and re-training courses to validate their studies, if they have any, or start from scratch. This long process results in people in their 40s applying for a job for the first time in a highly competitive market in which, even if they manage to find a job, their built-up pension will most likely be rather low.

\subsubsection{Caring in transnational social protection arrangements}

Intra-familial care obligations, needs and duties (or the need for social protection) are important triggers of migration for different types of migrants, including labour and professional migrants (Merla \& Baldassar, 2010) and, as Chapters 7, 8 and 9 illustrate, also refugees. The provision and circulation of care conducted between members of transnational families in its different dimensions (e.g. eldercare, childcare or healthcare) is an integral part of the TSP arrangements devised by migrants and their families, based on complex links of reciprocity and obligation (Dankyi et al., 2017). Particularly in countries with weak or non-existent social welfare systems, such as Sudan, extended families play a crucial role in the protection and sustenance of families and communities. In times of need or crisis-e.g. unemployment, sickness or old-age-families are the ones offering material, social, emotional and intergenerational caregiving support (Mokomane, 2013). Yet, rarely has the literature on care been incorporated into studies of social protection and migration. In fact, whereas the role of informal social protection for mobile populations has been established as crucial, scholars on social protection and migration have mostly focused on financial aspects, be it in the form of the migrants' remittances or on the support the social networks give to newly arrived migrants (Sabates-Wheeler \& Waite, 2003). Caring practices, on their side, have been mostly theorised within the field of transnational family studies (Baldassar \& Merla, 2014).

Care work ensures both the maintenance of individuals through the life cycle (e.g. feeding, clothing, affective work), as well as the systemic reproduction (e.g. education, social bonds, and ties) that sustains the social system (Yeates, 2008). Care 
and social reproduction are, in fact, inextricably linked concepts (Kofman, 2012). Barbara Laslett and Johanna Brenner (1989: 383) defined social reproduction as the 'various kinds of work - mental, manual, and emotional-aimed at providing the historically and socially, as well as biologically, defined care necessary to maintain existing life and to reproduce the next generation.' Care, on the other hand, can be defined as a multi-directional process 'that includes everything that we do to maintain, continue and repair our "world" (which) includes our bodies, ourselves, and our environment, all of which we seek to interweave in a complex, life-sustaining web' (Fisher and Tronto 1990: 40). Both care and social reproduction are unequally distributed, represented, sustained and sanctioned throughout the world, whereby some people have the means to practice and control reproductive activities, while others do not (Bonizzoni, 2012).

Recently, some scholars have criticised the current dominance of care as an analytical concept, which overshadows the long standing feminist works on social reproduction (Kofman, 2012; Locke, 2017). Particularly, scholars of gendered migration have been more disposed toward the concept of care as the primary object of inquiry (Baldassar \& Merla, 2014; Hochschild, 2000; Hondagneu-Sotelo, 1994; Parreñas, 2010; Spitzer, Neufeld, Harrison, Hughes, \& Stewart, 2003), whereas social reproduction has been most theorised in the field of feminist political economy (Bakker, 2007; Bakker \& Gill, 2003; Bakker \& Silvey, 2008) ${ }^{2}$. Scholars favouring a return to social reproduction instead of care as an analytical tool argue that care is a part of, rather than a substitute of, social reproduction, which encompasses the reproduction of societies as well as households and families (Locke, 2017). Yet, other prominent scholars in the study of care argue that care is, in fact, interrelated with but different from social reproduction, in that 'while both refer to social processes that emerge from human activities and relations, care as a critical concept is more amenable to unpacking the moral hybridity of human practices at the intersection between global forces and local' (Nguyen, Zavoretti, \& Tronto, 2017: 202). While acknowledging the weaknesses and strengths of both concepts, as well as their similarities, for the purpose of this research, I have favoured the notion of care for two main reasons. First, it resonates with the bodies of literature I draw from and to which debates I contribute (e.g. Baldassar et al., 2007; Boccagni, 2013; Kilkey \& Merla, 2014; Poeze et al., 2017). Second, because care allows me to analyse the processes and experiences of both caregivers and care-receivers. That is, the literature on social reproduction has tended to focus on care-givers, in that it focuses on the work done to reproduce the next generation. Care, however, allows for both caregivers and care-receivers to be conceptualized vis-à-vis care. In fact, as the following paragraphs explain, doing care is not only performed by the caregiver but also by the care-receiver.

\footnotetext{
${ }^{2}$ For a detailed discussion on this issue, see Kofman 2012.
} 
Transnational caregiving refers to the ways in which people care for each other across national borders. It is based on a series of relationships of obligation, trust and commitment concerned with the well-being of others, developed and negotiated over time, in line with the ordinary rules of generalised reciprocity, namely, the expectation and obligation that care will be returned, regardless of when or in which form (Baldassar \& Merla, 2014; Krzyżowski \& Mucha, 2014; Sahlins, 1965; Seltzer \& Li, 1996). In binding family members together in intergenerational networks of reciprocity and obligation, love and trust, transnational caregiving is simultaneously fraught with tension, contested and made of unequal power relations, where care is not given or received equally by all family members (Baldassar \& Merla, 2014).

Global care chain literature (Hochschild, 2000; Hondagneu-Sotelo, 1992; Parreñas, 2001) and recent studies on 'care circulation' have analysed the myriad of family arrangements undertaken across national borders to provide care. These studies have highlighted the intricacies of care from the perspective of intra-familial duties and solidarities, which fluctuate over the life course within transnational family networks subject to the political, cultural and socioeconomic contexts of both sending and receiving countries (Baldassar \& Merla, 2014; Mazzucato, 2008c; Poeze et al., 2017). However, most of this body of literature gravitates around the nuclear family and more specifically around the parent-child dyad. On the one hand, scholars have examined aspects of motherhood and fatherhood when children are 'left behind' in the origin countries (often in the Global South), while their parents migrate to find job opportunities abroad (mostly in the Global North) (Dreby \& Adkins, 2010; Hondagneu-Sotelo \& Avila, 1997; Kilkey, 2014; Parreñas, 2010; Poeze \& Mazzucato, 2016; Schmalzbauer, 2004). On the other hand, research has looked at families in which migrant adult children live separated from their elderly parents, who remain in the country of origin (Baldassar et al., 2007; Bryceson \& Vuorela, 2002; Gassmann, Siegel, Vanore, \& Waidler, 2017; Zickgraf, 2017). Moving beyond the mother-child dyad, a few prominent studies have recognised that in transnational care-giving arrangements, other kin often play important caregiver roles (Bernardi, 2011; Mazzucato \& Schans, 2011). Overall, however, the dynamics within extended family networks have been largely neglected. This is an important gap in the literature of transnational families because, especially in countries with weak or non-existent welfare systems, extended families are crucial in the sustenance of all their members. In this research I address this gap by looking at extended family dynamics.

Literature on transnational caregiving acknowledges the shifting roles from caregivers to care-receivers and vice-versa and mapping the multiple caregiving configurations. Yet, the focus of this body of literature has continued to be on the caregivers and caregiving activities, leaving aside the implications of what it means to receive care. Caring relationships are emotionally complex and they reflect power dynamics, in which agreeing on what 'needs' are and how they should be addressed is not straightforward (Bondi, 2008; Locke, 2017). In fact, power relations often 
shape the definition of needs to suit the dominant or the group interests, whereby care-receivers might have little control over how their needs are met (Fisher \& Tronto, 1990). Especially in a transnational context where face-to-face support is not always possible, it is important to conceptualise care as an ongoing process that involves 'taking the concerns and needs of the other as the basis for action' (Tronto 1993: 105). Perceptions of needs may be wrong, and even if they are correct, '(c)arereceivers might have different ideas about their needs (and) may want to direct, rather than simply be passive recipients, of caregiving that they receive' (Tronto, 1993:109). Moreover, care is a culturally embedded process where both caregivers and carereceivers do not just act out of self-interest but 'as the result of the particular constellation of caring relationships and institutions within which they find themselves', including families, welfare states, and the market (Tronto 1995: 142). Therefore, judgements made about care arise out of people's experiences and gendered expectations of collective institutions, such as the family (Tronto 1995).

In the same vein, when looking at care relationships within transnational families, the migration of some family members might have an impact on the provision and reception of care. Care-in terms of resources, burdens, rights and duties - is performed in the global context according to hierarchies of gender, class, race and ethnicity (Bonizzoni, 2012). Due to the different distribution of resources and social expectations, reproductive work and care are experienced and perceived differently by men and women, children and the elderly, or wealthy and poor (ibid.)(Chapter 9 further discusses this point). In fact, some research has shown that migration, as a social protection strategy, might actually have precisely the opposite effect: perpetuating old inequalities and creating new ones (Faist et al., 2014), especially within families. Migration might sometimes disrupt traditional social protection systems in the country of origin, which are extremely important in many origin country communities (Devereux, Roelen, \& Ulrichs, 2015).

\subsection{Conclusion}

In this chapter I have discussed the contributions of different bodies of literature, highlighting different perspectives relevant for the study of TSP. The different sections pull together diverse works, from which the forthcoming empirical chapters draw on. I have used a transnational lens to analyse and understand how transnational Sudanese families make use of a range of formal and informal mechanisms of social protection, both locally and transnationally, to cover for specific needs in particular moments in time. I have done so in three ways. First, I include the contexts of both the sending and receiving countries, and the ways in which social protection is envisaged and provided in each of them. Second, I include those who do not migrate but who are, nevertheless, bound to migrants through family ties across national borders. In doing so, I move beyond the individual migrant's access to social protection in the receiving country to also include and 
analyse the role of the migrant's extended family in shaping the different social protection arrangements. Third, to explain the findings in the different empirical chapters, I incorporate insights of the Sudanese family norms around social protection.

In line with the transnational scholarship on social protection, I problematize the clear-cut division between formal and informal social protection systems. Through the empirical chapters I demonstrate how analysing social protection for mobile populations from either formal or informal provisions becomes problematic. Making such a clear-cut dichotomy runs the risk of overlooking the ways in which formal and informal mechanisms of social protection constantly interact to accommodate the needs of both individual migrants and welfare-state institutions. To avoid such a dichotomy, throughout the empirical chapters, I use and build on the heuristic tool of the 'resource environment'. Looking at the resources available to the migrants and their extended families to cover for their needs, is useful in three ways. First, it allows me to account for all the resources available to transnational families not only in the sending and receiving country, but also beyond them. Second, looking at the ways in which people decide or not to access certain available resources to address specific needs, allows me to disentangle what are the family considerations behind the decisions to access, coordinate and circulate resources across borders. Finally, looking into the ways mobile populations access and use different resources to cover for certain needs, revealed the intertwined character of different social protection domains, which are often defined and addressed-especially from the Western welfare systems - as clear-cut and independent from each other.

From different perspectives, the empirical chapters delve into the tactics and strategies used by mobile populations in order to navigate different aspects of social protection. First, building on studies on migration and welfare regimes, I demonstrate that not only undocumented, but also documented migrants deploy tactics at the interstices of the formal and informal to cater to national and transnational social protection needs. Such tactics, are not always one-sided, that is, created and implemented by the migrants. In fact, I show how sometimes (un)documented migrants enter into symbiotic relationships with different welfarestate institutions, which in turn rely on the support of these migrants to provide social protection to people who would otherwise escape their purview. Second, to create the largest possible resource environment that covers the needs of the different transnational family members, migrants strategically move to (or stay put in) places that allow them to access and circulate resources to cover different and overlapping needs of family members scattered across multiple national borders. Finally, I demonstrate that tactics are also deployed — both my migrants and non-migrantswithin transnational families in order to avoid the consequences of unsolicited care and support.

Linking with the latter point in the previous paragraph, this dissertation brings the literature of care in conversation with studies of social protection and migration. 
Through the empirical chapters I show the crucial role of care in TSP arrangements. Indeed, care emerges as a key element in social protection arrangements within family networks, based on a system of reciprocity between migrants and their families 'back home'. Social norms on how care should be provided and by whom, shape the ways in which resources are mobilised and arrangements made. Through a transnational lens I look at care as a process across family members. In doing so, I illustrate how as a gendered and culturally-rooted practice, different family members are expected to give and receive care in specific ways. Like caregiving, care-receiving is fraught with tensions and conflicts, whereby care-receivers become tactical actors to protect themselves against the consequences of care while avoiding conflict with their families. 



\section{CHAPTER 3}

DATA AND METHODOLOGY 


\subsection{Introduction}

In this chapter I discuss the methodological and ethical considerations that guided this research. Following an illustrative vignette of one of the families in this study, Section 3.2 describes the research design that I used to understand how Sudanese transnational families navigate their and their families' social protection needs across three different settings: the Netherlands, the UK and Sudan. I provide a detailed account of how I delineated the highly dispersed field of this research and how the sampling process developed across settings. In Section 3.3 I discuss the main methods and relevant analytical aspects. Finally, in Sections 3.4 and 3.5, I reflect, respectively, on the ethical implications of this study and my positionality as a white non-Muslim female researcher in a Muslim patriarchal society.

\subsection{Research design}

During my fieldwork in the UK I met Hussein, a 55-year-old Sudanese refugee. Hussein used to be a university Professor, yet, the economic hardships in Sudan, coupled with his political activities, put him in a difficult situation to provide for himself and his family - a dependent mother, wife and five children. Thus, in 2014 Hussein left Sudan and arrived as an asylum seeker in the UK, where his sister, Fatima, and her family already lived (see Figure 2). They had arrived in the UK as EU migrants, after her husband became unemployed in Spain, where he had lived for 25 years.

Figure 2 - Hussein's family networks

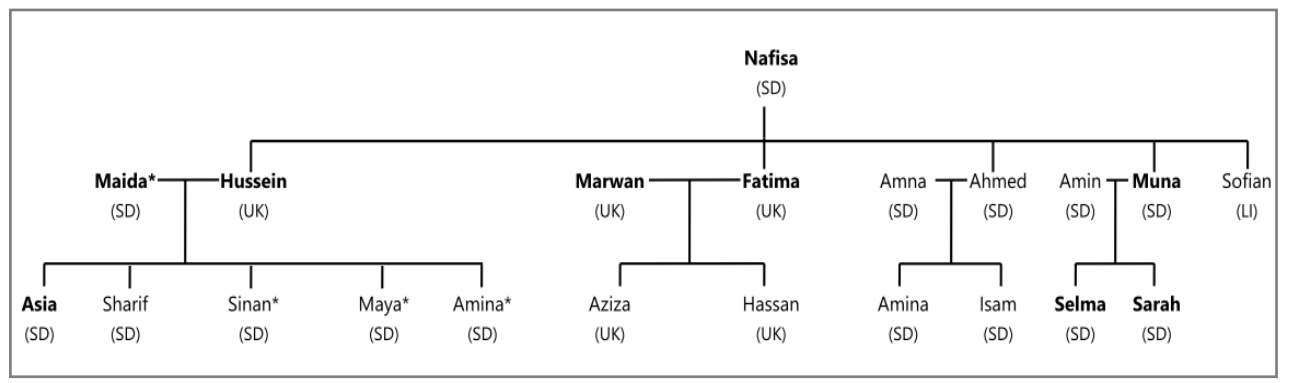

Source: Fieldwork.

NOTE: This family tree illustrates Hussein's family network at the time of the fieldwork (from February 2015 to November 2016). Below each person there is the abbreviation of their country of residence when I met them (SD-Sudan; LI-Libya). Only those people who participated in the research (e.g. observations, interviews and/or informal conversations) are marked in bold. Family members with a $\left({ }^{*}\right)$ moved to the UK under family reunion by the end of 2017.

Hussein's plan was to bring his wife, mother and children to England as soon as possible. However, his plans did not materialize as expected. His asylum process took 19 months, a time during which he lived on a $\$ 36.95$ weekly allowance and was not allowed to work, even though he was still responsible for his family in Sudan. When refugee status was 
finally granted and he started the family reunification process, he soon found out that according to family reunion regulations, he could only bring his wife, Maida, and his three minor children. In his first asylum interview, Hussein had explained that he had two more siblings in Sudan. The fact that both siblings lived hundreds of kilometres away from Khartoum-where his mother, Nafisa, and his children lived for education and health reasons - was not taken into consideration by the immigration services. Moreover, although as a recognised refugee, he was entitled to receive the job-seekers allowance (JSA), due to some bureaucratic mistake, he was still waiting to receive his National Insurance Number, without which Hussein could not receive the JSA. Thus, for the past couple of months he had been depending on the food vouchers provided by the Red Cross.

A couple of months later, when I started my fieldwork in Sudan, I went to visit Hussein's mother, Nafisa, in her humble house in Kalakla, on the outskirts of Khartoum. After Hussein had left, his wife, Maida, and their five children had remained in the same house, taking care of Nafisa. However, when Maida's father passed away, she and her children moved in with her own mother, leaving Nafisa alone. It was then that other two granddaughters, Selma and Sarah, moved in from the village, while their mother, Muna, travelled to Kalakla every weekend to make sure her mother and daughters were fine. Sometime later, I visited Maida and her children in their family house in downtown Khartoum. The house accommodated several of Maida's siblings with their respective spouses and children. As I spent hours at Maida's home, I realized how Hussein's children (aged from 11 to 18) were in a constant pilgrimage from this house and Nafisa's house in Kalakla, to keep her company and help her in daily chores. Hussein's eldest daughter, Asia, explained how, since their father left, life had become more complicated. Besides the financial costs of the constant travelling to and from Kalakla, they had to stop their health insurance because they could not afford it. Moreover, Asia had recently found out that she was not entitled to any type of scholarship anymore to continue with her Bachelor degree, when she told the university administration that her father was in the UK, they claimed she had no right to any scholarship because, being in the UK, he must have been making a lot of money. When Asia told me this, I could not help but thinking

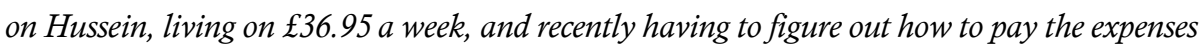
of DNA tests (around £500) to apply for family reunion.

\section{$\cos 80$}

Hussein's family story illustrates the puzzle that constitutes the transnational social protection (TSP) arrangements for transnational families. To understand how families, in their multiple configurations make sense of and organise their social protection locally and transnationally, I made use of ethnographic research methods and methodology. An ethnographic approach allowed me to understand the meanings that guide the behaviour of different family members across multiple settings, which is 'continually constructed, and reconstructed, on the basis of people's interpretations of the situations they are in' (Hammersley \& Atkinson 1995: 8). Studying how Sudanese transnational families navigate their social protection required direct and prolonged contact with the participants - the migrants and (when possible) their families - in the context of their daily lives. Due to the multiple 
unexpected events on the field, ethnographic research is an 'exercise of judgement in context; (it is) not a matter of simply following methodological rules' (Hammersley \& Atkinson, 1995: 23). Although the flexible and open-end character of ethnography has been often criticised as being deceptively simple, the complex social protection arrangements of these families called for a methodology that allowed for a combination of flexible methods, including participant observations and informal conversations. Through the flexible and inductive character of ethnography I adopted such an open-end approach, necessary to explore and interpret the complex realities of the migrants and their families, and how they make sense of them (Denzin \& Lincoln, 2011).

This study followed an iterative-inductive approach. It is iterative because both the design and analysis developed in a flexible manner as the research progressed, moving between reading theory, consulting experts, conducting fieldwork, and reframing the research questions. It is inductive because, rather than testing existing hypothesis, it aims at developing theory. Traditionally, inductive research often implies entering the field 'with an open mind and as few preconceptions as possible, allowing theory to emerge from data' (O'Reilly, 2012: 29). Yet, nowadays it is widely accepted that it is actually impossible to start any research without any preconception or theories about how the world works. Therefore, a usual way to conduct inductive research is to be open about one's preconceptions and proceed in a theoretically-informed manner, but open to surprises (ibid.). My study started with an extensive literature review on migration and social protection in general, and in Sudan, the Netherlands and the UK, in particular (Chapters 4 and 5), which I complemented with interviews with experts in the field. At the same time, as I unpacked the different approaches to social protection and migration, which shaped my theoretical framework, I started to make methodological decisions regarding the population to be researched and the specific geographical locations.

\subsubsection{Finding the field}

The selection of the Sudanese case was made on three main considerations. First, while much research has focused on 'old migrant groups', such as the Moroccans (Sorensen, 2004; de Haas, 2006), only few studies have focused on recent migrants from sub-Saharan Africa in Europe, such as the Sudanese. This is an important gap in the literature, since new migrant groups face different migration and receiving contexts than older groups (Grillo \& Mazzucato, 2008), which might have an impact on the way they engage in different TSP practices. For example, new migrant groups might have fewer and less developed social networks in the receiving country, including community organisations, which often provide social protection, locally and transnationally (Chelpi-den Hamer \& Mazzucato, 2010). Second, specific demographic aspects were also taken into consideration in the selection of the case. Whereas the Sudanese are not one of the most numerous migrant groups in Europe, 
they are quite a diverse group in terms of legal (e.g. documented labour migrants, refugees, asylum seekers or undocumented migrants) and socio-economic status (see Chapters 4 and 5). I expected such heterogeneity to allow for a maximum variation sample, to investigate the role of different socio-economic and legal statuses in the social protection arrangements that the migrants and their families 'back home' engage in. Finally, there was my personal interest and previous knowledge of Sudan. Exploring intimate and sensitive processes within family networks is at the core of this research, whereby having a thorough understanding of the context of the country of origin-including the language, social, religious and family norms, as well as the overall political and socioeconomic background-were key to gain access to the community, build rapport and conduct research in a respectful manner. The fact of having lived and worked in Sudan for 5 months in 2012 during my Masters, provided me with deep knowledge of the socioeconomic, cultural and political context of the country, its peoples and their main (official) language, Arabic. Speaking the language of the research population is not merely a useful practical communication tool, but also an important aspect in ethnographic research, whereby the researcher lays the ground for a non-exploitative two-way conversation (Spivak, 2004). Moreover, I expected my previous experience in Sudan, as well as my network of Sudanese friends and colleagues, to help me overcome one of the main challenges of multisited research: the difficulty of obtaining 'thick description' when the researcher has to move to different sites (Horst, 2012).

Once I had decided on the Sudanese population, I determined in which European country(ies) I would base my research on. The Sudanese community across Europe has different particularities, closely related to the demographic characteristics of the different groups arriving at particular moments in time (see Chapter 5). The selection of the UK and the Netherlands is based on three strategic reasons. First, both countries have different welfare and migration policy systems, which was expected to cast some light on the role that more or less restrictive policies have in the forms of social protection that migrants engage in. Second, the fact that the Sudanese community in the UK is bigger and older than in the Netherlands was also expected to have an impact on the way migrants make social protection arrangements, by relying to a greater or lesser extent on personal social networks. Third, many Sudanese living in the Netherlands have family members or close friends living in the UK. While some of them moved directly from Sudan to the UK, others moved after living in the Netherlands for some time. This allowed me to address the mechanisms of social protection across the borders of three nation states.

While the three countries were established at the early stages of the research, the specific locations - cities or villages - were shaped by the field itself, namely, by the web of relations that connected people. Since I was conducting my $\mathrm{PhD}$ at Maastricht University, where I had already established contact with some migrants and Sudanese organisations, I started the first part of my fieldwork in the Netherlands. During some preliminary investigations, I found out that the Sudanese 
community in this country was geographically dispersed, which might be explained by the Dutch housing policy for asylum seekers (van Heelsum \& Hessels, 2005). Moreover, my initial points of access, namely: two families I previously knew from Sudan, the Chair of a Sudanese community organisation and a key informant recommended through a colleague, all lived in four different Dutch cities. Therefore, rather than forcing the research in one single locality, my fieldwork in the Netherlands (from July 2015 to February 2016) extended across multiple cities, including but not limited to: Maastricht, Groningen, Amsterdam, and Nijmegen.

Conducting ethnographic research in geographically dispersed locations might seem disruptive, yet, it turned out to be not only revealing but extremely useful. On the one hand, it allowed me to observe the multiple connexions across people living in different areas. Although face-to-face meetings were scarce, friendships and other relationships existed over the distance and were kept alive through different means (e.g. Facebook, Whatsapp or phone calls). Similarly, I could also observe how people living in the same city, who would define each other as 'best friends', would only see each other once or twice a year. On the other hand, my constant need to move from one city to another led several families to offer to let me stay in their house while I conducted my interviews in that specific city. In doing so, I also conducted observations that would not have been possible if I had stayed in the same place (see Section 3.3).

Prior and during my fieldwork in the Netherlands, I interviewed staff members of different NGOs working with refugees and migrants in the Netherlands and the UK (via Skype), to better understand how the systems functioned in the two countries in a parallel manner. I complemented the scarce literature on the Sudanese context with Skype interviews with a Sudanese Professor, expert in migration issues, and the director of an NGO in Sudan. I also held conversations with Sudanese friends, activists, and potential respondents, who gave me their views on how social protection was understood in Sudan, both in theory and practice.

The second period of my fieldwork in the UK took place between March and July $2016^{3}$. In contrast to the Netherlands, the Sudanese population in the UK is not only bigger, but also clustered around major cities, such as: London, Birmingham or Cardiff (see Chapter 5). Whereas the relatively small geographical dimensions of the Netherlands had allowed me to easily move from city to city-the longest distance, from Maastricht to Groningen, was around 4 hours by train-the size of the UK prevented me from engaging in such a multi-local research. Rather than randomly choosing one of the major cities with a high concentration of Sudanese, I followed my respondents' advice and focused my fieldwork around Birmingham and its surroundings areas, where many Dutch-Sudanese had recently moved. Moreover, whereas in London the Sudanese community was longer established, the community

\footnotetext{
${ }^{3}$ The fieldwork in the UK took place before the Brexit. Therefore, this research cannot assess the impact that the Brexit had on the lives of my participants.
} 
in Birmingham had more similarities to that in Netherlands, namely, most of them had arrived seeking asylum from the late 1980s and early 1990s. The matched samples of three of my respondents in the Netherlands led me to spend some time in London, Manchester and Cardiff. Like in the Netherlands, during my visits to Manchester and Cardiff, I lived with the families themselves.

The third and final part of my fieldwork took place in Sudan (August to October 2017) and was geographically determined by the places where the matchedsamples of my respondents in Europe lived. Even though my respondents originated from different areas of Sudan, such as Darfur, or Eastern Sudan, all of them had some relative-parents, siblings or cousins-living in the state of Khartoum. Therefore, although security concerns limited my mobility only to the central states, I was able to meet all the matched-samples to whom I had been given access.

Figure 3 provides a geographical representation of the fieldwork conducted in the three countries and the matched samples. 
Chapter 3

Figure 3 - Geographical representation of fieldwork

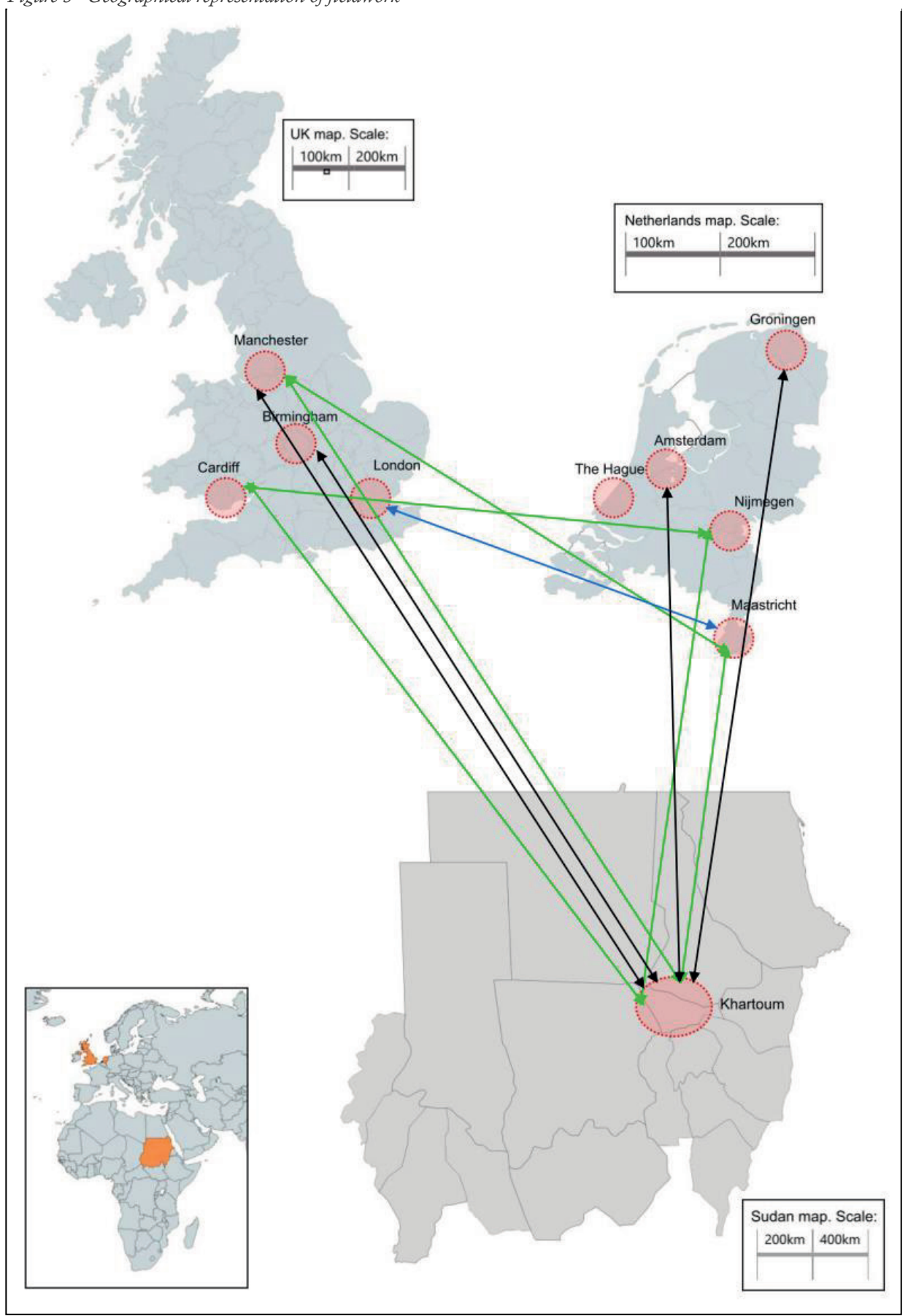

Source: Fieldwork.

NOTE: The aim of this figure is to provide a visual overview of the main geographical locations where fieldwork was conducted and the matched-samples location. Maps have been scaled accordingly to facilitate the visualisation. The shaded red circles represent the main areas around which most interviews and observations were conducted. The green arrows represent matched samples across the Netherlands-UK-Sudan. The blue arrow represents a matched sample across the Netherlands-UK. The black arrows represent matched samples across UK-Sudan or Netherlands-Sudan. 


\subsubsection{A multi-sited ethnography}

The vignette introducing this Chapter is an example of how the study of social protection arrangements within transnational families calls for innovative research methodologies beyond the borders of discreet nation-states. Migration research has usually taken place in ethnic communities within major European and North American cities (Fog-Olwig, 2007; Mazzucato, 2008a). As a result, much interest has been concentrated either on the push and pull factors leading people to migrate, or on the different integration processes in the receiving communities (Fog-Olwig, 2007). In our current globalised world, however, where increasing amounts of people choose or are forced to live outside their origin countries, such traditional geographically-fixed ethnographic approaches are not sufficient to capture the transnational realities of many people. To understand the experiences and practices of these families, both emotionally intimate and geographically distant, conventional research tools must be transformed (Baldassar et al., 2007). By moving the focus away from the individual migrant here (in the receiving country) to the migrant's family there (in the origin country or elsewhere) a much more complex picture emerges (Fog-Olwig, 2007).

\subsubsection{Studying migration from a transnational lens}

A transnational approach allows the researcher to consider both migrants and nonmigrants, as well as the multiple sites and levels of transnational engagements beyond either sending or receiving countries (Levitt \& Jaworsky, 2007). The strength of the transnational approach is that it avoids splitting migrants' lives into disconnected areas, and allows for a more comprehensive understanding of the different social situations and relationships that migrants must confront and reconcile, both here and there (Grillo \& Mazzucato, 2008). The development of the transnational approach to migration studies was accompanied by new methodological positions, highlighting the impossibility of restricting anthropological research on migration to the boundaries of nation-states (Amelina, 2010). This can be operationalized in two ways. One is by basing the research in one geographical location (usually the receiving country), but focusing on the migrants' accounts of home and their feelings of belonging. Another way is by studying both sending and receiving communities, or multi-sited research (Marcus, 1995; Mazzucato, 2008a). In this study, I opted for the latter. A multi-sited ethnography across the three contexts where families livethe Netherlands, the UK and Sudan-allowed me to understand the roles and guiding mechanisms of two key institutions in the provision of social protection: welfare and family. Moreover, by conducting research with different family members across multiple locations, I could unpack the complexities of providing social protection throughout diverse contexts when resources are limited.

Multi-sited research aims at observing social practices that are produced in different geographic locations, where the object of analysis cannot be accounted for 
by staying in a single place (Marcus, 1995). Following connections, associations, and relationships is, thus, at the heart of multi-sited ethnographic fieldwork (Marcus, 1995: 97). In the study of the cross-border flows of goods, services, people or ideas, the mobility of the researcher becomes crucial (Amelina \& Faist, 2012; Falzon, 2009; Marcus, 1995; Mazzucato, 2004). However, it is precisely the mobility of the researcher that challenges traditional long fieldwork stays as the core procedure of anthropological research (Amelina, 2010). Indeed, to get a sense of the cycle of social life, ethnography usually requires researchers to get immersed in a single social context for an extended period of time, preferably one year. Such long fieldwork stays tend to focus on settled and sedentary ways of life, usually in a particular site, like a village or an organisation (Baldassar et al., 2007; Mand, 2011). Therefore, some anthropologists might dismiss the 'being there... and there... and there!' (Hannerz, 2003: 2002), that characterizes multi-sited research, as shallow and useless.

Conducting ethnographic fieldwork in different geographical locations, with a thorough understanding of the different contexts, in a relatively tight time-frame, poses the researcher with the challenge of finding the right balance between depth and breadth (Mazzucato, 2009a). However, multi-sited fieldwork can produce insightful data on areas of study that have received little attention in anthropology, that is 'the non-local spheres of life that are not easily captured by traditional localized fieldwork methods, but that are of growing importance as people become more and more interconnected and mobile on a global scale' (Fog-Olwig, 2007: 22). Indeed, through a multi-sited approach, I gained a more holistic vision of the TSP processes by exploring 'the two sides of the coin', that is, both the migrants' and their families' accounts of their experiences, provision and reception of social protection. Therefore, the main units of analysis in this research are not the individual migrants, but families linked to each other across national boundaries; that is, a 'matched sample' (Mazzucato, 2008: 72). Matched-sample studies collect information from both sides, here and there, and they are particularly suitable to address questions about the working mechanisms of transnational flows. By collecting information from both sides (sometimes more, since families were spread across the three countries), I gained a deeper and more nuanced understanding of how reciprocal relations of support are sustained across borders and what the implications are for different family members. Whereas I produced relatively limited data on the specific local sites where the research took place, I could produce thick data on the family relations and their TSP arrangements, which are the ultimate field-site of this research. This does not mean, however, that the different geographical contexts were irrelevant. On the contrary, the specific welfare and social protection contexts in the three countries were extremely important to understand the families' strategies to cover for their social protection needs. Yet, nowadays local places are intersected by increasingly global movements of capital, people, labour relations, ideas, values or laws, whereby a place can no longer be fully understood by just staying there (Merry, 2000). Rather 
than becoming the centre of the research, the different sites should be seen as the background in which family relations and TSP arrangements develop.

\subsubsection{Some practical implications on conducting multi-sited matched-sample fieldwork}

Although multi-sited ethnographic fieldwork allows the researcher to gain invaluable insights on the transnational aspects of migration, it is important to consider some practical hurdles attached to it. Conducting multi-sited matched-sample research is time consuming and relatively uncertain. After having established initial contact with participants in Europe, time was needed to build the necessary rapport to identify their family members and their location, and to seek consent to contact them during fieldwork in Sudan. Bearing in mind the delicate political situation in Sudan and the fact that many respondents had fled the country for political reasons, gaining the necessary trust to access their families involved multiple meetings with the migrants in Europe. As pointed out by several participants and key informants, as well as through my own observations, in Sudan there is a generalized concern related to intelligence and security services of the Sudanese Government, whereby Westerners are an immediate source of security concern. Therefore, having a khawaja (white person) nosing around someone's house was seen as a possible threat to the security of the family.

Even when respondents would agree to put me in contact with their families, there was the uncertainty that they would change their mind, as happened in some cases. Therefore, the time invested to gain access to the respondents' families was not always fruitful. Moreover, between the fieldwork in the Netherlands and Sudan, I spent 4 months conducting fieldwork in the UK. During this time, I had to maintain a constant and regular contact with the respondents in the Netherlands to keep the relationship fresh and hope to guarantee the future access to their families in Sudan (Figure 4). Finally, conducting fieldwork in three different countries also required a considerable investment of time in arranging practical issues, such as: finding a new place to live in every location, making different travel arrangements (e.g. visas, tickets), finding a host organisation, or simply learning how to make an efficient use of the public transport in each site. 


\section{Chapter 3}

Figure 4 - Graphic representation of the multi-sited fieldwork.

October 2014

Drafting research plan and ethics selfassessment

Pre-fieldwork interviews with experts \& mapping Sudanese community in NL

Thematic outline of semi-structured interviews

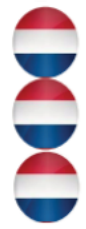

July 2015

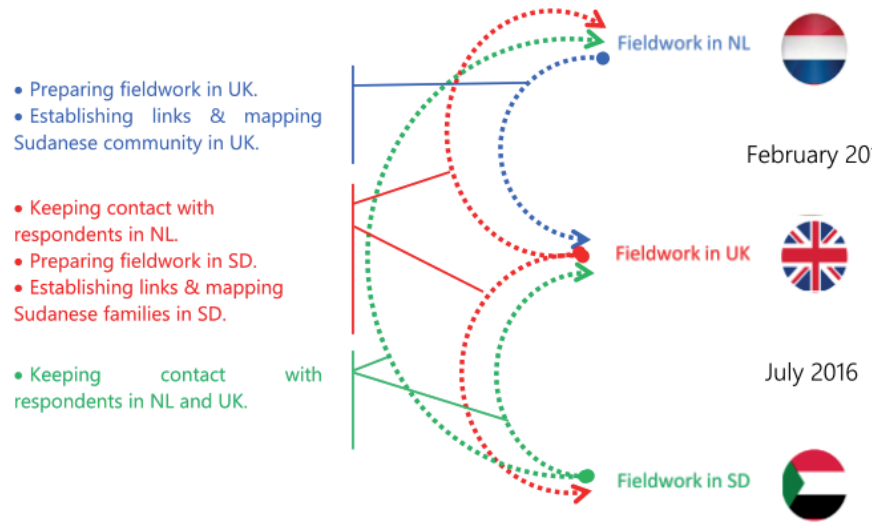

November 2016

Analysing data with Atlas.ti

Re-visiting respondents in NL

Writing up findings

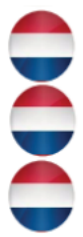

June 2018

Source: Fieldwork. 


\subsubsection{Sampling}

In my research I used purposive sampling by employing snowballing, whereby I started by approaching a contact person, through whom I could reach other willing participants (Bryman, 2004). Despite their good intentions, gatekeepers are very likely to shape the development of the research by channelling the researcher to the gatekeeper's existing network of friends or other specific boundaries (Hammersley \& Atkinson, 1995). To avoid such bias and end up with a demographically homogeneous group of respondents, I started several 'balls' with different gatekeepers in different cities, including: personal contacts, Sudanese organisations, NGOs, churches and social media.

Echoing Vertovec's (2007) call to do justice to the 'super-diversity' within ethnic groups, in my fieldwork in the Netherlands and the UK, I started by contacting and pre-selecting informants according to three main variables that I expected to have some impact on the engagement in different forms of TSP: legal status, socioeconomic status and gender. The heterogeneity characterizing the Sudanese community in the Netherlands and the UK allowed for a maximum variation sampling, through which I could investigate the impact of different socio-economic and legal status on social protection arrangements the migrants and their families 'back home' engage with. A maximum variation sampling seeks to gain access to a wide range of cases that maximize the variety of perspectives and differences (e.g. race, gender, legal status, etc.) (Bryman, 2004).

The Sudanese community across Europe has different particularities, closely related to the demographic characteristics of the different groups arriving at particular moments in time. First, diversity is visible in the legal and migration status of different migrant flows. The different migration routes characterizing the Sudanese migrants in Europe (see Chapter 5) have resulted in high diversity in terms of migration and legal status. Such diversity was expected to have an impact on the way migrants organise their social protection, in that different statuses might facilitate or prevent access to certain provisions, especially state-and market-based provisions.

Second, the migrant's socio-economic status, understood as combination of education, income, and occupation (American Psychological Association, n.d.), was expected to be relevant in understanding how people with different socio-economic status navigate their social protection. For example, individuals with a higher education should (at least theoretically) be able to access better jobs, which will subsequently facilitate access to resources to cover for their basic needs and cope with risks. However, migrants' qualifications and skills are often not recognised in the receiving countries, which results in different levels of socio-economic downward mobility (Portes \& Rumbaut, 2001; Godshaw, 2014; Falzon, 2009). Moreover, whereas assessing the migrant's socio-economic status here could be done by considering their employment situation, educational background and reception of social assistance among others factors, assessing the socio-economic status of their 
families back home was problematic. For instance, while several respondents in Europe faced difficult financial situations - fully depending on social assistance or, in the case of undocumented migrants, being homeless and without financial support - these migrants' accounts of their families in Sudan indicated a relatively accommodated life.

As the research progressed, the migrants' region of origin emerged as an important factor in their social protection arrangements. Although most of my respondents were refugees, people coming from Khartoum and the Nile region seemed to be in a better-off position than those from Darfur or the Nuba Mountains, for example. Most interviewees originating from Khartoum came from middle-class families, with some relatives living and working abroad - the Gulf, the United States, or Canada. Their family homes - where their parents often lived-were usually based in Khartoum or nearby, whereby receiving remittances or accessing resources (e.g. hospitals, banks, schools, etc.) was easier. However, in the cases of respondents originating from Darfur, many of their relatives used to live out of farming in remote areas far away from the capital, while some other family members stayed in IDP camps. In these cases, accessing resources, sending money, goods, or simply contacting them, became much more problematic. Those with some relatives in Khartoum, lived on the outskirts of the city, in quite underdeveloped areas without electricity or running water. Thus, the ways in which these people can access social protection is different. For example, the fact that most hospitals and universities are based in Khartoum might have an impact on the way social protection arrangements are made by a family living in Omdurman, as compared to a family living in A1Fasher, over $1,000 \mathrm{~km}$ away from Khartoum. Therefore, the region of origin was taken as a proxy for different socio-economic statuses.

Finally, the gender of the main respondents in Europe was another aspect considered in the sampling. Although Sudanese migration to Europe is dominated by men (see Chapter 5), who usually come alone seeking asylum, the presence of women is increasing. Having variation in terms of gender was expected to provide insights on how migration affects the development of traditional gender roles in the provision of social protection. Whereas in Sudan men are traditionally the main breadwinners and women's tasks usually revolve around the provision of care to different family members, when women migrate independently or become independent afterwards (e.g. after a divorce), different dynamics are expected to take place in the way social protection is organised within the family.

\section{Exclusion}

I considered two aspects for exclusion in the sample. First, the length of stay in Europe must have been over one year. Including people with different lengths of stay serves the aim of obtaining migrants' different experiences of social protection in the different stages of migration. Yet, people who have experienced very short stays (e.g. students, visiting relatives) might either not have faced significant protection needs, 
or have faced very specific ones, which are not considered in this research. Second, all respondents must have relatives in Sudan and/or in the other European country (the UK or the Netherlands) in order to be able to investigate TSP arrangements.

\section{Sample size and general characteristics of the sample}

Although the size of the sample varies enormously depending on the research question and other aspects, much qualitative research points to an average of 30 subjects (Baker \& Edwards, 2012; Guest, Bunce, \& Johnson, 2006). I conducted my research with 21 respondents in the Netherlands (one couple), 22 respondents in the UK (one couple) and 19 of their family members in Sudan or matched samples (Appendixes I, II and III). Several respondents in the UK had moved from the Netherlands, where they had first arrived as asylum seekers and then lived for several years as refugees. Therefore, three respondents in the UK were the matched side of the respondents in the Netherlands; that is, both families were 'linked to each other by being part of a same social network' (Mazzucato, 2009a). This fact allowed for a more insightful understanding of how these families navigate the different social protection systems beyond a single sending and receiving country.

In cases of couples (with or without children), interviews were usually conducted with either the husband or the wife, but the other partner was often around and sometimes intervened in the interview or in informal conversations. Those partners whose participation was very sporadic or random have not been included as respondents. Only those whose participation was meaningful enough and allowed me to understand their own family networks were included as respondents, although they were considered as one research unit. The sample included roughly half-andhalf men and women of ages varying from early 20 s to mid-50s, including: single men, married couples, and divorced mothers and fathers with children. The educational background of the respondents varied, but the majority had a university degree from Sudan. Previous research has found that the educational background of (northern) Sudanese arriving in Europe from 1989 was relatively high (Abusabib, 2007; Assal, 2004; van Heelsum \& Hessels, 2005). In particular, research conducted in 2006 on the biggest African migrant groups in the Netherlands showed that the Sudanese had higher education levels than other African groups, with $30.2 \%$ of Sudanese asylum seekers holding university degrees, including medicine, law and engineering (van Heelsum \& Hessels 2006). The high educational background of the respondents can be explained because the Sudanese middle class was the main target of the Islamist regime after the coup, whereby the civil service throughout the country was purged and professionals were massively dismissed (Abusabib, 2007). Moreover, research has shown that migrants are not usually the poorest of the poor (Bakewell, 2009), whereby those who manage to flee to Europe or beyond, often have the necessary socioeconomic capital to do so. 


\subsection{Methods}

The social protection needs experienced by transnational families throughout the years often involves complicated and prompt arrangements. Needs might emerge unexpectedly and require the immediate support of multiple family members, who might live abroad and face their own setbacks in their host societies. The sense of obligation and capacity to provide transnational support may shift with each interaction between migrants and other family members back home or elsewhere (Baldassar et al., 2007). Therefore, the most appropriate approach to such complex and family relations is ethnography, as described by Martyn Hammersley and Paul Atkinson, which allows the researcher to

'participat(e), overtly or covertly, in people's daily lives for an extended period of time, watching what happens, listening to what is said, asking questions in fact, gathering whatever data are available to throw light on the issues that are the emerging focus of inquiry' (1995: 1).

The initially open-ended exploratory character of ethnographic research means that it is often not clear from the beginning where observations should take place, or how sampling and interviews should be conducted. Decisions on who to interview, where and how to gain access involves drawing on interpersonal resources and strategies, which are shaped and developed over time (Hammersley \& Atkinson, 1995). In the following sub-sections I explain how the main methods of this research-interviews and observations-developed over time.

\subsubsection{Interviews and observations}

To understand how Sudanese transnational families navigate specific social protection needs over time and space, it is necessary to shift the focus from the individual migrant in the receiving country to the migrant's full family constellation, which might span across different nation states. Collecting life stories of different family members is a powerful and insightful tool to illustrate how resources are accessed and circulated over time. Enquiring about individual specific social protection needs in any particular moment might help us elucidate who the providers and receivers of support were in that concrete event. In doing so, however, we run the risk of splitting the different social protection domains in clear-cut and independent compartments, which is often not the case. Life stories entail an account of an individual's movements through life, not only in geographical, but also in socioeconomic and cultural terms (Fog-Olwig, 2007). The life stories of one or more individuals within family networks allowed me to map and understand both the personal and family situation when specific social protection needs occurred. In doing so, I was able to find out why certain support mechanisms were accessed or preferred over others, and how such mechanisms were implemented. Moreover, such 
accounts shed light on the cultural values and social norms associated with the individuals' family relations (ibid.).

All interviews were conducted by me in English, German or Arabic, often at the houses of the respondents, and in some occasions at their work-place, especially in the UK. Collecting data in 'natural' settings, such as public spaces or the houses of respondents, allows the researcher to observe interactions with other family or community members, as the interview develops (Hammersley \& Atkinson, 1995). Life-story interviews were person-centered and usually lasted between 2 and 4 hours, split across different days. The interviews were semi-structured and were developped in a conversational manner. I made use of a topic guide to make sure I covered all the revelant aspects with all respondents in a consistent manner (see Appendix IV Topic guide). During the first part of the interview, I invited my respondents to tell me about their life before and after leaving Sudan. Then, I asked them to elaborate on specific aspects, such as their professional situation, the evolution of their legal status, or the migration process. Once these aspects were covered, I asked them about their families in order to map the different family constellations, and later on, understand how resources were circulated. Respondents were given the freedom to describe 'family' according to their own views and experiences. Nevertheless, there seemed to be a clear pattern, which included: spouse and children, parents, siblings and very often nephews, nieces, cousins, uncles and aunts. Revealing family-related information was highly sensitive and required long contact with the respondents to build trust and eventually access this information. Indeed, several respondents, who had talked about their lives quite openly, became defensive when I asked them about their families. 'What do you want to know about my family?' one respondent asked me defensively. 'I don't like to talk about my family', another told me after having met him for the fourth time. Such reticence to provide family-related information was both frustrating and ellucidating of some interesting dynamics related to how families are displayed (Finch, 2007).

During the second and subsequent interviews, I asked my respondents to elaborate on specific social protection events, including: unemployment, health and disability, children and dependants, old age, education, housing and other life events. For each domain, I asked them to elaborate on some critial situation that they or their families had faced. Having asked about their family network before was helpful in two ways. First, it allowed me to focus some questions around particular aspects. For instance, respondents with elderly parents, orphan nieces or nephews, or disabled relatives back home, were specifically asked about who was caring and financially providing for them. These questions often led respondents to narrate specific events when, for instance, family efforts needed to be coordinated to finance the costs of some relative's medical treatment abroad. Second, more general questions on how the migrants and their families helped each other elucidated crucial insights on the concepts of 'help' and 'duty'. When I first asked my respondents how they helped their families back home, they usually answered vaguely, often claiming that they did 
not really help them much. However, when I asked more specific questions about how particular crises were handled, a full account of multiple instances of help were provided. As some respondents clarified, the support provided to family members was not considered help, but duty.

An ethnographic approach allowed me to draw on a range of multiple sources of data besides life-stories, including: informal conversations, and observations in social events and in family homes. Following the main interview, I continued to meet several of my respondents during the 14 months when I conducted fieldwork across the three countries. This allowed me to have multiple informal conversations with them and some of their relatives and visiting friends, while observing their daily practices. Indeed, a key tenet in qualitative research, especially in ethnography, is that 'the social world should be studied in its "natural" state' (Hammersley \& Atkinson, 1995: 6) to enable the researcher to describe what is happening in a specific context and to explore which are people's views on their and others' actions in a particular setting (ibid.).

By conducting interviews at the respondents' homes I could carry out observations, the other key method of my research. When I first entered the field in the Netherlands, participant observation was not meant to be a method of data collection in this research. How can a researcher observe a social protection crisis happening within a family? Living with them until something happened was not possible, especially because my respondents lived across multiple cities, and most of them had quite busy lives. Nevertheless, it was precisely my constant travelling to visit the different families across the country that allowed me to actually live with them. It happened quite often that after the first interview, the respondents would offer me to stay in their homes for several days until I had completed all the interviews in that particular city. This way I could observe how some crises were dealt with 'on the spot', such as the sudden death of a community member, or the development of some TSP arrangements within the family. It was precisely these observations that enabled a 'thick description' (Geertz, 1973) of my participants' experiences in the Netherlands, the UK and Sudan.

During my fieldwork in Sudan, observations were an invaluable tool. Whereas in some cases conducting life-story interviews was possible, in some other cases, different situations (such as: multiple social obligations, constant interruptions by children, neighbours or friends, or total lack of privacy) led me to rely mainly on observations and informal conversations. When I visited some families outside downtown Khartoum, I was invited to stay with them, whereby I could engage in conversations with different (mostly) female family members and observe their interactions with other relatives. These observations of the families' daily lives allowed me to gain depth in 'the biographies of the participants' (Hammersley, 2006: 4-5) and to triangulate the data I had obtained from their relatives in Europe. As stated by Holliday, this type of 'day-to-day research comprise(d) shortcuts, hunches, serendipity and opportunism' (2007: 7), which led me to participate in multiple social 
events, such as: wedding ceremonies, farewell gatherings for a relative moving to the Gulf, or the hosting of relatives who had moved to Khartoum from a remote area in Sudan to receive medical treatment or attend university. In some cases, I visited the families of my respondents in Europe with the respondents themselves, who had travelled to Sudan during their holidays. On these occasions I witnessed the development of specific social protection arrangements, such as: shopping around for a wheel-chair for a handicapped parent, choosing a piece of land for the future building of a house to retire to, or distributing medicine to elderly relatives or sick children.

Simultaneously, as the interviews and observations developed, I wrote up notes, transcribed interviews and regularly re-read my data. By the end of my fieldwork, I decided to use a qualitative analysis software programme to help me analyse the large amount of data I had gathered: Atlas.ti. The coding process took place in an inductive manner, that is, as I read the interviews, I created codes for each relevant piece of information. As the analysis continued and the number of codes increased, I dealt with this systematically, by periodically reviewing, merging and grouping codes in families of codes, which helped me to establish relations between codes and visualise the analysis. Figure 5 is an example of how I related and linked codes together. 


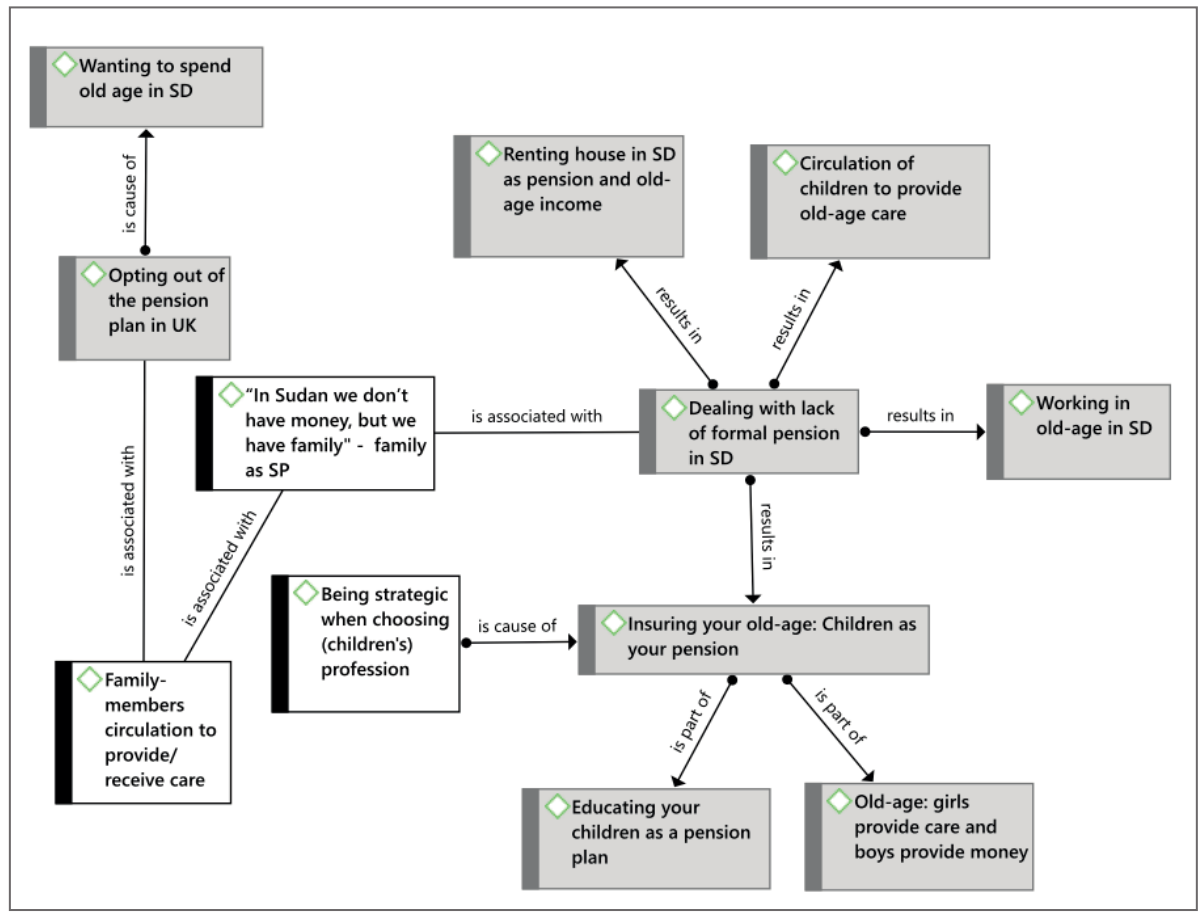

Source: Author's analysis of fieldwork data.

To keep contact with my respondents in the Netherlands while I conducted fieldwork in the UK, before going to Sudan, I deployed additional techniques such as postcard writing and telephone/Skype calls. Sending postcards, in particular, was highly appreciated by all respondents, and helped to keep the bonds throughout the research. A faster, less complicated but more mentally demanding strategy, was to call my respondents and ask them how they were doing. Showing interest in people's lives was always highly appreciated, and long conversations were held over the distance. Engaging in phone conversations, however, involved my having to re-read their interviews and notes while I was conducting fieldwork with new respondents in another country. This was, inevitably, disruptive, but also enriching, since it allowed me to observe-and sometimes be part of-links and interactions across transnational social networks. Yet, these instances raise some ethical considerations on the role of the researcher, who, as detailed in the following section, becomes to a greater or lesser extent, part of the network.

\subsection{Ethical considerations}

Before starting fieldwork, I drafted and submitted an ethics self-assessment to the Ethics Board at Maastricht University to be reviewed and approved. Some of the points addressed deal with issues, such as: confidentiality, personal data management 
and storage, dealing with vulnerable populations, the security of the researcher and obtaining a disclaimer to conduct research in Sudan. After some comments, revisions and changes, the ethics assessment was approved and the green-light was given to start conducting fieldwork. Nevertheless, despite the thoroughness of this assessment, other ethical considerations emerged during fieldwork.

To illustrate the ethical implications of conducting multi-sited matchedsampled research with transnational families, I start this section by introducing one of the cases.

Sharif was one of my respondents in the Netherlands, a 22-year-old Sudanese, who arrived in 2014 asking for asylum. His case had been constantly rejected, so for the last 3 years he had been undocumented. By the time I met him he lived in an occupied shelter with other irregular migrants. He agreed to be interviewed, but every time we met, his 'story' changed and he was quite evasive about his family situation. Therefore, after our third interview, I thanked him for his support and we parted ways. Under these circumstances, I did not hold any hope to ever meet his family.

A week after my arriving in Sudan, I got a message from Sharif, who had found out about my whereabouts in Facebook. Quite unexpectedly, he asked me to go and meet his mother. I agreed, but I started to wonder what version Sharif's mum had of his life in the Netherlands. As if on cue, he texted me his conditions: 'You don't have to tell them about me if they ask you about me, ok? Am just ok, fine'. I agreed, and a couple of days later I met his brother, Hakim, who drove me to their house in a well-off area of Khartoum, where he lived with their mother and the toddler of their deceased brother. In the car, Hakim asked me how Sharif was doing. I gave him a vague answer, avoiding disclosure of Sharif's situation. Much to my surprise, Hakim said he knew Sharif was undocumented and often ended up in detention. I did not know what to say, so I just kept quiet and let him speak about how he wished Sharif would return, join his business and help him and their mother. As we arrived home, I met Sharif's mum, Asia, a smiley woman in her mid-50s. She also asked me about Sharif. Following Sharif's instructions, I told her 'he was fine'. During that and other subsequent meetings, Asia told me about their life, which had nothing to do with the life Sharif had told me before. She also longed for Sharif to come back, because ever since her son had died, they needed help. Upon her son's death, she had had to move from the village-where she hoped to spend her old-age - to his son's flat in Khartoum, and go back to work to give her grandchild a good education in a private school. Although the child's mother lived nearby, Asia was the main care-giver and she and Hakim were the main providers. She was tired, and she told me how she was pushing Sharif to marry a decent Dutch Arab woman to get the papers and be able to work and help them financially. Otherwise, she just wanted him to come back.

When I returned to the Netherlands, I met Sharif to give him some presents his mother had given me for him. It was like meeting a completely different person: a much more relaxed and talkative Sharif, who told me 'his story' with striking honesty.

\section{$\cos 80$}


This vignette illustrates the strength - as well as the multiple ethical considerationsof conducting multi-sited matched-sample research with transnational families. Being able to hear the two sides of the story allows the researcher to understand the position of the migrants and those left behind in the handling of complex family processes in the provision of social protection, or the inability to do so. Accessing such information without becoming the conveyor of personal 'secrets' or family grudges on either side, takes an important emotional toll on the researcher, who must develop strategies to circumvent these situations without betraying the trust of the respondents.

Before starting my fieldwork in the Netherlands, I prepared an information brochure for potential respondents (Appendix V - Information brochure for participants (English), which explained the aim of the research and what was requested from the participants. I wrote one version in English and another one in Arabic, for which a Sudanese friend helped me. As soon as he finished the proofreading, he complimented me on the relevance of the research, but told me that I would not be able to conduct such research, because Sudanese migrants would never let me contact their families back home for several reasons. First, there were the security concerns mentioned before. Second, despite being highly educated, many Sudanese were stuck in menial jobs in Europe, which was shameful for themselves, and their families, who were often not aware of this downward mobility. Third, if I aimed to include undocumented migrants - which I did - they would never tell me their true story, let alone allowing me to meet their families and have any information leaked from either side.

I reflected on my friend's concerns-also shared by some of my key informants - and thought about how to address them. I decided to first focus on my respondents in Europe, get to know them, let them know me, gain their trust, and only in later stages ask them for permission to meet their families in Sudan. From this perspective, my respondents in Europe became the gatekeepers themselves for their families back home. As Hammersley and Atkinson explain, an 'argument for not always providing a full account of one's purposes to gatekeepers and others at the beginning of a research is that (...) they might refuse access in a way that they would not do later on in the fieldwork' (1995: 73). That is, once people get to know the researcher as a person who can be trusted, access may be granted that at an earlier stage would have been refused point blank (ibid.). This is not to say that I was hiding the fact that I would have to meet their families at some point. Indeed, upon the first meeting, all the potential respondents were given the brochure in the language of their choice and explained verbally about the research. In both cases, 'the family issue' was mentioned. However, rather than telling them that meeting their families was an absolute requirement from the beginning, I did not go back to this point until in later stages, when we both - the respondents and myself - felt we could trust each other. While this strategy was rather risky, in that I could not be sure of their agreeing 
with my meeting their relatives until later stages, it seemed the best way to go about it.

Whereas some respondents were not too keen on my meeting their families in Sudan, others were, from the very beginning, quite relaxed - and even excited - with the idea. As for those who were more hesitant about this issue, I focused my attention on our relationship here and only went back to the question of meeting their families when I started to plan my trip to Sudan. In both cases, the fact of me offering to bring money and things for their families was very useful, but not practical; on my way to Sudan I travelled with my suitcase full of presents and several thousand Euros that I delivered as soon as I could. However, in spite of me being the carrier of goods, very few people gave me the contact details of their relatives in Sudan before I left Europe. It was only when I arrived that things started to 'flow'.

Travelling to Sudan during the summer holidays allowed me to visit the families of some respondents with the respondents themselves, who spent their holiday break in Sudan. Being introduced by the respondents facilitated the access enormously and allowed me to observe the different family dynamics. However, it also became a sort of barrier, in that the migrant was always there, facilitating but also limiting the exchange of certain sensitive information. Indeed, in some of these cases, access to the family without the migrant's presence was not allowed.

To my surprise, respondents with whom I felt I had developed high levels of trust did not allow me to visit their families - in some cases this happened because some relative was seriously sick, and the respondents saw me as an additional burden to their families, who had already enough headaches taking care of the sick person, let alone a khawaja. In other cases, however, I found myself receiving phone calls from respondents with whom I felt I had not managed to gain enough trust, asking me to please visit their family. Therefore, even though trust is crucial when conducting multi-sited matched-sample research, there are other elements affecting the development of the research, whereby flexibility and adaptation to the changing circumstances was key.

Getting into the respondents' houses also raised ethical questions. My spending several days with them allowed me to observe very intimate practices and in some cases I became a sort of 'counsellor' in family issues. In these circumstances, drawing the line between what was research and what was not became very complicated and blurry. At the beginning, I opted for asking my respondents over and over again whether they were ok with being interviewed for the project. However, I soon found out that this was actually not a good idea. When I asked this question to one participant for the umpteenth time he became quite upset and said: 'Why do you ask me again? I already told you yes!' From this moment I stopped my constant asking. Instead, when I wanted to make sure that people understood that I was doing research I dropped lines like: 'Oh, this is so interesting for my research!', or 'Can you explain to me this with more detail so that I can consider it for my research?' 
In many of the family houses I visited there were small children. Whereas interviews with children were not conducted at any point, it was often the case that children would sit with me and tell me family gossip that I had no choice but to listen to. None of the information obtained this way was used in this thesis. Only in a few cases, when the information was extremely relevant, I invited the parents, only if they wished to do so, to elaborate on the stories the children had told me.

Finally, when my fieldwork time came to an end, 'leaving the field' became a slow and relatively incomplete process. The proximity and high levels of trust that I had reached with some participants put me in the personal and professional dilemma of whether and how I should put an end to our relationship. Up till now, I regularly receive phone calls or messages from some of my participants, asking about me and my family's wellbeing, while updating me on their life situations. Sometimes, these calls come together with some request for help, which I cannot turn down. In the case of the Netherlands, respondents living nearby would often ask me to pay them a visit, where we would simply talk about our respective lives. In cases where people had been going through difficult moments (e.g. a sick relative, a divorce or coping with their undocumented status) I felt the moral and personal duty to call them every now and then to ask them how they were doing. From this point of view, thus, one could say that I never 'left the field'. Nevertheless, as interesting and relevant as they were, none of the personal conversations and information exchanged during these encounters after fieldwork were considered as data to be analysed. This was because of two main reasons. On the one hand, there comes a point when fieldwork needs to end, so that the analysis can start. On the other hand, none of the additional information found after fieldwork substantively changed my findings. The only occasions when I collected additional data outside my fieldwork time, was when I had some doubt about some information given during fieldwork. In these cases, I called the respondents and asked them to clarify a particular point for the purpose of my thesis.

\subsection{Reflexivity and positionality}

The opposing notions of 'insider' and 'outsider' have been frequently used in qualitative research to describe the position of the researcher vis a vis the researched group. This clear-cut divide, however, is based too much on rigid categorical divisions (Kelly, 2013). In qualitative research, it is important to bear in mind the researcher's relationship to her participants, noting that not everyone will view her in the same way (ibid.). The work of feminists and some geographers has highlighted the importance of critically reflecting upon the multiple positionalities of the researcher and the ways in which different identities may shape research encounters, processes and outcomes (Hopkins, 2007; Kobayashi \& Peake, 1994; Mohammad, 2001; Vanderbeck, 2005). 
Unlike my participants, I am not Sudanese, I never experienced armed conflict or political distress that forced me to leave my country of birth, and I am not black or Muslim. Nevertheless, like many respondents, I am a remittance-sending labour migrant from a working-class family, who has often depended on social benefits, informal menial employment and family networks to make ends meet. During the first encounters with some respondents, there was a certain degree of distance. Some people threw accusations of 'us', Westerners, being individualistic, living 'the life' and not caring about our families, while 'them', Africans, had to live with the burden to provide for everyone back home. Such accusations created a bigger and unfair divide between 'us' and 'them', not only for my respondents, but also for me as a researcher. In addition to this, most participants assumed in our first encounters that I was Dutch and some of them even thought I worked for the Dutch immigration authorities (IND). Explaining that I was actually a student from Spain helped to create a much more relaxed atmosphere, and establish certain bonds. Indeed, sharing my stories became a useful tool to bond with participants, to overcome the 'us-against-them' barrier, and to build rapport (McKay, 2002). Being myself a migrant from Spain - a country with very low welfare support and where informal work is common practice-and coming from a working-class family, seemed to 'break down' some of these barriers. It was only when I started to share my personal stories of having worked informally as a cleaner or as a teacher, and of sending remittances and keeping close contact with my family, that people would share their own experiences too. Third, the fact that I had been to Sudan and studied at Ahfad University for Women, brought me much closer to many of my respondents, who either themselves or some female relative had studied there. Finally, my being able to speak Arabic was an important aspect to lay the ground for a non-exploitative two-way conversation (Spivak, 2004), which was extremely appreciated by all participants.

\section{A female white non-Muslim woman conducting research in a patriarchal Muslim society.}

'In many ways qualitative research is what we all do in everyday life. We have continually to solve problems about how we should behave with other people in a wide range of settings. (...) This would involve analysing behaviour and language, working out how and when to be formal or informal, learning new technical terms, specialist turns of phrase, what constitutes humour, when to be serious and when not - attitudes, values, relative status' (Holliday, 2007: 10).

As a white non-Muslim woman, conducting research in a patriarchal Muslim society across different settings resulted in having to overcome different problematic gendered situations. The gender of the researcher can play an important role in different aspects of the research itself, such as: accessing certain respondents, being taken more or less seriously, or having to follow certain social norms, which influence the outcomes of the study. As a young female researcher, I was often patronised by 
some of my male respondents and key informants, both in Europe and Sudan, who were older, more experienced and probably did not consider me a serious researcher. Usually, I tried not to take this behaviour personally and often played along with the role they had decided to assign me - a naïve young woman who needs help to do her work. Indeed, by being perceived as 'not threatening' I often benefitted from gaining access to information and places. However, on some other occasions I had to put a drastic end to certain patronising behaviours, which were certainly endangering my research or scaring away potential participants. Throughout my fieldwork I was sometimes introduced to potential gate keepers, often old Sudanese migrant men, who claimed to know every Sudanese in their city. When I would tell them about the difficulties I was experiencing to find respondents, they would often smirk and claim that they could find me hundreds of people to interview in a few days. Although I always explained to them very clearly the purpose of my research and gave them the informative brochure, they usually conveyed to the potential participants a very poor and inaccurate description of the project. Once, for instance, one of these men told potential respondents that my research was about how much money (remittances) they sent to their families. The result was that none of the people he contacted wanted to participate, even after I gave them the accurate objectives of my research.

Being a woman also affected the way in which I behaved and conducted fieldwork in the three settings. Whereas in Europe it was mostly ok to be alone with men, in Sudan the situation was different, and often I had no choice but follow the social rules and stick to the women in the families. The separation of spaces in Sudan (Nageeb, 2004) made it difficult for me to mingle with men as much as I did in Europe, especially when I was invited by some respondents to stay in their houses. As it happened very often, even when the main contact in Sudan was a male relative, as soon I stepped into their homes, I was left with the women. My gender, the gender of my participants and the myriad of social rules around it, shaped the way in which research was conducted across the different settings.

Doing ethnography is, indeed, a gendered process, where gender norms, the sexuality of the researcher, and multiple power relations directly influence not only the research, but also the researcher's wellbeing (Kloß 2017). Although it is a recurrent problem in ethnographic research, sexual(ized) harassment during fieldwork is often dismissed as something unremarkable (ibid.). Sexual(ized) harassment refers to 'a coercive behaviour, which may include gestures, actions, and other modes of verbal or nonverbal communication, with sexual connotations, which intimidate, humiliate, and exercise power over another person' (Kloß 2017: 399). As opposed to sexual harassment, 'sexualised harassment' highlights the fact that the core of this behaviour lies on ways of reinforcing patriarchal power, which is usually a combination of male economic power, gender-based social power, and role-based power (ibid: 400).

During fieldwork I experienced different situations of sexualized harassment. Probably the worst one took place in Sudan when, on our first meeting, the brother 
of one of my respondents in the UK tried to make unwanted sexual advances on me. Although I eventually managed to 'escape' the situation, my dilemma was whether I should meet him again to complete the interview. He was the only matched sample of that respondent, with whom I had invested a lot of time and effort to build up a trust relationship and gain access to her family, whereby letting go of this matched sample would have meant letting go of a lot of work. Eventually, I decided to bite the bullet and meet him one final time and finish the interview, which I did at the expense of some unwanted touching and awkwardly avoiding attempts of kissing. The other two occasions when I encountered sexualized harassment happened with a gatekeeper and a key respondent, in the Netherlands and Sudan respectively. The latter I had known for a very long time, and I believed to have a genuine relation of friendship with him. Aware of their role as gatekeepers, harassers are conscious of their power to restrict a researcher's access to the community and information, and therefore, the researcher's dependency on them (Kloß, 2017). In all three instances I felt unprepared to handle the situation and constantly asked myself if I had naively crossed some thin line that had led these men to make a pass at me. I felt confused at both personal and professional levels, and I wondered what to do, how to confront the situation and what would be the implications of me revealing the events. In the case of the key informant in Sudan, he was a friend of the host family I was living with and could possibly jeopardize my stay in Sudan. The gatekeeper in the Netherlands had the power to either facilitate or block my access to an already small and hard-to-access community.

Handling situations of sexual(ized) harassment in a foreign environment without a personal support network leads to additional stress, insecurities, and selfguilt in that a 'good anthropologist' would not 'have gotten herself into such situations in the first place' (Clark \& Grant, 2015: 2). In all three instances, especially the ones in Sudan, I felt the urge to share my experience with someone, but I did not know whom. Moreover, as described in multiple ethnographic works and colleagues, adventurous tales and different hardships are part and parcel of doing fieldwork, so I could not help but wonder whether I should consider these events as mere 'anecdotes'. A couple of days later, however, I overheard some Sudanese and nonSudanese colleagues at work talking about similar incidents with the same key informant. I felt relieved and told them about what had happened to me. They sympathised and explained that my being a Western female had nothing to do with these men's behaviour. On the contrary, it had actually become common practice for men in high social or professional positions to have their Sudanese young female students or employees paying them back for any type of support with sexual favours. Although I was not Sudanese, the fact of having created close bonds with the host society could have resulted in my trespassing the thin line between outsider/insider, whereby as a female student in Sudan I was being treated like many other Sudanese female students (Kloß, 2017). 
In my reflections on how to face these situations, confrontation was always my last option because of the devastating consequences it might have had on myself and the research. In all three cases I had to put up with the undesired grabbing, touching and kissing and quickly wriggle out of these uncomfortable situations by playing extremely dumb, talking about my made up fiancé or pretending to have another appointment. In the cases of the gatekeeper and the key informant, I simply decided not to meet them again, making up all sort of excuses, until they lost all interest in me. Yet, I could not do the same with the matched sample, who I had no choice but to meet again. Non-confrontation, however, should not be considered the norm, since 'good anthropology' must also take into consideration the personal safety of the researcher (Kloß, 2017).

Finally, it should be noted that sexualised harassment should not be considered only as a result of societal norms, but of an individual's agency (Kloß 2017). During the whole 14 months of ethnographic fieldwork, as well as during my previous experience in Sudan in 2012, I met men who treated me in a much more respectful way than I have been treated in Western countries. Throughout the fieldwork, I often stayed in the house of extremely generous single Sudanese men, who always treated me with absolute respect and without any hidden sexual interest. Ties of fictive kinship were developed with these men, with whom personal stories were shared, and this never led to their trying to take advantage of the situation. As a female researcher, however, it is essential to be prepared to deal with such incidents, avoiding the feeling of self-guilt or professional incompetence (Kloß 2017). Fieldwork is a gendered practice that takes place within gender hierarchies, whereby ethnographers 'are always approached from a gendered, sexual perspective by their informants' (Clark \& Grant, 2015: 7), and vice versa. The characteristics of the researcher -including gender, race or sexual orientation - with respect to participants may create the conditions for harassment in the field (Sharp \& Kremer 2006).

To avoid leaving young researchers to deal with harassment and other potential problems on the field, issues of gender and identity must be addressed during the research design process (Sharp \& Kremer, 2006). In my case, upon return from fieldwork, I shared my experiences with my supervisor, who consequently introduced this issue to the training sessions for the next $\mathrm{PhD}$ cohorts. Moreover, such experiences were shared and discussed in a series of different sessions and also at a personal level with new female $\mathrm{PhD}$ colleagues in the faculty, who were about to start fieldwork.

\subsection{Concluding remarks}

In this chapter I have discussed the methodological and ethical considerations that guided all the different stages of this research. Despite the challenges of conducting a multi-sited (partly) matched-sample ethnography with transnational families, I have aimed to adopt an approach that captures different aspects of social protection 
arrangements within transnational family networks. By linking people and practices across countries, I have obtained insights on migration and social protection beyond the borders of discreet nation-states. With the help of different illustrative vignettes, in each section I have reflected on the most important methodological and ethical aspects of this research. After having established both the theoretical and methodological background of this study, the next two chapters set the migration and social protection contexts in the three countries of study: Sudan, the Netherlands and the UK. 



\title{
CHAPTER 4
}

MIGRATION AND SOCIAL PROTECTION IN

\author{
SUDAN
}




\subsection{Introduction}

At the very early stages of this research, I presented a draft of the first analytical chapter in this dissertation, 'Mobile Populations in Immobile Welfare Systems', in a Sudanese diaspora conference in the UK. During the fifteen-minute presentation, where I mostly discussed different aspects of welfare for migrants and their families, I could see expressions of growing confusion in the audience. When the chair opened the floor for discussion, a young Sudanese man raised his hand and asked: 'But, what do you mean with welfare?' Several heads in the audience nodded in agreement, sharing the same doubt. It was through this man's question and our subsequent discussion on the topic that I realised that my understanding of welfare -where the state is usually responsible for providing its citizens with the basic social provisions such as healthcare, pension, education or unemployment benefits - had nothing to do with the realities of most people coming from Sudan, where the state provisions are weak or non-existent and the family is the most reliable source of support.

To analyse how transnational families navigate different forms of social protection locally and across borders, it is necessary to look beyond the resources available in the receiving countries and understand how social protection is envisaged and organised in the sending countries too. This is important because the needs of the migrants are closely linked to the needs of their families back home, whereby both social protection systems, from sending and receiving countries, shape the ways in which transnational families make use of certain resources throughout the life-cycle. Based on literature review and data collected in Sudan, this chapter provides an overview of the Sudanese migration and social protection contexts. The first section summarizes the different stages of Sudanese migration, highlighting the migration to the West. The second section provides an overview of the current landscape of the social protection schemes available in Sudan. In contrast to the Netherlands or the UK, where most basic needs are provided for by the welfare state (e.g. healthcare, education or pensions) (see Chapter 5), in Sudan, such needs are covered through a patchwork of resources, provided by different institutions -state, market, third sector organisations (TSO) and family networks - , where the state often plays a minor role. This section is therefore organised around these four institutions, highlighting their theoretical and practical roles in supporting people in times of need.

\subsection{Sudanese migration: An overview}

'If you manage to migrate to Europe, or America, life is better, but you have no money... Sometimes I wonder why I spent 37 years of my life in KSA (Kingdom of Saudi Arabia) and did not go to another country...' (Arkaweed, Khartoum, October 2016).

These were the words of Youssif, the 67-year-old father of one of my respondents in the UK, when I asked him about his experience as a labour migrant in the Kingdom 
of Saudi Arabia. Like other Sudanese of his generation, Youssif went to university in the UK, after which he secured a well-paid job in KSA as a computer engineer. When his finances allowed, he married his current wife, a Sudanese woman from Khartoum, who soon joined him abroad. His four children were born in Saudi Arabia, but when the eldest reached high school age, his wife and children moved back to Sudan. This was (and continues to be) common practice among Sudanese labour migrants in the Gulf. Whereas Sudanese children may attend high school in Saudi Arabia, they are not allowed to enrol in Saudi universities, whereby those wanting to access higher education must return to Sudan or move somewhere else. Attending high school in Saudi Arabia, however, makes it more complicated for the children's future enrolment in Sudanese universities, which depends on the score obtained in the Sudan School Certificate examination. Therefore, the most common solution for these families is for the wives and children to go back to Sudan -either to the house that the migrant has managed to build over the years, or to the husband's family house-while the husbands remain abroad working and only visiting each other on yearly holidays. Despite the financial benefits of this family arrangement, Youssif looked back at those times with regret, recalling how the extreme social stratification and the religious control of the Saudi society had led him to live a socially void life, where his main activities were: working, eating, watching TV and sleeping.

This vignette illustrates one of the oldest and most common labour migration trends in Sudan, as well as the family arrangements involved. Labour migration to the Gulf and other Arab countries, such as Libya or Yemen, has probably been the largest and most researched economic migration flow in Sudan. Such is the importance of this type of migration that these labour migrants are referred to by the specific term of mughtaribeen -an Arabic word to refer to those who stayed away from their homeland temporarily in order to work (Abusabib, 2007). Despite its magnitude-with around 700,000 Sudanese working in the Gulf in 2010 - , the overall Sudanese out-migration in the last four decades, involves mixed flows of both refugee and labour migrants (Di Bartolomeo, Jaulin, \& Perrin, 2012; Schapendonk $\&$ Steel, 2014). By the end of 2006 almost the same amount of Sudanese were reported to have fled the country as refugees-most of them to neighbouring countries, and a few of them to the West-, while around 4.5 million were internally displaced people (IDPs) (IDMC, 2007; UNHCR, 2007). The heterogeneous character of the Sudanese outward migration, both regarding the reasons to migrate and the countries of destination, has changed dramatically over the years along the different episodes of political and socioeconomic instability at national, regional and international levels.

Before going into the details of the characteristics of the Sudanese international migration, it is important to clarify two important issues: the lack of data and the separation of South Sudan. On the one hand, measuring the dimensions of Sudanese international migration is characterized by the lack of regular statistical 
data and the inadequate coverage of administrative sources (IOM, 2011). Data on Sudanese emigration usually comes from the Bureau of Sudanese Working Abroad and the Ministry of Labour and Administrative Reform, which only account for regular labour migrants mainly working in the Gulf states and paying taxes in Sudan (Mohamed-Ali, 2011). These data, thus, do not include the hundreds of thousands who left the country as refugees or irregularly. Moreover, as Table 1 and Table 2 show, data sources from destination countries is limited by the adoption of different definitions, exclusion of naturalized people and citizens of Sudanese descent and irregular migrants (IOM, 2011).

Table 1 - Data on Sudanese population in the Netherlands according to different organisations.

\begin{tabular}{|l|c|c|c|c|}
\hline \multicolumn{1}{|c|}{ ORGANISATION } & $\mathbf{2 0 0 0}$ & $\mathbf{2 0 0 5}$ & $\mathbf{2 0 1 0}$ & $\mathbf{2 0 1 5}$ \\
\hline UN-DESA (1) & 3,441 & 5,811 & 4,448 & 4,422 \\
\hline CBS Statistics-NL (2) & $3,453^{*} / 3919$ & $5,798^{*} / 7,285$ & $4,420 * / 6,329$ & $4,439 * / 6,448$ \\
\hline Eurostat (3) & 3,470 & 5,817 & 4,438 & 4,460 \\
\hline
\end{tabular}

Notes: (1) Sudanese migrant stock by origin; (2) $\left(^{*}\right)$ first generation/total population with Sudanese migration background or 'migratieachtergrond'; (3) Sudanese migrants by country of birth.

Source: CBS, 2018; Eurostat Database, 2018; UN-DESA, 2015.

Table 2 - Data on Sudanese population in the UK according to different organisations.

\begin{tabular}{|l|c|c|c|c|}
\hline \multicolumn{1}{|c|}{ ORGANISATION } & $\mathbf{2 0 0 0}$ & $\mathbf{2 0 0 5}$ & $\mathbf{2 0 1 0}$ & $\mathbf{2 0 1 5}$ \\
\hline UN-DESA (1) & 10,319 & 13,407 & 17,588 & 19,758 \\
\hline ONS (2) & n.a. & $\begin{array}{c}12,000(\mathrm{Cl}+/- \\
4,000)\end{array}$ & $\begin{array}{c}19,000(\mathrm{Cl}+/- \\
6,000)\end{array}$ & $\begin{array}{c}40,000(\text { in } 2016) \\
(\mathrm{Cl}+/-9,000)\end{array}$ \\
\hline Eurostat (3) & n.a. & n.a. & n.a. & n.a. \\
\hline
\end{tabular}

Notes: (1) Sudanese migrant stock by origin; (2) Sudan-born population resident in the UK; (3) Sudanese migrants by country of birth.

Source: Office for National Statistics, 2018; UN-DESA, 2015.

On the other hand, until the secession of South Sudan in 2011, Sudan used to be one country, whereby refugees and migrants arriving from Sudan were officially registered as 'Sudanese'. Several studies have focused on different aspects of the southern Sudanese diaspora in the United States (Akuei, 2005b; Shandy, 2003), Canada (Simich, Este, \& Hamilton, 2010) or Australia (Baak, 2015). Yet, very few studies have addressed issues related to the northern Sudanese in the West, and most of them were conducted before the separation of the country (Abusabib, 2007; Assal, 2004). While the focus of this study is the current Republic of Sudan, having an overview of the different migration flows when North and South were still one country is important to understand the different contexts in which the respondents of this study migrated. 
Since 1956, following the country's independence from the 1899 BritishEgyptian condominium rule, Sudan has been characterized by constant socioeconomic and political instability, and environmental degradation that escalated into a protracted civil war between the North and the South. The more acute phases of the conflicts, in 1956-1972 and 1983-2004, resulted in over two million deaths and four million IDPs (IOM, 2011). Peace negotiations led to the Comprehensive Peace Agreement (CPA) of 9 January 2005, which put an end (at least in theory) to the long-standing war, and eventually gave way to the independence of the South in 2011 (IOM, 2011). However, the new conflicts in the bordering regions of South Kordofan and Blue Nile in 2013, the ongoing conflict of Darfur since 2003, together with recurrent floods and drought, became additional sources of thousands of IDPs and asylum seekers spilling to bordering countries (IOM, 2015). Figure 6 illustrates the stock of Sudanese migrants by country of destination in 2015.

Figure 6 - Stock of Sudanese migrants by countries of destination (2015). Source: United Nations database, POP/DB/MIG/Stock/Rev.2015 (DESA, 2015). Map designed by the author.

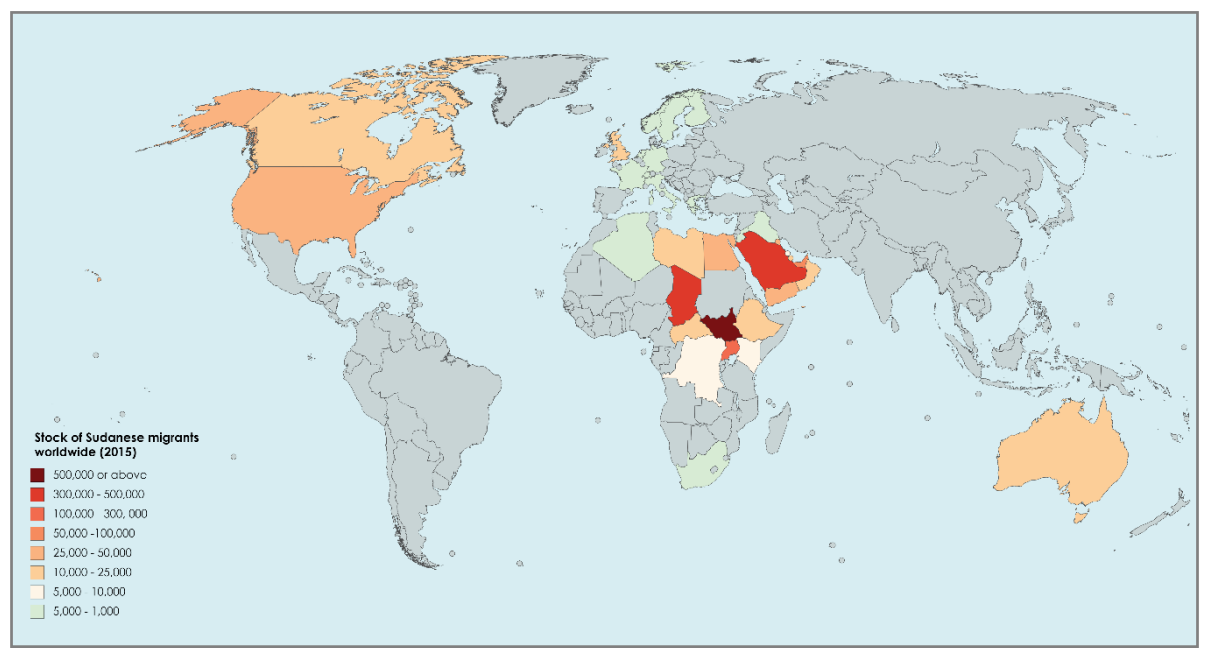

Source: United Nations database, POP/DB/MIG/Stock/Rev.2015 (DESA, 2015). Map designed by the author. Note: The figures for Ethiopia, Kenya, Uganda, South Sudan, Chad, Algeria, Egypt, South Africa, Iraq, Jordan, Kuwait, Saudi Arabia, United Arab Emirates and Yemen include refugees, as reported by the UNHCR. The figures for the rest of the countries refer to foreign-born Sudanese or foreign citizens.

The political instability in the country also accelerated the overall destruction of the Sudanese economy, which led many people to migrate to secure their families' subsistence (Abusharaf, 1997; Assal, 2010). The economic decline of the 1970s coupled with the oil boom in the Gulf countries and Libya, pushed thousands of Sudanese-mostly highly-skilled and white-collar workers from the Northern Islamic and Arabic-speaking region - to migrate to oil-rich Arab countries for work (ibid.). 
KSA, Kuwait and the United Arab Emirates were the preferred destinations of these migrants, especially of those from the Northern Islamic and Arabic-speaking region (Abusharaf, 1997). By 1990, around one million Sudanese migrants-78\% college graduates - had entered Gulf countries, where most of them were employed as physicians, engineers, university professors, and only $5.8 \%$ were relegated to unskilled occupations (Abusharaf, 1997). According to some estimates, by the end of the twentieth century, Sudan had lost almost two thirds of its university graduates to the Gulf and - to a lesser extent-to the West (Elnur, 2002). Whereas these highlyskilled migrants can be considered as voluntary labour movers, this type of outmigration must be understood within the context of an authoritarian regime, political repression and declining economy, whereby for many Sudanese expatriates coming back was not an option. This indicates the complexity of Sudanese migration, in that, many of those who initially left as labour migrants could easily become refugees (Assal, 2010).

\subsubsection{Sudanese migration to Europe}

The figure of 44,900 Sudanese migrants living in Europe in 2015 pales in comparison to the almost 600,000 Sudanese who lived in the Gulf countries in the same year (UN-DESA, 2015). Sudanese migration to 'the West' is, indeed, a relatively recent and rather under-studied phenomenon (Abusabib, 2007; Abusharaf, 1997). Prior to the late 1980s, modest amounts of doctors, engineers and academics started to arrive in Western countries, especially the UK (IOM, 2006). However, it was not until Islamist military coup of General Omer Al-Bashir in 1989, that the arrival of Sudanese to the West became more visible, mostly as refugees and asylum seekers. As Figure 7 shows, the UK continues to host the biggest Sudanese community in Europe. 


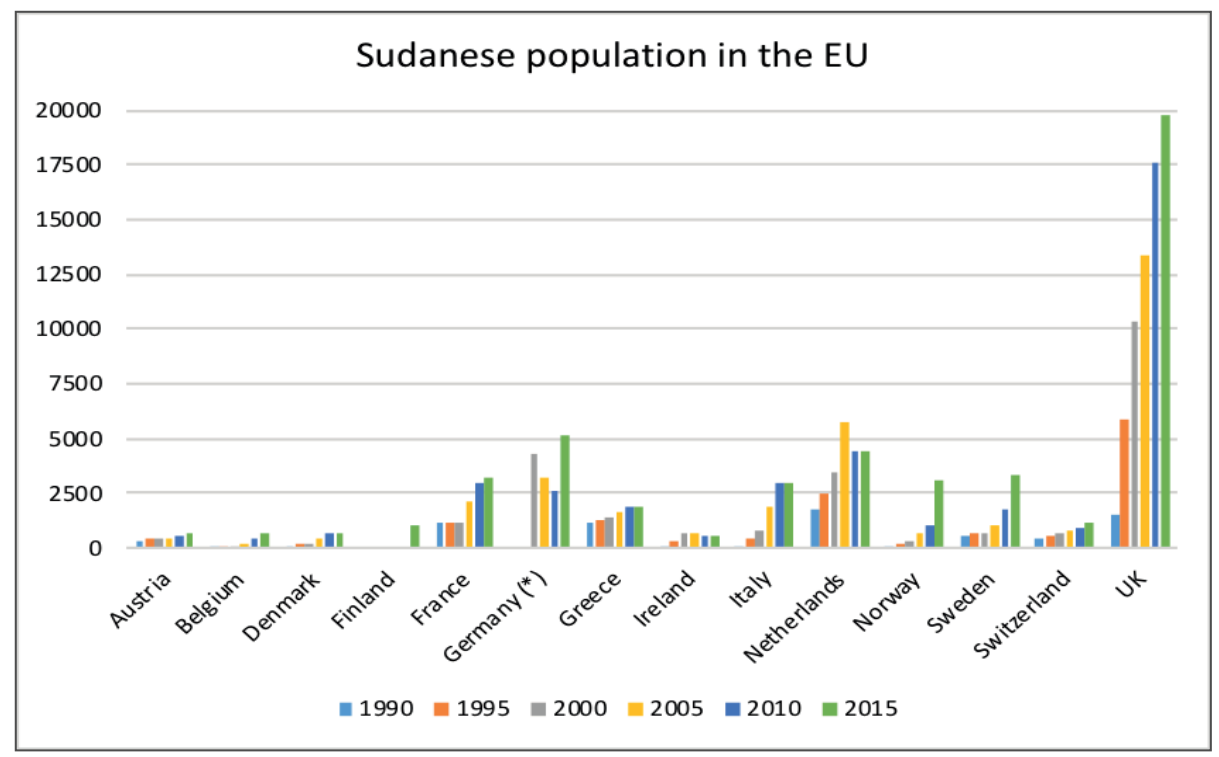

Source: Table based on the United Nations database, POP/DB/MIG/Stock/Rev.2015 (UN-DESA, 2015). (*) Data on Germany is based on DESTATIS, 2018. The German database was the only one clarifying that data prior 2011 includes both Southern-and Northern Sudanese, whereas data post-2011 is separates for the two groups. Note: The countries included in the graph are those in which by 2015 the Sudanese population was above 500.

The coup dissolved all political institutions and implemented strict Islamic laws, repressing individual liberties, including freedom of speech and assembly, trade unions, or the right to strike (Collins, 2008). In addition to this, the Islamisation of the economy limited international financial and commercial transactions, which deteriorated the Sudanese economy dramatically (Abusabib, 2007; Abusharaf, 1997). The economic destruction in the country together with the repressive Islamic regime pushed thousands of Sudanese to flee to Western countries -such as England, the United States, Canada, or Australia - and other neighbouring countries, either as refugees, asylum seekers or economic migrants (Assal, 2010). Besides those who came following resettlement programmes, most Sudanese in Europe come from Arabic-speaking central Nile valley region, who generally have better chances for mobility than rural people, especially because of economic and educational traits, which grant them more access to various networks and allow them to afford costly travel expenses (Abusabib, 2007).

In the last two decades, other factors have resulted in increasing flows of Sudanese migration to Western countries. First, the emergence of new regional violent conflicts in South Kordofan, Blue Nile and Darfur have continued to be the source of thousands of IDPs and asylum seekers (IOM, 2015). Second, the secession of South Sudan in 2011 -after which Sudan lost three-quarters of its oil production- 
together with the international and American sanctions in 1997 have resulted in an increasing inflation and multiple macroeconomic deficits, which have taken an important toll on the overall country's economy (IMF, 2014). Third, the violent conflicts in several Arab countries, such as Libya, Syria or Yemen, after the so-called Arab spring in 2010, pushed thousands of Sudanese migrant workers in these countries to return to an economically weakened and unemployment-ridden Sudan (IOM, 2015). The combination of these factors has resulted in thousands of Sudanese moving outside their country to be able to sustain their families. While many continue to migrate to the Gulf, in the last couple of years, the arrivals of Sudanese asylum seekers in Europe has increased considerably (Figure 8).

Figure 8 - Sudanese asylum application in selected European countries (2010-2016).

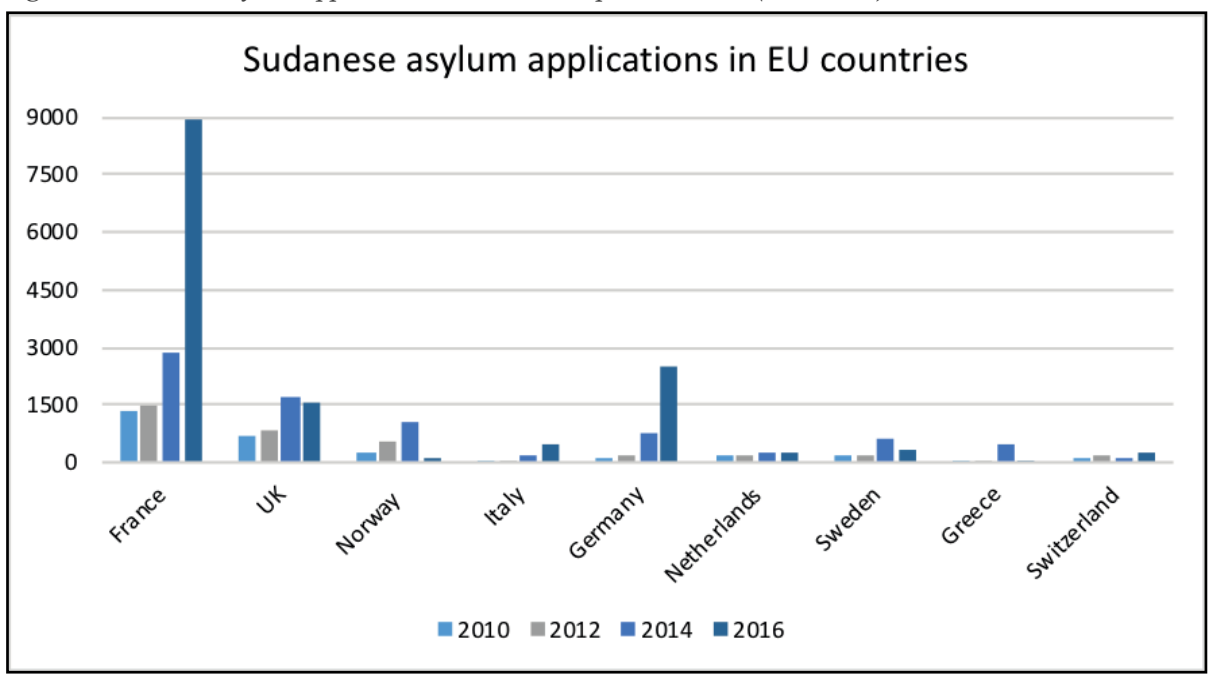

Source: Graph compiled based on the UNHCR mid-year population statistics 2017 (UNHCR, 2017)

\subsection{Social protection in Sudan}

One of the main reasons leading to the multiple conflicts that have ridden Sudan over the years has been the socioeconomic and political marginalisation of peripheral areas. The widespread inequalities, in terms of development and the provision of services, separate the State of Khartoum from the rest of the regions. For instance, whereas in 2010 around $30 \%$ of the population lived below the poverty line in Khartoum, the figure reached almost $70 \%$ in Northern Darfur in the same year (Crowther, Okamura, Raja, Rinnert, \& Spencer, 2014). It is within this context of regional inequalities, that the current structure of social protection in Sudan must be addressed. Besides families and social networks, whose role in the provision of social protection is crucial throughout the country, the state, the market and TSOs play different roles across regions. For example, most social protection schemes 
implemented by the government and TSOs are aimed to address the needs of extremely poor and vulnerable people who often live in a situation of displacement outside the central states. However, market-provided services, such as private hospitals and schools are mostly located in Khartoum. To capture this uneven availability of resources across regions, and the use people make of them, in my sample I include respondents originating from different regions, including Khartoum, Darfur, Red Sea, El Gezira, or the Blue Nile (see Appendix I - Respondents in the Netherland and Appendix II - Respondents in the UK), where the availability of resources varies.

The following sections are organised around the main social protection providers in Sudan-state, market, TSOs and families-highlighting their regional availability as well as the population and the needs they cover. Due to the lack of comprehensive literature on some aspects of the social protection system in Sudan, some of the following sub-sections have been complemented with fieldwork notes and observations.

\subsubsection{State}

In Sudan, social protection is officially classified under social development and comprises the state contributions to the pension fund and the social security fund, which includes providing medical staff for all health units, limited scholarships for students and social subsidies for the poor (e.g. free medication in emergencies and specific conditions) (Hassan, 2011). Even though Sudan has an institutional framework for social protection, it is a complicated system with many overlapping objectives, activities and providers, including, but not limited to: the Ministry of Welfare and Social Security (MoWSS); the Ministry of Health (nutrition and fee waivers for health); the Ministry of Education (school feeding); the Central Bank of Sudan (micro-financing policy); the Ministry of Finance (general food subsidies and cash transfers); and the Ministries of Agriculture and Water and of Animal Resources (Kjellgren, Jones-Pauly, El-tayeb Alyn, Tadesse, \& Vermehren, 2014). The MoWSS is the main institution responsible for the protection, prevention, and promotion of the poor and vulnerable. Some of its programs include: the Chamber of Zakat, a religious-based fund; micro-finance/income-generating programs; social services and rural development projects; and advocacy activities. However, despite the numerous governmental institutions, there is no comprehensive and common vision guiding the provision of social protection as a whole (ibid.).

The Chamber of Zakat is the main institution administering and implementing the largest social protection program in Sudan (Eissa, 2013). Based on the five Pillars of Islam and reflected in the Shari'a Law, the Zakat is an Islamic institution that was introduced as a mechanism for social solidarity and redistribution of income and wealth in society (ibid.). From this perspective, the Zakat could be compared to many of the current Western social security systems, that is, a 
compulsory tax-based contributory system ${ }^{4}$, meant to reach all the way down to the village level, at least in theory (Kjellgren et al., 2014). Revenues are collected in kind and in cash from all over the country, administered centrally, and then redistributed through state and local administrative structures. The Zakat law dictates that $61 \%$ of the revenue collected should be transferred to the poor and extremely poor households in four main kinds of support: direct in-kind or cash transfers; fee waivers for households' health insurance premiums or education fees; micro-credit; and the expansion of basic services, for example, by building a hospital or a religious school for a community (ibid.). Whereas, in theory, the Zakat constitutes an important financial and institutional framework for social protection in Sudan, overlapping beneficiaries, errors, lack of equity and transparency, fraud, exorbitant administrative costs or corruption are some of the major issues undermining this system of wealth redistribution (Kjellgren et al., 2014; Seesemann, 2002). Moreover, based on my fieldwork, two additional problems seem to prevent people from accessing the Zakat funds, namely: the lack of available information and the shame related to receiving these funds, in that this money is perceived as help for the poorest of the poor, whereby people often avoid to be seen waiting at the institution's doors to receive this support.

Besides the Zakat, Sudan's national Pensions Fund covers formally employed persons - excluding domestic servants, home workers, farmers and foresters-and has special provisions for civil servants, the police and armed forces personnel. The Pension Fund - one of the oldest in Africa and the Middle East-is administered by the National Social Insurance Fund and financed through the employers' and employees' contributions. It covers the pension for those aged 60 with at least 20 years of contributions, survivor's pension and disability pensions (Social Security Administration, 2007). Based upon fieldwork interviews and observations, however, the pension received by most people could barely cover their monthly food expenses, let alone their housing or medical emergencies. Therefore, those respondents who received a state pension needed additional support to survive. People like Youssif (see vignette above), who work in the Gulf are not entitled to receive any state pension in Sudan when they reach 60 years old, even though during their working years in the Gulf they were bound to pay yearly taxes in Sudan.

The Sudanese government, through the Ministry of Health, is also the main responsible for the healthcare system, funded through public taxation (WHO, 2006). Despite governmental requirements, the overall basic health service coverage is very low, with remarkable urban, rural, and regional disparities in the availability of health resources and services (A-Rahman \& Jacquet, 2014). There are multiple healthcare providers in Sudan-including the Federal and State Ministries of Health, Armed

\footnotetext{
${ }^{4}$ Sudanese Muslims earning over 10,000 SDG (about US\$3,575) per year must pay 2.5 percent of their annual income to the fund. Non-Muslims also pay a similar social-solidarity tax (Kjellgren et al., 2014).
} 
Forces, Police, universities, private sector (both for profit and philanthropic) and the civil society. However, they are unevenly distributed between and within states, and they all work in an isolated and uncoordinated manner (WHO, 2006).

The availability and quality of healthcare services varies dramatically between the major urban areas and the rest of the country, and has become one of the main causes of rural to urban migration (Berry, 2015). In some remote rural areas, standard healthcare is characterized by the lack doctors and clinics, so that whenever an illness occurs, home remedies or a visit to a faqih or sorcerer are often the only treatments available. Rural areas with public transport connection to bigger cities are often equipped with small primary-care units staffed by knowledgeable health workers, who may provide rudimentary care, advice and referrals to proper clinics in urban areas (ibid.). Provincial capitals have doctors and hospitals but in insufficient numbers and poor quality. The best medical facilities and doctors in Sudan are concentrated in Three Towns of the capital region (Khartoum, Omdurman and Bahri). Here, healthcare is provided in three types of facilities: government/public hospitals ${ }^{5}$, often overcrowded, poorly maintained and underequipped; private clinics, with adequate equipment and foreign-educated doctors, but only affordable by the middle and upper classes; and public clinics run by Islamist $d a^{\prime} w a$ (religious-based charities), where healthcare is available for a nominal fee (Berry, 2015; Yousif, 2016).

According to the Constitution of Sudan, free emergency services and primary healthcare-including child vaccination and nutrition, promotion of reproductive health, and treatment of injuries, diseases, and mental illness - should be provided for all citizens (A-Rahman \& Jacquet, 2014). Nevertheless, in 1991, a user fee was introduced, whereby nowadays patients must pay for medicine, technical tools and examinations (WHO, 2006; Yousif, 2016). In 1995, the current National Health Insurance Fund was implemented. It is a social health insurance scheme, financed by a premium of $10 \%$ from employees' salary, that only covers compulsorily formalsector workers, whereas informal workers may join voluntarily upon payment of annual fees (Baloul \& Dahlui, 2014). In 2003, the National Health Insurance Fund covered about $12.6 \%$ of the total population, most of whom were government employees (WHO, 2006). Based on fieldwork observations, the insurance of a male working adult covers also his parents, wife, children, and (often) dependant siblings. However, if the insured person is a woman, only her parents and children are covered. Regarding coverage, consultation, laboratory investigations and surgical procedures are often free. Yet, insured persons must purchase medicines at government pharmacies, paying $25 \%$ of the cost (WHO, 2006). In the current healthcare system in Sudan, the low public health spending (1.8\% of the GDP) and

\footnotetext{
${ }^{5}$ Despite the massive expansion in medical education since the 1990s, poor salaries, inadequate working conditions and high unemployment rates have resulted in substantial medical emigration from Sudan (Abdalla, Omar, and Badr 2016). In 2005, nearly $60 \%$ of the registered doctors in Sudan worked abroad (Berry 2015).
} 
the high out-of-pocket expenditure $(75.5 \%)$ has resulted in many people facing social exclusion in terms of services (World Bank, 2014).

Just like public healthcare, the Sudanese educational system is also characterised by the uneven distribution of facilities and staff across regions, with most schools and higher educational centres clustered in the vicinity of Khartoum and to a lesser extent in other urban areas (Berry, 2015). The history of modern higher education in Sudan goes back to the era of British ruling, with the founding of the University of Khartoum in 1902. Since then, there has been a remarkable expansion of higher academic institutions (Gasim, 2010). Sudan's current new education system came in place in 1990 with the Higher Education Act, generally referred to as the 'Higher Education Revolution'. One of the reasons pushing the implementation of this act was the urgent need to expand the higher education by the end of the 1980s due to the huge cost associated with sending students abroad ${ }^{6}$ (Gasim, 2010). The decision to make Arabic the official language of instruction-for which there was a lack of materials and qualified staff-together with the government controlling curricula, resulted in the dismissal of instructors who opposed such reforms, which led to the largest 'brain drain' since Sudan gained independence (Berry, 2015; Gasim, 2010).

The education revolution affected negatively other social aspects of education. On the one hand, the expansion of higher education occurred at the expense of elementary and secondary education, in that many newly established colleges and universities outside Khartoum were actually opened in buildings of former high schools (Gasim, 2010). On the other hand, public universities, such as the University of Khartoum, saw their social programmes disappear (Gasim, 2010). Until the full implantation of the policies of the higher education revolution, students at the University of Khartoum were fully sponsored by the institution, enjoyed free healthcare and transportation to their hometowns at the end of the academic year, and free accommodation for those coming from remote regions. After the higher education revolution, however, university students lost all these benefits. The government tried to limit the negative effects of the new educational and accommodation fees - unaffordable for many families - by establishing a Student Welfare Fund. Nevertheless, many poor families in Sudan are still facing economic challenges sending their children to college (Gasim, 2010).

In Khartoum State, around $80 \%$ of households are classified as low income, unable to afford the cost of housing (Hamid \& Mohamed-Elhassan, 2014). Moreover, the rapid increase of the population is much higher than the formal housing supply mechanisms, whereby the housing deficit in Khartoum State-estimated at 60,000 units annually - is filled by informal housing (ibid.). Besides a few anecdotal public

\footnotetext{
${ }^{6}$ At this time Sudan used to send thousands of students to study abroad in countries such as: Egypt, India, Russia, Iraq, Morocco, and Eastern European countries (Gasim, 2010). Several of my respondents studied in these countries.
} 
housing projects allocated to some low-income households, most people in Sudan remain responsible for their own housing. From 1977 to 1984 the sites-and-services became the predominant housing supply mechanism at a national level (ibid.). With government owning more than $90 \%$ of the unregistered land, the housing ministry allocated land at subsidised prices to households based on specified eligibility criteria (e.g. income level, family size, or hometown). In theory, the government is also responsible for providing minimum basic services (e.g. potable water) at an $80 \%$ subsidy, and other services (e.g. electricity, sewerage and roads) at a $20 \%$ government subsidy (ibid.). Reality, however, shows that most households end up getting only a plot of land, without any services, in a peripheral location, where they have to work together with neighbours to build water lines and public roads (fieldnotes). The work and money this involves, however, can take up to several decades. In 2008, the National Housing and Development Fund was established to build 150,000 'economic' housing units (i.e. a boundary wall, two bedrooms, kitchen and toilet) in 15 states over a period of five years. Yet, up till now, the developments have been insignificant (fieldnotes). The modest contributions of governmental housing support have resulted in a massive increase of squatting and informal housing arrangements. Thus, once a family obtains a piece of land, limited resources and manpower are mobilised to construct a modest shelter using mostly earth and recycled building materials and components. Families are responsible to develop the sewage, drinking water and electrical system. In 1990 there were around 83 informal settlements Greater Khartoum accommodating about $60 \%$ of its residents (Hamid \& MohamedElhassan, 2014).

This section has shown that, although in theory the Sudanese government has a range of instruments to provide for some of the most basic needs of its citizens (e.g. old-age pensions, healthcare, education or housing), the real accessibility of such provisions is highly limited and fragmented. Even when such provisions can be accessed, they are not usually enough to cover the needs of people, who must often rely on other resources.

\subsubsection{Market}

When I was doing fieldwork in Sudan, it was impossible not to notice the multiple billboards on the main roads advertising private schools for children and health insurances. Since the 1990s, the current Sudanese government has expanded privatization programs (Suliman, 2007), excluding a wide range of the population from covering some of the most basic needs, such as: education and healthcare (Yousif, 2016). Indeed, by 2011, private education-primary and secondary schools - made up $41.8 \%$ of the total number of schools in the state of Khartoum (Alredaisy, 2011). Based on my fieldwork, most families brought their children to private schools. Even the most humble families would make enormous financial efforts to pool resources together and have their children attending private education, which is considered of better quality and less crowded. The privatisation of education 
in Sudan also extends to universities. The University of Al-Mughtaribeen (literally, the University of the Expatriates), in particular, is one of the private universities in Khartoum, which deserves further explanation, since it was created by migrants and for migrants. As illustrated in the vignette above, the children of Sudanese migrants in the Gulf experience problems to access Sudanese universities when they return, because of the different curricula in the secondary school system in the Gulf. As a result, a group of Sudanese migrants in KSA initiated the idea of founding a university where their children could study upon returning to Sudan. The project was brought forward and the University of Al-Mughtaribeen was established in 2010. The institutions, staffed mostly with once Sudanese migrants in the Gulf, has a current $60 \%$ quota for children of Sudanese migrants, who must pay exorbitant annual feels to study (fieldnotes).

Regarding health, in 2006 in Khartoum state there were 39 governmental hospitals as opposed 83 private ones (WHO, 2006). Like private schools and universities, private health services are limited to few states, like Khartoum and Gezira States, and they are mainly concentrated in urban and a few better-off rural areas. Private healthcare providers are perceived to be of better quality than government services, although a very small section of society can afford them (WHO, 2006). In fact, based on fieldwork observations, the dubious quality of the Sudanese public hospitals and the exorbitant costs of the private ones, lead those who can afford it to arrange medical treatments and interventions abroad, in countries like Egypt, Jordan, or India, where healthcare is better and cheaper. Nevertheless, the role of the private healthcare providers has not been well documented, so far, and the poorly-enforced regulations governing the private sector have created several challenges, including: quality assurance, competition policies, price moderation, regulation and public-private partnership (Rahman and Jacquet 2014).

\subsubsection{Third-sector organisations}

The weak and often malfunctioning formal welfare programmes directed by the government do not reach the lives of many Sudanese, who wind up living under precarious situations. Such vacuum is partially filled in by a myriad of TSOs (Seesemann, 2002). For the purpose of this research, TSO comprise: international aid organisations (e.g. UN bodies, the World Bank, or the Red Cross, to name a few), non-governmental and non-profit-organizations, including charities, voluntary and community groups, self-help groups, faith-based organisations and cooperatives. TSOs can take a number of legal forms. Whereas some are informal associations of people with shared values and objectives, others have a company status and are formally registered under the Sudan Humanitarian Aid Commission (HAC). The HAC is a government body that works in parallel with the state's social protection programme and coordinates government's departments, civil society organizations, UN agencies, and NGOs. However, its poor coordination, coupled with multiple yearly restrictions and controls, and its powers to dissolve or forbid the presence and 
activities of any NGO or association under its register, pushes many organisations to remain informal (Berry, 2015; Kjellgren et al., 2014; Yousif, 2016).

Many international aid organisations and NGOs in Sudan are involved in delivering social protection and safety net programmes. As a reference, in 2012 there were around 70 international NGOs and 81 partner organisations under the United Nations Office for the Coordination of Humanitarian Affairs coordination mechanism, implementing food security, livelihoods and nutrition programmes (Kjellgren et al., 2014). Whereas assessing the specific activities of the different organisations is beyond the scope of this thesis, according to the UN Annual Report on the Sudan Humanitarian Fund, $84 \%$ of the budget was targeted to water, sanitation and hygiene, health, food security and nutrition projects, reaching large numbers of poor communities, vulnerable families, IDPs and refugees (SHF, 2016). Besides being the main basic service providers in IDP and refugee camps, these organisations play a crucial role in the sustenance of poor non-IDP families. For instance, poor families living near some IDP camp sometimes opt for splitting family members between the family house and the camp, where they are able to access free food, healthcare and schooling for children (fieldnotes).

International NGOs also play an important role in supplying some of the basic services that the government is not able to provide. Yet, in 2005, the Sudanese government evicted many NGOs, accusing them of working against Sudan's interest, leaving many vulnerable groups without any support. To avoid governmental control, many organisations define themselves as initiatives and not associations. In doing so, these informal groups of volunteers seek are more flexible and capable of adapting to the needs of communities in different circumstances, without being bound to regulations or hierarchies that can limit the work (Glade, 2015; Yousif, 2016).

Recent research conducted on the civil society in Sudan has pointed out the role of some youth initiatives or mubadra in Arabic (Glade, 2015; Yousif, 2016). These groups have been characterised by their capacity to mobilize people through the use of new technologies, involving even the Sudanese diaspora to work with those in Sudan on common causes (Glade, 2015). Here I will only focus on two initiatives due to their role in the provision of social protection: the Nafeer and Sharia' alHawadith.

The Nafeer is a youth-led initiative that emerged to provide flood relief in outlying areas of Khartoum, characterised by a lack of drains and poorly built houses. Technically, Nafeer refers to a traditional form of mobilization in rural communities to help those in need. In 2013, the Sudanese government's response to the over 300,000 people affected by the flooding was insufficient. In reaction to this situation, a group of Sudanese youth organized an initiative to directly help the affected families. The Nafeer made use of the current technologies to raise awareness nationally and internationally, gather funds directly via SMS, and disseminate information within the group. With their limited but efficient resources, they 
conducted surveys of the damage, set up a hotline for families in need to call, and delivered aid at a time that the state was incapable of doing so (Glade, 2015).

Sharia'

('Accidents
al-Hawadith road'), another unregistered initiative, began as a group to help children with cancer, but it expanded over time, organising resources to help impoverished children who need medical assistance (Glade, 2015). Volunteers sit daily in the same place, and take the names and medical needs of the children in the hospitals along 'Accidents road' in Khartoum. Through a Facebook group (Figure 9), volunteers post the monthly schedules for volunteers, and announce daily the medicine and amount of money needed for certain treatments (ibid.). This announcement is published with the name and phone number of a designated volunteer, who is in charge of receiving the donations and reports of children in need.
Figure 9 - Sharia al-Hawadith message on Facebook requesting for medical help.

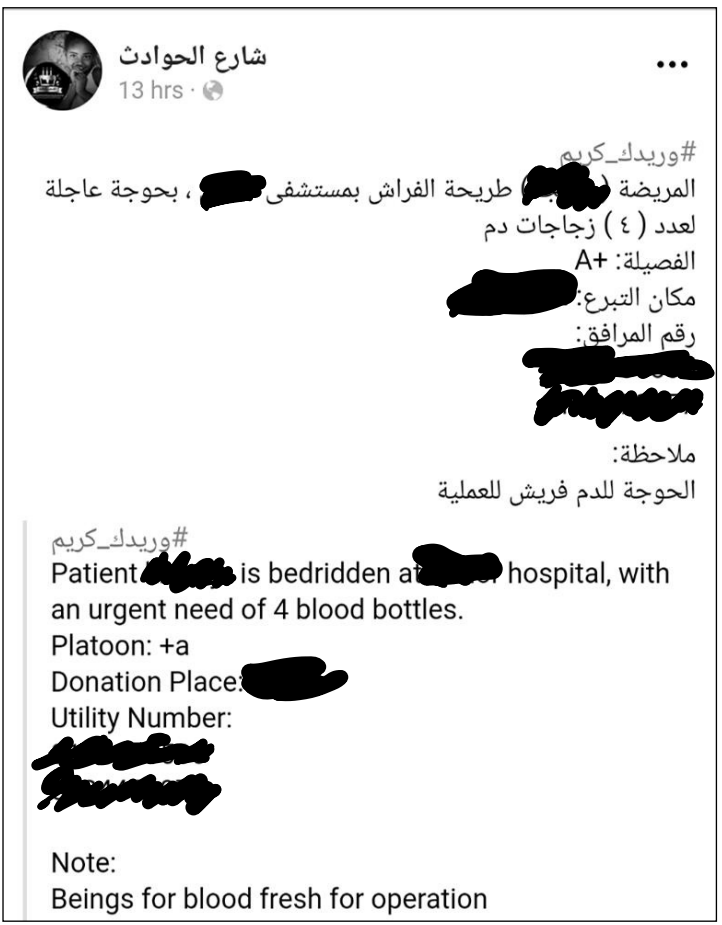

Source: https://www. facebook.com/SharAlhwadth/. Accessed on June $6^{\text {th }} 2018$. Multiple people, not necessarily affiliated with the initiative, such as pharmacists and/or doctors, provide medicine and money for tests. Contributions from the Sudanese diaspora in the US, Europe and the Gulf are also remarkable (ibid.).

\subsubsection{Family and social networks}

Although their socioeconomic status varied, all my respondents in Europe had some or all their family members living in some sort of owned or rented property in capital cities of different states, including Khartoum, Darfur, Blue Nile and Red Sea states. In fact, almost everyone had some relative in Khartoum. Most of these families were neither 'poor enough' to be eligible for most of the state or TSO-provided support, nor 'rich enough' to effortlessly access market provided resources. Most of them depended almost exclusively on family networks and remittances to cover for most of their basic needs. Before addressing the main mechanisms of support provided by families and communities in Sudan, this section describes the common structure of a Sudanese family, including its members and their main roles within the family and the community. The aim of this section is to illustrate the strong and intertwined mechanisms of reciprocity within extended family networks, which shape the ways 
in which transnational families navigate formal and informal resources in times of need. This is crucial to better contextualise the forthcoming empirical chapters.

\subsubsection{Sudanese family structure}

In Sudan, the family structure is patrilineal, whereby descent is determined through the paternal line. As a patriarchal society, social and public life is male-dominated and the ways in which individuals are expected to protect and sustain their families are highly gendered (Fluehr-Lobban, 2006; Oldfield-Hayes, 1975). Especially since the introduction of the Shari'a Law in 1983, gender norms have been increasingly shaped by religion (ibid.). Whereas men are traditionally the breadwinners, responsible of protecting and providing for their immediate (e.g. wives and children) and extended family (especially mothers, sisters and aunts), women are in charge of the overall management of the household and their families' reproductive needs, namely, the children, the elderly and the sick in the family (Fluehr-Lobban, 2006; Mokomane, 2013). Currently, however, many women, married or not, find employment outside the home and contribute to their families' finances.

The traditional Sudanese family structure is that of an extended family, including grandparents, mother(s) ${ }^{7}$, father, children, uncles, aunts, cousins, nephews and nieces, often, living together in compounds, where houses are located next to each other, with a common courtyard in the centre ${ }^{8}$ (Essien \& Falola, 2009). Marriage, which often happens between cousins, creates a bond between two families and does not take away couples' responsibilities towards their respective extended families, whereby they (especially men) continue to be accountable for their siblings and aged parents (ibid). After marriage, women become part of their husbands' families, but they still have a certain degree of responsibility to support their natal families in case of need. Yet, as observed during fieldwork, the parents of married women often avoid asking for financial support to their daughters, because they assume the money is provided by their husbands, since women are not expected to work. The degree to which married women and their husbands support the woman's natal families depends on a variety of factors, for instance, the woman's employment situation or the financial possibilities of her family.

Besides the gender stratification, traditional Sudanese families are also stratified on the basis of age, whereby the young are subordinate to the old. The elderly - even women - are highly respected and play important roles in decisionmaking processes. Indeed, grandmothers achieve a status similar to men and are as

\footnotetext{
${ }^{7}$ Marriages in Sudan are often polygamous, whereby men may have more than one wife. Yet, in polygamous marriages, each wife with her own children live in their own separate houses (DLIFCL, 2016).

${ }^{8}$ Currently, however, especially in Khartoum and other northern states, households are becoming more nuclearized. Yet, strong links within the extended family remain (Al-Awad \& Sonuga-Barke, 1992).
} 
respected as fathers (Oldfield-Hayes, 1975). Children are a shared responsibility within Sudanese extended families and communities, and particularly grandparents and uncles, play a prominent role in the childcare and discipline process. In the case of divorce, which is allowed and regulated by the Shari'a Law, children often move with the mother to her parental house, where she is expected to remain until she marries again (Nageeb, 2004). Technically, boys remain with their mother until the age of seven and girls until the age of nine (Rafiq, 2014). Yet, based on my observations, this rule is quite flexible and different arrangements are made, often based on the best interests of the children.

\subsubsection{Kinship networks of support in Sudan}

In Sudan, like in many other sub-Saharan countries with weak or non-existent welfare states, the extended family plays a key role in the sustenance of society and the provision of social protection. In times of need or crisis - such as when family members are unemployed, sick, or aged - families provide many of the social services not supplied by the government, and assumes responsibility for offering material, social, emotional and intergenerational care and support for its members (Adam \& Yousif, 2016; Akuei, 2005a; Mokomane, 2013; Rashad, Magued, \& Roudi-Fahimi, 2005). At the same time, each individual is responsible for protecting and sustaining the family in socially and culturally specific ways (Mokomane, 2013). Sudanese family members are thus highly dependent on relationships of intergenerational reciprocity and the multi-directional circulation of care and resources within extended family networks.

The head of the family and his wife(s) are not only obligated to care and provide for their own children, but also for their nephews, nieces and cousins (Adam $\&$ Yousif, 2016). This support can come in different shapes, for instance: paying for school fees and medical treatments, or hosting during the whole academic year (fullboard and free of charge) nieces, nephews or cousins from remote areas, so that they can attend university in Khartoum. All these examples were common practice among the families participating in this research. Once these children become adults, they are in turn responsible for caring not only for their own aging parents, but also for their grandparents, aunts and uncles. Children thus are the most available and reliable source of insurance, especially during old-age (Adam \& Yousif, 2016; Nauck $\&$ Klaus, 2007). Indeed, the lack of sufficient state-provided pensions leaves most elderly people dependant on their children and extended families, who are fully responsible for them. Pensions are mostly envisaged in terms of working hard in one's adult life, building a house and giving your children the best education so that they can provide for you in the future. As old-age insurance assets, providing one's children with tertiary education is not only a source of pride and prestige, but also a source of insurance based on intergenerational reciprocity (Gasim, 2010). By acquiring tertiary education - preferably in the UK, which is highly regarded and has a long-established tradition in Sudan-children are expected to have better 
employment opportunities in Sudan or the Gulf, with which to provide for their parents' and other elderly relatives' needs in the future (ibid.).

Besides the intergenerational care and support circulated to raise children and care for the elderly within the family, several community-based networks of support, mostly orchestrated by women, play a crucial role in the provision of social protection during specific life crises or events, both at a family and community level. During my fieldwork in Sudan, I observed how women were usually the first ones to find out about an upcoming wedding, a birth, a disease or the death of a relative or neighbour. In these situations, close and far relatives, friends, neighbours and other community members offer the affected family a contribution in cash or in-kind called wajib (Schultz, Makkawi, \& El-Fatih, 2009). Depending on the situation, this contribution is not only meant to help the family cover the exorbitant costs of weddings or funerals, for example, but also to temporarily support the family of deceased, especially when they are the main breadwinner. The wajib can be defined as a semiformal social protection scheme, in that it implies keeping up a kashif(written record) of the sum given, as well as an obligation to reciprocate, which results in a certain degree of investment and insurance (Kenyon, 1994; Schultz et al., 2009).

Many Sudanese (mostly women) also enter a form of rotating savings and credit association (ROSCA) called sunduq. The sunduq (box) is a saving scheme that started in the 1940s among middle class women in Central Sudan, who wanted to collect money to buy gold for their daughters' weddings. Nowadays it has become a significant institution on all levels of society to cover for different needs (Kenyon, 1994). Several of my respondents in Sudan were part of some sunduq. In most cases, sunduqs were made up by women living in the same neighbourhood or working together, whereby peer control assured the functioning of this saving scheme. Family sunduqs were also quite common.

Although current socio-economic and demographic changes (e.g. unemployment, migration or more female-headed households) have weakened these types of community-based support mechanisms, during my fieldwork-both in Europe and Sudan-I witnessed how such practices are still an invaluable resource for families of different socioeconomic statuses to cope with life crises. For instance, both in the UK and the Netherlands I observed situations where money was pooled together to facilitate the repatriation of someone's body to Sudan, or to financially support migrants to fly to Sudan and arrange the funeral of a parent or sibling. Similarly, during fieldwork in Sudan, the mother of one of my respondents, a woman in her late 60s, had recently started a special sunduq with family members, exclusively designated to cover for health emergencies. In another family, the mother, also in her late $60 \mathrm{~s}$, did a sunduq with her neighbours to provide for the expenses to rent and furnish a small building that she had recently turned into a school. Like many of the families I visited, the state-provided pension barely covered the weekly food expenses of the elderly, so working during old age was not uncommon. Moreover, social 
services such as schools, health centres and mosques are often built by people through community self-help organisations (Hamid \& Mohamed-Elhassan, 2014).

\subsubsection{Remittances}

For decades, remittances have played an essential role for families and communities in Sudan. Since the oil-crises of the 1970s, inflation has severely eroded real incomes of wage earners at all levels, especially in the public sector, whereby the current official minimum wage of SDG465 (US\$70) covers only five percent of the basic needs of an average family (Brown, 1992; Dabanga, 2017). In response to declining salaries and increasing unemployment, the number of migrants rose steadily. By 1985, it was estimated that around two-thirds of Sudan's professional and skilled workers were employed abroad (Brown, 1992).

The amount of formal remittances sent to Sudan in 2008 ranged from USD 1,6 billion (World Bank, 2016) to USD 1,9 billion (IOM, 2011). Being a major source of foreign currency, the government of Sudan seems to encourage migration, particularly to the Gulf countries, from where most remittances originate (Figure 10) (Assal, 2010).

Figure 10 - Migrants' remittances to Sudan by continent of origin.

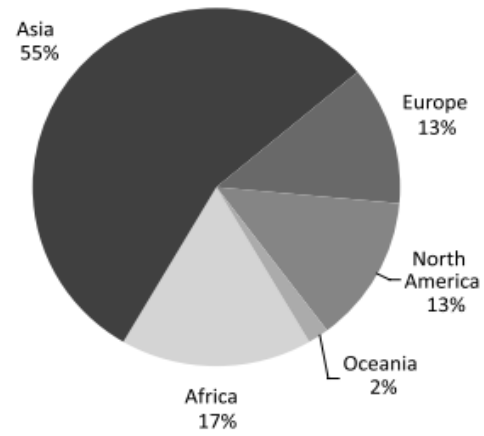

Source: IOM Report on Sudan (2011) based on data from the

UNDP Human Development Report, 2009 (UNDP, 2009).

Nevertheless, the prevalence of the informal economy, the lack of financial services and the international sanctions in 1997 indicate that the amount of informal remittances should not be underestimated (IOM, 2011). For instance, in 1984 surveys suggested that only $15 \%$ of total remittances were received directly via banks, while in 1986, the Central Bank of Sudan estimated around US $\$ 1,400$ million of yearly exchanges on the parallel market, as opposed to only US $\$ 400$ million on the official market (Brown, 1992). Indeed, many migrants prefer to send money through 
informal channels, because it is quicker, cheaper, tax free and more lucrative, since the black market conversion rates apply9.

Whereas there is not representative information on the use of financial remittances received by Sudanese households, empirical observations point to daily consumption, housing, education, health, and occasional events such as weddings, burial ceremonies and migration of other family members (Brown, 1992; IOM, 2011). The vignette presented at the beginning of this section is a representative example of the role that migration -especially to the Gulf-has on the provision of social protection. Like Youssif, the parents of many of my respondents had spent several years working in skilled jobs in the Gulf. Their salaries had allowed them to provide their families back home with a relatively comfortable life, cover health and other emergencies extended family members, provide their children with a good education, and build a house in Sudan, where they now spent their old age with, at least, one of their children and the help of some domestic service.

Remittances, however, might also have a negative effect on the family provision of support. As some of my respondents reflected, the fact of their being abroad resulted in their communities expecting for them to send substantial remittances to their families back home, as it is usually the case for those migrating to the Gulf. Yet, for those arriving in Europe as refugees, their realities are quite different. Still, the community and the extended family feel less obliged to provide support to those families with some member living abroad, even when the remittance-sending possibilities for those living in Europe, are often less than those working in the Gulf.

\subsection{Conclusion}

This chapter has provided an overview of the migration and social protection contexts in Sudan. The heterogeneous character of the Sudanese migration towards Europe and the predominant role of families and communities as the main providers of social protection, are important elements to take into consideration when interpreting the TSP arrangements of Sudanese families in the coming chapters. I have also highlighted the long-standing Sudanese migration trends to the Gulf not only because of their magnitude, but also because many social protection arrangements of Sudanese migrants in Europe described in this thesis involve current or expected linkages to the Gulf.

The chapter has highlighted the main social protection providers in the Sudanese context, namely: state, market, TSOs and family networks. A thorough review of the theoretical and practical roles of each provider has shown that the

\footnotetext{
${ }^{9}$ By the time I visited Sudan, from August to October 2016, the official exchange rate for $1 €$ was around 7 Sudanese Pounds (SDG), whereas exchanging $1 €$ in the black market resulted in around $15 \mathrm{SDG}$.
} 
insufficient, fragmented and often overlapping state-provided initiatives only cover small fragments of society. At the same time, the prohibitive costs of market-provided resources (e.g. schools or hospitals) and the focus of the TSOs in supporting the poorest of the poor, leaves a big sector of the Sudanese society mostly depending on their extended families and communities. The prevalent role of the family in supporting its members is sustained and reproduced based on a series of deeply rooted norms of intergenerational reciprocity and exchange, whereby individuals are bound to support and care for each other in specific ways. This type of intergenerational contract regulates exchanges throughout the life course, even when family members live separated across national borders. 


\section{CHAPTER 5}

MIGRATION AND SOCIAL SECURITY IN THE

NETHERLANDS AND THE UK 


\section{1 Introduction}

Since the late 1980s, migratory flows towards Europe have become more diverse in terms of country of origin, entry status or educational level. States, which remain the key actors in migration and welfare policies, have responded to these changing patterns by diversifying migrant categories and statuses, and restricting the social support the different groups are entitled to. These developments have resulted in a greater diversity and complexity of statuses and rights for each category (Kofman, 2002). The availability and accessibility to welfare or state-provided provisions for migrants varies not only across countries, but also across different socioeconomic and political momentums. Migrants' access to formal welfare schemes in the receiving countries depends on shifting political decisions about the social rights of non-citizens, but also on how far welfare is used as a tool to control migration at different times (Sabates-Wheeler \& Feldman, 2011).

A detailed historical overview of the different stages of immigration to the Netherlands and the UK, together with the development of their respective welfare systems is beyond the scope of this thesis. Instead, the aim of this chapter is to provide a sufficient background to contextualise Sudanese migration to the Netherlands and the UK, as well as the different provisions available to them in the Dutch and British social security systems. Sub-sections 5.2 and 5.3 address the contexts of the Netherlands and the UK respectively. Each sub-section is organised as follows. First, I describe the main characteristics of the Sudanese migrants and communities in each country. Second, I briefly summarise the main characteristics of each country's welfare system and their social security mechanisms for their citizens. This is important because, at the time when fieldwork was conducted, many of the respondents in this study had Dutch or British citizenship, which granted them access to the full range of welfare provisions. Since the respondents of this research held different legal statuses, which consequently granted them access to different social security rights, I finish each sub-section with a review the specific entitlements for migrants with different legal statuses, including: documented, undocumented, asylum seekers and refugees. This contextual information will support the interpretation of the analyses in the empirical chapters. 


\subsection{Migration and social security in the Netherlands}

Figure 11 - Brief timeline of the main migration stages and main welfare developments in the Netherlands.

Immigration from Dutch former colonies (Indonesia, the Dutch Antilles and Surinam).

Rapid post-war growth in the Dutch economy -> recruitment of migrants from the Mediterranean and the Maghreb, to fill up low-skilled jobs for short and limited periods of time.

Guest workers not expected to integrate in the Dutch society.

Family reunification and asylum seekers.

Many guest workers stayed and brought their families.

Oil crisis 1973 - economic recession:

- Restricted labour migration

- Guest-worker accommodation policies (e.g. social security and integration programmes)

- Tolerance towards undocumented migrants

High-skilled and labour migration. 


\subsubsection{Sudanese migration to the Netherlands}

In 2017, there were 7,199 Sudanese registered in the Netherlands (CBS, 2018). These official statistics do not include undocumented migrants, whereby the real number might be higher. As represented in Figure 12, the peak of the Sudanese migration in the Netherlands, took place between 1996 and 2004, when the total numbers of Sudanese officially living in the country increased from 943 to 7,626 respectively (CBS, 2018). The majority of the Sudanese arrived as asylum seekers. In 2003, for instance, out of 389 new arrivals in that year, $70 \%$ did so as asylum seekers, while $11 \%$ came on family reunification grounds and only $1 \%$ arrived as for working purposes (van Heelsum \& Hessels, 2006). Of the total number of registered Sudanese, almost $70 \%$ were first generation. The percentage of registered first-generation male migrants was over $64 \%$. The number of first-generation women increased from $20 \%$ in 1996 , to $36 \%$ in 2017 . The Sudanese population in the Netherlands is young, with $36 \%$ people younger than 20 years old, $54 \%$ between $20-50$ years old and only $10 \%$ over 50 years (CBS, 2018).

Figure 12 - Sudanese population in the Netherlands by sex (1996-2017).

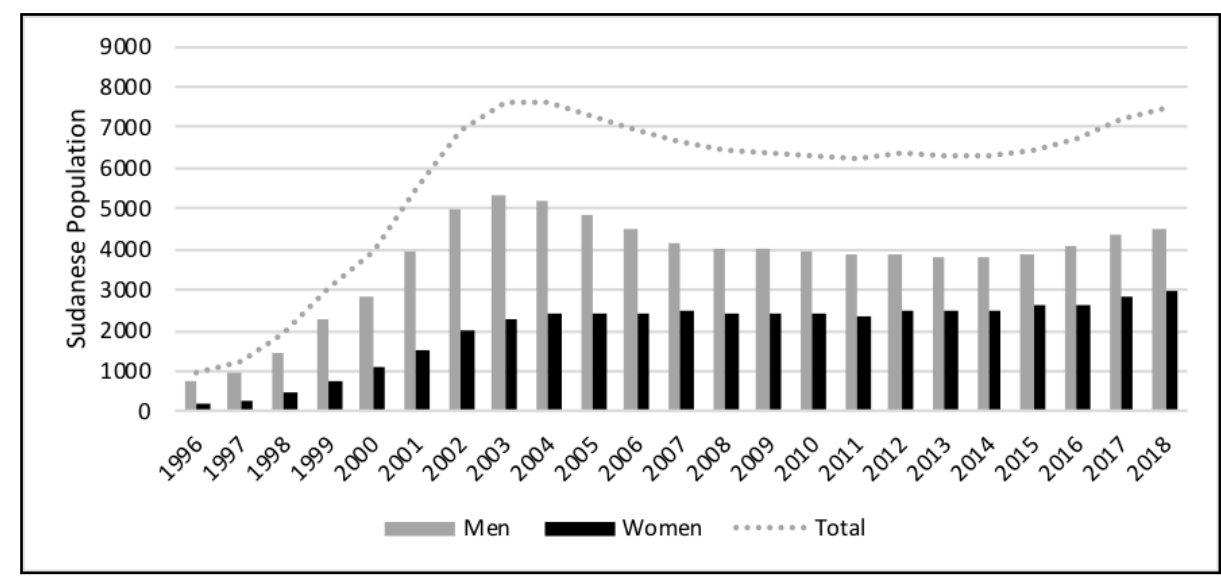

Source: CBS Statline 2018.

Figure 12 also illustrates how the Sudanese population in the Netherlands decreased in the early 2000s. Such decrease, might be due to the combination of two factors: the implementation of the CPA in Sudan in 2005, which technically ended decades of civil war, and the tightening of the Dutch migration and asylum policies in the early 2000s (see Figure 11)(Siegel \& de Neubourg, 2011). In the mid-1990s, following the continued outbreak of wars in Africa, the Middle East and Asia, the Netherlands attracted increasing numbers of refugees and asylum seekers, from 14,000 in 1988 to 45,000 in between 1999 and 2001 (Andrew \& Lukajo, 2005; van der Leun, 2003). Yet, since the late 1990s increasing public dissatisfaction about the growing number of asylum seekers, coupled with the believe that many were not 'real 
refugees', led to the introduction of restricted reception policies in the early 2000s to keep the so-called 'bogus' asylum seekers out (Ghorashi, 2005).

These two developments led to an increasing number of rejected Sudanese asylum applications, which might have resulted in relatively high numbers of irregular Sudanese living in the Netherlands not captured by the official statistics. Additionally, some studies have highlighted significant migration flows of certain migrant groups - especially Somalis - from the Netherlands to the UK, after having obtained their Dutch nationality (Ahrens, Kelly, \& van Liempt, 2016; Lindley \& van Hear, 2007; van Liempt, 2011). Whereas no such research has been conducted on onward migration flows of the Sudanese community, the fieldwork I conducted in both countries seems to point to similar trends (see Chapter 8).

\section{Sudanese community in the Netherlands}

The Sudanese community in the Netherlands is highly dispersed throughout the country, probably due to the housing policy of asylum seekers after they receive the refugee status (see sub-section 5.2.5) (van Heelsum \& Hessels 2005). Just like recent research on Sudanese diasporas in Sweden, Norway and the UK has shown (see Assal 2004; Abusabib 2007; Wilcock 2018), the Sudanese community in the Netherlands is also highly politicized, fragmented and heterogeneous. Divisions within the community exist along political, ethnical and regional lines, which reflects the reality of conflicts and civil unrest in Sudan (IOM, 2006). These studies have shown that the Sudanese abroad tend to identify themselves towards specific regions of Sudan, rather than Sudan as a whole (Wilcock, 2018). As Munzoul Assal rightly points out in his research on the Somali and Sudanese diaspora in Norway:

'The Sudanese in Norway are just individuals who lack any corporate body that would bring them together, like other immigrant communities. (...)(They) have very different backgrounds and histories, and many do not seem overtly interested in knowing about each other in a meaningful manner' (2006: 181).

Assal's description reflects to a great extent the situation that I observed in the Netherlands. For instance, throughout fieldwork in different Dutch cities I never came across any community organisation encompassing all the Sudanese in the Netherlands. In fact, most active Sudanese organisations I encountered were established along ethnic lines (e.g. Darfur Union, Nuba Mountains, etc.), with mainly political and/or cultural agendas. Some of these organisations provided support to its members-for instance, legal advice or repatriation insurances-but tensions among different groups were palpable. Moreover, mistrust played a crucial role in deepening community divisions. Especially those who had experienced repression in Sudan or were politically active, were often under a constant (and sometimes well-founded) suspicion that other Sudanese were actually from the Sudanese Secret Service (see sub-section 5.3.1). 


\subsubsection{Social security in the Netherlands}

The welfare states of the different European countries present significant differences in terms of development, policy design and institutional make-up (Hemerijck, 2013). Traditionally four main welfare regimes can be distinguished: Nordic, Continental, southern European and Anglo-Irish (Esping-Andersen, 1990; Hemerijck, 2013). The Netherlands, together with Germany, France, Austria and Belgium, belongs to the Continental regime, which follows a tradition of social insurance 'based on a tight link between work position and/or family status and social entitlements' (Hemerijck 2013: 157). Overall, the Dutch welfare system can be described as highly inclusive, structured, and one of the most generous in the world, providing a high degree of security and minimum living standards for all its legal residents, irrespective of ethnic origin and immigrant status (Zorlu, 2011; 2013).

The Dutch social security system is organised jointly by the Ministry of Social Affairs and Employment and the Ministry of Health, Welfare and Sport. It is financed both through taxes and insurance contributions (by residents, non-residents, employees, self-employed and employers), and comprises schemes covering: sickness and maternity, social assistance, occupational disability insurance, old-age pensions, survivors, unemployment, and child benefits (European Migration Network, 2014). The generosity and long-term character of this social security system is, consequently, bound to high spending and taxing levels (Hemerijck, 2013). Indeed, social benefits highly depend on having paid taxes through work, whereby to receive benefits, one must have officially worked for money (Evertsson et al., 2009).

In the last years, however, the generosity of the welfare benefits has been curtailed all over Europe, including the Netherlands and the UK, both in terms of amount and duration (Hemerijck, 2013). The eligibility criteria for social provisions has been tightened, whereby access to social insurance for inactive able-bodied persons has become conditional on participation in trainings, counselling, and behavioural requirements, such as job-seeking obligations (Hemerijck 2013: 30). The duration of the unemployment benefits in the Dutch system depends on the individual's employment history, ranging from 3 to 38 months. The amount received is $75 \%$ of the former salary for the first two months, thereafter $70 \%$. Dutch citizens without an employment history generally do not have access to unemployment benefits, but they can rely on welfare assistance, which covers the individuals' basic needs, and includes different types of allowances for house renting, health insurance or children support. Yet, to qualify for welfare assistance, the total accumulated wealth—including owned property—must be below 5,920€ for a single person (European Commission, 2017b).

Like social insurance and assistance, old-age pensions and social services have also undergone significant changes in the last years (Hemerijck, 2013; Pavolini \& Seeleib-Kaiser, 2016). Old-age pensions, in particular, continue to be one of the most resilient pillars of the European welfare states. Nevertheless, due to the growing aging 
population, steps have been taken to reverse the trends towards early retirement policies and to promote longer working lives (Hemerijck, 2013: 31). One of the main shifts in many European pension systems, including the Dutch, has been the growth of occupational and private pensions, and the development of multi-pillar systems, combining pay-as-you-go and fully funded methods (Hemerijck, 2013; Pavolini \& Seeleib-Kaiser, 2016). The Dutch old-age pension system is a mixed system of public and private provisions - often described as very generous - made up of three main pillars. First, the flat-rate state pension (AOW) is related to minimum wages, financed through payroll taxes, and it amounts to $1,150 €$ per month per single person approximately. From age 65 individuals lawfully living in the Netherlands are entitled to this pension, regardless of their working history. Second, the funded occupational scheme, comes on top of the basic state-funded pension and is a private pension system covering most employees. Finally, people can also engage in individual saving schemes by insurance providers (OECD, 2015). Despite the increased private or occupational pension provisions, the very low poverty rates among the elderly reflect the effectiveness of the basic state pension and the collectively bargained occupational pension in providing an adequate old-age income (Pavolini \& Seeleib-Kaiser, 2016).

Especially in the 2000s, spending on social services (e.g. family services, childcare, education, health, care for the elderly, and training and employment services) has increased in practically every member state of the European Union (Hemerijck 2013). In particular, family policy, including child care, parental leave, and work and family-life reconciliation policies, has suffered profound changes mainly to foster higher levels of female employment (ibid.). In the Netherlands, it was only in the late 1980s, that the traditional male-breadwinner model, with no publicly funded childcare support, was restructured to strengthen the economy by bringing more women into the labour force. Yet, the new system created a 'one-anda-half-earner' model, restructuring women's time while leaving men's untouched (Evertsson et al., 2009). Therefore, the high childcare costs together with tax deductions for breadwinners with dependents encourages mothers to withdraw from employment or to work part-time. Moreover, most childcare facilities are part-time, whereby women are expected to be caregivers first and foremost, and earners only secondarily and part-time (ibid.).

In the Netherlands, adults with children have the right to three different child benefits: a child allowance, a childcare allowance and a child budget (the two latter income-based). Dutch citizens - as well as those individuals lawfully residing in the Netherlands - are entitled to receive child allowance (Kinderbijslag) every 3 months, which ranges from 200.59 euro to 286.55 euro per child, depending on their age. When parents are legally working in the Netherlands and the children go to a childcare facility, childcare allowance (Kinderopvangtoeslag) can be claimed to cover part of the expenses, as long as the family income is below 35,000€/year. Yet, over the last years the consumption of formal childcare has decreased because of its high 
costs. In addition to this, there is a supplementary child budget (Kindgebonden) that depends on the parents' income and means, the number of children and their age (European Commission, 2017b). A major obstacle for parents (especially mothers) wishing to work full-time is the limited availability of childcare provision and the early end of the school day in classes for young children (Hemerijck 2013: 191). A study commissioned by the European Union Programme for Employment and Social Solidarity in 2014 showed that in the Netherlands, over half of the children under three were taken care for informally (Mills et al., 2014). The early end of the school day for young children together with the lack of relatives or social networks to whom entrust their children is especially problematic for female migrants and refugees with low income.

All schools in the Netherlands are state-funded, including religious ones, and all children have access to primary and secondary education for free. Moreover, public expenditure on education in the Netherlands-including financial aid-is above the average of the European Union as a whole. At the end of primary school (from age 4 to 12), all children must take a national examination. Based on the test result and the recommendation made by their teacher, children are assigned to follow a specific track in the secondary-school system: preparatory secondary vocational education, university preparatory education or senior general secondary education (Crul, 2009).

Since 2006, with the implementation of the Health Insurance Act (Zorgverzekeringswet; ZVW), the Dutch health insurance system became a combination of private health plans with social conditions, operated by private insurance companies but subsidised and regulated by the government. Purchasing a health insurance is compulsory for all people lawfully residing in or receiving a salary in the Netherlands, regardless of their migration background (Cuadra, 2010b). Besides the monthly premium - around $100 €$ a month for the basic coverageindividuals must pay an annual amount or 'own risk' if they receive some treatments and medicines before the health insurance will cover the rest (European Commission, $2017 b$ ). The standard basic package is free for children under 18 and generally covers a wide range of medical care, including care by general practitioners (GPs) and midwives, hospitalisation, dental care, medicines, maternity care, or ambulance among others. A wide range of chronic and mental healthcare services, such as home care and care in nursing homes, is also provided to citizens under the Exceptional Medical Expenses Act (AWBZ) (Cuadra, 2010b).

\subsubsection{Social security entitlements for documented migrants}

Since the 1950s, Dutch citizens enjoyed a high level of security in areas like unemployment benefits, healthcare, and retirement pensions (Ghorashi, 2005). Moreover, the Dutch social security system used to be quite open to the outside world, granting equal access for newcomers or allowing for long-term benefits to be exported throughout the globe (Vonk, 2002a). However, immigrant access to welfare 
provisions in the Netherlands has dramatically changed over time. Although the Netherlands had been a country of strong immigration since the early 1960s (see Figure 11), it was not until the mid-1970s that a series of policies started to be implemented to accommodate guest workers in the Dutch society, improving their access to public services and social security, especially housing (Siegel \& de Neubourg, 2011). Over time, municipalities started to provide better access to healthcare, social assistance or education. Family reunification trends in the late 1970s and early 1980s gave way to numerous national and local projects to provide migrants with better educational opportunities, improved chances on the labour market and access to social housing (ibid.). Nevertheless, in the second half of the 1990s, following a series of strong and explicit views on the role of migrants in the Dutch society, several legislative changes resulted in the end to this open character, affecting the access to welfare from different migrant groups (Vonk, 2002a).

According to the Ministry of Social Affairs and Employment (2008), all persons (legally) residing in the Netherlands, as well as those who work in the Netherlands and pay income tax, are required by law to be insured under the National Insurance Schemes (Siegel \& de Neubourg, 2011) and may in principle claim entitlement to social security benefits (European Migration Network, 2014). This is due to the so-called 'principle linking eligibility for benefits to residency status' or Linkage Act of 1998, that links all social security benefits-including rights and access to secondary or higher education, housing, rent subsidy, handicapped facilities and healthcare-to an immigrant's legal residence status (Bruquetas-Callejo et al., 2007). Therefore, migrants who do not reside lawfully in the Netherlands are not entitled to public services, except medically necessary care, education for their children and legal assistance (European Migration Network, 2014). Whereas in theory, all legal immigrants have access to the above mentioned social-security provisions, in practice, non-permanent residents and recent migrants, especially the low-skilled, have no or very limited access. Since their residence permit is linked to their labour contract, applying for social assistance with a temporary permit could result in the withdrawal of the residence permit and the cancellation of any benefits (Siegel \& de Neubourg, 2011; Zorlu, 2011). Moreover, pensions that are paid out of general tax revenues usually have long-residence requirements. People who have lawfully lived or worked uninterruptedly in the Netherlands between the ages of 15 and 65 are entitled to a state pension. The amount received is proportional to the number of years spent in the Netherlands, and every missing year results in a 2 percent decrease. Therefore, migrants tend to have lower pension incomes than their native-born counterparts (Koning, 2012). Regarding healthcare, migrants who legally reside in the Netherlands must have a Dutch health insurance - even if they already have one in their homeland-and therefore are entitled to receive healthcare (Cuadra, 2010b).

The entitlement for most benefits depends on the individual's paid employment history. Therefore, youth and newly arrived immigrants have limited or 
no access these benefits (Zorlu, 2011). Moreover, for some categories of immigrants, since 2006 access to social assistance, unemployment, and disability benefits depends on successful participation in integration and Dutch classes. At the same time, the number of subsidised immigrant-targeted services has been reduced, and all active labour market programs as well as state-funded interpretation services in healthcare have been abolished (Koning, 2012). Individuals who are legal residents but do not have a work history in the Netherlands are assigned social assistance for the household to cover their basic needs (Zorlu, 2011). The only requirement to receive social assistance benefit is to have a regular permanent residence permit, as stipulated in the Linkage Law 1998. Migrants can only receive such permanent residence permit after 5 years in the Netherlands. During this time, they have no access to noncontributory programs such as social assistance and child benefits (Koning, 2012). Moreover, applying for social assistance with a temporary permit could result in their residence permit withdrawn and benefits cancelled (Zorlu, 2013). Since 2006, EU migrants are not entitled to social assistance for the first three months of their stay (ibid.). People who arrive through family reunification (except refugees) have a more vulnerable status in their first years in the country, since their right of residence dependents on their sponsoring partners. This means that during the first 5 years the migrants have no access to any benefits, and if the relationship breaks down the newly arrived migrant might be forced to leave the country (Koning, 2012).

\subsubsection{Social security entitlements for undocumented migrants in the Netherlands}

In recent years, European countries like the Netherlands, Germany or Denmark have come to realise that 'keeping them out' is only one strategy to deal with undocumented migrants ${ }^{10}$. Recently, internal control mechanisms to protect the welfare state, the labour market, and the right of residence (with duties and privileges) from undocumented migrants, have been gaining relevance (Engbersen \& Broeders, 2011; van der Leun, 2003). Indeed, the informal policy of toleration of the 1980s, where migrants could easily access several welfare benefits (Broeders \& Engbersen, 2007), turned into a series of policies of restriction and explicit exclusion of irregular migrants through the implementation of different instruments: legislation, controls, documentation, registration and new digital surveillance mechanisms (Engbersen \& Broeders, 2011). Dutch policies of exclusion follow two main logics: exclusion from and through documentation. On the one hand, excluding migrants from legal documentation and registration translates in their not being able to access different institutions of society, such as the labour market and the housing market, and even from informal networks. Moreover, such strategy aims at delegitimising and criminalising those who somehow employ, house or aid irregular immigrants. On the

${ }^{10}$ The number of undocumented migrants in the Netherlands ranges between 40,000 to 200,000 (van der Leun, 2003). 
other hand, by identifying and 'documenting' irregular migrants, their detection and expulsion becomes more effective, in that expulsions can only take place when the migrant's identity can be established (Engbersen \& Broeders, 2011).

A crucial element of such policies is the Linkage Act of 1998, which links the access to public provisions to a valid residence status. By linking electronically all social economic data-bases, the authorities are able to register, track and identify immigrants as soon as they make use of health services, schools or parts of the social security administration (Siegel \& de Neubourg, 2011). In doing so, the Act aims to exclude irregular migrants from tax-based public services such as social assistance, public housing, adults education and nonemergency healthcare (Broeders and Engbersen, 2007; van Meeteren, 2014). Only publicly funded legal assistance, imperative or necessary medical care and education for children up to 18 years old are accessible to everyone (Engbersen \& Broeders, 2011; PICUM, 2002; Siegel \& de Neubourg, 2011).

Although in theory some basic services are still available to undocumented migrants, the system contains financial and practical hurdles. For instance, healthcare providers can only be reimbursed for providing 'medically necessary care' and care 'necessary to protect public health' (Biswas, Toebes, Hjern, Ascher, \& Nørredam, 2013). Since 2009, based on the Dutch Health Insurance Act, health-care providers can seek reimbursement for $80-100 \%$ of the cost of care, depending on the treatment (e.g. pregnancy and childbirth costs are fully reimbursed). To be reimbursed, though, healthcare providers must prove that they first attempted to collect the money from the patient (e.g. sending an invoice and investigating the patient's ability to pay) (ibid.). In principle, therefore, undocumented migrants should now pay for health services unless they cannot afford the bill. The new scheme distinguishes between 'directly accessible' services (general practitioners, midwives, dental care up to age 21 , and acute hospital care) and 'not directly accessible' services (e.g. non-emergency hospital care and nursing homes), which require a referral. Yet, the referral from primary to secondary care is not optimal, due to financial obstacles for healthcare providers. Moreover, several studies have reported a number of GPs are unwilling to treat undocumented migrants, leaving the responsibility to a small group of willing practitioners (ibid.). In addition to this, undocumented migrants avoid seeking healthcare services because of a lack of information about the entitlements to healthcare, coupled with the fear of having to pay the bill. This situation also extends to their children. Whereas undocumented migrant children are entitled to free vaccinations, free preventive care and check-ups at baby clinics, their undocumented parents are usually too scared to become visible to the government, or they move too frequently, whereby they do not register their children for the necessary preventive healthcare. These children, thus, never receive invitations for the vaccination program (Flegar, Dalli, \& Toebes, 2016).

Despite these policies of exclusion, governmental policies on irregular migration are notorious for their ambiguities. For instance, regulations that explicitly 
prevent undocumented migrants from accessing medical care, contrast with messages that everybody is entitled to receive the medical care they need; while national government emphasises that undocumented migrants should not receive any type of official support, representatives of municipalities openly support local initiatives to help the undocumented (van der Leun, 2003); whereas undocumented migrants do not have legal access to housing services, municipalities and local NGOs, often offer reception facilities for certain undocumented migrants (ibid.).

\subsubsection{Social security entitlements for asylum seekers in the Netherlands}

The Netherlands, as well as the UK, portrays itself as a nation with a long history of offering sanctuary and being tolerant of difference. Nevertheless, the arrival of increasing numbers of asylum seekers in the last years has given way to negative popular and media attitudes towards asylum seekers, who are often depicted as falsely claiming persecution in order to access housing, benefits and employment, taking advantage of generous welfare state (Bakker, Cheung, \& Phillimore, 2016). Both countries, thus, acted towards reducing asylum numbers and associated costs by adopting deterrent approaches to asylum support, namely, restrictive access to benefits, employment and housing, in an attempt to become less attractive asylumseeking destinations. Paradoxically, however, both countries recognise the importance of integrating recognised refugees, by providing them with equal access to work, health, and education (ibid.).

In the Netherlands, the legislation regarding asylum-seekers and refugees has changed considerably since the 1980s, following the increase of this migrant group during the 1980s and 1990s (Bruquetas-Callejo et al. 2007). In the early 1980s, mainly quota refugees entered the Netherlands with residence permits and places to live as soon as they arrived. Whereas they were not allowed to work until they obtained refugee status, they were entitled to unemployment benefits equal to the amount received by unemployed Dutch citizens. By the end of the 1980s, however, the number of asylum seekers increased dramatically (Ghorashi, 2005), which resulted in the introduction of the Regulation on the Reception of Asylum Seekers (Regionale Opvang Asielzoekers; ROA) of 1987. After the implementation of the ROA, asylum seekers had to first stay in asylum-seekers centres (asielzoekerscentrum; AZC) for some time, until they were transferred to the so-called ROA houses, which they shared with other asylum seekers. Asylum seekers pending refugee status were no longer entitled to unemployment benefits, but their rent and other costs were covered, and they received a small weekly allowance (Ghorashi, 2005). This temporary stay at the AZCs turned from a matter of months at the end of the 1980s to a matter of years at the beginning of the 1990s (ibid.). In 1992 the New Admission and Reception Model for Asylum Seekers was introduced, whereby municipalities became fully responsible for the reception and integration of those who had passed asylum procedures, namely status-holders and persons with a temporary expulsion waiver (Bruquetas-Callejo et al. 2007). In 2001, the new Aliens Act (Vreemdelingenwet 2000) was passed, aimed at 
shortening the asylum procedure, whereby nowadays around $82 \%$ of the asylum requests are processed within six months (Bakker, Dagevos, and Engbersen 2014: 434).

Currently, migrants who apply for asylum in the Netherlands must follow a specific process. After filing their application at the Immigration and Naturalisation Department (Immigratie- en Naturalisatiedienst; IND), and receiving initial legal and medical advice, they are dispersed - with very limited choice - to an AZC, where, in theory, they might wait up to six months for a decision (Bakker, Cheung, and Phillimore 2016). If the asylum application is granted, the person receives a residence permit and is put in contact with a municipality in the region of the AZC (European Migration Network, 2013). Under the new Aliens Act 2001, asylum seekers who are granted permission to stay in the Netherlands receive a temporary 5-year permit, during which they need to acquire a qualification of integration to be able to apply for a permanent status (ibid.). If the IND needs more time to make a decision regarding the asylum application, an extended asylum procedure begins. During this procedure, asylum seekers remain at the AZC, where they are provided for the basic needs. If the asylum application is denied, asylum seekers must leave the Netherlands within 28 days following the decision (or after their appeal is rejected) (European Migration Network, 2013). After this period, no voluntary departure period is granted, there is no right to reception conditions and they have the same rights as undocumented migrants (AIDA 2015). Unaccompanied minors may remain in the asylum reception centres and benefit from the services until they turn 18 (ibid.).

The Central Agency for the Reception of Asylum Seekers (Centraal Orgaan opvang Asielzoekers; $\mathrm{COA}$ ) is responsible for covering the basic needs during the whole process (AIDA 2015). The AZCs vary in type and size, but in average, a centre hosts around 400 people of some 40 nationalities (COA, 2017). These centres are often placed in rural areas, which might hinder the participation in the local community. Asylum seekers are free to move outside the centre but, they must report regularly (COA 2017; Bakker, Cheung, and Phillimore 2016). Units are designed for five to eight people, with a shared kitchen and bathroom. If possible, families share a unit, whereas single people share with strangers (Bakker, Cheung, and Phillimore 2016). Most daily activities happen in the company of a large group of other asylum seekers, whereby, privacy and autonomy are limited (ibid.).During the time asylum seekers live in the centres, their basic needs are covered for by the COA, including: accommodation, a weekly financial allowance-around $43 €$ for food, clothing and personal expenses-public transport tickets to visit a lawyer, recreational and educational activities, medical costs, civil liability insurance, and other exceptional costs (AIDA, 2017; Poptcheva \& Stuchlik, 2015). The weekly allowance amount depends on the family's size and any income they may have (COA, 2017). Whereas all their basic needs are provided for by the state, asylum seekers' access to the formal labour market, and formal education is rather limited (Poptcheva and Stuchlik 2015; Bakker, Cheung, and Phillimore 2014, 2016). Only those who have spent at least 6 
months at the AZC are allowed to work for a maximum of 24 weeks a year (Poptcheva \& Stuchlik, 2015). When working pending the decision on their asylum application asylum-seekers must contribute a certain amount of money to the accommodation costs for the reception facilities and the monetary allowance they receive. They are allowed to keep the first $25 \%$ of their earnings, up to a maximum of $€ 185$ per month. Asylum-seekers are also allowed to do internships and voluntary work, as well as maintenance jobs in the centre for a small fee (ibid.). Depending on the stage of the asylum application the COA offers educational programmes for adults. Yet, only those asylum-seekers who have been granted an asylum permit, can start the integration course to take the mandatory civic integration examination (ibid.). Research has found that lengthy stays in such an environment, with limited personal development and restrained social interactions with the outside world, reduces refugees' confidence and their ability to (re)gain the resources they need to integrate in the labour market once their asylum request has been granted, creating, thus, dependence on the state (Bakker et al., 2014; Ghorashi, 2005).

Asylum-seeking children have the same rights to education as Dutch children (AIDA, 2017). Indeed, about one-quarter of the asylum seekers at COA are under 18. All children go to school and can use a room with computers to do their homework. The reception locations have playgrounds and regularly organise activities for children. This allows the children to live an 'as normal as possible' life. Children are also offered courses such as resilience training (COA, 2017a).

Healthcare provided to asylum seekers in the Netherlands has varied over the years. Until the late 1970s, refugees were incorporated into the regular healthcare system (Siegel \& de Neubourg, 2011). However, considering the specific healthcare needs of the refugees, the Refugee Health Care Centre was established as part of the Ministry of Health in 1979. This centre offered counselling and first medical reception to refugees and asylum seekers, acting as a bridge towards a regular healthcare (ibid.). In 2000, Community Health Services (Gemeentelijke of Gemeenschappelijke Gezondheidsdienst), the COA and the Ministries of Justice and Public Health decided that asylum seekers should receive medical care from regular healthcare institutions, while the medical reception in the centres would focus on prevention and education (Siegel \& de Neubourg, 2011). Thus, the medical care provided to asylum seekers is as similar as possible to regular Dutch healthcare. Asylum seekers, like Dutch residents, can visit a general practitioner, midwife or hospital (COA, 2017).

\subsubsection{Social security entitlements for refugees in the Netherlands}

When asylum seekers receive their refugee status, they may remain for five years, and it is the municipality's responsibility to facilitate social housing. Officially, social housing should be provided in the same regions as the AZC within 14 weeks after obtaining refugee status. In reality, however, some people end up waiting several months. Even if social housing providers prioritise this target group, $13 \%$ of the 
allocated quota was not reached in 2014 (Poptcheva \& Stuchlik, 2015). Until the municipality can offer them suitable accommodation, asylum seekers live at the AZC. Under these circumstances, arrangements have been made to provide refugees with temporary housing of lower quality or enabling them to stay temporarily with relatives or friends. Whereas refugees may search for housing themselves in another municipality, they lose their priority access right to social housing (ibid.). The municipalities are responsible for the integration of refugees (as well as other unemployed people) into the labour market. The Dutch Council of Refugees (VluchtelingenWerk) and other NGOs play an active role in offering language and vocational training and labour market re-insertion projects (ibid.). New refugees must take an integration course, which is meant to facilitate access to labour market. Failure to pass this test results in their not being able to apply for permanent residence (Bakker et al., 2016).

Refugees and those with subsidiary protection are entitled to the same rights and benefits as those of Dutch citizens, including the right to social assistance, access to education, employment, and health services (Moret, Baglioni, \& Efionayi-Mäder, 2006). However, institutions might be reluctant to grant certain services (e.g. mortgages) to refugees with a temporary status (Bakker, Dagevos, and Engbersen 2014:435).

Research has shown that many refugees in the Netherlands are not satisfied with their social conditions, especially when it comes to labour (Moret et al., 2006). While they have the right to work and there are no formal restrictions preventing their access to the labour market, many refugees have pointed to the lack of, or limited, employment opportunities as a crucial problem (ibid.). This might be due to several reasons. First, the lack of employment possibilities during the asylum process creates a gap on the refugees' $\mathrm{CV}$ which can have negative effects when they are allowed to find a regular job. Second, the negative media attention on refugees and the lack of a strong professional network, limits their access to the labour market, since in the Netherlands 'a lot of jobs are granted to acquaintances' (van der Meer \& Bax, 2016: 5). In this regards, the Dutch Council for Refugees and the Foundation for Refugee Students (UAF)-provided by the COA-offer some support in this respect by trying to connect refugees with local companies and giving them the opportunity to learn Dutch. Third, the education refugees have followed in their home country is often not recognised by Dutch employers, whereby they often obtain temporary, unskilled, menial jobs. The UAF offers additional schooling to validate their degrees or start one from scratch (ibid.). However, age thresholds limit many refugees to University education, which forces them to remain in the low-skilled job markets (Moret et al., 2006).

Refugees who are not able to find remunerated employment receive social assistance. They are also entitled to extra aid from the tax department (belastingdienst) for different issues (toeslagen), such as: housing rent, healthcare insurance, and child care. Moreover, refugees obtain an initial bulk sum of money (to be returned or not 
depending on municipalities) in order to buy furniture and equipment for the house. This is a monthly allowance for everyone (e.g. those over 18 years old with a permanent residence permit) who cannot pay for their own life expenses. The amount received depends on different factors such as: municipality, age, family situation, or children. Moreover, people living on social assistance without savings might have the option to obtain extra income from their municipality for essential and unexpected living expenses, such as a new washing machine or sports club fees. Every three months all parents or guardians receive child benefits (kinderbijslag) per child, which range from around $200 €$ to $300 €$ per child per quarter (YALLA Foundation, 2016). 


\subsection{Migration and social security in the UK}

Figure 13 -Brief timeline of the main migration stages and main welfare developments in the UK.

'European Volunteer Workers' period.

Recruitment of mostly Eastern European workers to meet the British

labour market needs.

Immigration from former British colonies

Commonwealth workers to fill in labour market needs.

- Commonwealth Immigration Act (1962) limiting the entry of New Commonwealth citizens (e.g. West Indies, India, Pakistan and Bangladesh) to curb massive immigration.

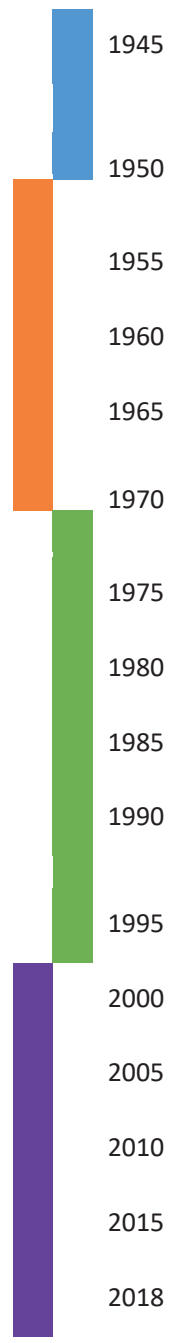

Stricter migration controls and asylum concerns

975

Limiting arrival and citizenship rights of migrants from the former British colonies.

Acts of Parliament (1993 and 1996) aimed at restricting asylum

985

applications and limiting migrants' access to public welfare.

1990

1995

'Selective openness'

2000

Commitment to economic migration \& development of tough security and control frameworks.

'White paper' (2002) on 'managed migration'

- Introduction of multiple-over 80 types-work permits and visas.

- Encouragement of circular migration.

Source: Author's own compilation based on literature review (Conway, 2007; Geddes, 2003; Hansen, 2017; Kofman, 2002; Wilkinson \& Craig, 2011) 


\subsubsection{Sudanese migration to the UK}

The UK is probably the oldest Western destination for Sudanese migrants (IOM, 2006). Sudanese migration to the UK can be divided in three phases, all three of them from different regions and for different purposes (Wilcock, 2018). From the 1960s and up to the late 1980s most Sudanese arriving in UK were professionals, business people or academics (IOM, 2006). This type of migration was enabled by colonial linkages and was mainly characterised by elite Arab Muslim men from the northern riverine regions, many of whom did not return to Sudan and remained in the UK in professional roles (Fabos, 2007; Wilcock, 2018). The second phase of Sudanese migration to the U.K. took place in the late 1990s and early 2000s, after Al-Bashir's coup in 1989 and the growing peripheral rebellions, which peaked in the 2003-2005 Darfur conflict. This situation opened the way to a new type of migrants, namely, asylum seekers from diverse ethnic background in impoverished regions, such as Darfur, Blue Nile, South Kordofan and East Sudan (IOM 2011). The third phase of Sudanese migration to the UK occurred after the secession of South Sudan in 2011. It was mainly characterised by political elites and student protesters of opposition parties, from all over Sudan (often over Khartoum), who fled the increasingly oppressive and violent regime (Wilcock 2018). According the Home Office statistics, between 2002 and 2017, 16,881 Sudanese applied for asylum in the UK, out of which less than half were granted some sort of protection ${ }^{11}$. As Figure 14 shows, the arrival of Sudanese asylum seekers is strongly dominated by men.

Based on my own fieldwork and observations, as well as on recent qualitative research conducted among Sudanese migrants waiting in Calais for an opportunity to move on to the UK (Zeghnoune, 2016), Sudanese migration to the UK in recent years is highly diverse. Such diversity refers not only to the region of origin, but also to the reasons to move and the educational background of the migrants (ibid.). As recent research has shown, while there are only around 3,200 Sudanese refugees living in the UK, many of the 22,000 Sudanese residents with the official status of economic migrant might have political motivations for leaving and/or remaining away (Wilcock, 2016).

As noted in the previous chapter, it is difficult to establish the size of Sudanese living in Western countries because of different national definitions, those who have obtained citizenship in Western countries and the fact that many statistics refer back to the time when Sudan and South Sudan were one nation state. This is particularly the case for 'older' destination countries like the UK (IOM, 2011). According to the Office of National Statistics UK, in 2017 there were around 40,000 Sudanese (by

${ }^{11}$ https://www.gov.uk/government/publications/immigration-statistics-october-to-december-2017/list-oftables 
birth) living in the UK, with a slighter higher proportion of men. Yet, estimates range from 21,000 to 80,000 (IOM, 2006).

Figure 14 - Sudanese asylum applications in the UK by sex (2009-2017).

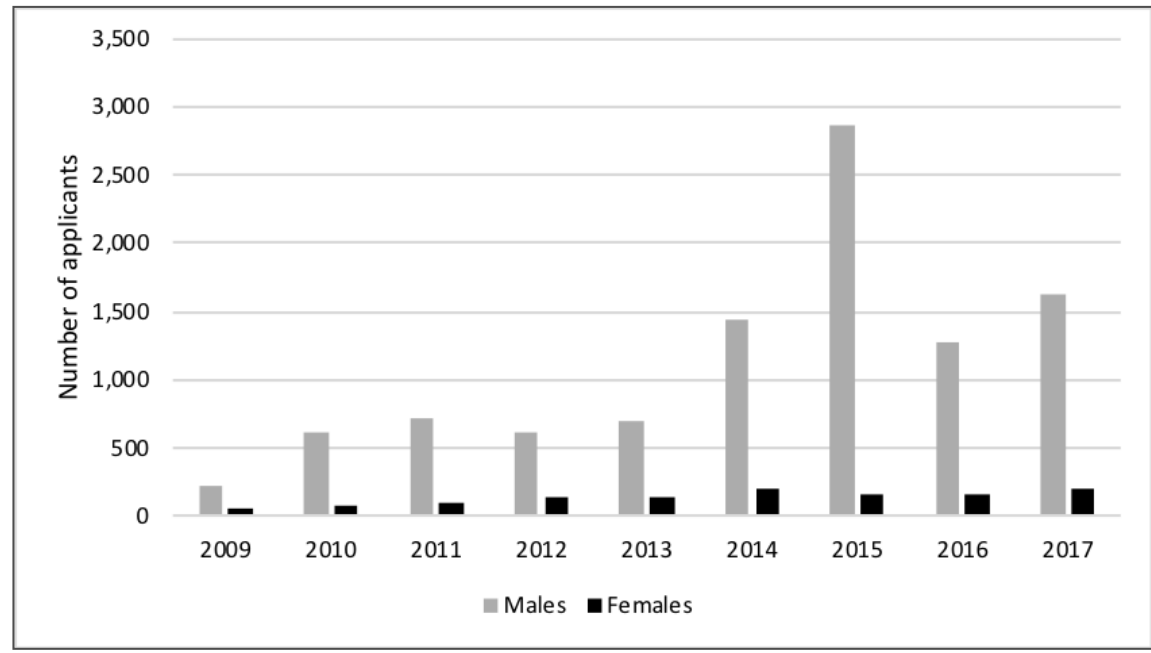

Source: Eurostat Database, $2018 b$

\section{Sudanese community in the UK}

The Sudanese community in the UK has been longer established than in the Netherlands, is clustered around bigger cities (e.g. London, Manchester, Leeds or Birmingham) and has more institutional bonds with Sudan, (for instance: the Sudanese Medical Union in the UK and Ireland). Yet, the Sudanese community in the UK is also highly politicized, fragmented and heterogeneous, with multiple divisions along political, ethnical and regional lines, which reflects the reality of conflicts and civil unrest in Sudan (IOM, 2006). Most Sudanese organisations in the UK are established along ethnic lines (e.g. Darfur Union, Nuba Mountains, etc.), and focused on political and/or cultural activities (Wilcock, 2018). Several (often) overlapping factors contribute to the divisions across the multiple associations. For instance, some organisations are mobilised towards the historical experience of genocide, excluding, thus, political elites from Khartoum- both current ones as well as those who arrived before 1989 (ibid.). Other associations are organised along political lines -e.g. government-critical groups; political opposition parties, social movements and rebel affiliates from the three migration phases-with no shared political agenda but a common emotional motivation to change the government (ibid.). To a certain degree, the political differences are based on the inequalities that have marked Sudan historically, and exacerbated by the hierarchies created by patterns of arrival (Wilcock, 2018). Upon arrival in the UK, new migrants from impoverished regions meet those from older-established communities of 
professionals (before 1989) and are often marginalised in decision-making processes, creating tension between the groups (ibid.). For instance, during my fieldwork in the UK, I realised that newly recognised refugees and asylum seekers, most of them with limited financial possibilities, did not attend collective events with 'older Sudanese'. In one occasion I asked one of my respondents - a newly arrived refugee, who had arrive through the Calais route - why he did not attend the gatherings organised by an old-established Sudanese group in Birmingham, and he said: 'They're not good, they change, they don't help'.

On top of these divisions, Sudanese associations are specifically divided into pro-and anti- Sudanese regime, referring to each other as 'the other Sudanese' (Wilcock 2018: 375). Indeed, one of my key informants explained during fieldwork, clashes among different groups had sometimes resulted in violent encounters in the UK. This situation has been exacerbated by the fact that, due to the politicised nature of the Sudanese migration to the UK, in the last years a number of pro-government Sudanese have arrived to monitor the opposition exiles (McElroy, 2014). Probably the main (and only) common aspect bringing together (to some extent) all the different organisations and individuals migrants from all the different periods is the shared sense of duty towards the people back home (Wilcock, 2018).

\subsubsection{Social security in the UK}

The establishment of the welfare system in the UK dates back to the 1942 Beveridge Report, which provided for most varieties of need 'from the cradle to the grave' (Jones \& Lowe, 2002). The traditional Beveridgean welfare state is based on the principle of providing minimum income as a basic social right, based on stateprovided poverty relief and equality of opportunity (Hemerijck 2013: 156). The British welfare regime belongs to the so-called Anglo-Irish or liberal group, which is characterised by means-tested assistance, little redistribution of incomes, low level of decommodification, modest social-insurance plans, individualism and the primacy of the market (Esping-Andersen, 1990). The state's encouragement of the market to guarantee and subsidise private welfare schemes leads to a higher degree of social stratification and inequality (ibid.). The Anglophone welfare has a strong poor-relief orientation, whereby transfers and social services are only provided on a meanstested basis for the most disadvantaged. Thus, people without sufficient income often have to rely on self-help or family support, which is often perceived as a private issue (Hemerijck 2013: 156). Moreover, the progressive contracting out of diverse areas of welfare and increasing involvement of private actors in the delivery of services, have altered the relationships between state, providers and citizens, and added additional layers of complexity and uncertainty. The complexity of the UK welfare system, thus, has resulted in a labyrinthine web of benefit schemes and administrative processes that determine access to individual entitlements (Palmer, 2016).

The UK social security system is organised by different government departments, including: the Department for Work and Pensions, responsible for cash 
benefits for unemployment, sickness and invalidity, old age, and other social assistance benefits; Her Majesty's Revenue and Customs, responsible for family benefits and means-tested in work benefits; the Department for Communities and Local Government, responsible for social housing and housing assistance; the Department of Health, in charge of health and social care support; and the Department for Education, responsible for funding children's social care (Broomfield, 2014). Contributory benefits-sickness, unemployment, invalidity, death, maternity and retirement benefits - are accessible by those people who pay NI contributions. Anyone who meets the employment criteria and has built up the necessary contributions can claim these benefits, regardless of their migration background. Non-contributory or state-funded benefits -income-based invalidity and unemployment benefit, long-term care benefits and family benefits-do not require NI contributions (Broomfield, 2014).

Like in the Netherlands, the generosity of benefits in the UK has been curtailed in the last years, both in terms of benefits amount and duration. Conditionality is being increasingly applied in an wide range of welfare policy areas, such as: social security, housing, education, and health (Dwyer, 2004). According to this, eligibility to certain basic, publicly provided, welfare entitlements-including social insurance and assistance, incapacity benefit, maternity allowance, bereavement benefits, industrial injuries disablement benefit, care allowance and the social fund-are dependent on an individual first agreeing to meet particular compulsory duties (ibid.). Conditionality is also a feature of current social housing policy in the UK, whereby the right to access and remain in social housing is linked to responsible behaviour. 'Anti-social' behaviour -ranging from children playing where they annoy neighbours, to serious criminal activity, racial harassment or violent attacks - might result in eviction and revoking the right to a future secure tenancy (ibid.). Conditionality has been criticised by NGOs for being not only problematic and counterproductive, but also for not taking into account of the reality of people's lives and becoming a threat to people's social protection (Poinasamy, 2011)

The eligibility criteria for unemployment benefits has also become conditional on participation in trainings, counselling, and job-seeking obligations (Hemerijck 2013). In the UK there are several types of income-related benefits, which make the system rather complicated to navigate. The Jobseeker's Allowance (JSA) is available under certain conditions for those who are actively looking for employment and can prove it. There are two types of JSA, contribution-based -paid for a maximum of six months to those who have paid sufficient NI contributions in the two years prior to the application - and income-based -payable to those who have not paid enough NI or are on a low income for the benefit. The amount received depends on the age of the beneficiary, but there is a weekly maximum amount of $£ 73.10$ for a single person (European Commission, 2017b). Those who are unable to work because of illness or disability are entitled to the Employment and Support Allowance (ESA). The ESA 
also provides support to those who are able to work (European Commission, 2017b). The amount received depends on multiple factors, such as the income, the age and the savings of the beneficiaries, which must be below $£ 16,000$ (European Commission, 2017b).

In the UK, pensions are not conditional and included in the NI. However, even though they are often assumed to be universal, they are actually a demanding contributory social insurance scheme (Béland, Blomqvist, Andersen, Palme, \& Waddan, 2014). Pensions are paid with a flat rate in the UK, whereby means-tested benefits and private pension schemes play a crucial role to complete pensioners' incomes. This makes the UK's basic pension system one of the lowest in comparison to the benefit level from mandatory schemes in most OECD countries. In 2015, the basic state pension for a single person was $£ 113$ per week (OECD, 2015). The amount of private pension schemes to complement the state pension depends on different factors, such as: the amount invested in the scheme or the age of the beneficiaries. The State Pension age is currently between 63 and 68, depending on the year of birth and on the gender. In order to access the full basic state pension, 35 years of contributions are required (European Commission, 2017a). Therefore, only pensioners with a generous private or occupational pension can expect an adequate old-age pension (Pavolini \& Seeleib-Kaiser, 2016). Thus, many people reach retirement age without the necessary contributions and need to get financial support from a means-tested benefit programme to avoid deep poverty (Béland et al., 2014). As Figure 15 shows, the risk of poverty for persons over 64 years old is much higher in the UK than in the Netherlands.

Figure 15 - Risk of poverty for persons over 64 (2005-2010-2015).

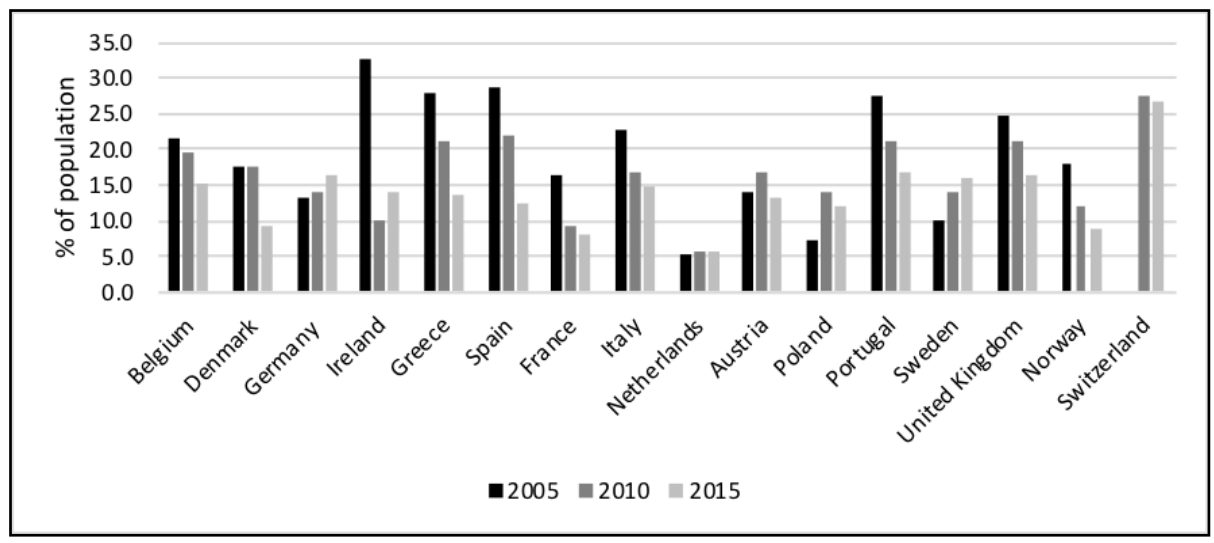

Source: Eurostat Database, $2018 b$

In the UK, children between 3 and 4 -or children over 2 from disadvantaged families - are entitled to free non-compulsory pre-school education for 15 hours a 
week. For working parents, 15 additional hours of free education over 38 weeks is possible. Beyond the initial 15 free hours, parents must pay for any additional hours of childcare, which may amount to $£ 115$ per week (Harding, Wheaton, \& Butler, 2017). Adults responsible for children under 16 or under 20 if they are in approved education are entitled to child benefits -around $£ 20$ weekly for the first child and $£ 14$ for additional children.

In the UK all children aged between 5 and 16 receive free education. Schools can be classified in two main categories: (1) state schools that are free of charge, and (2) independent schools, which cater for about $6 \%$ of UK pupils and charge an average fee of $£ 5,225$ per term per pupil. School attendance for youngsters aged between 16 and 18 is not compulsory but they must continue in education or training. Financial aid - provided by local education authorities, governing bodies, parents' associations, and charities - depends on the type of school, the parents' financial situation and the child's age. Financial includes: free school meals, school milk, school uniform, materials, books, exam entry fees, necessary equipment for the national curriculum and school transport (Citizens Advice, 2017a).

In 2010, the system of universal credit was introduced in the UK. This system, gradually implemented from 2013-2017, was designed to replace six existing payments for people of working age: income support, income- based job seekers allowance, income-related employment support allowance, housing benefit, child tax credit and working tax credit. Although its aims were simplifying the system of working age benefits, making work pay, increasing take-up, and reducing fraud and error, it soon became clear that it caused an increase in hardship and poverty to many vulnerable groups (Palmer 2016).

Despite the overall liberal character of the British welfare system, the UK has universal provisions, such as a National Insurance (NI) system, which includes the National Health Service (NHS), provided to everyone on a free of charge basis. Since its establishment in 1940, the British NHS provides free access to healthcare to all UK residents. In 2011 , only $11.1 \%$ of the population had some form of private insurance (Béland et al., 2014). Free access to NHS treatment is based on ordinary residency and does not depend on nationality, tax payments or national insurance contributions. Therefore, those who lawfully live and are settled in the UK (and can prove it) are entitled to free healthcare.

\subsubsection{Social security entitlements for documented migrants in the UK}

Like the Netherlands, the UK became a country of immigration after the Second World War (see Table 5). Whereas early migration flows were mainly driven by the British market needs, from the late 1980s onwards, asylum-seekers became the greater concern (Somerville, W. Sriskandarajah \& Latorre, 2009). Throughout the years, different migration regulations and increasing limitations on migrants' access to public funds have been used by the government to curb certain types of migration (Kofman, 2002). 
The UK has one of the least regulated labour markets of all 'developed' economies. The government's invitation to labour migrant to meet the needs of the 'flexible' economy has resulted in high numbers of exploitable, largely unprotected workers, who often 'under levels of exploitation that would meet the international legal definition of "forced labour"' (Wilkinson \& Craig, 2011: 177). Indeed, the 2002 white paper set out an ambitious plan for 'managed migration', whereby multiple work permits - with over 80 different routes for visa and employment for different categories of workers-were introduced (Hansen, 2017). Such complicated system of employment rights resulted in many migrants not knowing about their rights and ending up in highly vulnerable situations. Recent research has found that migrant workers worked for low pay (100-200GBP per week), longer hours (over 60 hours per week), had no sick pay, paid holidays nor written contracts. Many migrants are overqualified for the jobs they occupy and very often end up living under poor housing conditions (Wilkinson \& Craig, 2011). Yet, as Figure 16 shows, the unemployed rate of native-born as compared to foreign-born population was much lower in the UK than in the Netherlands.

Figure 16 - Unemployment rate of native-born versus foreign-born population (15-64 years), 2015.

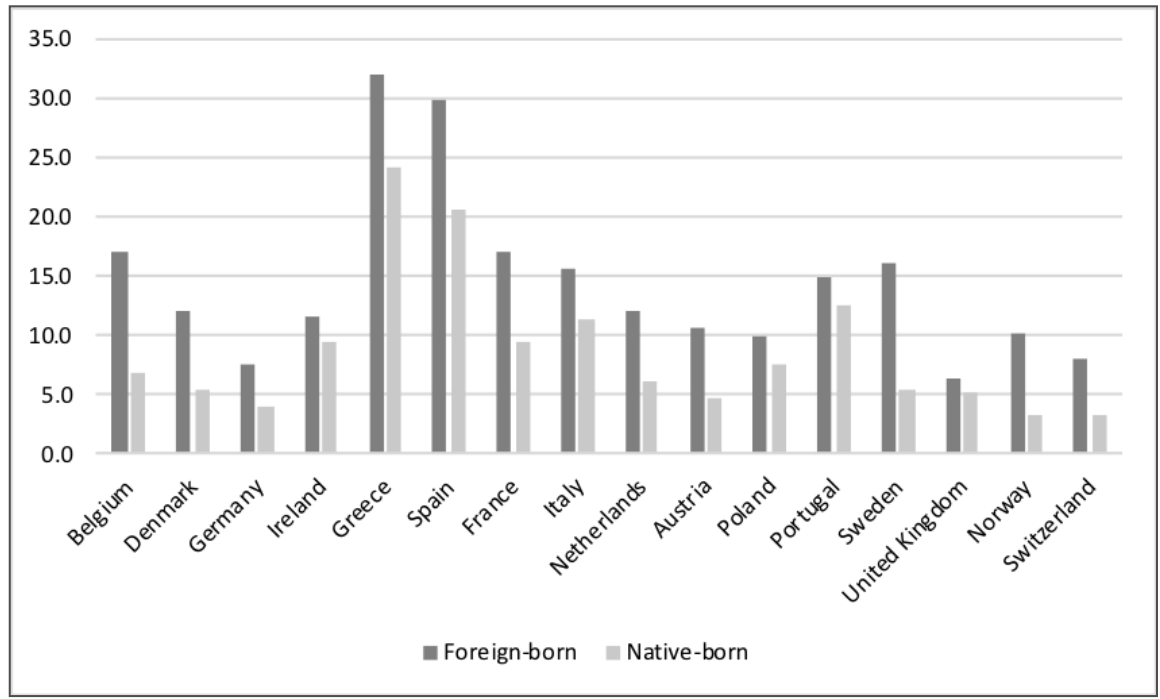

Source: Eurostat Database, $2018 b$.

Migrants are seen as a problem, in that they compete for scarce jobs, housing, and social services; undermine social solidarity and the welfare state; fail to identify sufficiently with Britain and British values; and push down wages and limits opportunities for Britain's poorest citizens (Hansen, 2017). Since 2013, access to welfare benefits for EEA nationals is being increasingly restricted. Migrants must fulfil certain conditions to access non-contributory benefits. For instance, to claim 
most family benefits and certain means tested disability benefits migrants must be able to proof that they are habitual residents in the UK (Broomfield, 2014). Thirdcountry nationals with indefinite leave to remain in the UK can access noncontributory benefits. Generally, people under immigration control cannot claim public funds, including most non-contributory benefits, with some exceptions where individuals may claim certain sickness and invalidity benefits. When non-EEA nationals are given limited leave to remain, they may access non-contributory benefits (Broomfield, 2014).

From 2014 onwards, EEA citizens are not entitled to income-based JSA, childcare-related benefits or housing benefits during the first three months of their stay in the UK. After these three months, EEA citizens can claim for a total of 91 days, which can be split across several periods of job-seeking. Moreover, EEA citizens must prove that they are 'habitually resident' in order to meet the required eligibility criteria (Fitzpatrick et al., 2015; Sumption \& Allen, 2015). Similarly, EEA jobseekers cannot claim either child benefit or tax credits until you've been living in the UK for three months. Since 2014 EEA jobseekers cannot claim housing benefit (Citizens Advice, 2017b). Similar to the Netherlands, third-country nationals subject to immigration control, are not normally entitled to means-tested benefits, such as income support or housing benefit, and their claiming them might damage their chances of being allowed to stay in the UK. Only third-country nationals with an indefinite residence permit are entitled to claim benefits (Broomfield 2014).

Regarding healthcare, the Immigration Act (2014) introduced changes to migrant's access to healthcare. Prior to the Act all migrants lawfully residing in the UK could access the NHS free of charge. Under the current legislation, however, only migrants with an indefinite leave to remain and those granted refugee status or humanitarian protection in the UK have free access to healthcare. Therefore, temporary non-EEA migrants coming to the UK for more than six months must pay a surcharge (Broomfield, 2014). In addition, access to free healthcare differs between primary -ordinary visits to general practitioners, dentists or pharmacists-and secondary care-specialized treatments provided by hospitals. The former is free and available to everyone, including migrants who do not fulfil the ordinary residency criterion and undocumented migrants. The latter is free to any person in case of emergency and life-threatening situations independently of the patient's immigration status. In other cases, however, the hospital can charge fees for treatment, which often must be paid in advance (Citizens Advice, 2017c).

\subsubsection{Social security entitlements for undocumented migrants in the UK}

Since 2002, policies on illegal migration started to develop rapidly, and included external (visa regime, biometric identification data) and internal measures (mainly employer and public service compliance and regularisation) (Cuadra, 2010a). In the $\mathrm{UK}$, as well as in other EU countries, policies of deterrence and restriction have limited the access to the asylum process and regular migration routes, leading people 
to use irregular means of entry and stay (Sigona, 2012). A result, there has been an increasing number of undocumented migrants, which ranged between 400,000 to over 850,000 in 2007 (Cuadra, 2010a). Like in the Netherlands, undocumented migrants include rejected asylum seekers, who remain after having been refused to settle and become destitute, unable to access most services, other than basic healthcare (Wilkinson \& Craig, 2011).

The Immigration Act 2014 presents a series of enforcement measures to create a hostile environment for the undocumented, such as: preventing them from accessing local authority housing, employment protections or social security benefits (Spencer et al., 2015). The Act also requires private landlords to confirm the immigration status of their tenants prior to signing a tenancy agreement. Failure to do so might imply fines of up to $£ 3,000$. Moreover, the Immigration, Asylum and Nationality Act 2006 imposes civil penalties on employers who hire undocumented migrants (ibid.).

Access to primary care, walk-in centres, emergencies, as well as diagnosis and treatment of infectious diseases are free for everybody. However, undocumented migrants are often denied urgent and immediately necessary care because of their inability to pay. Many are frightened to access essential healthcare because they have received aggressive letters or bills in advance of their care, or they fear being arrested (Doctors of the World, 2015). Immediately necessary or urgent treatment, including antenatal care, must be provided but it is subject to payment. Failed asylum seekers are not entitled to secondary care unless the treatment started before their asylum claim failed, or for an illness with 'public health implications'. Upfront charges apply in all other instances and treatment can be denied. Exceptions are made if the person needs to receive 'immediately necessary or life-saving treatment', namely treatment provided in an accident and emergency department (Reeves et al., 2006). Under the Immigration Act 2014, people without indefinite leave to remain, who want to stay in the UK for more than six months must pay a healthcare surcharge of $£ 200$ per year (Doctors of the World, 2015). Moreover, the Department of Health introduced the Migrant and Visitor NHS Cost Recovery Programme to expand charging and identify existing chargeable patients, which has led to hospitals routinely asking about someone's immigration status before care is provided and issuing more people with bills for treatment (ibid.). Children of undocumented migrants experience the same barriers to healthcare as adults -including lack of access to essential vaccinations - and are often turned away from GPs because they do not have a formal ID or proof of address (ibid.). 


\subsubsection{Social security entitlements for asylum seekers in the UK}

In the 1990s, the number of asylum applications in the UK increased dramatically (Figure 17), from an average of 35,000 per year from 1991 to 1998 , to 84,132 applicants in 2002 (Hansen, 2017). Such an increase led to the implementation of more restrictions to asylum applicants and limitations on migrants' access to public funds. Indeed, legislation regarding asylum was driven by the idea was asylum seekers were pulled to the UK because of the generous welfare provisions (Geddes, 2003). In particular, the creation of the new 'fast-track' procedures for asylum applications, allowed the detention of asylum seekers while their claim was being decided, and reduced asylum seekers' benefit entitlements (Kofman, 2002).

Figure 17 - Asylum applications the UK (1984-2015).

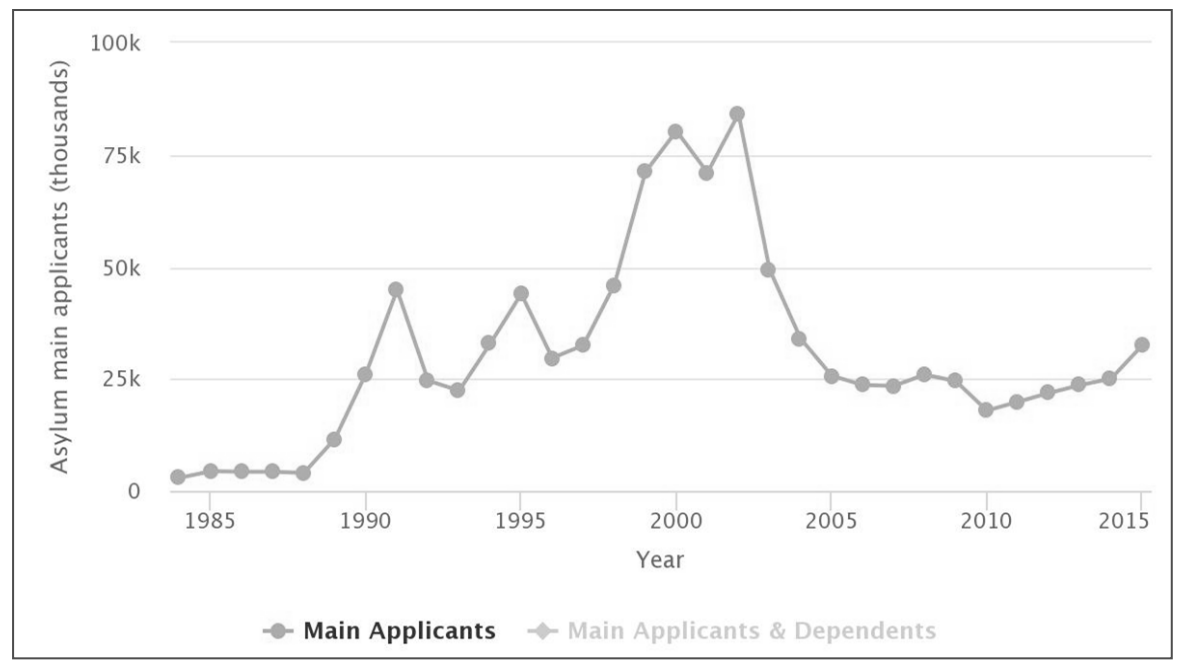

Source: Migration Observatory (2017)

Along the directives of the Dublin Convention that developed the regulation of asylum seekers in Europe, the UK also attempted to restrict access to the labour market and the welfare system -e.g. by offering only subsistence benefits through a voucher system or keeping them waiting in detention and removal centres while their applications are processed-in order to reduce the 'attractiveness' of the UK to potential new asylum seekers (Wilkinson \& Craig, 2011).

Most asylum seekers entering Britain from the 1990s have been non-quota refugees, that is, that they travel to Britain independently (often through 'illegal' channels) rather than as part of a refugee programme (Palmer, 2016; Sales, 2002). Once an individual makes an application for asylum in the UK, they are eligible for support from the National Asylum Support Service (NASS) of the Home Office, which centralises most support provided to asylum seekers in the UK since 1999. The NASS is responsible for providing housing through a network of regional consortia, 
who secures contracts with local authorities, private landlords and housing associations (O'Donnell, Higgins, Chauhan, \& Mullen, 2007). Asylum seekers can opt for or staying with friends and family on a support-only basis, or apply for subsistence and accommodation. Those opting for the latter must accept accommodation-flats, houses, hostels or bed and breakfasts - in a no-choice dispersal area, outside of London and the South East (Fitzpatrick et al., 2015; O'Donnell et al., 2007). Implemented under the 1999 Immigration and Asylum Act, dispersal is one key element of UK asylum policy, which determines the geographical distribution of asylum seekers across the country. The reason behind dispersal of asylum seekers is to spread the burden, to discourage settlement in the South East England and relieve housing and social pressures in this region (Mayblin, 2014). The selection of dispersal localities, is largely driven by available housing, rather than by the existing presence of ethnic communities, which has led to removing individuals from kinship and social networks, and to concentrating asylum seekers in urban areas located within areas of socio-economic deprivation, including Newcastle, Birmingham, Liverpool or Manchester. Whereas families in NASS housing are usually allocated self-contained housing, single individuals have their own bedroom but must share houses with strangers (Mayblin, 2014; O'Donnell et al., 2007).

The NASS is also responsible for providing a small amount of money for subsistence- $£ 36.95$ for each person in the household-which can be collected weekly from a local post office. This money is meant to help people pay for food, clothing or toiletries (Gov.UK, 2017). Pregnant women and mothers of children under 3 receive an additional $£ 3$ per week plus a one-off $£ 300$ maternity payment if the baby is due in 8 weeks or less, or if the baby is under 6 weeks old (ibid.). Recent research has shown that current levels of asylum support fail to meet the so-called Minimum Income Standard, understood as 'the items a household would need in order to reach a minimum acceptable standard of living that allows its members to participate in society' (Mayblin 2014: 380).

Asylum seekers may get free NHS healthcare, for instance: seeing a GP, getting hospital treatment and dental care, getting free prescriptions for medicine, and help paying for glasses (Gov.UK, 2017). All children aged between 5 and 17 must attend school, which is for free and may include free school meals (ibid.). Although they are entitled to free healthcare and must be registered with a GP, some studies have shown that asylum seekers face several barriers, including access to interpreters, language barriers, difficulty in accessing dental care, or problems obtaining appointments (O'Donnell et al., 2007).

Asylum seekers can only apply for permission to work if they have waited at least 12 months for an initial decision on their asylum claim (Mayblin, 2014). Prior to 2002, the waiting period was six months. Moreover, if granted permission to work, they are restricted to jobs on the shortage occupation list -classical ballet dancers or nuclear medicine technologists were some of the jobs offered in 2003-which is a barrier to employment (ibid.). Moreover, asylum seekers willing to work often have 
qualifications from their home countries, which require additional and expensive conversion courses or recognition processes (Phillimore \& Goodson, 2010).

Changes in the Nationality, Immigration and Asylum Act 2002 increased control over the asylum-seeking process by introducing accommodation and removal centres, as well as the so-called Section 55, which prohibits support for asylum seekers who do not make their claim as soon as 'reasonably practicable' after arriving in the UK (Fitzpatrick et al., 2015). After a Court Appeal against this regulation, asylum seekers can only be denied support if NASS understands that they have alternative means of support (ibid.). Indeed, even though several studies confirm that refused asylum seekers are most commonly destitute, destitution has been found at all stages of the asylum-seeking process, from the application, to the transition to refugee status. Administrative errors, delays, the poor quality of decision-making or the difficulties experienced to navigate the asylum system are some of the major causes of destitution among refugees as well as asylum seekers, many of whom become destitute after receiving leave to remain (ibid.).

Asylum seekers whose applications are rejected and do not have an outstanding appeal, are not allowed to work or access benefits, and they are expected to leave the UK within 21 days $^{12}$ (Mayblin, 2014). If refused asylum seekers can prove that they are taking the necessary steps to leave the country, they may apply for Section 4 support, that is, a voucher payment card -equivalent to the JSA-which is only accepted in designated shops (ibid.). Rejected asylum seekers present a greater burden on local authorities and local health services -e.g. using homeless hostels, or needing emergency treatment when earlier intervention by a GP would have avoided such a situation (ibid.). The lack of adequate welfare provisions has led to an increasing number of community groups and charities to support the most basic needs of asylum seekers by mainly relying on citizens' donations (ibid.).

\subsubsection{Social security entitlements for refugees in the UK}

Once their leave to remain is granted, most refugees are evicted from NASS accommodation within 28 days, and within this period they must register for a National Insurance Number to access benefits (Bakker et al., 2016). Unlike in the Netherlands, they have no access to a state integration programme, whereby they do not have to pass the citizenship test in order to remain permanently, (ibid.). Families with children and disabled people can access social housing, but single individuals must locate their own housing in the private sector. This is problematic because they often lack cash to pay the deposit and usually must wait for months until they receive their National Insurance Number, without which they cannot apply for benefits (ibid.). As a result, many refugees end up homeless or sharing illegally with asylum-

\footnotetext{
${ }^{12}$ In 2005 the National Audit Office estimated the number of rejected asylum applicants with no right to work and no recourse to public funds awaiting removal from the UK at between 155,000 and 283,500 (Mayblin, 2014).
} 
seeker friends. Even those who access social housing continue to experience difficulties, since housing is unfurnished and they lack resources to buy furniture and other goods (ibid.).

Once their status is granted, refugees are entitled to social rights just like British citizens (Sales, 2002). Many initiatives to promote settlement are left to the voluntary sector. The Home Office provides grants to refugee agencies (mainly the Refugee Council) for projects to help people gain access to services, and it also encourages the development of self-help through refugee community organisations. Some local councils and health authorities provide assistance towards settlement such as language courses, translation and advocacy services (ibid.).

\subsection{Conclusion}

This chapter has provided an overview of the Sudanese migration trends to the Netherlands and the UK in the last decades. It has also given an overview of the main social security mechanisms in the two European contexts, differentiating the entitlements for people with different legal statuses. In doing so, it has highlighted how developments in different welfare provisions have developed hand in hand with shifting and increasingly restrictive migration legislations over the years. Whereas different regulations apply in the British and Dutch contexts, in both countries there is a clear link between migrants' legal status and their right to access social security.

The overview of the Dutch and British social security systems aims to provide a background and contextualise the coming analytical chapters. As an article-based thesis, the analytical chapters cannot include a detailed contextual overview of the different social security and social protection systems. Therefore, the goal of this chapter is to provide the necessary background to understand the social protection environment navigated by the migrants, who are the protagonists of the next empirical chapters. 


\section{CHAPTER 6}

\section{MOBILE POPULATIONS IN IMMOBILE WELFARE SYSTEMS: A TYPOLOGY OF INSTITUTIONS PROVIDING SOCIAL WELFARE AND PROTECTION WITHIN A MOBILITY FRAMEWORK ${ }^{13}$}

${ }^{13}$ This article has been published as Serra-Mingot, E. \& Mazzucato, V. (2017). Mobile Populations in Immobile Welfare Systems: A Typology of Institutions Providing Social Welfare and Protection within a Mobility Framework. The European Journal of Development Research, 29(4), 787-805. DOI: $10.1057 / \mathrm{s} 41287-016-0061-4$. 


\subsection{Introduction}

According to the latest report on social protection by the International Labour Organisation (ILO), only one quarter of the global population enjoys access to comprehensive social security systems (ILO, 2014). Many migrant workers are often inadequately covered - or not covered at all - by social protection programmes in either their country of employment or their country of origin (van Ginneken 2013). Indeed, most institutions providing formal social protection only cater to sedentary populations, who are tied to a particular nation-state. However, in the current globalised world, with new and increasingly frequent flows of people, goods and information, more and more people choose or are pushed to live across national borders, developing attachments and responsibilities in more than one nation-state. Therefore, the traditional and geographically-fixed social-protection systems have become problematic.

International migration presents migrants with particular dilemmas. On the one hand, migrants move not only between countries, but also between differently regulated labour markets and social-protection systems, with different institutionalised levels of formality and informality (SASPEN 2014). Newly arrived migrants may lack strong social networks, and they usually have to wait several years before they have access, if at all, to the formal social-protection system in the host country. At the same time, any contributions made to the social-protection systems in their country of origin might cease to exist after arriving in the new host country, and vice versa (Avato et al., 2009).

On the other hand, international finance and development organisations, as well as governments, are increasingly looking to migrants to be promoters of economic growth and development in their home countries through their remittancesending practices (Castles \& Delgado-Wise, 2007; de Haas, 2007a). Such remittances are not only used for productive investments, but also contribute to ensuring social protection and wellbeing for migrants and their families, locally and transnationally (Mazzucato \& Schans, 2011). It is through migrants' remittances that sendingcountry governments benefit from funded health, education and other social services that they could not otherwise afford (Levitt et al., 2015).

Indeed, migrating in and of itself is often considered a mechanism for social protection, both for the migrants and for their families back home (DRCMGP 2008). Several studies have investigated how migrants in the Global North strive to access formal forms of social protection for themselves and for their accompanying families, and they have mainly focused on the impact and the degree of access to and portability of formal welfare benefits in the receiving country (van Ginneken, 2013; Vonk, 2002b). Another group of studies has viewed migrants, especially those from the Global South, as the informal providers of health, education and other basic needs for their families back home because of their remittance-sending practices (Agrawal \& Horowitz, 2002; Azam \& Gubert, 2006; Brown et al., 2014; Tevera, 
2013). Others have introduced concepts like 'resource environment' (Levitt, Lloyd, Mueller, \& Viterna, 2015) or 'assemblages' of formal and informal social protection schemes (Bilecen \& Barglowski, 2015), casting some light on the blurriness and combinations of different forms of social protection. Much less research, however, has focused on the role of those left behind in the provision of diverse services to the migrant, or 'reverse remittances' (Mazzucato, 2011). As these studies have shown, transnational relationships between migrants and their family and friends at home maintain and create new ways of providing social protection, both in the destination and the origin countries. The transnational nature of migration, whereby migrants 'forge and sustain multi-stranded social relations that link together the societies of origin and settlement' (Basch et al., 1994: 7) calls for a transnational approach to social protection that considers both the migrants and their families left behind (Opiniano, 2010). Social protection strategies to cope with social risks (such as unemployment and lack of health-care or education) extend across the borders of nation-states and involve a number of different formal and informal actors. This calls for more holistic research on the challenges and opportunities emerging from the interconnectedness of the existing social-protection systems of the two ends of the migration process (Tognetti Bordogna \& Piperno, 2013).

In this article, we review literature on social protection and migration using a transnational lens, which looks at social protection provision within a mobile context in both origin and destination countries. In doing so, we provide several examples mainly from a labour migration context from the Global South towards the Global North. Based on this literature review we offer a typology that includes a more complete spectrum of institutions providing social protection for mobile populations than is currently available. Existing literature on social protection and migration focuses on the different forms of state-provided social protection for migrants, including aspects of accessibility or portability (Avato et al., 2010). Yet, much less attention is given to other forms of formal provisions, like private insurance schemes for migrants and their significant others back home. When informal social protection is studied, it is conceived as family support needed to fill the gaps of formal protection schemes, often related to child and elderly care (Bilecen \& Barglowski, 2015; Boccagni, 2015). Based on a review of the wide span of social protection arrangements that mobile populations use, we propose adding a category to the above dichotomy of formal/informal to include semi-formal social protection schemes. Such schemes are not publicly provided, but they operate as institutions with accountability and coordination mechanisms (Bhattamishra \& Barrett, 2008), and they can provide prompt support to their members in a broad range of contingencies (Kasente et al., 2002). This broader typology allows us to include the role of emerging actors and institutions that provide social protection transnationally, that is, beyond nation-state borders.

The article is structured as follows. In the next section we review the full range of social protection providers for mobile populations, from highly formalised public 
and private ones to informal ones, highlighting the basic principles on which the schemes are based, the people they serve, the domains they cover and their main advantages and disadvantages. In so doing, we identify some of their main challenges and describe examples of emergent institutional arrangements in response to the needs of mobile populations. The article then addresses the emergence of semi-formal social protection schemes and discusses the need to explore new approaches to create inclusive global social-protection systems for mobile populations that are outside of the traditional framework of the nation-state. In this section, we present a succinct table (Table 3) with a typology of the different social protection schemes for mobile populations. With this typology we contribute to a more comprehensive view of the different constellations of social protections used by migrants and their significant others back home, which allows for the mixing of principles that often guide how migrants obtain and provide social protection. In the concluding section, we summarise the main findings and explain the main implication of this research.

\subsection{Social protection across borders: Between formality and informality}

Social protection does not have a universally accepted definition. Not only is there variation in what is provided, but also to whom and by whom it is provided. Despite the different views, all of the definitions highlight the main goals of social protection: reducing poverty, managing vulnerability and enhancing economic growth and human development (Avato et al., 2010; Sabates-Wheeler \& Waite, 2003; Shepherd et al., 2004). In addition, many definitions make an explicit distinction between formal and informal mechanisms of social protection, the first referring to protection provided by the market, or public entities and the latter referring to that provided by individuals, families and communities (Avato et al., 2009; Mendola, 2010; Oduro, 2010; Verpoorten \& Verschraegen, 2008).

A growing body of scholarship has analysed the consequences and impact of migrants' lack of access to formal social protection, i.e., immobile and state-provided protections, guided by economic and social principles (Avato et al., 2009; Taha, Messkoub \& Siegmann, 2013; van Ginneken, 2013). Some authors have highlighted the importance of informal schemes, such as community or family networks that support migrants in the host countries (Sabates-Wheeler and Koettl 2010) or migrants' remittances to their families back home to help them cover basic social protection needs (e.g., housing, schooling or hospitalisation) (Amuedo-Dorantes \& Pozo, 2006; Azam \& Gubert, 2006; Sabates-Wheeler \& Koettl, 2010).

Addressing social protection for international migrants from either a formal or an informal perspective poses some limitations. First, both research and policies on formal social protection for migrants tend to focus on the formal support (e.g., welfare) that is accessible to primarily documented migrants within the receiving country, disregarding the needs of their families back home (Boccagni, 2015). 
Second, although informal social protection refers to the support received through social networks, most studies focus on the individual migrant as the receiver of support from social networks within the receiving country or as the provider of remittances to their families back home. Seldom are migrants conceived to be receivers of support from social networks in the sending country, despite the fact that this phenomenon exists (Mazzucato, 2009b). Migrants may be receivers of services from people back home such as when extended family members take care of their children in the country of origin, or when they help them resolve paperwork issues needed for the regularization of their stays abroad (ibid.). Yet such services have remained largely outside of the purview of research in part due to the tendency of research to focus on migrants rather than those who are tied to them in the origin country (ibid.).

In sections 6.2.1 and 6.2.2 we address the primary formal and informal instruments that provide social protection for international migrants discussing the main challenges they provide for migrants and their families. Rather than focusing on either one or the other, we draw on what Bilecen and Barglowski refer to as 'assemblages of social protection' (2015) and argue that the dividing line between formal and informal and receiver and provider of social protections for international migrants is not clear-cut and that these concepts should be addressed simultaneously. In a third section, we suggest the inclusion of a third type of scheme: semi-formal institutional arrangements. While such arrangements have been studied in the context of developing countries, much less attention has been given to their role and potential in the context of international migration. We argue that to understand and explore new and inclusive perspectives on social protection schemes across borders, there is a need to address the formal and the informal as intertwined pieces of a system from which new and more comprehensive schemes can emerge. Ideally these new schemes will consider not only the individual migrants, but also those left behind.

\subsubsection{Formal social protection across borders}

Formal social protection usually involves publicly funded state programmes that are reinforced by laws or statutes, institutionalised in policy and legislation, and conveyed in the form of eligibility criteria (Bilecen \& Barglowski, 2015). In addition to this, international organisations and private market-providers also fall within the formal category, although they have received less attention in the literature on migration and social protection.

In one of the most comprehensive overviews of the status of social protection for international migrants, Sabates-Wheeler et al. (2010) focus on state-provided social protection and identify three main components: access, portability and labour market conditions. The authors refer to informal networks in the receiving country as the only informal component of social protection. Access to formal state-provided 
social security and services ${ }^{14}$ in the receiving country is determined at the national level and is often not fully available for migrants, either because access is granted sometime after their arrival or because their family members are spread across countries (Avato et al., 2009). By definition, undocumented migrants are excluded from access to welfare benefits (Sabates-Wheeler and Waite 2003). Moreover, even for documented migrants with temporary residence permits, claiming social benefits is grounds for discretionary expulsion or reduction of their permits (Mayer, Bauer, \& Müller, 2013; Olivier \& Govindjee, 2013). Some authors have also referred to the issue of accessibility from the sending country's perspective. Indeed, sending states, like the Philippines, have set up welfare funds for migrants abroad and their families back home. Whereas this example shows how sending countries can take responsibility for their migrants' social protection (van Ginneken 2013), research has found that some of these state-based programmes did not deliver the promised services (Lafleur \& Lizin, 2015). While accessibility has been mostly dealt with from the perspective of state-provided benefits, we argue that it is a useful concept through which to assess all other forms of social protection, such as the ones provided by the market, the third-sector and social networks.

Second, the portability of social security rights, from one's country of employment to another, is important for migrants to avoid financial losses when they leave their origin or host country (Avato et al., 2009). Some bilateral and multilateral agreements have been established between some EU and non-EU countries to facilitate the portability of old-age pensions, disability and (to a lesser extent) healthcare benefits (van Ginneken, 2013). Besides the high administrative complexities, these agreements sometimes reflect a balance of power between the parties and result in sending countries opening their labour markets in weaker positions ${ }^{15}$ (Swemmer, 2013). Similarly to accessibility, the concept of portability is linked to state-provided benefits that can be transferred from 'here' to 'there'. In the following sections, we suggest that portability could be also seen as a component of both informal and semiformal strategies of social protection.

Third, labour market conditions are essential for migrants' social protection, as often formal social protection is linked to one's job. Especially for the low-skilled and undocumented, formal social protection is inaccessible due to their labour market conditions such as being unemployed or working with informal or now labour contracts (Avato et al., 2009). In response to these challenges, formal social protection for mobile populations in the form of private insurance and micro-

\footnotetext{
${ }^{14}$ Social services include health care benefits, long-term benefits (old-age and disability benefits), and short-term benefits (social assistance, maternity, and unemployment benefits, family allowances, public housing and education) (Sabates-Wheeler et al.2009).

${ }^{15}$ An alternative to the portability and accessibility issues is the one adopted by the Gulf Cooperation Council, which denies migrants access to their social security systems but exempts them from making any contributions. Migrants are thus responsible to provide for benefits (e.g. pensions) on their own, in the form of voluntary contributions to the public system or buying products from the private insurance market (Avato et al., 2009).
} 
insurance products for migrants have emerged (Magnoni, Lovoi, Brown, \& Thornton, 2010).

The scarce research conducted on private insurance for migrants distinguishes three main categories of insurance products - mainly covering healthcare and repatriation- that depend on the location of the insurer relative to the migrant: home, host and hybrid insurance models (Magnoni et al., 2010). In the home model, the insurer operates in the migrants' home country and covers the migrant (abroad) as well as his/her family back home ${ }^{16}$. In the host-country model, the insurer operates in the host country and usually covers the migrant, irrespective of his or her country of origin ${ }^{17}$. The hybrid models, although much less developed, seem to be the most interesting from a transnational perspective because they offer tailored products to cover specific risks on both sides. In these models, the insurer is usually based in the host country, although coverage is offered in the home country ${ }^{18}$.

Nevertheless, these forms of market-provided social protection for migrants are not free of challenges. First, most of the examples above mainly pertain to Latin America, leaving other parts of the world uncovered. Second, most of them cover only migrant repatriation and accidents, and only a few of them provide health coverage for those left behind. None of them address other benefits, such as pensions, education, or unemployment. Third, all of these models are accessible for documented migrants only (Magnoni et al., 2010). Fourth, most of the models are based on Western insurance models, which do not factor in the cultural and socioeconomic necessities of home country contexts (Lafleur \& Lizin, 2015).

Finally, the role of so-called third-sector organisations such as the World Bank, United Nations Development Programme (UNDP), International Organisation for Migration (IOM) and others, is rather broad. Most of their initiatives are not strictly about social protection for mobile populations per se; rather, they are related to the engagement of diasporas in knowledge transfer activities and the development of their home countries (see for instance the IOM's Temporary Return of Qualified Nationals (TRQN) Project or the UNDP's Transfer of Technology through Expatriate National (TOKTEN) Program) (Pasha, 2012). Other organisations, such as the Red Cross and local NGOs, implement activities for migrants to respond to their specific needs, vulnerabilities and risks, including legal and social advice on how to access services, distribution of food parcels, water, hygiene kits, clothes, blankets or medicine, and the provision of free medical care in a number of European countries (www.redcross.eu/en/What-we-do/Asylum-

\footnotetext{
${ }^{16}$ For example, BancoSol in Bolivia offers life insurance, including repatriation and funeral costs for the migrant, and health and accident insurance for the migrant's family in Bolivia. The product is sold in Spain through a BancoSol agent to Bolivian migrants (Magnoni et al., 2010).

${ }^{17}$ La Caixa/SegurCaixa, in Spain, offers two main products for documented migrants in Spain: repatriation ( $6 € /$ month) and/or accident disability (7€/month) (Magnoni et al., 2010).

${ }^{18}$ Some of these schemes are active between Mexico, Canada and the USA (e.g., Sekure Healthcare) (Magnoni et al., 2010).
} 
Migration/Areas-of-work/Undocumented-migrants/). Most of these provisions are only accessible by migrants in the receiving countries, and in many cases with requirements, such as being in an extremely vulnerable situation, or cooperating to return 'home'.

\subsubsection{Informal social protection}

Formal social protection in developed countries (delivered by governments, markets and international organisations) has for the most part generally overlooked the array of informal social protection mechanisms, provided by extended families and communities. Informal social protection for migrants is usually defined as a set of risk-reducing practices that are provided by 'social networks based on collective norms such as community solidarity, reciprocity, altruism, and obligations' (Bilecen \& Barglowski, 2015: 208) to reduce human reproduction risks, such as financial protection, child rearing, healthcare, elderly care (Faist, Amelina, Bilecen, \& Barglowski, 2012). Migrants engage in a web of social relations and are embedded in reciprocal normative structures with other members of society (Vonk \& van Walsum, 2012). Indeed, Avato et al. (2009) refer explicitly to informal social and family networks as one of the four basic and most protective components of social protection for migrants, especially those who are undocumented. Given the limited outreach of social protection schemes provided by the state, markets and third sector, complex informal and semi-formal social protection schemes based on kinship and extended families provide the first and only source of support for many people (Devereux \& Getu, 2013).

In addition to the social networks in the receiving countries, migration itself has been considered to be a form of versatile informal social protection because it might fulfil different functions. At an individual level, migrating might improve income and life opportunities to cover the migrant's current and future needs. At the family level, migrants' remittances might help secure consumption and income levels, provide investment capital, and old age security for those who receive them (Sabates-Wheeler \& Feldman, 2011; Schrieder \& Knerr, 2000).

Yet, some research is more sceptical about the insurance role of migration. For instance, because remittances are frequently sent as a co-insurance arrangement (e.g., the migrants expect to inherit land or other goods in the future), sometimes migrants tend to send more to relatively wealthy receivers (Lucas \& Stark, 1985). Additionally, migration can result in the disruption or disintegration of traditional social-protection systems, which are extremely important in many origin countries' communities (Devereux et al., 2015), especially for vulnerable groups, such as the elderly (Fonchingong, 2014).

Whereas most literature on migration has focused on the migrants as the providers of diverse socio-economic remittances to their relatives back home (Agrawal \& Horowitz, 2002; Azam \& Gubert, 2006; Brown et al., 2014; Tevera, 2013), a few studies have focused on the role of those 'left behind' in the provision of 
diverse services to the migrant, or 'reverse remittances' (Mazzucato, 2009b). Be it by providing migrants with the necessary means to migrate or by providing care to their children or dependants 'left behind' (Baldassar et al., 2007; Mazzucato \& Schans, 2011) the services rendered by those 'back home' should be taken into consideration in the study of the transnational two-way provision of social protection. Moreover, often the informal arrangements back home cover different social protection needs simultaneously. For example, research in Ghana and Guatemala shows how migrants' children can provide care for their elderly minders, be it by offering companionship, performing specific household services or maintaining the link which keeps migrants actively sending remittances (Mazzucato, 2009b; Schmalzbauer, 2004). From this perspective, access to informal social protection extends beyond the national borders of the receiving country and proves to be more flexible in covering different social protection needs simultaneously (Mazzucato 2008c).

\subsubsection{Either formal or informal? Moving beyond the dichotomy}

Despite the fact that social protection structures imply formal and informal, state and non-state dimensions, only a few studies have focused on combinations of informal and formal protection, especially with regards to migrants (Bilecen \& Barglowski, 2015). While informal social protection is particularly important in areas where formal schemes are weak or non-existent, formal protection schemes can also be used to extend practices of informal social protection (Faist et al., 2014) thereby blurring the boundaries between the two forms. For example, by having access to healthcare and other social benefits, migrants can send higher remittances which in turn can be used to ensure social protection for those at home. Research on Ghanaian migrants shows the practice of purchasing state bonds and making their elderly parents back home the beneficiaries in order to ensure their health care costs (Mazzucato, 2008c). This is a clear example of how accessing formal activities in one part of the world is aimed at covering a social protection need through informal practices in another part of the world.

Thus, in order to understand the social protection strategies of migrants and their families back home, it is necessary to investigate the exchange of resources in informal networks and in formal social protection structures, both in the receiving and the sending countries. To do so, we construct a comprehensive typology of the different social protection resources for mobile populations. Table 3 shows who these different social protection schemes serve, what they provide or where, and their main funding principles. Based on the analysis of the different schemes that we have presented in this article, the table provides their main advantages and disadvantages.

By systematically compiling the state-, market-, third-sector-, and familyprovided resources, we identify a third category of social protection institutions: semi-formal social security arrangements. Such schemes in developing countries are not publicly provided, but they operate as institutions with more or less strong 
accountability and coordination mechanisms (Bhattamishra \& Barrett, 2008). Semiformal social protection strategies, also called self-help organisations, have different functions, which include security or insurance (including life cycle events such as births, marriages and deaths or education), economic (provision of loans, collective investments and community development works), and socialising (Bouman, 1994). They offer services that are mainly financed by member contributions and are delivered by NGOs, faith-based organisations, and community-based organisations (Devereux and Getu 2013). Furthermore, they include a range of activities, such as finance and credit (rotating credit associations), mutual insurance (funeral associations, risk-sharing arrangements) and production (self-help groups with income generating activities) (Mendola, 2010).

Semi-formal social security schemes have proved to be quite successful in different parts of the world because they can provide support to their members in a wide range of contingencies arising from different realities, such as the death of family members, urgent domestic expenditure, school fees, sickness, cultural ceremonies or investment (Kasente et al., 2002). Moreover, the support is offered promptly and with little or no paperwork involved. Nevertheless, semi-formal schemes usually have weak management structures, mainly due to an inadequate knowledge of the bookkeeping, and their financial capacity is usually too small to address all contingencies (ibid.).

Semi-formal social protection schemes, however, have been mainly addressed in developing countries as a response to the absence of formal schemes and to the gradual weakening of the extended family system (Kasente, 2006). Yet such semiformal schemes of social protection in the context of migration has received little attention. In their report on Globalisation and Development in 2000, the African Foundation for Development (AFFORD) made a comprehensive categorisation of migrant organisations based on the different forms and degree of transnational engagement. These categories are as follows: individuals and families, hometown associations, ethnic associations, alumni associations, religious associations, professional associations, development NGOs, investment groups/businesses, political groups, national development groups, welfare/refugee groups, supplementary schools, and virtual organisations (AFFORD, 2000). Although this classification was not developed for social protection specifically, we adapt it in the following section to propose a typology of semi-formal schemes with a potential role in the provision of social protection for mobile populations, both locally and across borders.

Hometown associations (HTA), also referred to as diaspora or ethnic associations, are organisations formed by migrants with a common village, region or institution who are seeking to support their place of origin and maintain connections, through cash or in kind, while retaining a sense of community as they adjust to life in their home country (Orozco, 2003). Their main goals are often the welfare of their members followed by the development of their village of origin (Bouman, 1994; 
Mercer, Page, \& Evans, 2009; Otieno Ong'ayo, 2014; L. Smith \& Mazzucato, 2009). A growing number of HTAs have shown potential in the field of microfinance ${ }^{19}$ and social protection by providing small loans to families or individuals back home to help them raise household welfare and ease poverty (Otieno Ong'ayo, 2014).

Transnational Health Insurance (THI) organisations. These organisations are similar to the so-called Community-based Health Insurance Schemes (CBHI) or voluntary risk-pooling schemes. They are run by non-profit organisations, which collect fees among the users in the village and organise access to healthcare providers. In THIs, however, the migrants join forces with mutual health insurances in the receiving country and healthcare providers in the origin country to set up a transnational health insurance scheme (Lafleur \& Lizin, 2015). Because of the multiple players involved in the THI, these schemes blur the line between state-based, market-based and civil-society-based provision of social protection across borders. The functioning of these schemes, however, is still challenging. First, they only include a limited number of covered relatives and healthcare providers, which might be inconsistent with local socio-cultural norms. Second, for this scheme to succeed, it requires (sometimes non-existent) trust towards institutions. Finally, these schemes lack versatility in remittances, and they allow no flexibility in the type of health expenditure; in developing countries, expenditures might be related to social determinants that still have an impact on health (e.g., remittances used for housing or education purposes might have a positive impact on health) (ibid.). Thus, these schemes deserve further investigation to assess their potential to be healthcare providers across borders.

Social clubs and professional migrant associations are groups of migrants from a certain country without (necessarily) a common sub-national geographic or ethnic origin. These groups raise money for development, and they transfer those funds to the origin government to be used in national budgets in areas such as health or education (Henry \& Mohan, 2003). Medical organisations of migrants have played an important role in the provision of medical services to individuals in countries of origin $^{20}$.

Faith-based associations ${ }^{21}$ sometimes play an active role in the social protection domain, including homes for the elderly and the disabled. While such services are not usually sought out by migrants in the receiving countries, some churches support them in other ways, such as: offering employment (cleaning the

\footnotetext{
${ }^{19}$ Some examples are the AfroEuro Foundation, which created a farmers' cooperative funded by microfinance and remittances or the ASDA foundation, which supports women traders (Otieno Ong'ayo, 2014).

${ }^{20}$ The association of Cameroonian Doctors in Belgium (MEDCAMBEL), for instance, conducts short-term medical missions in Cameroon, offering treatment and information to local populations (Lafleur \& Lizin, 2015).

${ }^{21}$ Sometimes faith-based organisations also help families 'back home'. However, this is on an incidental basis, and the main focus is on the migrants.
} 
church, gardening, etc.), providing food and clothing (Fokas, 2013), and supporting single migrant mothers (Yeung, 2006). The Zakat, or Muslim charity, is another example of a system, which is usually described as informal, but is nevertheless applied by the government (Devereux \& Getu, 2013) to support the most disadvantaged people in the community. The Zakat Foundation in the UK is a noteworthy example of how a local organisation can become transnational (www.nzf.org.uk/).

Rotating Credit Associations (ROSCAS) ${ }^{22}$ are groups of individuals who meet regularly to make regular financial contributions to create a fund. At every meeting, the fund is allocated to one member of the group at a time (Thieme, 2003). ROSCAs are sometimes preferred over the formal banking systems, since they keep the money in local circulation and offer their members more than only financial support; they also disseminate information on housing, employment opportunities, remittance transfer or on socialising issues.

Burial societies $^{23}$ (Bouman 1994; Mazzucato, Kabki, and Smith 2006) provide mutual aid when there is a death in the community. They work on a membership basis, which was traditionally restricted to individuals living in the same geographical area (Bhattamishra \& Barrett, 2008). Currently, however, funerals are becoming multi-site events in which migrants play an important role in the organisation, financing and practice of funeral ceremonies 'back home' (Bähre 2007; Mazzucato et al., 2006).

Although these organisations are considered informal in the literature (not related to social protection of migrant populations) because they are not bound to legal regulations, we argue that as social protection arrangements these institutions go beyond the informality of individual remittances sent by migrants to their family back home for two reasons. First, these systems are socially binding contracts with strong accountability mechanisms in the countries of origin (Bouman, 1994). Second, some of these organisations have the necessary political and economic power to engage governments (usually in the sending countries) in the joint funding of different projects $^{24}$.

${ }^{22}$ This discussion also applies to the variant called Accumulating Savings and Credit Associations (ASCAs), but for simplicity we refer to these types of associations as ROSCAs in the remainder of the paper.

${ }^{23}$ Whereas burial associations are sometimes created with the lone goal of managing burials, burial arrangements are often managed within HTAs.

${ }^{24}$ In Mexico, HTAs engage at different levels with governmental bodies in the fulfilment of their goals (Orozco, 2003). In the Pacific Islands, the Japan Fund for Poverty Reduction (JFPR) supports cashfor-work programs and semiformal social safety net pilot models, to 'provide the basis for country-led social protection policy development and implementation' (Asian Development Bank, 2010: 6). Paradoxically, as an example of how migration can produce new social protection needs, the JFPR supports women who are left alone in rural areas when their husbands move to urban areas in search of employment. 
Mobile populations in immobile welfare systems

\begin{tabular}{|c|c|c|c|}
\hline 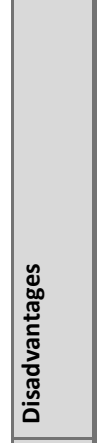 & 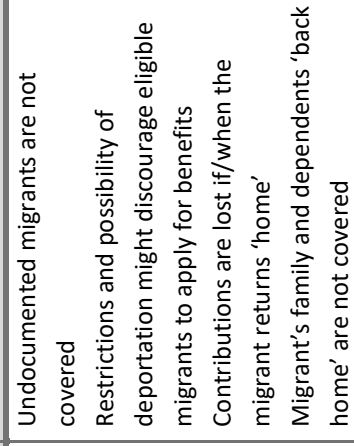 & 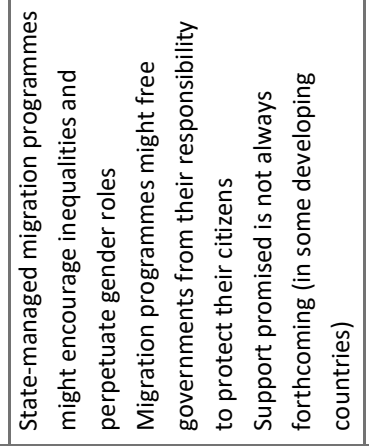 & 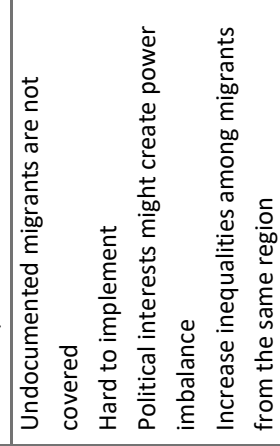 \\
\hline 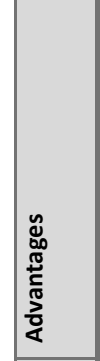 & 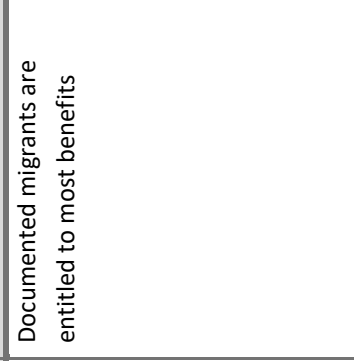 & 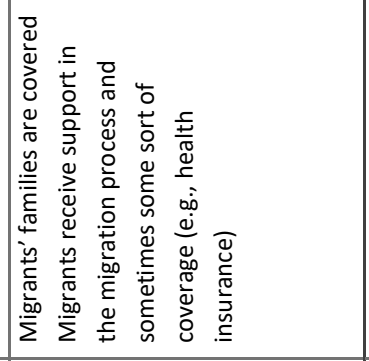 & 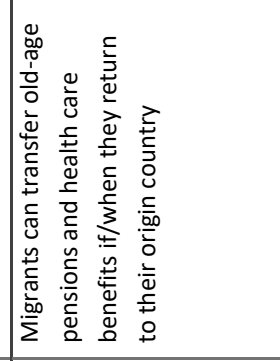 \\
\hline 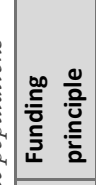 & 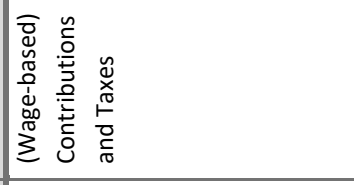 & 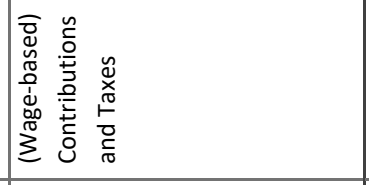 & 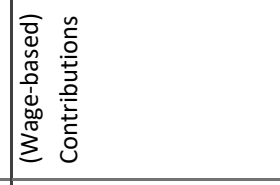 \\
\hline 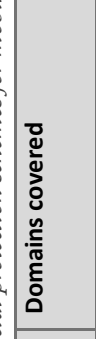 & 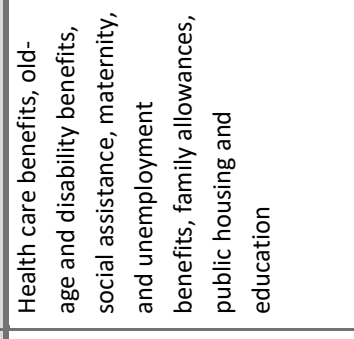 & 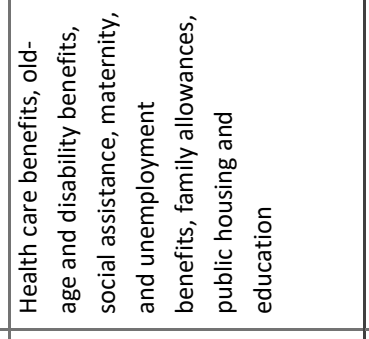 & 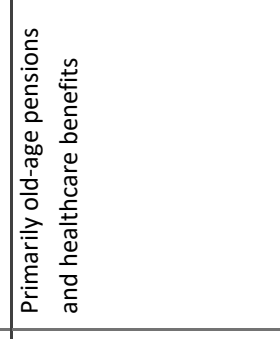 \\
\hline 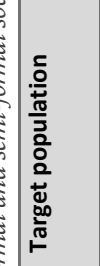 & 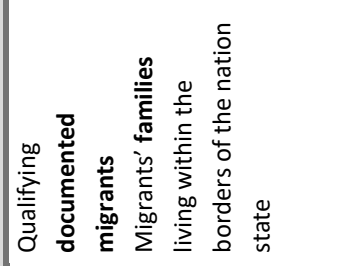 & 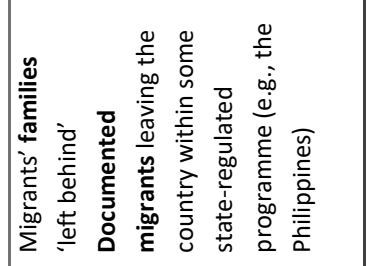 & 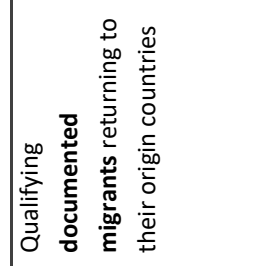 \\
\hline 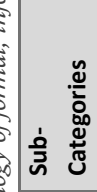 & 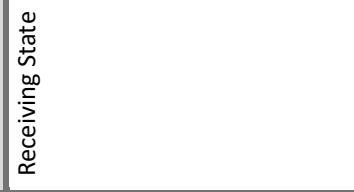 & 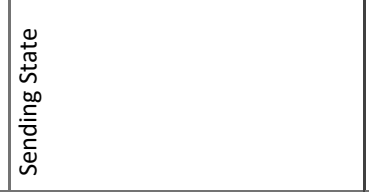 & 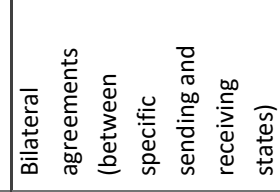 \\
\hline 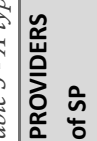 & & dS $7 \forall W y O A$ & \\
\hline
\end{tabular}




\begin{tabular}{|c|c|}
\hline 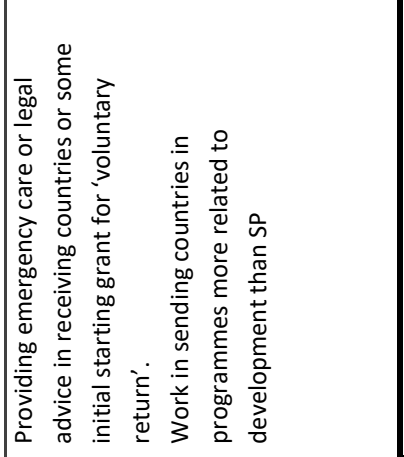 & 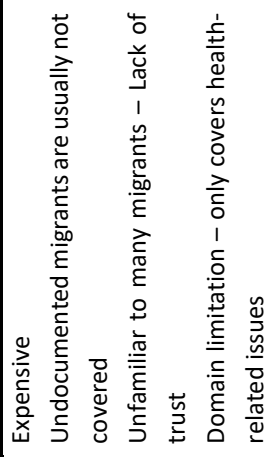 \\
\hline 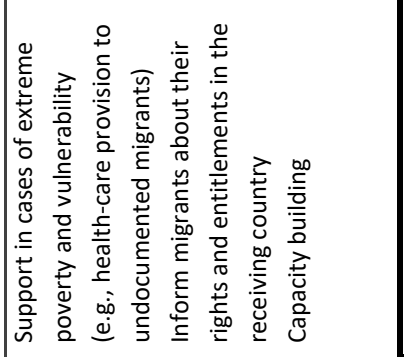 & 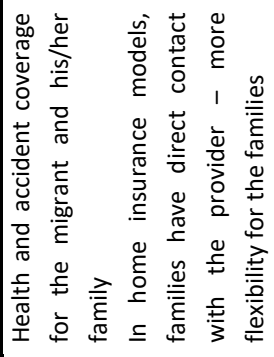 \\
\hline 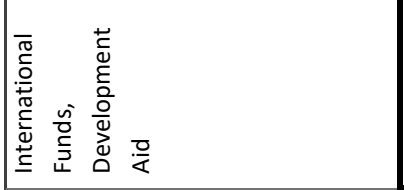 & 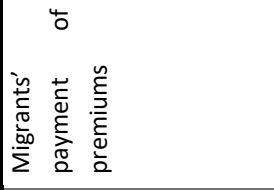 \\
\hline 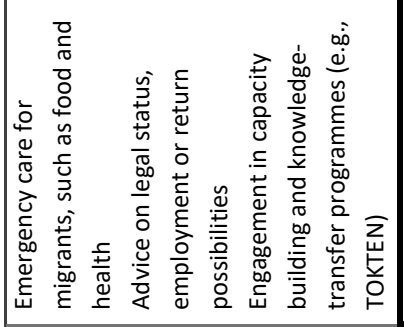 & 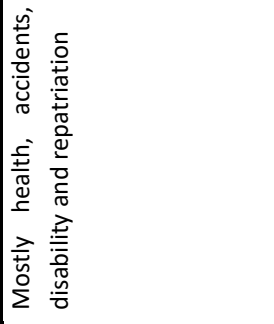 \\
\hline 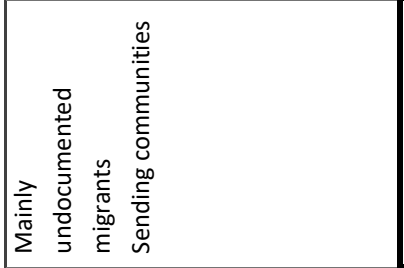 & 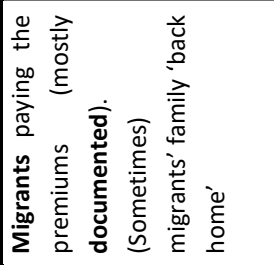 \\
\hline 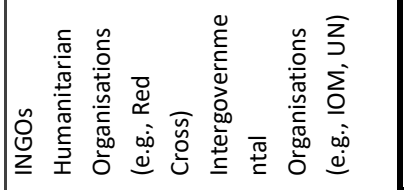 & 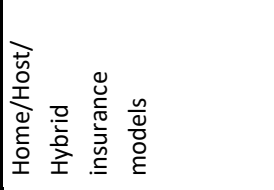 \\
\hline 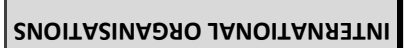 & ІэухуУҰW \\
\hline
\end{tabular}

(128) 


\begin{tabular}{|c|c|c|c|}
\hline 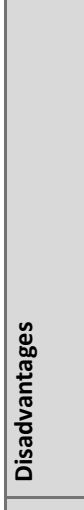 & 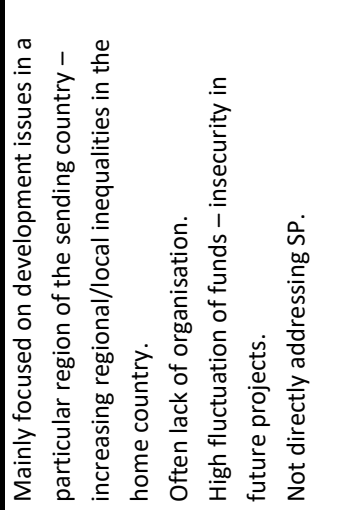 & 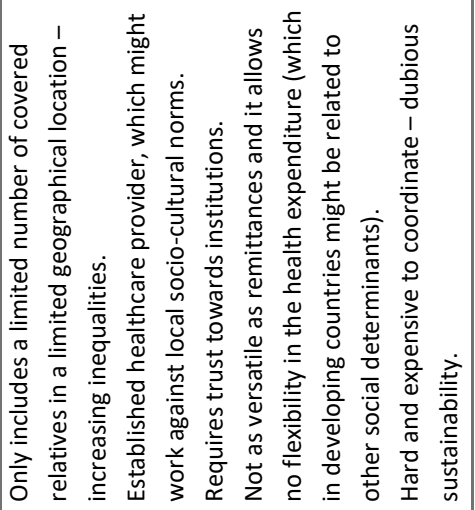 & 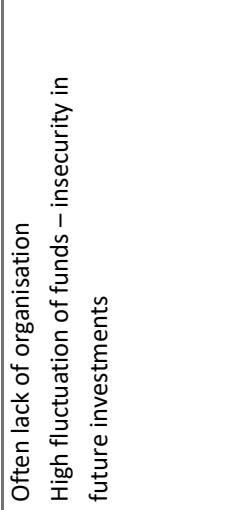 \\
\hline 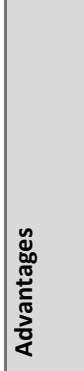 & 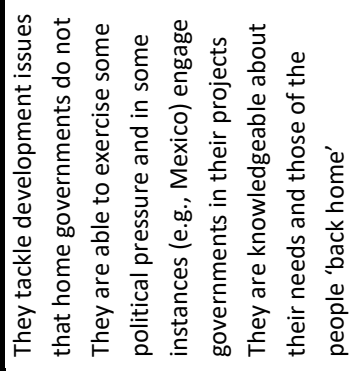 & 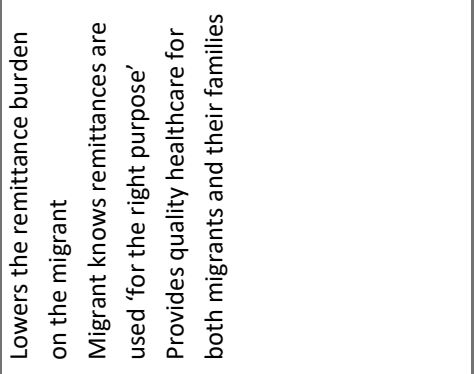 & 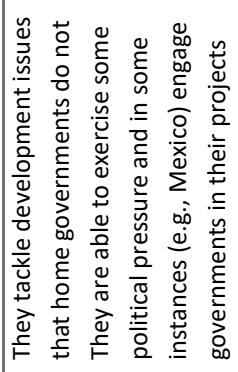 \\
\hline 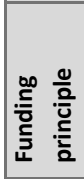 & 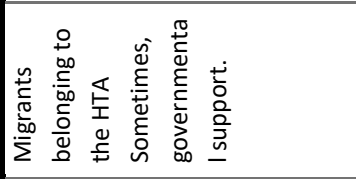 & 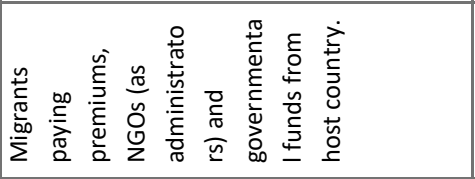 & 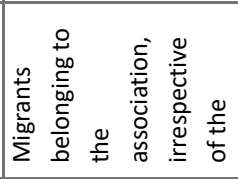 \\
\hline 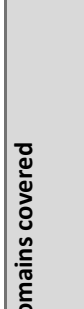 & 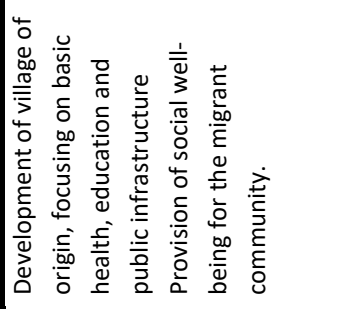 & 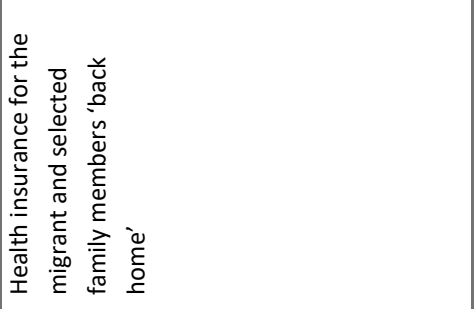 & 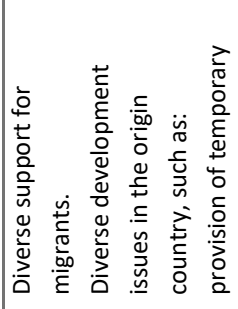 \\
\hline 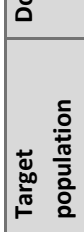 & 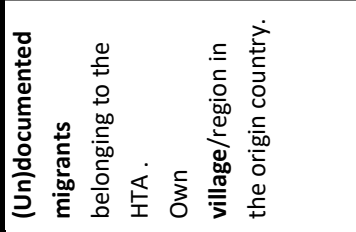 & 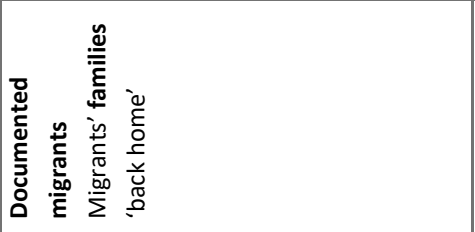 & 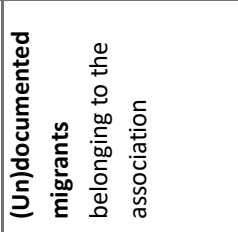 \\
\hline 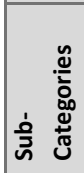 & 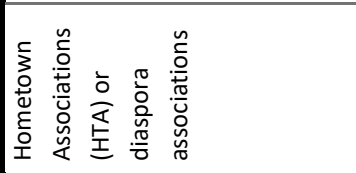 & 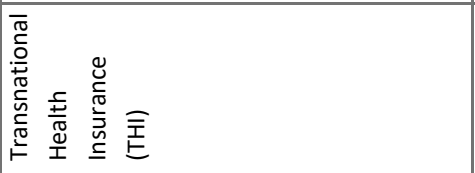 & 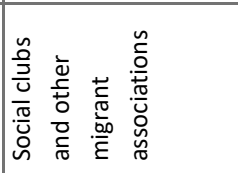 \\
\hline 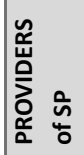 & & \multicolumn{2}{|c|}{ 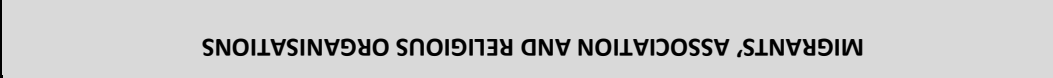 } \\
\hline
\end{tabular}




\begin{tabular}{|c|c|c|c|}
\hline & 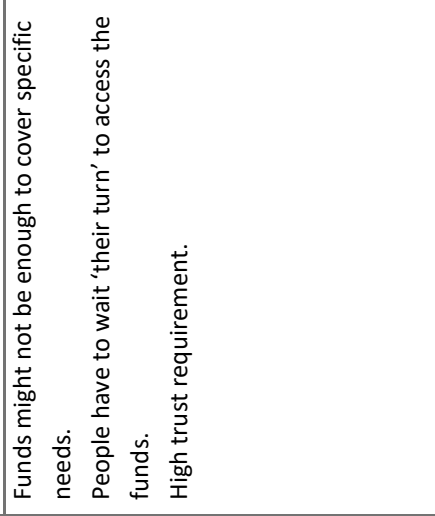 & 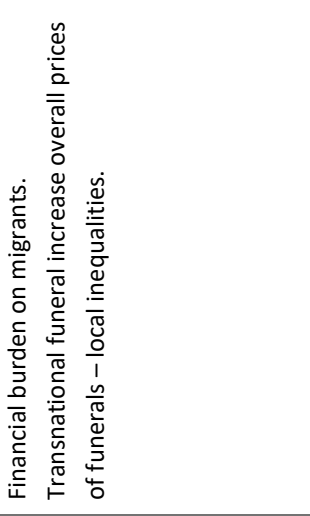 & 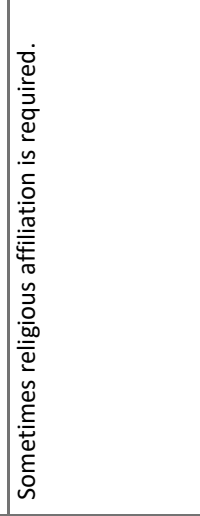 \\
\hline 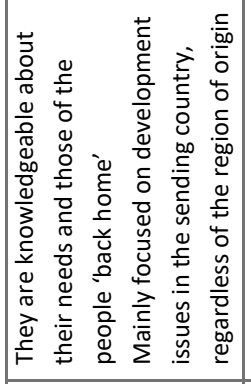 & 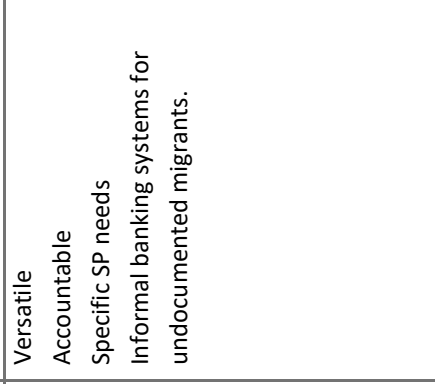 & 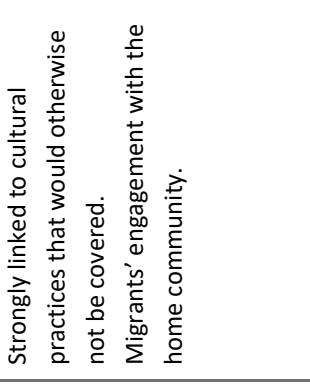 & 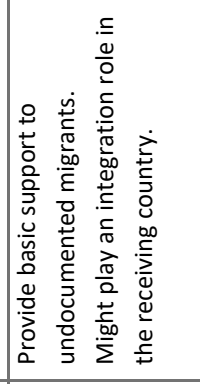 \\
\hline 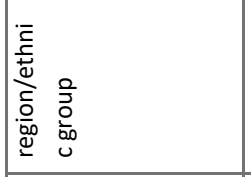 & 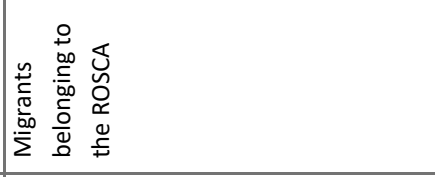 & 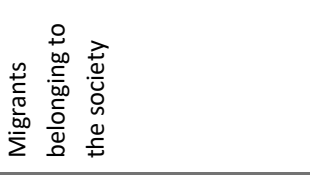 & 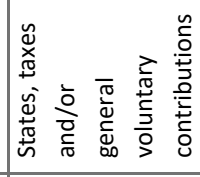 \\
\hline 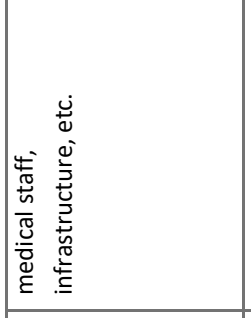 & 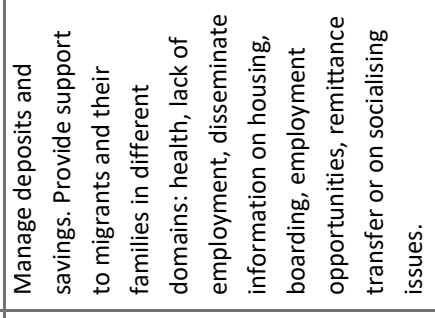 & 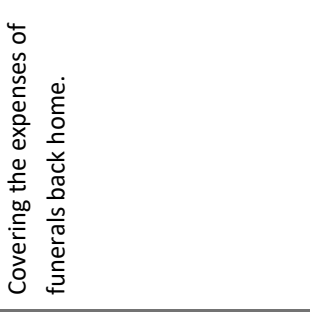 & 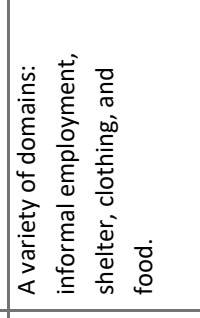 \\
\hline \multirow[t]{2}{*}{ 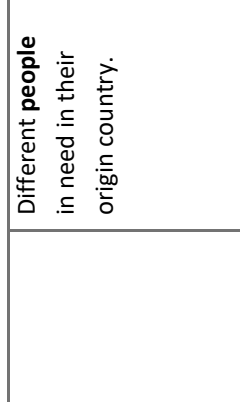 } & 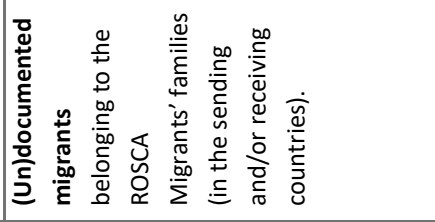 & 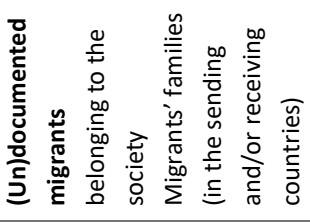 & 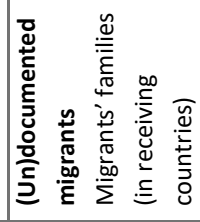 \\
\hline & 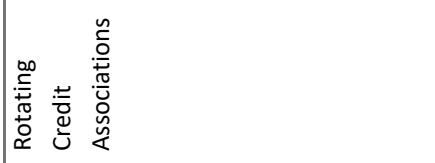 & 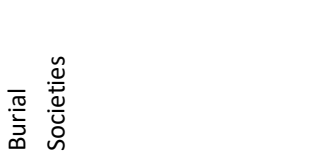 & 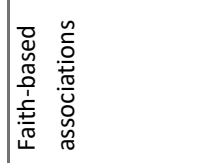 \\
\hline
\end{tabular}




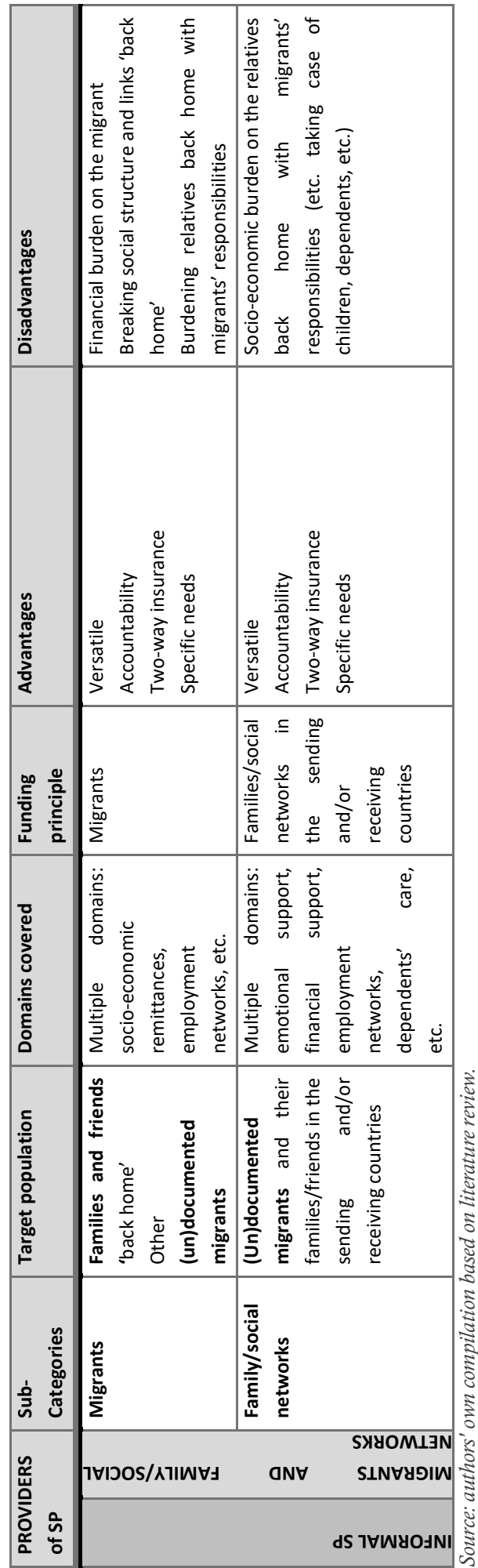




\subsection{Conclusion}

As migration is one of the main societal issues of the 21 st century, aspects related to the provision of fair and inclusive social protection and welfare schemes in a mobile setting are becoming a pressing policy and development issue. This is reflected in the fact that governments and other institutions worldwide have introduced new social protection measures (e.g., bilateral agreements). Most of these initiatives, however, pay little attention to the potential of informal and semi-formal social-protection systems (Devereux \& Getu, 2013), despite the fact that in many developing countries from where many migrants originate, people depend on these kinds of institutions. Indeed, the possibility of building on existing informal and semi-formal socialprotection systems and creating complementary linkages between them and formal systems is rarely considered by policy makers.

In this article, we present a review of the literature on social protection and migration through a transnational lens to offer a typology of institutions providing social protection for mobile populations, highlighting the basic principles on which the schemes are based and to whom they cater. In doing so, we have contributed to a more complete view of the different forms of social protection used by migrants and their families both at home and abroad. This typology introduces a third category of institutions, those semi-formal arrangements that have been studied in the development literature but not as social protection in the context of international migration. Examples provided in this article demonstrate their importance in the provision of targeted social services to vulnerable mobile populations, such as undocumented migrants, whose needs are not covered by formal state-provided schemes. Furthermore, this paper has argued that the boundaries between these categories are blurred when we look at the multiple combinations of institutional arrangements that migrants use to ensure social protection for themselves and their families in a transnational context.

We have argued that one of the main challenges in the current provision of social protection for mobile populations is the fact that most institutions in receiving countries are tied to a particular nation-state and only cater to sedentary populations. The social protection needs of mobile populations, however, extend beyond the borders of the nation-state because migrants maintain responsibilities both here and there. In order to better understand the role of emerging actors in the provision of support to mobile populations across borders, there is a need to move beyond the current dichotomy of either formal or informal social protection schemes. Understanding the social protection strategies of migrants and their families back home requires a deeper insight into the intertwined mechanisms and linkages between formal, semi-formal and informal social protection structures, both in the receiving and the sending countries. 
Two main issues need to be addressed when approaching social protection for international migrants. First, although social protection has traditionally focused on formal state-provided provisions, given the increasing number of mobile individuals, there is an urgent need to find, understand and implement an appropriate mixture of formal, semi-formal and informal institutional forms that are able to support communities, households and individuals within and across the borders of nationstates. The extent to which non-formal schemes should be involved in the provision of social protection is highly debated; a greater involvement of such schemes might encourage the state to retreat from its obligations to its citizens. Indeed, in 2011, a report on Social Protection in EU Development Cooperation, which involved a wide range of stakeholders (e.g., Member States, partner governments, international agencies, civil society organisations, and citizens), tackled this issue. While acknowledging the role of civil-society organisations in enhancing political support for social protection, advocacy, accountability, and provision of specific services (e.g., child protection or community-based care), the report limited the scope of civilsociety organisations to only recognised NGOs and maintained that 'civil society should not be seen as a major instrument of provision, as the state should remain the main provider' (Davies et al. 2011: 10). Although it is important to acknowledge this risk, other examples have shown that semi-formal schemes could have the capacity to assist governments in overcoming capacity and financial resource constraints to reach specific needs (Asian Development Bank, 2010). Furthermore, under conditions of high human mobility, we should ask ourselves whether the state is actually the most appropriate institution to provide social protection across borders. While in most Western societies, the provision of social protection and social security is a state responsibility, in many developing countries, from where many forced and labour migrants originate, the state is either absent or itself a source of insecurity (von Benda-Beckmann, 2015). Even Western industrial states have recently come to the realisation that public social security systems can only be sustainable with a combination of private forms of social security (ibid.). The way these three types of institutional forms can work together in providing social protection for migrants requires more in-depth empirical research.

Second, there is a need to analyse the synergy between informal, semi-formal and formal social-protection systems here and there. As the increasing flow of remittances shows, migrants maintain and renew links with those left behind, indicating that what happens here influences what happens there, and vice versa (Basch et al. 2005). No social protection instrument in isolation is able to address the different risks mobile individuals face (Shepherd et al., 2004). As some of the previous examples show, one of the main advantages of the semi-formal models is that they build on traditional community mechanisms to provide targeted social services to vulnerable groups with specific needs, including documented and undocumented migrants. Most formal approaches to social protection assume that migrants documented or not - need access to all of the existing welfare benefits in the receiving 
country (e.g., pensions, disability benefits) to cover their needs. However, a report by the ILO in 1999 on the extension of social security in sub-Saharan Africa to informal workers showed that neither old age pensions, disability or survivor benefits were top priorities for these workers (Fultz \& Pieris, 1999). By studying how migrants access and combine different systems and institutions to receive and provide social protection for themselves and their families, policies and institutions can be developed to provide better social protection for mobile populations. 
CHAPTER 7

\section{PROVIDING SOCIAL PROTECTION TO} MOBILE POPULATIONS: SYMBIOTIC RELATIONSHIPS BETWEEN MIGRANTS AND WELFARE INSTITUTIONS25

${ }^{25}$ This article has been published as Serra-Mingot, E. \& Mazzucato, V. (2018). Providing Social Protection to Mobile Populations: Symbiotic Relationships between Migrants and Welfare Institutions. Journal of Ethnic and Migration Studies. DOI: 10.1080/1369183X.2018.1429900 


\subsection{Introduction}

The current context of strict migration controls and welfare-state institutions linked to nationality and residency makes it difficult for migrants to access and provide social protection for themselves and their families abroad. Supporting family members abroad becomes not only problematic but at times is even penalised. In the case of Sudan, which is the focus of this paper, sending money through bank transfers is not allowed from the US and many European countries since the US introduced sanctions in 1997. At the same time, lack of access to formal welfare in receiving countries leads migrants to rely on their informal social networks for support. While access to social protection in host countries is essential for the wellbeing of individual migrants, migrants are often responsible for providing their families 'back home'. This context of lack of access to formal social protection in the receiving country, especially for the undocumented, and the hindering of transnational support lead migrants to develop tactics that encompass formal and informal practices. This paper studies such tactics as a means to gain a better understanding of how social protection is practiced nationally and transnationally. These tactics problematize the clear-cut divide between formal and informal social protection that guides much of this body of literature (see Holzmann \& Koettl, 2011; Sabates-Wheeler, 2009). Furthermore, we find that such tactics can be explained not only by the migrant's needs but also by the needs of different welfare-state institutions that must address the concrete realities of catering for populations that fall through the cracks of the formal social protection system.

Migrants' encounters with formal social protection providers in the Global North have received increasing attention from scholars from different disciplines (Cuadra \& Staaf, 2014; Holzmann \& Koettl, 2011; Sabates-Wheeler, 2009; van Ginneken, 2013). An important stream in this literature has considered the implications of migrants' lack of access to welfare in receiving countries, emphasising the role of informal social networks in providing support. Formal social protection is conceptualised as being provided by the state, market and organisations, whereas informal social protection is understood as that provided by interpersonal networks. Recently, research has also investigated the interactions between the welfare-state and migration regimes, particularly regarding the policies of control and exclusion and the counterstrategies or tactics that they trigger in undocumented migrants (Broeders \& Engbersen, 2007; Vasta, 2011). Whereas national and European political strategies aim at preventing irregular migration, local authorities must address the existence of undocumented migrants, and appeals are made to their compassion when they use their discretion to navigate a static welfare system. This situation results in inclusive, yet ambiguous, mechanisms (Ambrosini, 2017; Barberis \& Boccagni, 2014; Gendera, 2011; Verloo, 2017) or 'foggy social structures' (Bommes \& Kolb, 2002). Rather than drawing such clear-cut dichotomies into these interactions -migrants sneaking their way into the formal system and street-level 
bureaucrats helping them out of compassion -we argue that there are clear symbiotic elements in such interactions, in that both parties can benefit from them.

Most research on migrants' encounters with formal providers of social protection focuses on the migrant as an individual receiver of support in the host nation-state. Migration, however, is seldom an individual affair. Indeed, migration and, to a great extent, social protection are all about families (Cooke, 2008). Recently, transnational migration scholars have addressed how migrants enter into different social protection arrangements to provide for themselves and their families back home. These arrangements are usually a mixture of formal and informal provisions, and they are often related to the provision of care (Baldassar et al., 2007; Boccagni, 2013; Mazzucato, 2008c), while at the same time, they might create new inequalities within families (Faist \& Bilecen, 2015). Drawing on Peggy Levitt's (2016) and Neubourg and Weigenad's (2000) works on social protection, we define transnational social protection (TSP) as the combination of provisions provided by the state, the market, the third sector (i.e., NGOs, churches, international organisations) and, family and social networks to protect individuals and families against declining living standards arising from a number of basic risks and needs (e.g. employment, healthcare, housing, nourishment, education and social participation) in a transnational manner. Whereas TSP can be bi-directional, that is from the migrants to their families back home and the other way around (Faist \& Bilecen, 2015; Levitt et al., 2017), for the purposes of this article -which focuses on how migrants navigate formal state-bounded social protection provisions to informally provide for themselves or their families back home-we concentrate on what goes from migrants to their families back home. In a forthcoming article we address the bi-directional character of TSP. This article draws on an ethnography conducted over 14 months of multi-sited fieldwork with a partly matched sample of Sudanese families across the Netherlands, the UK and Sudan between 2015 and 2016. However, the empirical data in this article draw on from the fieldwork in the Netherlands and Sudan. The Sudanese case is relevant for two main reasons. First, the Sudanese constitute a relatively new migrant group in the Netherlands. New groups face different migration and receiving contexts (Grillo \& Mazzucato, 2008), which might impact the manner in which they engage in different TSP practices. For example, new migrant groups might have fewer and less developed social networks in the receiving country, including community organisations, which often provide migrants with social protection, locally and transnationally (Chelpi-den Hamer \& Mazzucato, 2010). Second, in terms of legal status, the Sudanese are a highly heterogeneous group, including asylum seekers, documented and undocumented migrants. This inevitably impacts the rights of these different groups to access formal social protection and allows us to better understand the social protection mechanisms accessed by migrants of different legal statuses.

This article investigates how migrants navigate formal state-bounded social protection provisions to informally provide for themselves or their families back 
home. In doing so, we show how migrants sometimes enter into symbiotic relationships with formal institutions, which in turn rely on the support of these migrants to provide services for which they are not mandated. While this interplay allows migrants to informally participate in the formal social protection system, such relationships are not without their risks, especially for migrants. Rather than addressing only cases of undocumented migrants, which have been the focus of the aforementioned literature, in this article we aim to compare how migrants with different legal statuses enter into symbiotic relationships with formal institutions to access specific social protection. Indeed, accessing formal social protection is not only problematic for the undocumented but for any migrant with transnational aims (e.g., caring for sick relatives back home).

This paper is structured as follows. Section one discusses the current scholarly debate on migration, social protection and welfare regimes. Section two briefly presents the history of Sudanese migration to the Netherlands. Section three discusses the data and research methodology used. Section four illustrates how migrants attempt to navigate the current, formal state-bounded social protection provisions. The section discusses the symbiotic relationships that emerge as a result of such practices between migrants and formal welfare institutions. The last section concludes.

\subsection{Migration and social protection}

Research on migrants' lack of access to social protection in the Global North has received increasing attention in the literature on social protection (van Ginneken 2013; Holzmann and Koettl 2011). These studies acknowledge four dimensions of social protection: accessibility, portability, labour market conditions and informal networks of support (Sabates-Wheeler, 2009). Migrants' (lack of) access to and portability of welfare resources in receiving countries have important implications for their wellbeing. However, informal social protection plays also an important role, be it in the form of family or social networks of support in the host country or in the form of migrants' remittances to their families back home to help them cover basic social protection needs (Amuedo-Dorantes \& Pozo, 2006; Avato et al., 2010; Azam \& Gubert, 2006; Sabates-Wheeler \& Koettl, 2010). Thus, social protection tends to be defined in terms of either formal or informal mechanisms of support for the migrant in the receiving country; the first referring to protection provided by public and private entities and the latter referring to the support provided by individuals, families and communities (Avato et al., 2009).

Moving beyond these dichotomies, scholars in transnational studies have analysed migration and social protection using a transnational lens, that is, including both migrants and non-migrants, as well as considering the multiple levels of engagements beyond either the sending or receiving countries (Levitt \& Jaworsky, 2007). A transnational approach avoids splitting migrants' lives into disconnected 
areas, and it allows for a more comprehensive understanding of the different social situations and relationships that migrants must confront and reconcile, both here and there (Grillo \& Mazzucato, 2008). Transnational migration scholars have problematized the clear-cut distinction between the formal and informal dimensions of social protection, advancing the existence of a semi-formal category, in which the formal and informal merge (Serra-Mingot and Mazzucato, 2017 [Chapter 6 of this thesis]). Social protection can be described as an interrelation or 'assemblage' of formal and informal elements, with social actors constantly negotiating and combining the use of formal and informal provisions (Bilecen \& Barglowski, 2015). Informal mechanisms not only fill the gap in formal social protection schemes, but they also can be perceived as more viable or appropriate for covering specific needs (ibid.). To operationalise the concept of TSP Levitt and co-authors (Levitt et al., 2017) introduced the concept of 'resource environment', understood as all of the possible resources available to migrants from the four potential sources of protection (e.g., state, market, third sector and social networks), based on migrants' individual characteristics, including their nation of origin and residence, their social networks, gender, race, ethnicity, religion, class, and education. A transnational approach to migration and social protection, thus, allows for a more comprehensive understanding of how migrants navigate their resource environments to receive and provide support locally and across borders.

\section{Welfare states' strategies and migrants' tactics}

Recent research has considered the interactions between the welfare state and migration regimes, particularly regarding the policies of control and exclusion and the actions they trigger for irregular migrants (Broeders \& Engbersen, 2007; Vasta, 2011). Against the current context of national and European political strategies aimed at preventing irregular migration, undocumented immigrants use different 'counterstrategies' (Engbersen \& Broeders, 2009) to cover their basic needs, avoid deportation and obtain legalisation in receiving countries in the Global North (Chauvin \& Garcés-Mascareñas, 2012; van Meeteren, 2012). Such counterstrategies can be described as the 'weapons of the weak' (Scott, 1985) or 'tactics' (de Certeau, 1984), that is, the strategies of powerless groups to resist and undermine the power that the state, public authorities and elites have over them.

The bulk of this literature focuses on undocumented migrants as tactical actors. While lack of access to basic social rights, such as healthcare or housing, leaves the undocumented in a vulnerable situation, in this article, we also show that documented migrants must devise tactics between the formal and informal to achieve their social protection aims. Documented migrants and refugees have sometimes been described as tactical actors in that 'they are systematically excluded from accessing the strategic possibilities of official systems' (Williams, 2006). The lack of family and strong social networks to provide childcare while parents work, or the lack of access to certain social benefits are some examples of how regular migrants 
might need to resort to tactics to cover their needs in receiving countries. Using a transnational lens, we contribute to this body of literature by looking beyond the tactics that migrants use to meet for their own individual needs in the receiving country. While their own needs might be covered, documented migrants sometimes informally interact with official institutions to cater to their social protection obligations for family members back home.

In addition migrants' own tactics, research has also focused on compassionate civil servants (Ambrosini, 2017), who might use their discretion to interpret rules in a manner that allows for the provision of certain services, even to undocumented migrants (Björngren-Cuadra \& Staaf, 2014; Barberis \& Boccagni, 2014). While the current discourse and policies aim at preventing irregular migration, local authorities must address the realities of undocumented migration and use their discretion to navigate a static welfare system (Ambrosini, 2017; Gendera, 2011; Verloo, 2017). Such discretion allows for significantly inclusive, but ambiguous, mechanisms and interactions, which give way to uncertain frameworks or so-called 'foggy social structures' (Bommes \& Kolb, 2002). Foggy structures 'emerge from efforts by individuals and organizations to avoid the production of knowledge about their activities by making them either unobservable or indeterminable' (Broeders \& Engbersen, 2007: 1594). Recent research has shown that welfare states and migration regimes can interact with each other and that irregular migrants play at times crucial roles in the informal provision of welfare services (Gendera, 2011). For instance, in the current context of shrinking public expenditures, the pressure of a growing elderly population is often managed by hiring inexpensive irregular workers for elder care. Welfare-state institutions allow for the emergence and perpetuation of such paradoxical mechanisms by turning a blind eye to these practices (ibid.). Foggy social structures are, therefore, the result of contradictory socio-economic and judicial forces, such as the labour market demands and humanitarian concerns of civil society and state actors against the political-judicial rejection of irregular migration by the state (Engbersen \& Broeders, 2009). Rather than being exclusive to undocumented migrants, in this article we show how also documented migrants might get involved in such foggy social structures.

In this literature, formal and informal systems co-exist in parallel, without any interaction: either formal institutions turn a blind eye or operate out of compassion, or informal institutions operate on the margins. Moreover, undocumented migrants are often presented as the direct and only beneficiaries of this 'fog', be it through their own sneaky tactics (e.g. acquiring false papers from legitimate others to access certain rights and benefits) or through the compassionate discretion of civil-servants. Welfare-state institutions, however, are usually presented as actively fighting the 'fog' (e.g., creating internal controls) or as passively tolerating it. Only a few studies have portrayed the welfare system as a beneficiary of the irregular work performed by the undocumented, for example, in the elder-care sector. However, even in these cases, welfare institutions simply turn a blind eye to the issue. In this article, we take a step 
forward and illustrate how, in some cases, it is actually local authorities, organisations and even immigration institutions that actively seek the support of migrants to help them to provide services that would otherwise be out of their purview. These interactions question compassion and discretion as the main motivating factors for formal institutions to engage in informal tactics, as well as the clear-cut divide between formal and informal social protection schemes. What we emphasise in this article is the symbiosis that exists at times between the two systems, in which they each use the other to achieve their aims.

\subsection{Sudanese migrants in the Netherlands}

The peak of Sudanese migration in the Netherlands occurred between 1995 and 2003, after the coup d'état of General Omer Al-Bashir in June 1989, when most Sudanese arrived seeking asylum due to the worsening political situation and the protracted civil conflict (van Heelsum \& Hessels, 2006). At this time, Sudan and South Sudan were still one country, and most of the refugees came from the South (ibid.). It was only in 2011 that Sudan was divided into Sudan and South Sudan. In this research, we focus only on migrants from Sudan, which covers only the northern part of the former Sudanese territory. Moreover, since the implementation of the Comprehensive Peace Agreement (CPA) in 2005 - which technically ended decades of civil war - there has been a gradual increase in the number of rejected Sudanese asylum applications, which might result in relatively high numbers of irregular Sudanese living in the Netherlands not captured by these statistics. This fact, together with the lack of literature on this group and many Sudanese having moved to the UK after having obtained their Dutch citizenship, makes it difficult to gather accurate estimates. Nevertheless, according to the Eurostat database, in 2016 there were approximately 4,600 Sudanese migrants in the Netherlands (van Heelsum and Hessels 2006).

\subsection{Data and methods}

This article is based on a 14-month ethnography with Sudanese migrants in the Netherlands and the UK and with their families back in Sudan, conducted during 2015-16. The empirical data in this article draw only from the Netherlands and Sudan. A forthcoming publication explores the British context. Multi-sited research was conducted using semi-structured, open-ended interviews and observations with 21 respondents in the Netherlands and with 9 of the migrants' matched samples (mostly parents, siblings and cousins) in Sudan. A matched-sample methodology is especially suited to study social protection for transnational families since it allows for the sampling of individuals who are connected across different sites (Mazzucato $\&$ Schans, 2011). This methodology allowed us to better understand the roles of local institutions in both sending and receiving countries (ibid.). 
Research participants were recruited through multiple gate-keepers and by snow-ball sampling with different starting points, including personal contacts, Sudanese organisations, NGOs, churches and social media. The heterogeneity characterising the Sudanese community in the Netherlands in terms of legal statuses, allowed for maximum variation sampling, through which we could investigate the roles of different legal statuses in different social protection arrangements. This sampling method is also appropriate for maximising the diversity relevant to the research question by selecting a small number of cases (Sandelowski, 2000). The sample included roughly half men and half women, who ranged in age from their early 20 s to late 50 s, including single men, married couples and divorced parents with children. The four cases presented here, however, correspond to male migrants. The educational background of the respondents varied, although the majority had a university degrees from Sudan, reflecting that Sudanese in The Netherlands are one of the most highly educated African migrant groups (van Heelsum and Hessels, 2006). This fact could be explained by the Sudanese middle class being the main target of the Islamist regime after the coup, whereby the civil service throughout the country was purged, and professionals were massively dismissed (Abusabib, 2007). Interviews and observations were conducted by the first author in English, Arabic or German in familiar environments for the respondents, mostly in their homes. The interviews lasted between two and four hours, while the observations ranged in duration and entailed attending social events with the participants, to spending a full week living with them in their homes. At the request of the respondents, most of the interviews were recorded through note-taking. The interviews followed a themecentred approach, focusing on the main spheres of social protection (e.g., unemployment, old-age, children and dependents, healthcare, education and housing). We analysed interviews and observations through thematic analysis, whereby through careful reading and re-reading of the data, relevant analytical themes emerged (Boyatzis, 1998). Data were coded with Atlas.ti, through which the three main themes in this article emerged, namely: tactics and resource environments, symbiotic relations and unbalanced power relations.

\subsection{Foggy structures of support}

We begin this section with four different vignettes that illustrate how and why migrants sometimes enter into symbiotic relationships with local authorities, nongovernmental organisations and other immigration institutions to be able to receive or provide social protection locally and/or transnationally. We have chosen these particular cases because they clearly illustrate how and why migrants with different legal statuses (e.g. two documented and two undocumented) sometimes enter into symbiotic relationships with local authorities, NGOs and other immigration institutions to be able to receive or provide social protection locally and/or transnationally. Whereas the dynamics illustrated here were also observed in other 
cases, these particular four examples encompass, to different degrees, the three main analytical themes of this paper, namely: different tactics to access their resource environment, varying degrees of symbiosis, and unbalanced power relations.

While migrants are often seen as partaking in an informal system of reciprocal relationships to ensure social protection for themselves or their families back home, and welfare institutions are seen as the main formal social-protection systems, little is known about how these two systems interact. The following cases illustrate how migrants implement different tactics to navigate their particular resource environments, which include state, third sector and informal networks. The resources available to them are shaped by their legal status and by their personal social capital and the trust relationships established with different formal institutions. These relationships show that formal institutions are not simply passive entities from which the migrants benefit. On the contrary, in these relationships, both migrants and formal institutions become givers and receivers of services, thus creating a certain degree of symbiosis. Whereas these relationships allow migrants to acquire certain power positions vis-à-vis the formal institutions with whom they interact, this symbiosis might not always benefit both parties equally.

\section{Atif (56) - Establishing mutual relationships of support through former professional networks.}

Soon after starting fieldwork in 2015, Imet Atif $f^{6}$, a 56-year-old Sudanese man who had arrived in the Netherlands as a refugee 22 years ago. After working for several years at the Office of Regional Planning in his municipality, Atif was made redundant in 2004, only 3 days before his permanent contract would have started. Since then, he had not found a steady job and had been mostly living on unemployment benefits, which were sufficient to cover Atif's needs in the Netherlands. Receiving benefits, however, comes with some conditions, such as monthly appointments at the unemployment office. This 'sedentary condition' had become an obstacle for him to support his family back home. Atiffelt responsible for providing for his sick mother in Sudan, not in terms of money, which his siblings covered, but in terms of care. While bringing his mother to the Netherlands was not an option because she falls outside of the family reunification regulations, regular short-term visits to Sudan were also not possible because, to be back in time for his meetings with the unemployment office, the trips would need to be numerous, making this option unaffordable. Moreover, having two children in the Netherlands from a former relationship prevented him from permanently moving to Sudan.

Sometime later, at one of our meetings, Atif told me how he had just returned from a 2month stay in Sudan. Thanks to his former experience and contacts in the Office of Regional Planning, he was developing an environmental project between the Dutch municipality and the city council of Khartoum. Based on his knowledge from his former job, Atif knew this project would be of interest to the municipality, and he was able to arouse its interest so that it funded the initiative. If his plan succeeded, it would exempt him from having to regularly appear to

\footnotetext{
${ }^{26}$ Pseudonyms are used to ensure the informants' anonymity.
} 
receive his unemployment benefits. While the environmental and social goals of this project were legitimate, in doing so, Atif had also managed to fulfil his personal needs: gaining more time in Sudan to care for his mother while upholding his rights and responsibilities in the Netherlands.

In addition to this long-term plan, for the last few years, Atif had registered his home as a 'crisis address'. In the Netherlands, municipalities offer different housing possibilities for people facing crisis situations (e.g., homelessness, domestic violence). While women, children and other vulnerable groups are placed in specific shelters, it is often the case that such shelters are full, so the only possibility is to place these people in over-crowded shelters that often accommodate people with drug or alcohol addictions. Being aware of this issue, Atif registered as a 'crisis address' in his municipality, whereby he occasionally hosts Sudanese women with children until their issues are resolved. Additionally, Atif is registered as a foster parent at an $N G O$ helping refugee minors, whereby by hosting minors, he receives an allowance compatible with the unemployment benefits.

\section{Mohamed (46) - Entering into a tacit agreement with formal institutions.}

I met Mohamed at an NGO in 2016. He had a toothless smile, pebble glasses-caused by illtreated diabetes - and a non-functional knee that caused him to be dependent on an old pair of crutches. Mohamed arrived in the Netherlands seeking asylum in 2003, but 13 years later, he was still undocumented. Although during these years he had spent long periods in the streets or in detention centres, since 2010, the NGO together with the municipality had started to support him, mainly in terms of shelter and healthcare. Such support is meant to be temporary until people find solutions to their problems, namely obtaining refugee status or returning to their countries of origin. However, Mohamed was in neither of those situations: not only had he extinguished all of his opportunities for appeal but also, when he had agreed to a'voluntary return' in 2012, the Sudanese authorities had questioned his true nationality and warned him of the possibility of being deported to Ethiopia should they determine he was not Sudanese. Mohamed, thus, was 'stuck' in the Netherlands.

Despite his irregular situation, over the years, Mohamed had been 'unofficially' supporting the NGO and the municipality: translating for newly arrived migrants or assisting them with bureaucratic formalities. As a common friend told me, 'Mohamed has helped every Sudanese in (city)'. Whereas neither the NGO nor the municipality could officially offer Mohamed a paid and stable job, for 6 years, they expressed their 'gratitude' by offering him shelter-although he was not officially entitled to it anymore - healthcare and other gifts, such as a new bicycle.

Due to his irregular situation and lack of financial resources to support his family in Sudan, Mohamed's contact with his family consists of short phone calls with limited exchanges of information. Nevertheless, whereas Mohamed can rarely send monetary remittances, his access to healthcare through the NGO, allows him to obtain some medicine and materials to treat his diabetes. Rather than receiving the recommended daily injections, Mohamed saves a couple of them every week, as well as syringes and other medical equipment, which he sends to his mother, who cannot afford proper diabetes medication in Sudan. 


\section{Youssif (35) - Helping authorities to deal with those who are 'left out' in exchange for safe visibility.}

One of the days I visited Youssif at the squat building where he and more than 100 undocumented migrants lived, Youssif was receiving a group of university students and their professor to talk to them about 'the other side of hospitality'. Almost every time I met him, he was engaged with some event or other. He said it kept him busy, active and sane. Youssifarrived in the Netherlands in 2002 seeking asylum, but 14 years later he remained undocumented. This fact had not stopped him from helping himself and others. In addition to being an active member of an informal undocumented-migrant organisation that provides legal advice and Dutch language and other courses to undocumented people, Youssif was often contacted by immigration authorities to care for newly rejected asylum seekers who were, like him, left in the streets without official support. Youssif was not afraid to talk openly about his situation in newspapers or even to participate as a speaker in national and international forums (via Skype). It was likely this visibility that put Youssif in a situation in which, on the one hand, he was asked for support by immigration authorities while, on the other hand, he could navigate the formal system to address complicated issues, such as Haider's funeral, one of his undocumented friends at the shelter. Funerals are one of the most deeply rooted traditions in Sudan. Upon someone's death, community members pass around a donor list or kashif, on which people write their names and financial contributions to the family of the deceased. Since funerals involve several days of countless visits of relatives and friends, and everyone is expected to be fed, the kashif is meant to help the family of the deceased cover such expenses and to help the survivors to 'get by' for some time. Even for Sudanese in the diaspora, this tradition is extensively practised, although its implementation is more complicated when the deceased is undocumented. In Haider's case, Youssif managed to contact Haider's family, collect the necessary money through different social media, buy a ticket, and negotiate the repatriation of the body with the Ministry of Justice and the hospital involved.

\section{Ismail (46) - 'Being forced' to help authorities in expectation of a better life.}

Ismail arrived in the Netherlands in 2003 as an asylum-seeker. After spending more than 5 years in and out of the Dutch asylum system, Ismail's case was eventually accepted, and he was officially recognised as a refugee. As a politically engaged Sudanese, Ismail soon became the chairman of a Sudanese civil-society organisation in the Netherlands working with and for Sudanese people at home and in the diaspora. In addition to the different activities performed by this organisation, often the immigration police, the Immigration and Naturalisation Service of the Netherlands (IND), requests the services of this organisation to determine whether someone comes from Darfur. Darfur is a conflict-ridden area in Sudan, so being identified as a Darfurian usually translates into having one's asylum case accepted.

On several occasions, after having obtained his refugee status but before obtaining a permanent residency permit for the Netherlands, Ismail, as a member of the Sudanese organisation, was requested by a lawyer for a rejected asylum seeker to assess whether this person was Darfurian. When Ismail told me this, I immediately thought of the emotional toll of this task for someone who had gone through 5 years of fighting a system that would not accept the 
truthfulness of his own story. I did not think, however, of more practical implications. As Ismail put it, 'whatever the decision, it is always a problem'. On some occasions, when he had agreed that the person in question was actually Darfurian, he and other colleagues in charge were questioned by the IND. In one particular situation, Ismail recalled how an IND officer accused him of helping someone only because he was Sudanese, hinting that he should be careful with what he did because Ismail did not have permanent residency yet. At the same time, whenever he considered people not to be Darfurian or Sudanese, the person concerned would accuse him of destroying their lives and even threaten him. This was the case Ismail experienced once when, after concluding that an interviewed asylum-seeker was actually not Sudanese, he received a threatening phone call from this person with a clear message: 'Blood will be shed'.

\subsubsection{Resource environments and tactics}

These vignettes show how migrants navigate their personal resource environments to devise tactics to cover their social protection needs. Rather than being a mere 'combination of all the possible protections available to them from our four potential sources (states, markets, third sector, and social networks)' (Levitt et al., 2017: 6), these cases show that migrants' resource environment also entails the resources with which they can contribute to the formal systems. Atif's case is an example of how documented migrants might become tactical actors to cover specific social-protection needs. Whereas Atif has full access to welfare benefits in the Netherlands, he has transnational responsibilities that cannot be met through existing formal channels. For Atif, the main trigger of his interaction with official institutions is his desire to spend more time in Sudan to care for his mother without being penalised in the Netherlands, where his children live.

In Sudan, providing for elderly parents, in terms of money and care, is deeply rooted, both socially and culturally. The case of Sudan is particularly problematic in regard to supporting those back home. On the one hand, due to current international sanctions, sending remittances to Sudan through formal means is not only problematic but also penalised. As some of our respondents experienced, even buying goods online (e.g., orthopaedic shoes or agricultural tools) with a Dutch bank account and sending them to Sudan resulted in blocking of the transaction and closing of the migrant's Dutch account. On the other hand, under the current migration regulations, bringing over parents from third countries is highly restricted and costly. Under these circumstances and after having exhausted all of the possible formal channels, some migrants decide to return to Sudan temporarily or permanently to fulfil their family obligations. Migrants like Atif, however, for whom leaving the Netherlands for a long period would result in neglecting their family obligations here, opt to navigate the system in a manner that allows them to maintain their attachments and responsibilities here and there. Atif's resource environment - his previous employment with the municipality, the existing relationship of trust between them, and his knowledge of the municipality's needs and interests - allows him to engage with local authorities and an NGO to obtain additional time and 
income to fulfil his obligations with his mother in Sudan while maintaining his responsibilities towards his children in the Netherlands.

In the case of Mohamed, his main reason for engaging with local authorities is to satisfy his basic needs. Nevertheless, this relationship also allows him to provide support to his family back home. Many asylum seekers and refugees feel responsible for people back home. Long asylum processes take a toll not only on the migrants' wellbeing but also on their families' and their relationships with each other. Like Mohamed, many people reduce communication to a minimum, while others reduce their calorie intake to be able to send some money home. In one of our meetings, Mohamed explained how, for a long time, a Sudanese friend in the shelter had been living on bread and rice only so that he could send to his family in Sudan most of the $€ 30 /$ week allowance that the NGO gave them. Whereas his undocumented situation limits Mohamed's resource environment in many ways, by using his language skills and his thorough knowledge of the Dutch asylum and migration system, Mohamed's support to the municipality and the NGO, in terms of translation and the introduction of new arrivals, results in his securing access to shelter, pocket money and healthcare. Moreover, by having access to healthcare, Mohamed can sporadically support his mother, which enables him to maintain links with his family in Sudan.

Research on the counterstrategies used by undocumented migrants often describes them as 'underworld' tactics, such as using illegitimate institutions or sabotaging the bureaucratic process of migration management by manipulating their identity (Broeders \& Engbersen, 2007). The cases above, however, show that many tactics used by migrants actually develop not only in the 'overworld' but also with the support of public authorities. In contrast to Broeders and Engbergesen's definition of foggy social structures as 'unobservable or indeterminable' (2007: 1594), one of the main tactics implemented by both Atif and Youssif is quite the opposite. Visibility might be a powerful tactic for both documented and undocumented migrants to navigate their available resource environments and engage with formal institutions. For Atif, by actively informing the municipality of his services as a 'crisis address', he ensures that they will easily turn a blind eye to his longer stays in Sudan. For Youssif, by becoming visible, he can interact with local and migration authorities in a relatively safe fashion and access shelter, healthcare, nourishment and security. Rather than hiding his undocumented presence in underworld activities, Youssif's tactic is the opposite: being as visible as possible. His visibility, however, is rather strategic. By engaging with different universities, NGOs and other public organisations, he is not only building a strong and supportive social network at different levels (e.g., legal, health, intellectual), but he is also tolerated and even consulted by immigration authorities. His engagement with the undocumentedmigrant organisation and a long-established squatting platform allows Youssif, and other undocumented migrants, to live in empty buildings within the limits of legality. On one of my visits, a couple of police officers walked into the squat building to 
ensure that the migrants had new locks and keys in the main door to be safe. They left after exchanging several handshakes and friendly hugs with Youssif and asking him to call them should something happen.

Sometimes becoming a tactical actor is not so much initiated by the migrant as by formal institutions, whereby refusing to assist could be counterproductive for the migrant. Such is the case of Ismail, whose position as a tactical actor seems to be somewhat imposed. Assisting the IND in the assessment of certain cases can be seen as a tactic 'to gain points' in the eyes of the immigration services, which will eventually grant him or his permanent residence permit or not.

As all four cases show, becoming a tactical actor to access certain resources is not exclusive to undocumented migrants. Specific TSP needs that cannot be covered with the exiting formal provisions lead also documented migrants to become tactical. Moreover, what these cases show is that often migrants -regardless of their legal status - become providers of resources to formal institutions, who, in turn, are also tactical actors.

\subsubsection{Symbiosis}

Local authorities and NGOs support migrants or ignore their tactics not only out on compassionate grounds, as has been emphasised in the literature, but also because they directly benefit from their informal interactions with migrants. Documented and undocumented migrants provide services that formal institutions might not be equipped to provide. Migrants, thus, are not exclusively receivers of social protection, but they can sometimes become the informal providers of support acting on behalf of formal institutions. At the same time, the migrants' engagements with formal institutions yield some benefit for them. We call these mutual exchanges of support 'symbiosis', understood as a simultaneous, cooperative and interdependent relationship between two different actors (institutions or individuals), who work together, often outside the limits of legality, to cover for each other's individual interests, filling an existing gap that cannot be filled otherwise. Symbiotic relations, however, might not be equally beneficial for both parties.

Regardless of their legal statuses, both Atif and Mohamed are able to engage with municipalities and NGOs for which they provide valuable services. The blind eye that the municipality turns to Atif's extended visits to Sudan or the shelter and healthcare provided to Mohamed, when his legal status does not allow him to access such services, are not simply cases of compassion. On the contrary, this support is reciprocated by services, such as hosting vulnerable people or translating for new arrivals. As one of Atif's case worker told him once, 'You help people, but you also help us indirectly'. These two cases exemplify how migrants and front-line staff enter into relationships of mutual support, or symbiosis, while managing the current geographically fixed regulations and policies of exclusion and rejection of irregular migrants. 
For Youssif and Ismail, however, the symbiosis seems to be less obvious. In both cases, they are directly approached by formal institutions to assist them in handling asylum-seeker cases. While this involvement is a gain for the formal institutions, the benefit reported by the migrants is rather indirect. For Youssif, his engagement with the immigration authorities gives him the chance to be more visible - without fearing detention - and to become involved with educational platforms and to assist his colleagues in delicate issues, such as Haider's repatriation. His collaboration with universities often results in individual or collective donations in terms of furniture and food. Moreover, both Youssif's and Mohamed's involvement in and support for educational organisations or NGOs play important roles in their physical and mental health. As Mohamed once begged the NGO, 'Let me do anything because I don't want to lose my mind'. Strict Dutch regulations impose high penalties on employers hiring undocumented migrants. The NGO thus could not risk hiring him, but it did continue to benefit from his informal services while paying him in terms of shelter, gifts and healthcare. In Ismail's case, however, the main benefit he obtains from his support of the immigration police is the hope that this support will eventually help his application for permanent residency.

All four cases show different types of symbiotic relations, whereby both documented and undocumented migrants enter into symbiotic relationships with formal institutions, both parties benefitting from each other. At the same time, the cases illustrate how a symbiotic relation may be initiated by a formal institution. In these cases, the benefits received by the migrant are indirect or may even put them in a worse situation.

\subsubsection{Unbalanced power relations}

The cases presented above illustrate how both documented and undocumented migrants, as well as the involved institutions, need and benefit from such interactions. The migrants' legal status, however, affects the type of relationships that they might develop with different institutions in that the power-relations between the actors are much more unbalanced and can even pose a risk to the migrant. The symbiotic relationships presented here should not be understood as an equal balance of services.

Indeed, there are unequal power relations between the migrants and the formal institutions, in which inevitably the migrants have more at stake. Whereas the migrants' tactics above can be identified as Scott's 'weapons of the weak' (1985), in that they are able to undermine the power that public authorities have over them, important power imbalances exist and should not be underestimated. While their support of local authorities and immigration institutions gives them a certain degree of power with which they can negotiate their access to certain social protection resources, the power imbalance, especially in the cases of Youssif and Ismail, places migrants in more vulnerable situations. For Youssif, his being asked to care for newly rejected asylum-seekers might create an additional burden and source of stress for him. His accepting of the request makes him responsible for the wellbeing of new, 
undocumented migrants, while his refusing to help could result in his detention. For Ismail, both refusing or accepting to support the immigration police result in threats to his residency permit and his personal safety.

In the case of Atif, his former employment at a regional institution and his support of the municipality by hosting vulnerable people provide him with the necessary knowledge and power to negotiate his situation with the different formal institutions involved. In doing so, Atif can negotiate the length and frequency of trips to Sudan, without having his rights in the Netherlands compromised. Having a strong network in the Netherlands and the capacity to provide certain services places migrants in a more balanced power relationship vis-à- vis the formal institutions.

\subsection{Conclusion}

This article has explored an issue rarely discussed in the literature on migration and social protection, that is, the different manners in which both welfare-state institutions and migrants work together at the interstices of the formal and informal to cater to national and TSP needs. A detailed analysis of how these relationships occur and the consequences they have for migrants with different legal statuses has been the main focus of this article. A transnational approach has allowed us to understand how not only undocumented migrants, who do not have access to welfare provisions, but also highly skilled documented migrants are pushed to navigate a system that does not cover the needs of their dependent others abroad. Whereas migrants with different legal statuses seem to engage in symbiotic relations with formal institutions, achieving an equally beneficial relation for both parties is marked by unbalanced power relations. Such power imbalances are directly related to the migrants' legal status, which affects their leeway to negotiate demands or simply having to obey to imposed requests.

Our findings contribute to the emerging body of literature on TSP in three manners. First, by illustrating how different formal institutions enter into symbiotic arrangements with migrants - in which mutual trust, knowledge of the current welfare and migration regimes, and social needs are essential elements -we argue that migrants are not simply receivers of support from the 'protective arm' of the state (Levitt et al., 2017: 5) but are also the providers of services to state-linked institutions. That formal welfare institutions must resort to informal means to support individuals for certain provisions shows that the geographic fixity of social protection institutions is problematic for both migrants and the institutions themselves. Our analysis further points to an addition to the concept of 'resource environments' as recently theorised by Levitt and co-authors (2017). They argue that a person's social protection resource environment is composed by the resources they are able to receive from formal and informal institutions. We add that a social protection resource environment also consists of the resources that individuals can offer to formal institutions in their quest to improve their and their family's social protection. 
Second, we find that local authorities, NGOs and immigration institutions are not only acting out of compassion or solidarity, as emphasised in street-level bureaucracy literature (Cuadra \& Staaf, 2014). Formal institutions are also receivers of support provided by migrants. One of the contributions of this paper lies in the fact that welfare institutions do not only ignore migrants' tactics when it is convenient for them, as has already been pointed out in some literature, but that welfare state institutions actively use migrants to achieve their own aims. This change of roles, in which migrants become not only receivers but also providers of services to formal institutions, has an effect on how these relationships develop. Adding to the current literature on the tactics of irregular migrants in the 'underworld' (Engbersen \& Broeders, 2009), we argue that the symbiotic element in these relationships leads migrants to become strategically visible, while institutions strive to keep these tactical engagements 'low profile' and unregistered. Visibility can be a powerful tactic for migrants to position themselves in these symbiotic relationships of support. By being visible to certain formal welfare institutions, migrants secure themselves a degree of protection against existing exclusionary regulations, while they become an informal source of support for formal institutions. Paradoxically, it is the institutions that, in attempting to keep the support received by migrants invisible and unregistered, become tactical actors.

Finally, symbioses do not always translate into even power relations or equally beneficial outputs for both parties. On the one hand, in seeking the migrants' assistance, welfare-state institutions give migrants a certain degree of power to negotiate their access to services, to 'manipulate the mechanisms' and to reshape existing power relations (de Certeau, 1984). On the other hand, these power relations are far from balanced, especially for those in unclear legal situations. When the formal institutions are those directly requesting support from people with uncertain legal statuses, the only benefit that these migrants obtain is the prospect of a better or more secure legal status. In fact, the immediate result of their support is directly detrimental to them (i.e., receiving threats or having to provide for an additional person). While this situation gives migrants a certain power to navigate their own needs, it also subjugates them to the power of the institutions in that refusing support might have a negative impact on their legal status. Formal institutions, thus, can force migrants into becoming tactical actors.

Our research has three main implications for the further study of TSP. First, in the study of TSP, it is necessary to consider the migrants' responsibilities towards those 'back home'. Even when the migrants' basic needs here are covered by the welfare state, their ability to provide for family members abroad continues to be limited, which leads them to seek alternative means across formal and informal provisions. Second, more research is needed towards a deeper and more nuanced understanding of the heuristic tool of resource environment. Not all resources - in principle, available to everyone - are equally accessible. Availability and accessibility to resources greatly depend on the migrant's capital (e.g. knowledge, skills, networks) 
and on the resources that migrants themselves can provide in return. In this regard, the role of gender could bring relevant insights in future research on TSP in understanding how women navigate their different resources, and the implications for themselves and their families. Finally, rather than drawing a clear-cut division between formal and informal social protection provisions, it is crucial for future research on TSP to acknowledge that existing gaps in the formal system are not exclusively filled by people's informal practices but by a combination of formal and informal mechanisms working in symbiosis. 


\section{CHAPTER 8}

\section{MOVING FOR A 'BETTER WELFARE'? THE CASE OF TRANSNATIONAL SUDANESE}

FAMILIES 27

${ }^{27}$ This article has been accepted for publication as: Serra-Mingot, E. \& Mazzucato, V. (forthcoming). Moving for a better welfare? The case of transnational Sudanese families. Global Networks. 


\subsection{Introduction}

This article aims to contribute to the current debates on migration and welfare, by investigating what kinds of considerations underlie the decisions of migrants and their families to move to (or remain in) certain places, in order to address social protection needs. In trying to better understand the role that social protection plays in shaping peoples' decisions to move, the article analyses the mechanisms guiding the access, circulation and coordination of different resources to cover for different but related social protection domains. The growing body of literature on the relationship between migration and a country's welfare system has yielded mixed results (for a detailed overview of these works, see Brueckner 2000). Whereas some research claims that more generous welfare states work as a magnet, especially for unskilled and poor migrants (Borjas, 1999; Enchautegui, 1997; McKinnish, 2007), other studies do not find such a straightforward correlation (Levine \& Zimmerman, 1999; Talleraas, 2018). Despite these mixed results, media, public opinion and political discourse have sustained the widespread idea of 'welfare shopping', that is, that migrants move to specific countries to make use of the country's welfare system.

Adding to the mixed results, recent qualitative studies (prior to Brexit in 2016) have pointed to important 'onward movements' of certain migrant groups, from countries with some of the most 'generous' social welfare states, such as the Netherlands, to the UK, where welfare benefits are relatively smaller (Ahrens et al., 2016; Bang-Nielsen, 2004). Ahrens and colleagues map the factors that push these migrants away from certain EU countries and pull them to the UK, highlighting the discrimination (e.g. difficulty to access the desired job or education) experienced in their previous country of residence. Research, however, has shown multiple instances of migrant discrimination in the UK, wherein migrants often face restricted access to career opportunities or housing, or end up working extended hours in jobs for which they are overqualified (Batnitzky \& McDowell, 2011).

Interestingly, many of these 'onward movers' (e.g. Somalis, Iranians) first arrived in Europe as refugees, and then moved to the UK after obtaining their respective European citizenship, which granted them full access to welfare benefits (Ahrens et al., 2016). In the case of the Netherlands, which is the focus of this paper, once refugee status - and Dutch citizenship five years thereafter - has been granted, refugees have access to all welfare benefits, like any Dutch citizen. In spite of this, many move to the UK as EU labour migrants, with all the restrictions this implies, such as having to wait a certain amount of time to access social housing or obtain unemployment benefits (Broomfield, 2014; Fernandes, 2016). From a social protection perspective, thus, moving from the Netherlands to the UK seems to be paradoxical at best.

In the last years, the generosity of the welfare benefits all over Europeincluding the Netherlands and the UK-has been curtailed, both in amount and duration. Accessing certain social benefits has thus become harder and conditional, 
whereby having the right, does not always result in accessing it (Hemerijck 2013: 30). However, both Dutch and British welfare systems present differences in terms of development, policy design and institutional make-up (Hemerijck 2013). The Netherlands belongs to the so-called Continental regime (see Esping-Andersen 1990 for further details), which has been described as highly inclusive, structured, and one of the most generous in the world, providing a high degree of security and minimum living standards for all its legal residents, irrespective of ethnic origin and immigrant status (Zorlu 2013). The UK welfare regime belongs to the so-called Anglo-Irish or liberal group, characterised by means-tested assistance, little redistribution of incomes, low level of decommodification, modest social-insurance plans and individualism (Esping-Andersen, 1990; Hemerijck, 2013). The system, with a strong poor-relief orientation, and the state's encouragement of the market to guarantee and subsidise private welfare schemes has led to a higher degree of social stratification and inequality (Esping-Andersen, 1990). There is thus a need to better understand how migration and social protection may or may not be related. We aim to contribute to this body of literature by investigating the role of social protection in people's migration and onward movement decisions.

To do so, we draw on literature on transnational families and the circulation of care. In the current context of geographically-fixed welfare systems, the circulation of informal support, especially care, is crucial in understanding how families organise their transnational social protection (TSP). Drawing on literature on care, migration and social protection through a transnational lens, this article aims to disentangle what kinds of considerations underline the decisions that Sudanese migrants and their transnational families make to move and/or circulate certain resources to cover for the needs of different members across time and space. Transnational families are defined as 'families that live some or most of the time separated from each other, yet hold together and create something that can be seen as a feeling of collective welfare and unity, namely 'familyhood', even across national borders' (Bryceson \& Vuorela, 2002: 3). We provide an in-depth, multi-sited analysis of one transnational Sudanese family to show how resources in terms of people, finances and care are accessed over multiple locations, beyond just sending and receiving countries, through multiple persons and institutions, ranging from formal healthcare and education institutions to informal networks. All of this is carefully orchestrated in consideration of the various needs that are to be met among diverse family members over time.

This article draws on an ethnography conducted over a period of 14 months of multi-sited fieldwork with a partly matched sample of Sudanese families across the Netherlands, the UK and Sudan between 2015 and 2016. The Sudanese case is relevant for two main reasons. First, Sudanese migrants constitute a relatively new migrant group in Europe, facing different migration and receiving contexts relative to more established groups such as former so-called 'guest workers' (Grillo \& Mazzucato, 2008), which might have an impact on the way they engage in different TSP practices. Second, in past years there has been an important trend of Dutch- 
Sudanese moving to the UK (see van Liempt 2009), which makes it a relevant case for understanding the role of onward migration in TSP.

\subsection{Transnational social protection arrangements}

In the current context of increasingly mobile populations, the traditional geographically-fixed welfare systems are problematic. As a step in making welfare systems more mobile, the bilateral agreements that have emerged in recent years have enabled the portability of social benefits (such as pensions) from a receiving country to a migrants' origin country (see Holzmann \& Koettl 2011). Yet such agreements face multiple challenges and have only taken place between a very small number of countries, of which Sudan is not part (van Panhuys et al., 2017). Therefore, migrants who want to ensure their and their families' social protection face multiple challenges. Such challenges have been mainly addressed by three bodies of literature: migration and social protection, TSP and transnational care. Literature on migration and social protection tends to focus on the individual migrant's (lack of) access to formal social protection or welfare in the receiving countries in the Global North and its implications for the migrants' wellbeing- (Avato et al., 2010; Cuadra, 2012; Sabates-Wheeler, 2009). Whereas the important role of informal social protection is acknowledged in these studies, it has been mainly conceived in terms of filling the gaps of the formal system (Amuedo-Dorantes \& Pozo, 2006; Avato et al., 2010). Moreover, informal social protection is mainly addressed from a financial perspective, mostly referring to either social networks in the receiving country providing newly arrived migrants with financial help, or to the remittances migrants send to cover the needs of those back home (Sabates-Wheeler \& Waite, 2003). Social protection, thus, is defined in terms of either formal or informal support mechanisms for the migrant in the host country, largely neglecting the role of the migrants' families 'back home' as providers of services to the migrant.

Recently, literature on TSP has problematized such clear-cut distinction between the formal and informal dimensions of social protection (Bilecen and Barglowski, 2015; Serra-Mingot and Mazzucato, 2017 [Chapter 6 of this thesis]). Social protection can be defined as an 'assemblage' or interrelation between formal and informal elements, where social actors constantly negotiate and combine the use of formal and informal provisions (Bilecen \& Barglowski, 2015). Rather than filling the gap of formal social protection schemes, informal arrangements may be perceived as more viable or appropriate to cover for specific needs, especially the provision of care (ibid.). A transnational approach to migration and social protection also avoids splitting migrants' lives into disconnected areas and allows for a thorough understanding of the different social situations and relationships that migrants must confront and reconcile, both here and there (Grillo \& Mazzucato, 2008). TSP studies move the main focus away from the individual migrant in the receiving country, to include both migrants and non-migrants, considering the multiple sites and levels of 
transnational engagements across sending and receiving states (Levitt \& Jaworsky, 2007; Poeze et al., 2017). These studies have highlighted the heretofore neglected services that people 'back home' provide for migrants, especially when migrants are not entitled to access formal social protection (Mazzucato, 2011). A transnational approach, thus, allows for a more comprehensive understanding of how migrants navigate resources to receive and provide social protection, both locally and across borders.

To operationalizes the concept of TSP, Levitt and co-authors (2016) introduced the concept of 'resource environment', understood as all of the possible resources available to migrants from the four potential sources of protection (e.g., state, market, third sector and social networks) in the sending and receiving country, based on the migrants' individual characteristics, including their nation of origin and residence, their social networks, gender, race, ethnicity, religion, class and education. For the purposes of this research, TSP is thus defined as the shifting constellation of resources provided by the state, the market, the $3^{\text {rd }}$ sector (i.e., NGOs, churches, international organisations) and/or family networks to protect individuals and families against declining living standards arising from a number of basic risks and needs, such as employment, healthcare, housing, nourishment, education and social participation (de Neubourg \& Weigand, 2000; Levitt et al., 2017).

The multiple engagements within transnational family networks usually involve a mixture of formal and informal provisions, often related to the provision of care (Baldassar et al., 2007; Boccagni, 2013; Mazzucato, 2008c). The care conducted between family members living across national borders is, indeed, an integral part of TSP mechanisms, based on complex links of reciprocity and obligation that families engage in (Dankyi et al., 2017). Particularly in countries with weak or non-existent social welfare systems, such as Sudan, extended families play a key role in the protection and sustenance of families and communities in times of need or crisis (Mokomane, 2013).

Although the provision and circulation of care in its different dimensions (e.g. eldercare, childcare or healthcare) is an integral part of social protection, rarely has the literature on care been incorporated into studies of social protection and migration. Global care-chain literature (Parreñas 2001; Hochschild 2000) and recent studies on 'care circulation' have analysed the myriad of family arrangements undertaken across national borders to provide care, highlighting the circular character of care from the perspective of intra-familial duties and solidarities, which fluctuate over the life course within transnational family networks subject to the political, cultural and socioeconomic contexts of both sending and receiving countries (Baldassar \& Merla, 2014; Mazzucato, 2008c; Poeze et al., 2017). Yet most of the literature on transnational care gravitates around the nuclear family, and more specifically around the parent-child dyad.

In this article, we draw on these three bodies of literature on migration and social protection, TSP and transnational care, to explain what kind of considerations 
are behind the decisions made by a Sudanese transnational family to move people and resources around the globe to cover for certain social protection needs. We use a TSP perspective to expand our unit of analysis from the individual migrant, as commonly done in social protection literature, to an extended family network. This approach allows us to understand how transnational families enter in different social protection arrangements beyond sending and receiving states only. Additionally, our analysis, expands beyond the financial aspects of social protection for migrants by incorporating the literature of care as an intergenerational and reciprocal process underlying the social protection arrangements of transnational family networks.

\subsection{Data and methods}

This article is part of a bigger research project, based on 14 months of ethnographic fieldwork with Sudanese migrants in the Netherlands and the UK and their families back in Sudan conducted during 2015-16. Multi-sited research was conducted using in-depth biographic interviews, informal conversations and observations with 21 and 22 respondents in the Netherlands and the UK, respectively, and with 19 of the migrants' matched family members (mostly parents and siblings) in Sudan. Several respondents in the UK had moved from the Netherlands, whereby, in some cases, matched samples spanned across the Netherlands, the UK and Sudan, allowing for a more complete view of how migrants navigate different social protection systems. Using a matched-sample methodology is especially suited to study social protection for transnational families, since it allows for sampling individuals who are connected across different sites (Mazzucato, 2009a).

Research participants were recruited through multiple gatekeepers and snowball sampling with different starting points. The sample included roughly half men and half women of ages varying from early 20 s to their late $50 \mathrm{~s}$, including single men, married couples and divorced parents with children. Although our overall sample included refugees and (un)documented migrants, in this article we only focused on people with documented status. The educational background of the respondents varied, although the majority had a university degree from Sudan. This can be explained because the Sudanese middle class was the main target of the Islamist regime after the coup, as the civil service throughout the country was purged and professionals were massively dismissed (Abusabib, 2007).

Interviews and observations were conducted by the first author in English, Arabic or German, in familiar environments for the respondents, mostly in their homes. Interviews lasted between two and four hours, while observations ranged in duration, from attending specific events with the participants, to spending a full week living with them in their homes. At the request of the respondents, most interviews were recorded through note-taking. The in-depth interviews and observations allowed us to construct the life histories of the different family members, focusing on the moments when some social protection needs occurred. We could then place 
individual experiences and attitudes within the extended family and capture a living picture of family constellations and relations across time and space.

This article is based on the TSP arrangements of one Sudanese extended family, whose members are spread across multiple locations. We draw on the 'modified extended family' definition, understood as 'a social unit in which parents, children and other relatives do not necessarily live under one roof' (Medora 2007, 164). Despite the geographical distance, family members keep in constant contact with each other and exchange practical assistance in a variety of tasks, such as: financial support, child-rearing support, or attendance at life-cycle events, which continue to be obligations and integral components of the modified extended family (Litwak, 1959; Medora, 2007). The reason why we chose this family is because its composition, the geographical situation of its members - in the Netherlands, the UK, Sudan and elsewhere-and their management of different social protection events allowed us to deeply investigate the variety of elements that enter into people's decision-making surrounding migration and social protection. All these elements were encountered-in varying degrees, forms and combinations-in the other 43 Sudanese transnational families in this research. Because of the good relationship we were able to establish with different members of this family, spread over the three countries, we could obtain particularly rich material on their decision-making and how these differed across members. It is beyond the scope of this paper to explain the prevalence of such mechanisms but rather to uncover and provide a rich account on the wide array of mechanisms at play in decision-making around family welfare.

To visualise the different family configurations, trajectories and arrangements for specific social protection needs at specific times in the family's life-cycle, we adapt existing visualisation tools in the fields of demography and time geography (Antoine, Bry, \& Diouf, 1987; Hagerstrand, 1970). Such analytical tools have recently been used by migration scholars (Carling, 2012) to present the migration histories of different family members in specific turning points at particular moments in time.

\subsection{A transnational family's resource environment}

Noor and Ibrahim are part of an extended Sudanese family (Figure 18). Here, we show how they have dealt with different social protection needs across borders over time. Decisions concerning social protection arrangements entail multiple considerations that involve a combination of formal and informal resources, where the mobility and the geographical distribution of individuals play a crucial role. After a brief introduction of the family and their migration background, this section is structured around three specific social protection arrangements. We analyse how resources in terms of people, finances and care are accessed over multiple locations, and through multiple persons and institutions, spanning formal and informal arrangements. Each arrangement is represented with a graph (Figure 19, Figure 20, and Figure 21), which illustrates the movements of family members to assist different 
people on specific moments. Only those directly involved in the provision or reception of support are illustrated in colour to facilitate the visualisation of the graph. Dotted lines represent the children.

Noor (42) arrived in the Netherlands with her mother, Aziza, seeking asylum in 1999, after all her siblings had long left Sudan, also as refugees. Ibrahim (43) also arrived in the Netherlands as an asylum seeker around the same time. They both met and married in the asylum-seeking camp in the Netherlands, where they waited around eight years to obtain their refugee status. After obtaining the status, Ibrahim, Noor and her mother moved to social housing and began receiving social assistance. However, as soon as Ibrahim validated his university degree and found a job, they stopped receiving social assistance from the Dutch state.

Figure 18 - Noor's and Ibrahim's family constellations at the time of the research (2015-2017).

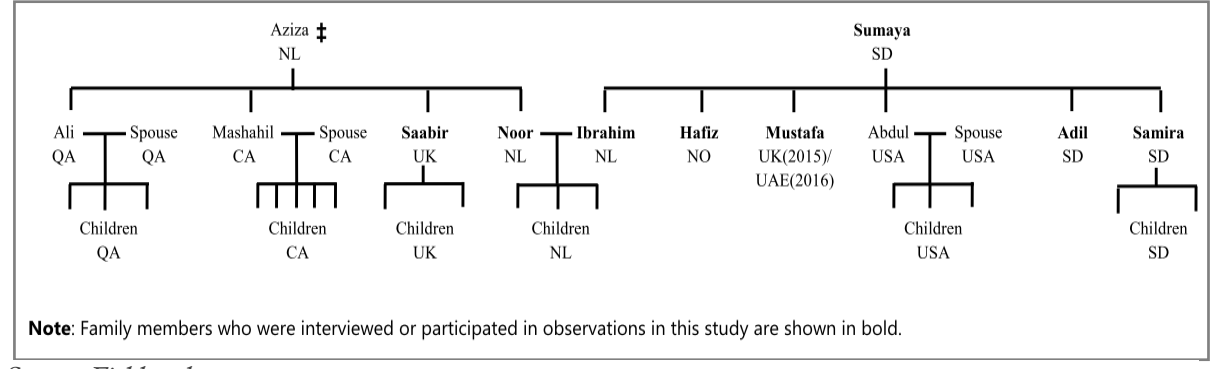

Source: Fieldwork

Like many Sudanese, Noor and Ibrahim come from big families with whom they keep close contact. Noor is the youngest of four siblings: Saabir, a professional artist, currently working as part-time security staff in the UK; Ali, a professor in Qatar (QA); and Mashahil, a full-time mother of five in Canada (CA). Ibrahim is the oldest of six siblings: Abdul, a doctor in the USA; Hafiz, a recently recognised refugee in Norway (NO), now doing a master's degree; Mustafa, a UK-trained engineer currently working in the United Arab Emirates (UAE); and Samira, a young widow with two children, living in Sudan (SD) with their mother, Sumaya, and teenage brother, Adil. 


\section{Mobilising family members to cover for simultaneous care needs across the globe}

After having spent 11 years in the Netherlands and having the Dutch citizenship, in 2010 Noor and Ibrahim decided to move to the UK as EU migrants with their two children (Figure 19). Like many Sudanese, Noor and Ibrahim favoured the British educational system over the Dutch, due to a perception of being discriminated against. In the Netherlands, depending on the end-of-primary-education test results and especially on the teacher's advice, students are transferred into different types of secondary education (OECD, 2016). Research has documented that such advice often underestimates and discriminates migrant students (Rijksoverheid, 2016). In Sudan, providing one's children with tertiary education is not only a source of prestige for the family, but also a source of insurance rooted in the principle of intergenerational reciprocity, in that highly educated children are expected to have better employment opportunities, with which to provide for their parents and other elderly relatives in the future (Gasim, 2010). Additionally, studying at British universities is highly regarded and has a long-established tradition in Sudan. Up to the late 1980s, many northern Sudanese arriving in the UK were professionals, business people or academics (IOM, 2006). Acquiring a British education often translated into securing a highly-paying job in Sudan or the Gulf, which allowed migrants to build a house and provide for their extended family needs in Sudan.

Figure 19 - Trajectories of different family members to cover for simultaneous needs across the globe (2008-2015).

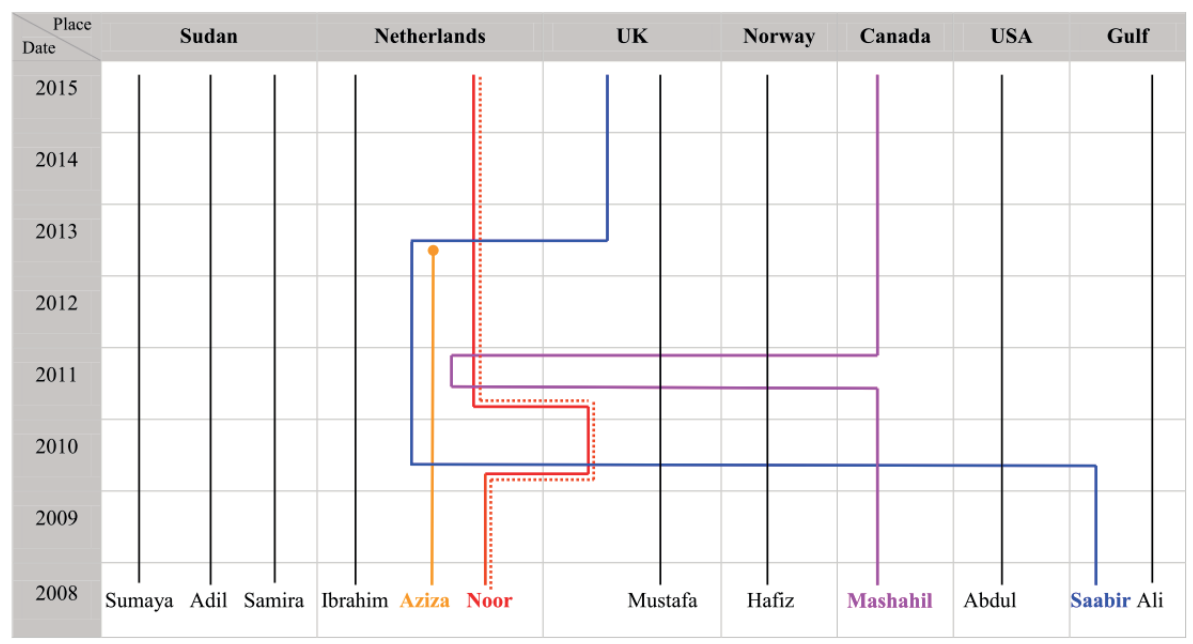

Source: Fieldwork

Noor and her children went to the UK first while Ibrahim remained in the Netherlands to finalise his formal registration as a doctor. Although Ibrahim held a medical degree from a university in Eastern Europe, he needed several years to validate his degree and gain work experience in the Netherlands. Noor's mother, 
Aziza, who was old and too sick to travel at the time, remained in the Netherlands with Ibrahim. Ibrahim's professional obligations, however, prevented him from taking care of Aziza. Although as a Dutch citizen Aziza was entitled to stateprovided support - e.g. care worker - the family preferred that Aziza's son Saabir, who was unemployed, move in and take care of her. While providing for elderly parents, both in terms of money and care, is deeply rooted in the Sudanese society, this informal arrangement was also seen as more beneficial, in that at the time Aziza needed care, Saabir was unemployed in the Gulf. Saabir had arrived in Germany as an asylum seeker in 1990. In 2008, Saabir, his wife and children became 'onward movers' and left Germany for the UK to give their children a better education (Figure 20 ). Once his wife and children settled, Saabir moved to the Gulf to find a better paid job than in the UK. However, in 2010, after two years of unsuccessful job-hunting in the Gulf and in view of his mother's needs, his moving to the Netherlands to take care of Aziza, while Noor settled in the UK and Ibrahim finished his medical registration, seemed to be the best solution for the family. This arrangement not only benefitted Noor and Ibrahim, but also put an end to Saabir's unemployment and costly living expenses in the Gulf and allowed him to visit his wife and children in the UK more regularly.

When Noor and her children arrived in the UK, they moved in with her brother-in-law, Mustafa, who was studying there at the time. Mustafa had been born in England while both his parents studied there in the 1970s. Nevertheless, Mustafa had only returned to the UK for his university studies. Soon after arriving in the UK, Noor became pregnant with her third child. Like her previous pregnancies, this one was also complicated. Though in the Netherlands she had been kept under close observation and given the necessary treatment, in the UK they had sent her home, telling her 'it was normal'. Despite the Dutch medical reports, treatment in the UK did not live up to Noor's expectations, which led her to return to the Netherlands in a much-deteriorated health condition. Soon after returning to the Netherlands and giving birth, Noor's sister, Mashahil, came from Canada to help her and the newborn for a couple of months, while Saabir continued to take care of Aziza until she died in 2013.

Looking at the whole family network, instead of the single individual migrant, allows us to understand the basis on which certain decisions are taken and how resources are balanced. Noor's moving to the UK with her children is intertwined with other social protection events that occur simultaneously to different people in different places and function thanks to a combination of formal and informal mechanisms. Moving to the UK to provide her children with a better education in turn results in a new social protection gap, that is, leaving her ailing mother unattended in the Netherlands. In this situation, it is Saabir's migration to the Netherlands that actually allows Noor to move to the UK, for which she also is supported by the accommodation provided by her brother-in-law, Mustafa. If we take only Noor's account of this event, we will not be able to fully understand the reasons 
why her brother, Saabir came to take care of Aziza. However, when we consider Saabir's personal story in this puzzle, we see how his coming to the Netherlands not only served the purpose of caring for their mother, but also of putting an end to his unemployment, while allowing him to be closer to his children in the UK. Moreover, in Sudan, taking care of elderly parents is a deeply rooted type of intergenerational reciprocity, whereby care and support are exchanged between and across family generations, with the type, timing, direction, recipient, and provider of care changing over the life course (Baldassar et al., 2007). Such relations are characterised by a pattern of 'generalized reciprocity', whereby supporting one person in a particular moment in time, may result in future reciprocation of a non-predefined order, either for oneself or others in one's network (Sahlins, 1974). Therefore, whereas access to formal social support would have been possible, it was preferred that Aziza's son, Saabir, move in from the Gulf to take care of her and fulfil the intergenerational contract.

Noor's return to the Netherlands for healthcare reasons also involved her sister moving temporarily from Canada. As a Dutch citizen, Noor was entitled to kraamzorg (postpartum care in Dutch), whereby a maternity nurse comes to the new mother's home in the initial ten days after birth-giving. However, following the Sudanese tradition of female relatives providing care in these circumstances, it was preferred that this type of care was provided by her sister instead, even though she lived thousands of miles away. As most informal support, this arrangement was more flexible and versatile than the formal postpartum care. Indeed, Mashahil not only tended to Noor and the newly born, but also helped Noor with her other children and house chores, and cared for their mother, which allowed Saabir to travel to the UK to visit his children. Of all the social protection arrangements this family engaged with in this particular moment, only one (e.g. returning to the Netherlands for better healthcare) is related to formal state-provided provisions. Moreover, even in this case, additional support is needed from other family members, whereby individual mobility - be it in terms of having the necessary time, money and legal status - is crucial in the provision of intertwined social protection needs for different family members. In this dynamic, thus, formal social protection becomes subsumed within the norm of generalized reciprocity within the extended family network, that is, it becomes one of the many resources that can be mobilised to cover certain needs.

\section{Mobile people navigating immobile welfare systems: investing in flexible, mobile and reliable pensions.}

As the case above showed, moving to the UK for the children's education was hindered by more pressing and serious health issues, which led Noor to return to the Netherlands. In the following case, however, we show how the children's education is prioritized, not only over the current needs of other individuals, but also over accessing a more generous welfare system elsewhere. This was the case of Saabir, who, after his mother's death in the Netherlands, moved to the UK with his children 
and then wife. Saabir's family had moved to the UK from Germany to give their children a better education and future chances. Soon thereafter, however, Saabir's marriage broke down. Since his children stayed with his ex-wife, Saabir moved to a social housing small single flat (his current place). Shortly after their divorce, however, Saabir's ex-wife returned to Germany, while his children eventually decided to move in with him in the UK. For the last five years, the three of them had been living in a tiny one-bedroom flat. Besides the absolute lack of privacy and difficulties of living in such a small space with two teenagers, the lack of space prevented Saabir from pursuing his career as an artist. Since he had not been successful in finding a job in the UK as an artist, Saabir had found a part-time job as a security guard, so that he could use his free time to paint at home and then sell his work as a freelancer. However, the lack of space and his children's needs to study and carry out school projects at home had prevented him from doing so.

As Saabir told me, this living arrangement had just come to him unexpectedly.

Figure 20 - Trajectories of Saabir's nuclear family to deal with unemployment, healthcare and education needs (2006-2015).

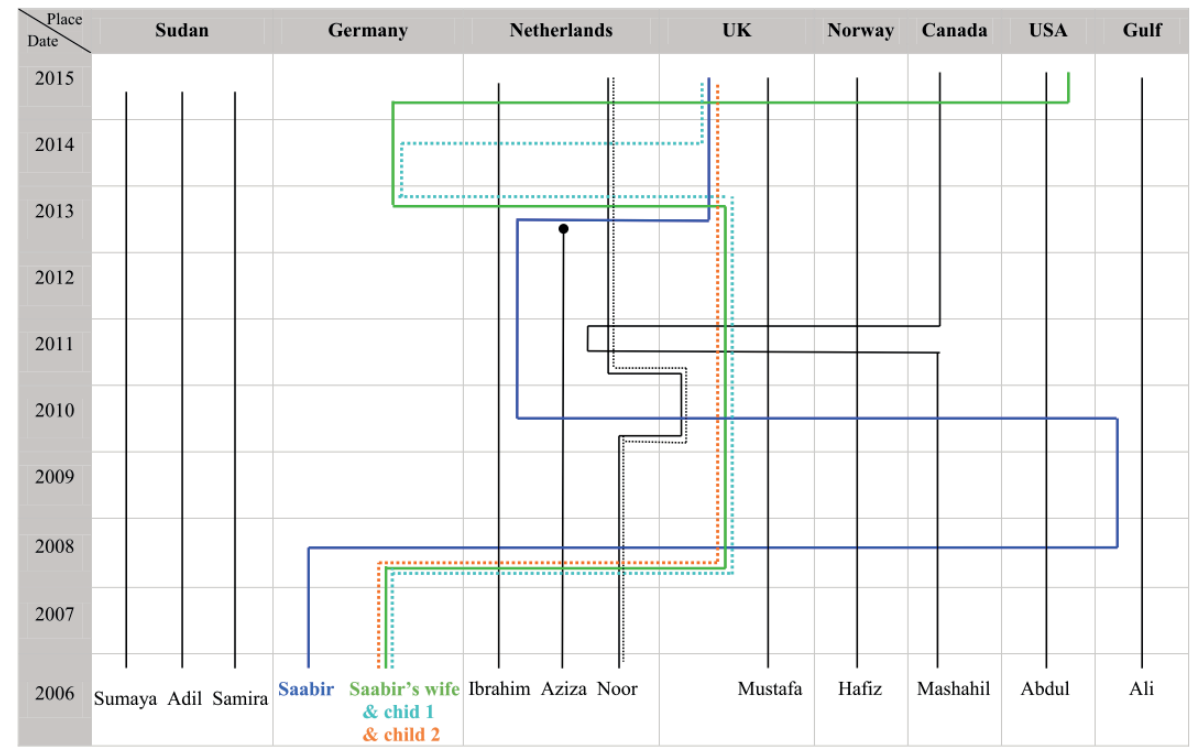

Source: Fieldwork

He described it as a burden he could not escape, and that now he could do nothing but cope with it for the wellbeing and future of his children. Saabir had recently got a job offer from his former employer in Germany, where he was keen to return, not only because of the job opportunities, but also because, according to him, the welfare system was much better, especially healthcare. Having suffered torture in Sudan, Saabir's foot needed regular treatment. In Germany appointments and treatments were promptly provided, whereas in the UK Saabir often had to wait for weeks. 
However, his children preferred to stay in the UK, where they were already planning their college studies.

Despite having the possibility and the right to move back to Germany and make use of its better welfare system, Saabir prioritized his children's education over his personal needs-working as an artist and having better healthcare-and their current living standards. After all, their children could have also accessed good and free education in Germany, while enjoying better housing. Moreover, moving to Germany and working for his former employer would have resulted in a better financial situation now and in the future, in that he would have the chance to build a better pension (OECD, 2017).

The issue of pensions is particularly relevant. For most of our respondents, pensions, understood as a welfare-state-provided benefit, did not seem to be a priority. This can be explained through two main mechanisms. On the one hand, in Sudan pensions are rarely seen as a state-provided benefit, not only because it is almost non-existent, but also because the amounts provided are extremely low. Pensions are mostly envisaged in terms of providing one's children with the best possible formal education in expectation of elder care in the future. These social protection arrangements are, thus, embedded in the idea of intergenerational reciprocity. As a Sudanese doctor in the UK told me, 'This is my insurance. I'm investing in them (his children) now.' The resources needed to cover for certain social protection needs must be analysed beyond the Western welfare-state models, bearing also in mind the context of the sending country and its social protection institutions.

On the other hand-just as the case of Noor and Ibrahim showed-many refugees spend years waiting in the asylum process to obtain the refugee status. During this time, they are not allowed to work or study. Once the status is given, they must go through integration and re-training courses to validate their studies, if they have any, or start from scratch. This long process results in people in their 40s applying for a job for the first time in a highly competitive market in which, even if they manage to find a job, their built-up pension will most likely be rather low. In addition to this, Noor, Ibrahim and Saabir, as well as most of our respondents, expressed their desire of not wanting to grow old here, whereby the expected returns of the welfare state in terms of pensions greatly lose their meaning. Migrants for whom mobility is part of their lives and future plans might face insecurities when it comes to securing their formal pensions through geographically-fixed institutions. Thus, it might be safer to invest in assets that will stay, such as their children, who are, in turn, the most common way of organizing old-age care in Sudan.

\section{Coordinating financial and professional resources around the globe to cover for healthcare needs.}

To cover for Noor, Aziza and Saabir's needs, the mobility of different family members was crucial to access formal and informal social protection. None of the people involved in the different arrangements faced any migration-status related 
issues that prevented them to move or stay in a specific place. In the case we present now, however, the mobility of a family member to access healthcare treatment is restricted by current migration regulations and high financial costs. In these cases, the mobility of other resources - such as knowledge or professional networksbecomes crucial (Figure 21).

In one of my visits to Noor and Ibrahim in the Netherlands, when I asked them the customary courtesy questions about their families' wellbeing, Ibrahim told me, matter-of-factly, that everyone was fine, especially their mother, whom they had recently sent to India for a complicated spine operation. Ibrahim explained to me how for several months he and his siblings had been looking for a solution for Sumaya's delicate health condition, which could not be treated in Sudan. Bringing her to Europe or the US, where his brother Abdul lived and worked as a doctor, was not only complicated but also prohibitively expensive. This was coupled by the negative experience Ibrahim went through in 2013, when his father was operated in the US. At that time, Abdul had been able to include their father in his own insurance, which had not been possible for Sumaya. However, when Ibrahim's father's health deteriorated in the post-operative period, Ibrahim's visa application, to visit his father in the US before he died, was rejected. To avoid a similar experience and the high financial costs, Ibrahim and his siblings had been assessing other viable options. Eventually, through Abdul's professional network, they contacted one of his former colleagues from India, a country where their mother could easily travel to and where they could afford the associated medical costs. While Ibrahim and Abdul provided around 12,000\$US for the operation in India, Mustafa - who had finished his degree in the UK and was still unemployed - was, at that moment, the only one available to travel to Sudan, sort all the necessary paperwork, accompany Sumaya and provide all the hands-on care during the process. Only after the operation and recovery in India, Mustafa accompanied Sumaya back to Sudan with his other siblings, Samira and Adil, and then he moved to Qatar to find a job, which he had not managed to do in the UK. 
Figure 21 - Trajectories and mobilisation of support among family members to facilitate Sumaya's healthcare (2012-2017).

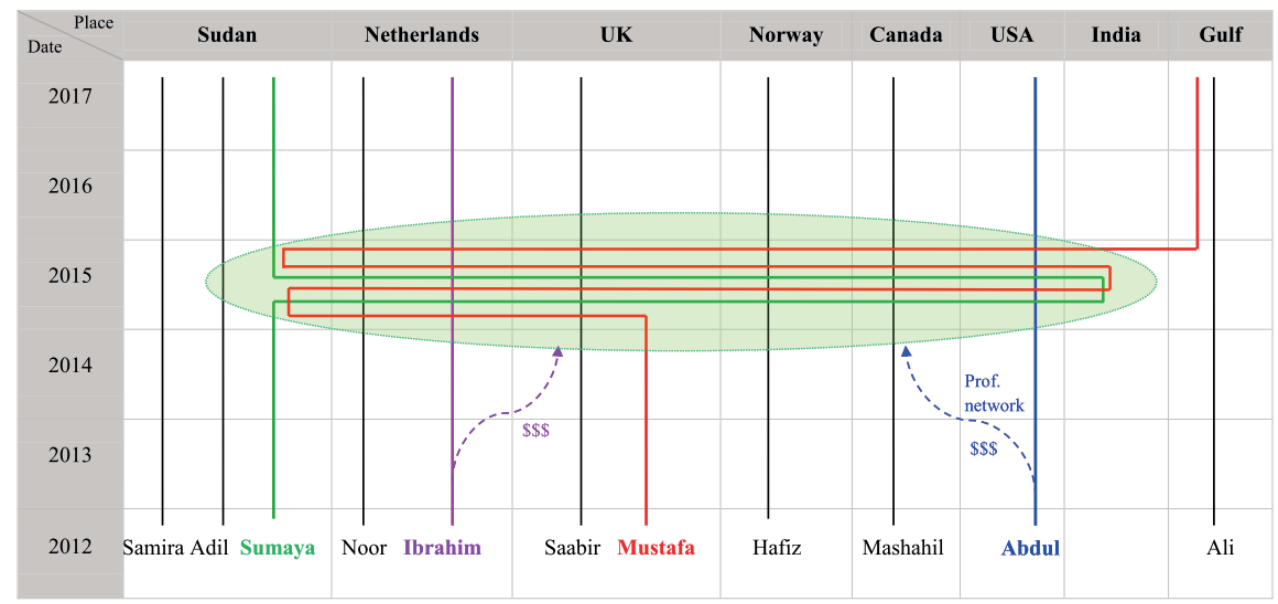

Source: Fieldwork

A couple of months later, I visited Sumaya in Sudan. Despite being nearly 70, she was an energetic lady with the strong character of a woman used to run a Sudanese household on her own. She lived with her teenage son, Adil, and her 30year daughter Samira, a widow with her two little children, in an impressive twostorey house in Omdurman. Both Adil and Samira suffered slightly hindering physical disabilities which prevented them from work and made them highly dependent on Sumaya, who also managed the household finances, based on the small income from her late husband's business and her sons' remittances. Sumaya was also the cornerstone in keeping extended family relations alive, which in turn played a vital role in sustaining Sumaya and her children's wellbeing. Regular meetings at each other's houses - when money for emergencies was circulated - or free school support for Samira's children provided by some aunts working as teachers, were some of the tasks that Sumaya was constantly arranging. This support given to Sumaya is clearly embedded in the norm of generalised reciprocity, in that, ensuring Sumaya's wellbeing results in the wellbeing of their younger siblings, Samira and Adil, and the nurturing of the family and social networks in Sudan.

Although Sumaya was almost recovered from the operation, she still experienced pain that had to be checked again by the doctor. In this occasion, however, rather than travelling to India again, she told me how it was actually her Indian doctor who was soon going to fly to Sudan to follow up on his several patients he had operated in India. Moreover, it was though this event that they had started to bring medicine from India (of better quality than in Sudan) for Adil's condition and Samira's diabetes, since doing it from Europe is not allowed.

Like in the previous cases, Sumaya's need of healthcare is covered by the support provided by different family members in combination with other formal 
resources, beyond sending and receiving nation-states. However, in Sumaya's case, her physical mobility was limited by visa regulations and financial costs, whereby having an operation in Europe or the US, where her children live and could have provided hands-on care more easily, becomes problematic. At the same time, besides the hands-on care provided by Mustafa, Sumaya's healthcare need is covered by the coordinated mobilisation of other resources - money and professional network - put together by different family members across multiple locations. Therefore, to have access to different resources to cover for the family's social protection, the strategic physical, economical, legal and professional position of different family members becomes crucial.

Western social security systems are often devised to cover for their sedentary citizens. While migrants might be fully covered by the welfare regime of their receiving country, they remain responsible for their family members abroad, who fall outside the umbrella to the welfare system. Thus, despite Ibrahim's contributions to the Dutch welfare system - in terms of work-related taxes and health insurancewhen his mother became ill, access to the Dutch healthcare was not possible. Therefore, covering for the social protection needs of family members abroad requires sometimes a careful coordination of resources besides care, namely money, knowledge and a wide professional network.

\subsection{Conclusion}

This article has investigated the multiple considerations underlying the decisions of migrants and their families to move (or not) to certain places, to address social protection needs. To better understand the role that social protection plays in shaping peoples' decisions to move, we have analysed the complex mechanisms guiding the decisions of one transnational Sudanese transnational family to access and circulate resources to cover for different needs. Such complex mechanisms are rendered visible through a transnational perspective, whereby we have expanded our unit of analysis from the individual migrant, as commonly done in social protection literature, to an extended family network scattered across different countries. In doing so, we have shown the intertwined character of different social protection needs, and the crucial role of mobility and the strategic geographical distribution of individuals in the orchestration of complex social protection arrangements. An in-depth multi-sited analysis has shown how decisions concerning social protection arrangements for different family members entail accessing and organising resources (in terms of people, finances and care) over multiple locations, through multiple persons and institutions.

Our findings contribute to the literature on TSP in three ways. First, analysing mobility from the perspective of TSP allows us to move away from nation-states as the main 'containers of everything'. The ways in which Noor and Ibrahim's family deal with different crises and needs over the years, questions the idea that the 
'receiving' nation-state in general, and the specific welfare state in particular, are the main triggers of mobility to access social protection. Recent research on social protection for mobile populations has claimed that the lack of formal social protection in a first country of asylum can prompt refugees to engage in onward movement (Long \& Sabates-Wheeler, 2017). Our analysis, however, shows that it is not the lack of formal social protection in the first host country to trigger onward movements, but the lack of possibilities for people to arrange their own and their families' social protection when such families are extended and located in multiple nation states. This is not to say that formal state-provided provisions are unimportant. On the contrary, people do move to countries where specific resources are deemed better for specific needs, such as education in the UK, healthcare in the Netherlands or possibilities for family-provided care. As the analysis has shown, decisions to move are not based on the fact that education, healthcare or home care are not available in the first country, but on the fact that a specific type of education and care are deemed better in the family's understanding of social protection, which is strongly embedded in practices of generalised reciprocity. Looking at migrants' and their families' access to social protection from the extended-family perspective shows that migrants' decisions to move or stay in a specific location are not based on the nation-state and its welfare system per se, but on their and their families' needs and how best to fulfil them, formally or informally, now and in the future. To do so, migrants move to create the largest possible resource environment, including the access and provision of care not only for themselves, but also for their families abroad. These movements do not necessarily mean moving to a country with a more generous welfare state, but to a country with the preferred resources, such as care, education or specific medical treatments that are deemed necessary and have priority at a particular point in time from the perspective of the needs of the extended family. In this dynamic, welfare systems become subsumed within the norm of generalized reciprocity within extended family networks, that is, they become one of the many resources that can be mobilised to provide reciprocity.

Moreover, our case has shown how people with an extensive history of mobility or with a highly geographically-scattered family network especially face insecurities when it comes to securing their social security benefits, like formal pensions, in that, in moving to another country, such social security rights might cease to exist. Indeed, studies on the portability of social security rights - especially pensions and healthcare-from the migrants' host country to their home country show that only $23 \%$ of international migrants benefit from these bilateral social security arrangements (Holzmann, 2016: 1). Moreover, from these 23\%, the vast majority ( $86 \%$ ) are migrants from high-income countries living in other high-income countries (ibid.). Sudan is not part of any of these, whereby formal social security rights cease to exist upon return. Therefore, it might be safer to invest in people (e.g. children) and other assets that can be easily accessed and circulated (e.g. education) across time and space. 
A second way that our findings contribute to the TSP literature is that to understand the social protection arrangements of migrants and their families, it is crucial to understand the normative context of the sending country and its social protection institutions. To date, most studies addressing transnational social protection for migrants (Bilecen \& Barglowski, 2015; Faist, 2013) as well as those studies addressing onward movements (Ahrens et al., 2016) have focused on the migrants in the receiving countries, and ignored the context of the sending country. This is an important gap that this article has addressed, because in countries without a formal and comprehensive welfare system, social protection is envisaged in terms of investing on reciprocal relations and long-lasting, versatile assets. Having children, giving them a good education, building a house, or cultivating a strong and diverse social network are some of the main sources of social protection, deeply rooted in norms of intergenerational and generalised reciprocity (Dankyi et al., 2017; Sahlins, 1974), whereby by supporting others, people (expect to) ensure their protection in times of need.

In contrast to the classical Western clear-cut compartmentalisation of social protection domains, in these informal social protection systems, different domains are closely intertwined. In the case of transnational families, where elements from formal welfare systems combine with informal systems of support and reciprocity, there is also a high degree of intertwinedness between the different domains. It is precisely such intertwinedness that leads people to prioritize specific needs over others, in this case, investing on the children's education as an old-age pension that formal provisions may not be able to cover. Thus, despite the availability of formal social protection institutions, the access and circulation of formal and informal resources within transnational families can be explained in the practice of reciprocity and norms of social exchange, and not by welfare shopping, as some studies and most public debates claim. However, this sort of intergenerational contract (e.g. investing in the children as a form of old-age insurance), raises the question of whether the children of migrants, born and raised in the context of Western welfare systems, will provide for their aging parents in the future (Mazzucato, 2008c).

Third, our analysis has shown the importance of bringing the literature of care in conversation with studies of social protection. Although the provision of care in transnational families is an important component of the social protection arrangements, transnational care has been mostly theorised within the field of 'family studies' (e.g. Baldassar \& Merla, 2014). Moreover, studies highlighting the importance of informal social protection arrangements (Sabates-Wheeler \& Waite, 2003) have mostly focused on financial aspects, disregarding the care-work. This article has shown that the care conducted within transnational families is an integral part of a system of TSP. Even when access to formal care is possible, socio-cultural norms about who should provide care and how, shape the way in which resources are accessed and circulated. 
Finally, our analysis points to an addition to the concept of 'resource environments' as recently theorised by Levitt et al. (2017) in two ways. Until now the concept has been used to refer to the resources available to individual migrants in their sending and/or receiving countries (Levitt et al., 2017). Our case shows that the social protection needs of transnational families can occur simultaneously across multiple locations, beyond sending and receiving states. In these circumstances, a range of formal and informal resources must be accessible across different locations, from where they can be carefully circulated and coordinated-often ranging across more than just sending and receiving states. , Additionally, our case indicates that while certain formal state-provided resources might be available for individual migrants, they might not be the preferred option for the social protection of the family as a whole. The availability and accessibility of resources, thus, must be analysed from the perspective of the family, not only the individual migrant.

There are several implications of our findings for future research on TSP. First, there is a need to look beyond clear-cut providers of formal and/or informal social protection for individual migrants in the receiving countries. Even when formal providers, such as the welfare state or the market, cover for a particular need, informal resources must often be mobilised to access the formal ones. In other words, the informal is necessary for the formal to happen. This has important implications for transnational families, whose members might be scattered across multiple countries, which restricts the ways in which informal support might be provided. Rather than focusing on the individual migrant here, it is necessary to take into account full family constellations to understand how resources are circulated to provide all the members with the necessary social protection. Second, future studies on TSP should consider the different forms of social protection beyond the Western welfare states, in particular, those pertaining to the sending states. Understanding how social protection is arranged in the Global South - the role of families, private market and reciprocity norms - should inform any development towards a more inclusive social protection system, where catering to a mobile population is increasingly a crucial factor. 



\section{CHAPTER 9}

\section{THE GENDERED BURDEN OF CARE- RECEIVING IN TRANSNATIONAL SOCIAL PROTECTION ARRANGEMENTS. THE CASE OF SUDANESE FAMILIES 28}

28 This article has been accepted with minor revisions for publication as: Serra-Mingot, E. (forthcoming). The gendered burden of care-receiving in transnational social protection arrangements. The case of Sudanese families. Gender, Place and Culture. 


\subsection{Introduction}

Families play a crucial role in the provision of care to different family members in need. Grandparents taking care of grandchildren, parents taking back their unemployed adult children without resources, or aging parents moving in with their children to be taken care of - these are only some examples of how care circulates within families. Especially in countries with weak or non-existent welfare systems, like Sudan, the reciprocal and multi-directional circulation of care and other resources within extended families is crucial for the family's social protection and reproduction. Nowadays, however, an increasing number of people live separated from their families across national borders, which inevitably has an impact on the intergenerational circulation of care and support. International migration does not necessarily sever the obligations and responsibilities between family members living apart (Baldassar, Baldock and Wilding 2007; Baldassar and Merla 2014). On the contrary, members of transnational families maintain a sense of 'family-hood' (Bryceson and Vuorela 2002), in that they 'retain their sense of collectivity and kinship despite being spread across multiple nations' (Baldassar et al. 2007: 13). Whereas the exchange of face-to-face care is not always possible, care work continues to be at the core of transnational families (Coe 2011; Poeze, Dankyi, and Mazzucato 2017; Baldassar, Baldock, and Wilding 2007).

For the purposes of this article, care is defined as a reciprocal, asymmetrical and multi-directional process 'that includes everything that we do to maintain, continue and repair our "world" [including] our bodies, ourselves, and our environment, all of which we seek to interweave in a complex, life-sustaining web' (Fisher and Tronto 1990: 40). As an intrinsic part of many social relationships, care goes beyond the performance of intimate personal activities for another person (e.g. bathing, dressing, or preparing meals) and it includes everyday acts of practical and emotional support, which are better described as the proactive interest of one person in the well-being of another (Wiles 2011). Moreover, care is a culturally embedded process where both caregivers and care-receivers do not just act out of self-interest but 'as the result of the particular constellation of caring relationships and institutions within which they find themselves', including families, welfare states, and the market (Tronto 1995: 142). Therefore, judgements made about care arise out of people's experiences and gendered expectations of collective institutions, such as the family (Tronto 1995).

Just like in geographically close families, transnational care relations are embedded within, produce and reproduce unequal power relations, influenced by gender, age and socio-economic status (Baldassar and Merla 2014). Transnational caregiving refers to the ways in which people care for each other across national borders. It is based on a series of relationships of obligation, trust and commitment concerned with the well-being of others, developed and negotiated over time, in line with rules of generalised reciprocity, namely, the expectation and obligation that care 
will be returned, regardless of when or in which form (Baldassar and Merla 2014; Krzyżowski and Mucha 2014; Sahlins 1965; Seltzer and Li 1996). In binding family members together in intergenerational networks of reciprocity and obligation, love and trust, transnational caregiving is simultaneously fraught with tension, contest and unequal power relations, where care is not given or received equally by all family members (Baldassar and Merla 2014).

The care conducted between family members living across national borders is an integral part of transnational social protection (TSP) mechanisms, based on links of reciprocity and obligation that families engage in (Serra-Mingot and Mazzucato, forthcoming). Yet, to date, the complexities of transnational caregiving arrangements have been predominantly addressed by transnational family scholarship. Global carechain literature (Parreñas 2001; Hochschild 2000) and recent studies on 'care circulation' (Baldassar and Merla 2014) have analysed the myriad of family arrangements undertaken across national borders to provide care, highlighting the gendered nature of care, whereby women often carry a heavier burden to provide care (Poeze, Dankyi and Mazzucato 2017; Kilkey 2014; Spitzer et al. 2003; Baldassar and Merla 2014). Yet, with a few notable exceptions (see Madianou and Miller 2011), most of these studies have focused on the emotional and financial burdens experienced by caregivers, overshadowing the implications of care-receiving.

Care, however, looks and feels different depending on the perspectives of the provider and the receiver, and it has the potential to oppress both (Bondi 2008; Dankyi, Mazzucato and Manuh 2017; Locke 2017). Although care-giving is inherently meant to be a 'good thing', receiving care can actually be experienced as oppressing and disabling, whereby care-recipients are subject to paternalistic overprotection, demand for gratitude and control, in the name of care (Bondi 2008; Russell, Bunting and Gregory 1997; Smith 2016). To date, mostly nursing and disability scholars have addressed the role of care-receivers in different face-to-face caring processes. As these studies show, care-receivers do play an active role in managing the unwanted consequences of care, in what Cynthia Russell coined as 'protective care-receiving' (1997). This gap in the literature of transnational families should be addressed because the perceptions of care may significantly differ between those delivering care and those receiving it, especially when care-work takes place across geographically distant contexts.

Drawing on ethnographic data collected during 14 months of multi-sited and partly matched-sample fieldwork with Sudanese transnational families across the Netherlands, the UK and Sudan, I investigated women's agency and strategies in navigating the reception of unsolicited care provided by family members abroad. A multi-sited matched-sample approach provides insights into the multi-actor process of care, and allows for a better understanding of the different perceptions of care (Poeze, Dankyi and Mazzucato 2017). Bringing together literature of transnational families, social protection and migration and nursing studies, this paper looks into how migrant and non-migrant female care-receivers navigate the burdensome care 
provided by their relatives abroad. Instead of focusing on the migrants as care-givers and those 'left behind' as care-receivers, or the other way around, the article concentrates on how female members of transnational families deal with the unwanted consequences of care-receiving, from the two different standpoints, namely as migrants and as non-migrants or 'left behind'. I draw on the concept of 'protective care-receiving' to analyse the agency of care-receivers in transnational caring processes, not only by manoeuvring unsolicited care through different strategies, but also by avoiding conflict and gaining control of their and their children's wellbeing.

The next section provides a comprehensive overview of transnational caring processes, focusing on the aspect of care-receiving, while addressing the cultural and gendered dimensions of care in the Sudanese context in particular. After presenting the data and methodology of this study, I introduce the three cases and analyse the different strategies in which care-receivers navigate care within the family network. The final section concludes.

\subsection{Care-receiving in transnational social protection arrangements}

The care conducted between family members living across national borders is an integral part of the TSP arrangements, based on complex links of reciprocity and obligation that families engage in (Dankyi, Mazzucato and Manuh 2017). Yet, studies of social protection and migration have rarely incorporated literature on care. The bulk of studies tends to focus on the migrant's access to formal social protection in the receiving countries and its implications for the migrants' wellbeing (see Sabates-Wheeler and Waite 2003). Although these studies acknowledge the importance of informal social protection, they mainly conceive it in terms of filling the gaps of the formal system from a financial perspective (e.g. migrants' informal remittances) (ibid.). Recently, transnational migration scholars have started to bring the literature of care into conversation with TSP literature, illustrating how sociocultural norms about who should provide care and how, shape the way in which formal and informal social protection resources are accessed and circulated (SerraMingot \& Mazzucato, forthcoming; Vivas-Romero, 2017). Rather than filling the gap of formal social protection, informal arrangements are sometimes perceived as more viable or appropriate to cover for specific needs, especially the provision of care (Bilecen and Barglowski 2015; Serra-Mingot and Mazzucato, forthcoming).

Caring practices have been mostly theorised within the field of transnational family studies (Baldassar \& Merla, 2014). Global care chain literature (HondagneuSotelo 1992; Parreñas 2001; Hochschild 2000) and recent studies on care circulation have analysed different family caring arrangements undertaken across national borders, highlighting the circular character of care, which fluctuate over the life course within transnational family networks (Baldassar \& Merla, 2014; Poeze et al., 2017). While acknowledging the shifting roles from caregivers to care-receivers and 
mapping multiple caregiving configurations (Baldassar \& Merla, 2014; Kilkey \& Merla, 2014), these studies have mostly focused on the caregiving activities, leaving aside the implications of what it means to receive care (see exceptions: Madianou and Miller 2011, Zickgraf 2017). Caregivers are thus seen as the main active actors carrying the burden of delivering care to relatively passive care-receivers. Moreover, although care work involves a series of human experiences, which also include the able-bodied (Yeates, 2005), the bulk of this research has tended to focus on caregiving activities towards dependent (grand)children or aging (grand)parents (Fresnoza-Flot 2014; Poeze and Mazzucato 2014).

Rather than being a mere 'one-way' process of someone giving face-to-face care to a dependant other, care relationships cover a wide range of activities characterised by reciprocity and interdependence, whereby caregiver and carereceiver are interconnected and care for each other in practical and emotional ways (Tronto 1993; Sevenhuijsen 1998). Especially in a transnational context where faceto-face support is not always possible, it is important to conceptualise care as an ongoing process that involves not only taking the needs of others as the basis for action, but also evaluating the extent to which the care provided meets the actual needs (Tronto 1995; Fisher and Tronto 1990). Indeed, care is a process made up of four intertwined phases: 'caring about' or recognizing a need for care; 'taking care of' or assuming the responsibility to respond to that specific need; 'care-giving' or the actual physical work of providing care; and 'care-receiving' or the responsiveness or evaluation of how well the care provided has met the caring need (Fisher \& Tronto, 1990).

Although care is commonly meant to be a 'good thing', receiving care may actually be experienced as oppressing, whereby care-recipients are subject to overprotection and control (Bondi, 2008; Smith, 2016). Nursing and disability scholars have shown that giving and receiving care is often instilled with dependence, revealing a certain degree of acceptance of the role of being more or less capable (Russell, Bunting and Gregory 1997; Shakespeare 2000; Wood 1991; Watson et al. 2004). Inextricably bound up with human vulnerabilities and the connections thereby, caring relationships are emotionally complex and they reflect experiences of power dynamics (Bondi, 2008; Locke, 2017). To some extent, conflict is unavoidable between caregivers and care-receivers because the definition of 'need' might not equally satisfy both parties. Agreeing on what 'need' means becomes more difficult in relationships with bigger differences in power (such as gender relations), especially when such relationships take place across culturally and geographically distant places. Perceptions of needs may be wrong, and even if they are correct, '[c]arereceivers might have different ideas about their needs [and] may want to direct, rather than simply be passive recipients of caregiving' (Tronto 1993:109).

Nursing and disability studies have shown that care-receivers do play an active role in managing the care they receive, protecting themselves and others against the unwanted consequences of care. Cynthia Russell coined this process as 'protective 
care-receiving', defined as the efforts of the care-receiver 'to defend her/himself from problems associated with receiving care and shielding others from difficulties they could experience as caregivers' (Russell 1993: 184). In their study, Russell and colleagues show how, through different strategies (e.g. cancelling appointments, controlling one's medical treatments or educating themselves about treatments), care-receivers actively shape the caregiving process and protect themselves or others from the unwanted consequences of care, while maintaining a certain degree of autonomy and control over care interactions (Russell 1997). Drawing on the notion of 'protective care receiving', the cases presented in this article illustrate how carereceivers in different contexts navigate the reception of care provided by relatives abroad. In doing so, they are not only protecting themselves, but also avoiding conflict with their extended families, who are the main providers of social protection in the Sudanese context.

\subsubsection{Care as a culturally embedded practice: Women's bodies and social protection in Sudan}

As a socio-culturally embedded practice, care cannot be understood in the abstract. Care depends on cultural notions of gender roles relating to rights and obligations to give and receive care, whereby men and women are expected to behave according to the appropriate gender roles prevalent in a specific society (Nguyen, Zavoretti and Tronto 2017; Mazzucato and Schans 2011). Therefore, in analysing the lived experiences of those giving and receiving care, it is crucial to understand the role of context, where structures and power-relations impact the difficult moral decisions and the practical tasks of care (Barnes, 2012).

Particularly in countries with weak social-welfare systems, such as Sudan, informal networks of support, especially extended families play a key role in the sustenance of society and the provision of material, social and emotional support in times of need or crisis (e.g. unemployment, sickness or old-age) (Mokomane, 2013). Research conducted with Sudanese families showed that the individual perception of the family is that of an entity of 'respect and understanding following a common interest, which is the well-being and status of the family' (Schultz et al. 2008: 5). At the same time, however, each individual family member is responsible for protecting and sustaining the family in socially and culturally specific ways (Mokomane, 2013).

Sudan can be described as a patriarchal society, whereby different social institutions and practices institutionalise the physical, social and economic power of men over women and children in the family. Especially since the introduction of the Sharia Law in 1983, religion has increasingly shaped gender norms and defined the role of men and women in society. Women are mainly identified with their reproductive roles, namely childbearing, childrearing and nurturing. The ideal Sudanese woman, thus, should remain at home to take care of herself, her children, her home, her husband and her family's reputation (Oldfield-Hayes, 1975; Ouis, 2009). Male family membersare traditionally expected to be the main breadwinners 
and actively protect the honour and dignity of their families, which implies the control of other family members' behaviour, mostly women and children (Nageeb, 2004; Schlytter \& Linell, 2010; Smith, 2016). In patriarchal societies, a woman's virtue is crucial to the honour of her family, especially to the men responsible for her (Cindoglu, 1997). Although with some and increasing exceptions, women's lives develop under a constant male guardianship. Before marriage, women are legally under the control and care of their fathers and brothers. Even after marriage, when women also become accountable to their husbands, their immediate male kin retain moral responsibility for their welfare and the right to allocate the woman's reproductive potential (Boddy, 1989). These men thus share the responsibility to protect women and the consequences of whatever happens to her (Schneider, 1971). This is why controlling family members can be understood as an act of care provided for the sake of the individual and the group (Smith, 2016).

In traditional kinship societies, with weak welfare states and where many economic activities are based on trust, keeping the family honour has important socioeconomic and political implications for families' social protection. A family maintaining strict control over their women benefits from a good reputation in the community, which has economic implications (Cindoglu, 1997; Ouis, 2009). In these contexts, honour has the economic and material functions of maintaining the wealth within the family. Indeed, when economic capital is missing, honour can also be seen as symbolic or social capital, understood as 'the advantage created by a person's location in a structure of relationships and implies status and connections in social networks' (Ouis 2009: 454).

In the cases presented here, care practices must be understood within this specific context, whereby the lack of a strong welfare state is filled by the family. Drawing on literature on migration and social protection, transnational caregiving, and nursing and disability studies, this article analyses how female care-receivers situated in different contexts manoeuvre the reception of care in different TSP arrangements. In interpreting the dynamics of caring relationships as a crucial element in the social protection and reproduction of transnational families, the article points to a series of power imbalances related to aspects of gender, age and socioeconomic status of the actors involved.

\subsection{Data and methods}

Conducting transnational research comes with the challenge of having to deal with relationships between people living in separate geographical realms. A multi-sited matched-sample approach allows the researcher to overcome this issue by collecting information from both sides - the migrants and their families back home-, which provides invaluable insights about transnational family relations (Mazzucato, 2009a). By hearing the two sides of the story, I could understand the position of the 
migrants and those left behind in the handling of complex family relations in the provision of social protection (especially care), or the inability to do so.

For many respondents, revealing family-related information was highly sensitive, whereby I had to invest long periods of time to build trust. Two main aspects related to my positionality, vis a vis my respondents', facilitated access to the migrants and their families. First, as a young female researcher, I was perceived as 'harmelss', which facilitated accessibility to the migrants' and their families' homes in Sudan - often dominated by women. Second, the fact that I spoke Arabic and had studied in a female University in Sudan-where many respondents had a relative studying-gave me a commonality with my respondents that created a closer relationship.

Conducting multi-sited matched-sample research involved several ethical considerations. Often family members provided me information that was unknown to other relatives. Managing this information without conveying personal 'secrets' or grudges on either side was emotionally burdensome, and required careful strategies not to disclose information to family members and not break my promise of confidentiality and anonymity to my respondents, which I ensured throughout the research. In this article I anonymised names, locations and other tell-tale details to protect my respondents, their families and their relations.

This study is based on 14 months of ethnographic fieldwork with Sudanese migrants in the Netherlands and the UK and their families back in Sudan during 2015-16. My main methods of data collection were: in-depth biographic interviews, informal conversations and observations with 21 respondents in the Netherlands, 22 in the UK and 19 of the migrants' matched family members (mostly parents and siblings) in Sudan. I conducted all interviews in English or Arabic, in familiar environments for the respondents, mostly their homes. Interviews lasted between two and four hours, while observations ranged in duration and involved attending events with participants such as concerts and family reunions, to spending a full week living with them in their homes. Research participants were recruited through multiple gatekeepers and snow-ball sampling. The sample included roughly half men and half women, who ranged in age from their early twenties to late fifties, including single men, married couples and divorced parents with children. The respondents' educational background varied, although the majority had a university degree from Sudan. This can be explained by the fact that the Sudanese middle class was the main target of the Islamist regime after the coup (Abusabib, 2007).

\subsection{Protective care-receiving in a transnational context}

I begin this section with three vignettes that illustrate how women in different contexts and transnational family networks experience and navigate the care provided by their male relatives when facing - or being perceived to face-particular needs related to their childbearing or childrearing tasks. I have chosen these particular 
cases because they illustrate the complexities of care-receiving in transnational families, whereby receiving care might be problematic for both migrants and nonmigrants. While much attention has been given to the burdens women experience as care-givers, these cases show that care-receiving is also a burdensome and gendered process. Whereas some of the care dynamics illustrated were also observed in other cases in this research, these three cases encompass the two main analytical points of this paper, namely: the different perception of care needs across distant social protection contexts, and the degrees to which the position of the female carereceivers - in terms of being or not a migrant and their capacity to access other resources - shapes their power to navigate the reception of unsolicited care. Rather than making any empirical generalization, these cases are relevant for showing the complexities of care-receiving in a transnational context.

After the vignettes, I discuss how these women deploy different strategies to navigate family caring processes. While taking control over their own bodies, and protecting themselves and their children from the unwanted consequences of care, all three women avoid conflict with their caregivers and their families. My argument underscores that the performance of caring roles in transnational families is filled with contradictions and conflict, whereby geographical and sociocultural distances, together with the resources available and the capacity to access them, shape the ways in which female care-receivers engage in negotiations and exercise their agency to circumvent care.

\section{Talia (37) - Postponing the reception of care through distance}

Talia is one of the sisters of Ashraf (42), a Sudanese refugee in Europe. During my fieldwork there, Ashraf hosted me in his house as I conducted interviews in his city. Every evening, after I finished my interviews and he returned from his informal job as a security guard, we had dinner together and he would tell me stories about his extended family 'back home' in a remote village in Eastern Sudan. The shine in his eyes every time he talked about them, especially his mother and sisters, showed his love for them. Come what may, Ashraf spent every single Friday evening calling his parents and siblings, giving business advice to his brothers, orchestrating new living arrangements for elderly family members in need of care, pressuring younger siblings to perform good at school, or simply checking that everybody was doing fine.

Besides his close contact with his family and his participation in collective decisionmaking processes, Ashraf also sent them money regularly. Part of this money went to help his sister Talia to go through a fertilization treatment. After having been married for several years, she could not get pregnant, so Ashraf had been paying for an expensive treatment-including several operations - to help her fulfil her wish to become a mother.

Some months later, almost by the end of my fieldwork in Sudan, I was fortunate to meet Talia in Khartoum, after she returned from her four-month stay at her parents' home in her native village to recover from the last unsuccessful operation. Although Talia had initially gone for a short break, she had in fact over-extended her stay by four months in her native village, hundreds of kilometres away from the hospitals in Khartoum. 
I visited Talia in her house in Khartoum, which she shared with other male relatives. Soon after we started talking, Ashraf called her to ask how she was doing. It was a Friday. After having lunch, Talia invited me to go and rest with her in her bedroom. To my surprise, as we lay on the bed, she told me about her pregnancy issue. In the last year, she had had surgery five times, the last of which had taken over five hours and had left her in a very bad state. She lifted her toub and showed me a massive and messy scar stretching vertically from her belly button down to her pubis and horizontally to her hipbones. Although she wanted to become a mother, she was tired of trying and did not want to go through having surgery again, but she felt pressured by the financial efforts made by her husband and especially Ashraf.

\section{Fatima (40) - Preventing the unwanted consequences of care through medical surgery}

Fatima arrived in the Netherlands as a refugee in the mid-1990s. Like many single refugee women travelling alone, she quickly met and married a Sudanese asylum seeker in the camp, with whom she had a child, Haisam. In 2005, after divorcing her husband and not being able to find a job, Fatima moved to the UK with her son, where she raised him alone. Although she soon found a well-paid job and was able to take care of Haisam, for whom she also received welfare support, ever since her divorce Fatima had lived under the constant pressure from her father and brothers pushing her either to re-marry again or come 'back home', as traditionally expected from divorced women in Sudan. None of these options was in Fatima's plans.

To cope with the pressure from her relatives, Fatima took a very drastic decision. Several years before, she had been diagnosed with ovarian cysts, and when she decided to undergo surgery to have them removed, she requested to have both her ovaries removed as well. In the event that she could not withstand her family's pressure to remarry, she reasoned, at least she would be able to avoid having more children out of an unwanted relationship.

Besides her marital status, Fatima's family was also concerned about Haisam. During the time I spent at her house, it was a rare day when she did not receive a call from her father or brothers to check up on her and Haisam. At the time, he had decided to pursue an artistic career rather than go to university. Whereas Fatima was not too worried about it and wanted to give him the chance to explore other options, her family strongly disapproved of Haisam's decision. Fatima told me that her father in Sudan, as well as her brothers across Sudan, the Netherlands and the Gulf, would call Haisam almost every day to persuade him to go to university. One day, even I received a call from one of her brothers, whom I knew from my fieldwork, asking me to intervene in the issue. To protect her son against the strong family pressure, Fatima would often tell them that Haisam was asleep or not at home whenever they called.

\section{Suheila (58) - Ensuring her preferred type of care through calculated family negotiations.}

Suheila and her four daughters came to the Netherlands in 2002, following her husband who got a job at a Dutch university. Soon after her arrival, Suheila also found a job at the university. Sometime before the end of her husband's contract, Suheila decided to return to Sudan with her daughters, where her husband would later join them. One of their daughters, Huda, was 
disabled. She attended special schools in the Netherlands and received assistance from different organisations, but in Sudan she had trouble coping with her disability, after which Suheila decided to return to the Netherlands again.

At the time, her husband found a new job that required him to spend long periods abroad. Although this job allowed him financially to support his family, Suheila now had to run the household on her own. In view of this situation, her four brothers, who lived in the UK at the time, came to the Netherlands to talk her into moving to the UK, arguing that British schools for children with special needs were better, and that they themselves and other relatives would be there to help her taking care of her daughters.

For Suheila, however, moving to the UK, where several of her extended family members lived, did not seem like a good idea. Although she appreciated her brothers' concern and good intentions, she feared that in the UK she would also have to fulfil multiple social commitments, which would inevitably divert her attention from Huda. Still, Suheila acknowledged and valued the care her extended family had provided to her and her daughters in times of need. By staying in the Netherlands, Suheila nevertheless felt she had more freedom to take her own decisions and manage her time as she saw fit, while the proximity of the UK allowed a certain level of involvement by her brothers in raising and caring for her daughters. Indeed, some years before, Suheila had had the opportunity to move to the US, where Huda had received funding to attend a special school. Yet, she decided against it, because it was too far from her family.

Circumventing her brothers' requests to move to the UK in a non-conflictive way was all but easy. As one of her older brothers told her: 'We have to make sure where [Huda] is going... and if we don't find it is the most appropriate, I'm afraid you may need to change your plans.' In response, Suheila had to convince them that life in the Netherlands was the best option for her and Huda. To do so, she arranged a meeting between her brothers and the director of Huda's school, who also contributed to persuading Suheila's brothers. Despite the pressure, Suheila described the full week that her brothers spent in the Netherlands 'inspecting' the schools and the general environment, as 'family support'. When I asked her about her husband's opinion and role in all the negotiations, she explained that he agreed with her brothers' behaviour. They were family, after all, who wanted the best for her and Huda.

\subsubsection{Perceiving care across different social protection contexts}

The vignettes presented above show how care, as a gendered and culturally embedded practice leads to differing perceptions of needs, especially when caregivers and care-receivers live in geographically and culturally distant places with different social protection systems. Given the difficulties to provide face-to-face care, recognising the need of support ('caring about') and taking responsibility to provide it ('taking care of') are essential in the sustenance of transnational caring processes. However, the perception of such needs and the way to address them might conflict with the care-receiver's interests.

In the case of Talia, her brother Ashraf perceived her infertility problem as a crucial need. In the Sudanese context, children are the most reliable source of insurance, especially during old-age (Serra-Mingot and Mazzucato, forthcoming). 
Based on deeply rooted norms of intergenerational reciprocity, children are expected to care for their parents when they are old and sick. In realising Talia's need, Ashraf expressed genuine care for her. Apart from perceiving the need for care, Ashraf also made the assessment that this need should be met, based on Talia's initial wishes to get pregnant and the idea of the value of children for Talia and the family's wellbeing. Therefore, he took the responsibility to do something about it, by arranging an expensive medical treatment for her. While the perception of need was correctTalia initially wanted to become a mother - the way in which Ashraf chose to meet his sister's need put her through excruciating physical pain. Although she wanted a baby, she was also tired of suffering and was ready to either live without children or adopt one of her sisters' children. But she felt she could not tell this to her brother because of all the efforts and money he invested in her.

Being thousands of kilometres away, Ashraf could not assess first-hand the impact of his support. Seeing the result of multiple operations on his sister's health and body might have resulted in exploring other reproductive options. Moreover, his economic situation in Europe, although far from buoyant, had given him the necessary financial resources to facilitate medical interventions. As Ashraf explained, the salary of Talia's husband was too low to cover such expensive treatment. Whereas financial resources pooled together from the extended family might have paid for the initial treatment, its high costs would have probably made it difficult for the family to provide long-term financial help for this purpose. The socioeconomic imbalance between Talia and Ashraf gives Ashraf more power to decide how and by whom care should be provided.

In the cases of Fatima and Suheila, their families' perceptions of their needs are related to their childrearing abilities. Whereas care is often described as a dyadic relationship between two people, often mother and child, very few societies conceive of childrearing as the sole responsibility of the biological mother (Tronto, 1993). In Sudan, parents are often responsible not only for their own children, but also for children of their siblings and other extended family members. When these children become adults, they are in turn responsible for providing for their aunts and uncles in times of need. Therefore, childbearing and childrearing are concerns of the entire family (Schlytter \& Linell, 2010). In the cases of Fatima and Suheila, their male relatives were concerned about the decisions of these women and their capacity to provide for their children, especially because they were living alone and abroad. This is rather paradoxical because even though women are often viewed as 'natural caregivers', they are also pictured as ignorant and unable to be in charge of providing care (Fisher \& Tronto, 1990), causing other family members to intervene. In this regards, the different contexts, and the different ways in which social protection is organised in each context plays a crucial role. Whereas in Sudan it could be problematic for a single working woman to take care of her children alone, both in the Netherlands and the UK state-provided benefits and other sources of supporte.g. foundations or specialised schools for children with special needs-facilitate 
childrearing tasks of single parents. For Suheila, the schools in the Netherlands are seen as more valuable than family support, which could even be counterproductive. Similarly, Fatima prefers to allow her son to develop his career outside the university, rather than forcing him to do something he does not want. Whereas in Europe, going to university is not a requirement to succeed professionally, university education in Sudan is highly regarded, to the extent that multiple resources are mobilised to send children to university (Serra-Mingot and Mazzucato, forthcoming). Becoming a doctor or an engineer is not only a source of pride for the family, but is also expected to translate in high income, through which children will sustain their parents and other aging relatives in the future.

Fatima's status as a divorcee living abroad also contributes to her family's perception of need. Divorced Sudanese women living abroad are expected either to marry again or to return to their family in Sudan, where they can be taken care of. Failure to do so may result in a source of disgrace for the family, with disastrous consequences for the social protection of its members (Nageeb, 2004). But Fatima, who is living in the UK where she gets child benefits and is building a pension through her employment, does not plan to re-marry or return to Sudan. In other words, the social protection environment in which she lives allows her to cope with her needs without the support of the extended family. The perceived need of care remains closely linked to the sociocultural norms of the sending country, whereby the care-receivers' needs and how to address them might differ from the caregivers' perspectives. In Sudan, Fatima's divorce would have probably pushed her to go back to her family, because without any state-provided support, raising a child and running a household on her own would have been complicated. Yet, the availability of a strong welfare state in Europe puts Fatima in a more powerful position to negotiate the extent to which she may allow her family decide upon her and her child's wellbeing.

\subsubsection{Circumventing burdensome care and avoiding conflict}

As the cases illustrate, power relations often shape the definition of needs to suit dominant interests, whereby traditional practices of care within families sometimes result in the control of individual family members, based on gender and generational ideas of how care should happen. Yet, in these situations of imbalanced power relations and conflicting perceptions of needs and how to address them, carereceivers have an active role in circumventing care while avoiding conflict with their families.

One aspect of Talia's strategy to avoid, or at least postpone, more medical interventions and avoid conflict with her brother involved over-extending her visits home as much as possible, so as to be far away from Khartoum's hospitals. By being unavailable or cancelling appointments when feeling vulnerable to pressure from others, care-receivers protect themselves from receiving care while they purposefully avoid confronting their caregivers (Russell et al., 1997). The geographical distance 
Talia puts between herself and Khartoum helps her to gain control over her body, at least temporarily.

In Fatima's case, her extended family's efforts to provide unrequested care to her and her son are closely intertwined. To protect Haisam from the overwhelming good intentions of the extended family, Fatima makes up excuses to prevent her family from talking to him too often. In doing so, however, she takes up the burden of being constantly told to take better care of him, to discipline him more. Haisam's perceived lack of discipline and educational achievements translates in additional pressure for Fatima either to re-marry or to come 'back home', for her own and Haisam's good. Thus, to avoid conflict with her family and protect herself from the consequences of unsolicited care - namely, re-marrying and having more childrenFatima arranges a medical intervention that will prevent her from having more children. Whereas to prevent conflict with her family it may prove to be unavoidable to re-marry, Fatima's geographical distance from her relatives allows her to take control over her body and her reproductive capacity. Living and working in the UK allowed her to undergo such an operation not only in a safe and inexpensive manner, but also without her relatives finding out.

In Suheila's case, her brothers in the UK worried about her capacity to take care of her children in the Netherlands. By moving to the UK, her brothers reasoned, her disabled daughter Huda would have better educational opportunities, and she would also receive the care of her extended family. Yet, for Suheila this caring arrangement was not ideal, since family support would come with multiple commitments that would distract her from her main priority: taking care of Huda. Rather than accepting her brothers' caring arrangement, Suheila drew a detailed and convincing plan-e.g. having her brothers talk to the school principal and inspect her living conditions in the Netherlands - to prove to them that staying in the Netherlands was actually a good decision.

Suheila's strategic navigation of the physical distance between her and her extended family in the UK allows her not only to avoid the consequences of unsolicited care but also to receive care in a specific way. For Suheila, the hands-on practical and emotional care that her extended family would give her in the UK does not satisfy her needs. Yet, although she had the chance to move to the US, where the geographical distance would have limited much more her brothers' intervention, Suheila appreciates her brothers' concern and care, and therefore she refrains from moving to a place where family care would be quite difficult to receive. Instead, she opted for staying in the Netherlands, striking a balance between being far away enough to avoid constant social commitments and take more control over her own and her daughter's life, and being close enough to receive care and support from her brothers whenever urgent needs arise. 


\subsection{Conclusions}

This article explored an aspect commonly overlooked in the literatures of migration and social protection, and transnational caregiving: the role and experiences of female care-receivers in navigating the care provided by their male relatives abroad. Rather than being passive actors, the female care-receivers in this article exercise different levels of power and agency to protect themselves from the unwanted consequences of care, while avoiding family conflict, which remains to be the main source of social protection in Sudanese. The geographical distance, the resources available in each context and the capacity to access them, shape the ways in which female care-receivers engage in negotiations and exercise their agency to shape the reception of care in different ways.

These cases showed that care is not a one-way relationship of someone doing something to someone else in a dyadic relationship, but a process based on interdependency, reciprocity and multidirectionality, involving multiple family members (Milligan \& Wiles, 2010). In taking the extended family as the main unit of analysis, this paper shows that care is expressed as an act of generalised reciprocity, in that, in caring for these women and their children, there is a degree of expectation that these children will be the future caregivers for aging family members. Often more than one caregiver is providing some kind of distant care for their female relatives and their children (e.g. orchestrating medical operations or checking up on their children's wellbeing). At the same time, these women are also care-providers in two different ways: providing hands-on care towards their own children, and sustaining the family network by carefully circumventing unsolicited care and avoiding conflict.

This study contributes to the current debates of the role of care in TSP in three ways. First, by bringing the literature of nursing and disability studies in conversation with the literature on transnational care and social protection, this article has shown that in transnational caregiving arrangements, care may be burdensome not only for the providers - as many studies have shown - , but also for the receivers. The multisited matched-sample methodology allowed for a better understanding of the two sides of the caring relation, and revealed how sometimes well-intended but unsolicited care becomes an additional burden for the care-recipient. Rather than being merely passive actors who accept the care provided by relatives abroad, what this article has shown is that female care-receivers do play an active role in protecting themselves against the consequences of unsolicited and burdensome care. 'Protective care-receiving' (Russell, Bunting and Gregory 1997) is a useful concept in the study of transnational caregiving and social protection arrangements because it allows us to investigate the care-receivers' agency to accept or circumvent care to accommodate their actual needs, while avoid conflict with their families, who are the main source of social protection in Sudan.

Second, this study has shown that, in transnational caring arrangements, the power imbalances (inherent to all care relationships) are shaped by the geographical 
distance and the different institutionalised levels of formality and informality of the social protection systems in which care-receivers are based vis a vis their caregivers. The different cases showed that care relationships take place in interlaced frameworks of power and powerlessness (related to gender, generational and socioeconomic aspects), whereby agreeing on what 'need' means becomes more difficult in relationships with bigger differences in power (Milligan \& Wiles, 2010). In situations with limited face-to-face contact, the caregivers' efforts to cover for the care-receivers' perceived needs may not satisfy the ways in which care-receivers wish to have their actual needs covered. While this situation might lead care-givers to exercise more pressure on the care-receiver, it is precisely the distance between caregivers and care-receivers that offers more power to the latter to circumvent care and take control of their own needs and lives. At the same time, the (lack of) resources available in each context, gives the care-receivers more or less power to cover their own needs (e.g. lack of hospitals preventing more operations, reliance on the welfarestate to cover their own and their children's wellbeing).

Finally, this article highlighted the importance to recognise the cultural context of the sending country and the role of extended families in caring and TSP arrangements. By bringing in the Sudanese context and the ways in which social protection and care relations are envisaged, this article has contributed to understand the complex family care relations and the gendered cultural norms in which care is embedded as part of TSP arrangements. Decisions on when, how and by whom care should be provided are based on factors including (perceived) needs, norms and values around gender and kinship bonds, (perceived) ability to cope, geographical distance and available sources of support (Milligan \& Wiles, 2010). In the cases presented here, women are perceived as being in need of family care and support in specific aspects of their lives, namely, the reproductive tasks of childbearing and childrearing. The ways in which their male caregivers care for them is based on the needs perceived from the Sudanese perspective, where women's bodies and the children's socialisation and wellbeing are crucial for the family sustenance. Therefore, rather than simply interpreting these dynamics as mere acts of patriarchal domination and control over women, analysing care from the perspective of social protection allows for a more complex interpretation of care as a multi-directional process to protect and sustain the family, which is the ultimate provider of social protection.

This study has two main implications for further studies on TSP. First, more research is needed to better understand the role of care-receivers in care and social protection arrangements within transnational families. Whereas in this article I explored women's perspectives as care-receivers, as a gendered process, men's experiences as recipients of care should also be addressed. Similarly, while the women in this study had a middle-class and a high educational background, future research should investigate further the role of these factors in shaping care-receivers' strategies to circumvent care. Second, it is important to recognise the cultural context 
of the sending country and the role of extended families. Understanding how social protection is arranged in the Global South, where extended families play a crucial role in the sustenance of individuals, families and communities, is important for understanding the particular mechanisms through which migrants and their families navigate their individual and familial needs. 

CHAPTER 10

CONCLUSIONS 


\subsection{Introduction}

This dissertation has examined how Sudanese transnational families navigate different forms of social protection, locally and transnationally. In analysing the mechanisms guiding the decisions of migrants and their families to access, circulate and coordinate resources to cover for different but intertwined social protection needs, this dissertation has aimed to contribute to the broader body of literature on migration and transnational social protection (TSP). Through a transnational lens, this study has looked at migrants as individuals bound to their extended families, whose members are embedded across multiple contexts (Basch et al., 1994; Levitt \& Jaworsky, 2007). I have done so in three ways. First, I have included the contexts of the sending and receiving countries, and the ways in which social protection is envisaged and provided in each of them. Secondly, I have included both migrants as well as those who do not migrate, but who are bound to migrants through family ties across geographical borders. In doing so, I moved beyond the individual migrant's access to social protection in the receiving country to also include the role of the migrant's extended family in shaping social protection arrangements. Finally, I have incorporated insights of the Sudanese family norms around social protection, which allowed me to interpret the findings in the different empirical chapters.

The central research question of this dissertation is: How do Sudanese migrants in the Netherlands and the UK and their families back home navigate their social protection, locally and across borders? To address it, this question has been broken down into the following sub-questions that are addressed in the three empirical chapters (7-9) of this dissertation:

1. How do migrants navigate formal state-bounded social protection provisions to informally provide for themselves or their families back home? And, in doing so, in which manners do both welfare-state institutions and migrants work together at the interstices of the formal and informal to cater to national and transnational social protection needs? (Chapter 7).

2. What kinds of considerations underlie the decisions of migrants and their families when moving to certain places to address social protection needs? Which are the mechanisms guiding the access, circulation and coordination of resources to cover for different but related social protection domains? (Chapter 8).

3. How do female care-receivers in transnational social protection arrangements circumvent the unwanted consequences of unsolicited care provided by their male relatives abroad? (Chapter 9).

In particular, this thesis has concentrated on the case of Sudanese migrants in the Netherlands and the UK and their families 'back home' in Sudan. As Chapters 4 and 5 have shown, the Sudanese are a relatively new and highly heterogeneous 
migrant group in Europe. In the Netherlands, while much research has been conducted on 'old migrant groups', such as the Moroccans or the Turkish (Grillo \& Mazzucato, 2008; Mazzucato, 2008b), very few studies have looked at more recent migrants from sub-Saharan Africa in Europe, such as the Sudanese. This is an important gap to address, because new migrant groups face different migration and receiving contexts than older groups. For instance, between 1945 and 1973 many migrants were recruited in industrialized countries in North-Western Europeincluding the UK and the Netherlands - as part of labour workers' or guest-workers' systems, whereby they were not only quickly incorporated into the labour market of the host country upon arrival, but were also given official status, even if with the intention that it would be temporary, and soon became part of the state system (Mazzucato, 2008b). Newly arrived migrant groups, however, are not embedded within such guest-worker programs and face different conditions upon arrival. Therefore, their often limited knowledge about the functioning of the labour market in the receiving country or about the skills valued by employers, together with less developed social networks of support, might have an impact on how they engage in different TSP practices (Chelpi-den Hamer \& Mazzucato, 2010; Demireva, 2011; Grillo \& Mazzucato, 2008).

The Sudanese in the Netherlands and the UK are a highly diverse group in terms of legal (e.g. documented labour migrants, refugees, asylum seekers or undocumented migrants) and socio-economic status. Such heterogeneity is relevant in the study of TSP, because of two reasons. On the one hand, to date, most studies addressing social protection for migrants have tended to focus on labour migrants (e.g. Alpes, 2015; Boccagni, 2013; Olivier \& Govindjee, 2013; Sienkiewicz \& Bilecen, 2015). The lack of research on how refugees and asylum seekers navigate their social protection locally and transnationally contributes to the idea that refugees are- to a great extent-devoid of agency and dependent on the welfare states. Yet, as the empirical chapters of this thesis have shown, this is not always the case. On the other hand, as illustrated in the introduction of this dissertation, respondents in this study experienced changes in migration status over time, and with it, their access and entitlements to different social protection provisions. Including respondents with different migration statuses allowed me to observe common aspects in the social protection needs and the strategies to address them, which expand beyond migration labels.

The analysis of the data collected over 14 months of ethnographic multi-sited fieldwork with a partly matched sample of Sudanese families across the Netherlands, the UK and Sudan has been the basis of the analysis in this dissertation. This research design not only was innovative, but also highly insightful in the study of TSP. To date, studies of migration and social protection have often gravitated around the migrants' lack of access to social protection in the receiving countries (Alpes, 2015; Avato et al., 2010; Cuadra, 2012). In neglecting the sending context and the role of the migrants' families back home, these studies have failed to capture the 
complexities of making social protection arrangements across national borders. Although studies of transnational families - mostly addressing caring practices between parents and children-are adopting multi-sited methods to understand migrants' transnational practices, only few of them have used matched-samples (see exceptions: Osili, 2007; Mazzucato, 2008a; Vivas-Romero, 2017; Schmalzbauer, 2004). A multi-sited matched-sample ethnography allowed me to follow connections and relationships (Marcus 1995), and collect data from 'two sides of the same coin', that is, both the migrants' and their families' accounts on their experiences in accessing, providing and receiving social protection. This allowed for more nuanced insights on the processes guiding social protection arrangements within transnational families, as well as on how reciprocal relations of support are sustained across borders and what the implications are for different family members.

The following sections reflect on the main findings of this research (Section 10.2) and address the main theoretical and methodological implications for the study of migration and TSP (Section 10.3). Section 10.4 discusses some of the limitations of this research and suggests some ideas for future studies on TSP. Section 10.5 concludes with some policy recommendations.

\subsection{Main empirical findings}

To answer the main research question and the three subsequent sub-questions, this dissertation consists of three empirical chapters (7-9), based on published or submitted research articles. The remainder of this section summarises the research findings of each of these chapters.

Chapter 7 addresses the first research sub-question and investigates how migrants navigate formal state-bounded social protection provisions to informally provide for themselves or their families back home. In doing so, the chapter also addresses the ways in which both welfare-state institutions and migrants work together at the interstices of the formal and informal to cater to national and transnational social protection needs. Based on data collected in the Netherlands and Sudan, the findings of this chapter show how migrants sometimes enter into symbiotic relationships with different welfare-state institutions, such as municipal offices, non-governmental organisations and other immigration institutions, which in turn rely on the support of these migrants to provide services for people who would otherwise escape their purview. The analysis further points to the fact that sometimes, such relations are actually initiated by the state-based institutions which due to their geographical fixity are not prepared to cover the needs of mobile people. This finding suggests that local authorities, NGOs and immigration institutions are not only acting out of compassion or solidarity, as emphasised in other studies (e.g. Cuadra \& Staaf, 2014), but out of need.

A transnational approach allowed us to find out that accessing formal social protection is not only problematic for the undocumented but for any migrant with 
transnational aims (e.g. caring for sick relatives back home). Therefore, not only undocumented migrants, who lack access to welfare provisions, but also highly skilled documented migrants are pushed to navigate a system that does not cover the needs of their dependent others abroad. The analysis further shows that although migrants with different legal statuses seem to engage in symbiotic relations with formal institutions, achieving an equally beneficial relation for both parties is marked by unbalanced power relations, which are related to the migrants' legal status. This affects the migrants' leeway to negotiate demands or simply having to submit to enforced requests, which might place them in a risky situation.

Chapter 8 aims to better understand the role of social protection in shaping peoples' decisions to move. In particular, this chapter investigates what kinds of considerations underlie the decisions of migrants and their families to move to certain places for their social protection needs. To do so, the chapter draws on the life-stories of a Sudanese transnational extended family based in the Netherlands, the UK and Sudan and whose members are scattered across multiple countries, and uses a transnational approach to analyse the mechanisms guiding the access, circulation and coordination of different resources to cover for different but related social protection domains. As opposed to the wide-spread idea of welfare shopping, that is, migrants moving to countries with more generous welfare states, one of the main findings of this chapter suggests that it is not the lack of formal social protection in the first host country to trigger onward movements, but the lack of possibilities for people to arrange their own and their families' social protection when such families are extended and located in multiple nation states. The way in which migrants deal with different crises and needs over the years questions the idea that the 'receiving' nation-state in general, and the welfare state in particular, are the main triggers of mobility to access social protection. This does not mean that formal state-provided provisions are unimportant. Yet, the analysis shows that decisions to move to another country are not based on the fact that state-provided or welfare provisions are not available in the first country, but on the fact that a specific type of education or care is deemed better in the family's understanding of social protection, which is strongly embedded in practices of generalised reciprocity.

The chapter also demonstrates that people with an extensive history of mobility or with a highly geographically-scattered family network especially face insecurities when it comes to securing their social security benefits, in that, in moving to another country, such social security rights might cease to exist. This is coupled with the fact that many refugees spend years waiting in the asylum process, where they are not allowed to work or study. Even when the status is given, they must go through integration and re-training courses to validate their studies. Thus, many people apply for a job for the first time at a relatively advanced age in a highly competitive market in which, even if they find a job, their built-up pension will probably be rather low. On top of this, most of the respondents expressed their desire of not wanting to grow old here, whereby the expected returns of the welfare state in 
terms of pensions greatly lose their meaning. Thus, people for whom mobility is part of their lives and future plans, securing their social security through geographicallyfixed institutions is problematic. Therefore, it is deemed safer to invest in people (e.g. children) and other assets that can be easily accessed and circulated (e.g. education) across time and space.

The last empirical chapter (9) investigates how female care-receivers in TSP arrangements circumvent the unwanted consequences of unsolicited care provided by their male relatives abroad. In the particular case of the Sudanese patriarchal society, social and public life are male-dominated, whereby the individual's role in the different caring and protecting practices is highly gendered. It is within this backdrop that this chapter examines the agency and strategies of three different migrant and non-migrant women to manoeuvre the reception of unwanted care while avoiding conflict with their relatives and gaining control of their own and their children's bodies. In doing so, the chapter suggests that, just like care-giving, care-receiving is also a highly gendered process, in which men and women have different roles to play. Drawing on a multi-sited matched-sample ethnography with Sudanese transnational families across the Netherlands, the UK and Sudan, this chapter examines the strategies of these women to manoeuvre the reception of unsolicited care. One of the main findings is that care is not always a good thing to receive. Especially in relationships with bigger differences in power, such as gender, it may become more difficult to agree on the meaning of need, and those perceived as vulnerable might have limited control over how their needs should be met and therefore suffer the consequences of unsolicited care. The multi-sited matched-sample methodology allowed for a better understanding of the two sides of the complex power dynamics reflected in the different caring relationships, and revealed how well-intended but unsolicited care can be an additional burden for the care-recipient. Indeed, the chapter shows that, despite the caregivers' good intentions, their assistance is not always perceived as helpful by the recipients. Perceptions of care and the ways in which it should be provided differ between those delivering and those receiving it, especially when care occurs in the distance. While distance may exacerbate the perception of different care needs, it also seems to give the care-receivers more space to navigate the reception of unsolicited care. In caregiving arrangements, thus, geographical distance has the potential to be both problematic and beneficial when it comes to navigating the reception of care.

The chapter further points out that in TSP arrangements care-receivers are not merely passive actors who accept the care provided by relatives abroad. On the contrary, another finding of this chapter is that female care-receivers do play an active role in protecting themselves against the consequences of care. The chapter points to different factors (e.g. geographical distance, the strength of the welfare state and the wish to avoid family conflict) shaping the ways in which the female care-receivers engage in negotiations and exercise their agency to shape the reception of care in 
different ways, such as: postponing care, avoiding contact, taking control of their reproductive capacity or justifying their desire for a different type of care.

\subsection{Main contributions to the literature}

This dissertation has contributed-theoretically and methodologically-to the studies of migration and TSP in four different ways, by: 1) evidencing the importance of contextualising transnational families and social protection in both receiving and sending countries; 2) demonstrating the importance of moving beyond welfare-statecentred approaches to better understand the mechanisms of social protection for mobile populations; 3 ) contributing to the understanding of the working mechanisms of the resource environment; and 4) elucidating the role of care-receiving in TSP arrangements and family relations.

\subsubsection{Contextualising transnational social protection: The roles of the extended family and the sending country context.}

Taking into account family and kinship norms and the structure of social protection system in the origin country is necessary to interpret the findings of this dissertation on how Sudanese transnational families navigate their social protection locally and across borders. In Sudan, like in other African countries with weak or non-existent welfare states, extended families continue to play a key role in the sustenance of society and the provision of social protection, assuming the main responsibility for offering material, social, emotional and intergenerational care and support for its members in times of crisis (Adam \& Yousif, 2016; Akuei, 2005a; Mokomane, 2013; Rashad et al., 2005). Despite current processes of modernization and trends towards the nuclearization of the family (Al-Awad \& Sonuga-Barke, 1992), the role of the extended family remains crucial (Caarls, 2015; Mokomane, 2013). In the same vein, in a context of migration, the importance of the extended family as a crucial social protection provider remains. In fact, this dissertation has shown how migrants continue to maintain close links with their extended families back home, with who they share obligations.

Considering the role of the extended family in the sending country and sociocultural norms on how social protection is sustained across generations has been crucial in order to interpret the findings on the mechanisms guiding the orchestration of social protection within transnational family networks. In contrast to most Western social protection systems, with a clear-cut compartmentalisation of social protection domains (e.g. pensions, healthcare, unemployment, or family support), the weak formal social protection system in Sudan, leaves most people fully dependant on informal support mechanism, in which different domains are closely intertwined. In this context, the role of children and the elderly in the family network play a crucial and intertwined role in how families make their social protection arrangements, locally and transnationally (see Chapter 7-9 and vignettes in Chapters 
1 and 3). In the Sudanese context, providing for elderly parents, in terms of money and care, is a social and cultural duty, mostly to be performed by their children, but also by grandchildren or other relatives. At the same time, children are not the sole responsibility of their biological parents, but of other family members in the extended family, including uncles or grandparents, who care for the family children in specific ways. Therefore, children are the most available and reliable source of insurance, especially during old-age (Adam \& Yousif, 2016; Nauck \& Klaus, 2007), when they are expected to be responsible for caring not only for their own aging parents, but also for their grandparents, aunts and uncles.

In the case of transnational families, thus, this thesis has shown that elements from formal welfare systems here combine with informal systems of support and reciprocity there, resulting in a high degree of intertwinedness between the different domains. It is precisely such intertwinedness that leads people to prioritize specific needs over others (e.g. investing on the children's education as an old-age pension that formal provisions may not be able to cover if the migrants move back to Sudan). The access and circulation of formal and informal resources within transnational families can be explained in the practice of reciprocity and norms of social exchange from the sending country. By including the sending country context, and expanding our unit of analysis from the individual migrant to an extended family network scattered across different countries, this thesis brings out the intertwined character of different social protection needs, and the crucial role of mobility and the strategic geographical distribution of individuals in the orchestration of complex social protection arrangements.

Understanding and bringing into the analysis the context of Sudan has also added insights on gender-related aspects of TSP. The prevalent role of the extended family in supporting its members is sustained and reproduced based on a series of deeply rooted norms of intergenerational reciprocity and exchange, whereby individuals are bound to support and care for each other in specific ways. As a patriarchal society, social and public life in Sudan is male-dominated, whereby the individual's role to care and protect is highly gendered (Fluehr-Lobban, 2006; Oldfield-Hayes, 1975). As Chapter 9 shows, understanding how men are expected to deliver care and protection to their female relatives in the Sudanese context is important to interpret the ways in which migrants and non-migrants navigate the provision and reception of care. In the patriarchal Sudanese society, a woman's virtue is crucial to the honour of her family, especially the men under whose responsibility she is (Cindoglu, 1997). This is important because in traditional societies, where many economic activities are based on trust, keeping the family honour has important socioeconomic and political implications for families' social protection (Cindoglu, 1997; Ouis, 2009). By bringing in the Sudanese context and the ways in which social protection is envisaged by male and female family members, respectively, I contributed to the understanding of care relations in TSP arrangements, rather than simply interpreting these dynamics as mere acts of 
patriarchal domination over women, as has often been the tenet of much feminist literature, where patriarchy is often the main theoretical basis (for a detailed overview of this literature, see: Pilcher \& Whelehan, 2004; Kandiyoti, 1988) Theories in which patriarchy is central often lead to a rather limited conceptualisation of gender relations, under-acknowledging the full extent of such relations (Pilcher \& Whelehan, 2004).

\subsubsection{Moving beyond welfare-state-centred approaches in the study of transnational social protection.}

Although in our current globalised world more and more people live across national borders, developing attachments and responsibilities in more than one nation-state, most institutions providing formal social protection only cater to sedentary populations, tied to a particular nation-state. Not surprisingly, thus, migration and social protection has increasingly caught the attention of policy makers and researchers (Holzmann \& Koettl, 2014; van Ginneken, 2013). The bulk of these studies and reports have tended to address migration and social protection from the perspective of the receiving nation-state, in general, and the welfare state in particular, focusing on the individual migrant's lack of access to the welfare in the receiving countries in the Global North and its implications for the migrants' wellbeing (Avato et al., 2010; Cuadra, 2012; Holzmann \& Koettl, 2011; Sabates-Wheeler, 2009; Siegel \& de Neubourg, 2011). Such focus on the nation state has led scholars and practitioners to address social protection in terms of formal-mostly stateprovided-and informal provisions. The role of informal social protection mechanisms, however, although important, has mostly been described as filling the gap of welfare provisions.

While acknowledging the importance of welfare and nation states, the transnational approach of this dissertation resonates with the contributions of transnational migration scholars, stressing the need to address social protection for mobile populations avoiding nation-centred perspectives (see Faist, 2000; Kivisto, 2001; Levitt \& Jaworsky, 2007; Mazzucato, 2008a; Vertovec, 1999; Wimmer \& Glick-Schiller, 2002a). In particular, these scholars have problematized such clearcut dichotomy between the formal and informal dimensions of social protection, mapping a myriad of strategies through which migrants access social protection resources beyond the nation-state (Faist, 2014; Levitt et al., 2017; Serra-Mingot \& Mazzucato, 2017). Rather than formal or informal, social protection is in fact an 'assemblage' multiple resources, where social actors constantly combine the use of formal and informal provisions (Bilecen \& Barglowski, 2015).

Chapter 6 draws on these bodies of literature and contributed to a more comprehensive view of the different forms of social protection for mobile populations and their non-migrant families. Based on an in-depth literature review on social protection for migrants, the chapter compiles a comprehensive typology of the wide span of formal and informal social protection institutions and arrangements that 
mobile populations use. Making use of a range of examples, the chapter shows that the boundaries between formal and informal categories are blurred when we look at the multiple combinations of institutional arrangements that migrants and their families use. In doing so, we introduce a third category, the so-called semi-formal arrangements, which have been studied in the development literature but not in the field of migration and social protection (Bhattamishra \& Barrett, 2008; Devereux \& Getu, 2013). Semi-formal arrangements are not publicly provided but they operate as institutions with relatively strong accountability and coordination mechanisms and they can provide prompt support to their members in a broad range of contingencies (Barrett \& Bhattamishra, 2008; Kasente et al., 2002). This broader typology allows us to include the role of emerging actors and institutions that provide social protection transnationally, that is, beyond nation-state borders. With this typology we contribute to a more comprehensive view of the different constellations of social protections used by migrants and their significant others back home, which allows for the mixing of principles that often guide how migrants obtain and provide social protection.

Addressing migration and social protection with the main focus on the receiving state also reinforces the idea of establishing and labelling different types of migrants, depending on the 'entry' categories-e.g. labour migrants, refugees and asylum seekers, family members, and undocumented migrants-and the specific welfare rights and obligations attached to them (Sainsbury, 2006). Whereas some research has questioned such migration labels (see Betts, 2013), studies on migration and social protection have continued to mostly focus on and make clear-cut differences between labour and undocumented migrants (Ambrosini, 2015; Bilecen \& Barglowski, 2015; Boccagni, 2015; Engbersen \& Broeders, 2011; Vivas-Romero, 2017). Whereas the undocumented migrants' lack of access to most forms of formal social protection puts them in a very disadvantaged situation (e.g. lack of access to healthcare or housing), their TSP needs might present commonalities to those of documented migrants or refugees. In this thesis I brought together different types of migrants, and showed that, despite the different migration statuses, the current geographically-fixed welfare systems and the restrictive migration regimes limit the ways in which all of them might be able to engage with TSP practices. In doing so, this study has contributed to the body of literature addressing the interactions between welfare states and migration regimes, which has mostly focused on how, under the current restrictive migration and welfare contexts, undocumented migrants must use different tactics to cover their basic needs (Ambrosini, 2012; Broeders \& Engbersen, 2007; Vasta, 2011; Wilmes, 2011). By taking a transnational approach and also including migrants with different legal statuses, this thesis has contributed to these studies by showing that also documented migrants and refugees are pushed to restore to different tactics in order to cover their own and their families' needs. Yet, although both documented and undocumented migrants, as well as the involved institutions, need and benefit from such interactions, it is important to acknowledge 
that achieving an equally beneficial relation for both parties (e.g. institutions and migrants) is marked by unbalanced power relations. Such power imbalances are directly related to the migrants' legal status, which affects their leeway to negotiate demands or simply having to obey to imposed requests. Indeed, power relations between the migrants and the formal institutions are unequal, and inevitably the migrants have more at stake.

Finally, by investigating the role that social protection plays in shaping peoples' decisions to move to another country, this thesis has contributed to the current debates on migration and welfare. Whereas some research claims that more generous welfare states work as a magnet, especially for unskilled and poor migrants (Borjas, 1999; Enchautegui, 1997; McKinnish, 2007), other studies do not find such a straightforward correlation (Levine \& Zimmerman, 1999; Talleraas, 2018). Adding to the mixed results, recent qualitative studies have pointed to important 'onward movements' of certain migrant groups, from countries with some of the most 'generous' social welfare states, such as the Netherlands, to the UK, where welfare benefits are relatively smaller (Ahrens et al., 2016; Bang-Nielsen, 2004). All these studies, however, have focused on the individual migrant in the receiving country. By looking at migrants' and their families' access to social protection from the extended-family perspective, this thesis has shown that migrants' decisions to move or stay in a specific location are not based on the nation-state and its welfare system per se, but on their and their families' needs and how best to fulfil them, formally or informally, now and in the future. These movements do not necessarily mean moving to a country with a more generous welfare state, but to a country with the preferred resources, such as care, education or specific medical treatments, which are deemed necessary and have priority at a particular point in time from the perspective of the needs of the extended family. In this dynamic, and linking with Sub-section 10.3.3, welfare systems become subsumed within the norm of generalized reciprocity within extended families, and become one of the many resources that can be mobilised in reciprocal exchanges of social protection.

\subsubsection{A transnational resource environment}

In order to cover for their own and their families' social protection needs, migrants often rely on different resources, other than those provided by the welfare states. To operationalize social protection beyond discreet nation states and identify the different institutions that migrants and their families may access to satisfy certain needs and take care of risks, in this study I drew on the concept of 'resource environment' developed by Levitt and colleagues (2017). Migrants' resource environment refers to the 'combination of all the possible protections available to them from our four potential sources (states, markets, third sector, and social networks)' (ibid.: 6). The findings of the different empirical chapters contribute to the theorisation of this concept in three ways that I now explain. 
First, the findings in Chapter 7 suggest that a person's social protection resource environment includes more than the resources they are able to receive from formal and informal institutions. Migrants are not only receivers of support from the 'protective arm' of the state (Levitt et al. 2017, 5) but they can also provide services to state-linked institutions, who actively use migrants to achieve their own aims. This change of roles, in which migrants become not only receivers but also providers of services to formal institutions shows that the social protection resource environment also consists of the resources that individuals can offer to formal institutions in their quest to improve their and their family's social protection. This also points to the fact that not all resources - in principle, available to everyone-are equally accessible. In other words, availability and accessibility to resources depend on the migrant's capital (e.g. knowledge, skills, networks) and on the resources that migrants themselves can provide in return. Moreover, the migrants' capital and the resources they can offer to the formal institutions place migrants in a more balanced power relationship vis-à- vis the formal institutions with whom they interact. Yet, as mentioned above, such relationships might not always benefit both parties equally.

Second, until now 'resource environment' has been used to refer to the resources available to migrants in their sending and/or receiving countries (Levitt et al., 2017). By looking at the extended family rather than the individual migrant, this thesis has pointed to the multi-national character of the resource environment. The social protection needs of transnational families can occur simultaneously across multiple locations, beyond sending and receiving states. Therefore, a range of formal and informal resources must be accessible across different locations, from where they can be carefully circulated and coordinated. This study showed how families that had members spread in three or more countries carefully coordinated their social protection arrangements so as to make the best use of the resources available in each country. A bifocal view of these families - only focusing on one sending and receiving state- would have missed how the availability and accessibility of resources from third countries influence the way in which TSP is coordinated between the sending country and the country where the research respondent is currently located.

Finally, this research indicates that while certain formal state-provided resources might be available and accessible for individual migrants, they might not be the preferred option for the social protection of the family as a whole. For example, it is often the case that accessing formal state-provided resources come with a series of restrictions (e.g. receiving unemployment benefits limits the time a migrant can spend back home to take care of a sick relative, for instance). Similarly, and linking to Sub-section 10.3.1, sociocultural rules from the sending country on how intrafamilial support - especially care-should be provided, might lead migrants not to use certain formal resources that are accessible to them. As a result, this thesis has highlighted that availability and accessibility of resources must be analysed from the perspective of the family, not only the individual migrant nor from only a dichotomous sending and receiving country perspective. 


\subsubsection{Care in transnational social protection arrangements}

Although many social protection arrangements within transnational families are often related to the provision of care (Baldassar et al., 2007; Boccagni, 2013; Dankyi et al., 2017; Mazzucato, 2008c), literature on social protection and migration has rarely incorporated the care work involved in transnational families. As the empirical chapters in this thesis show, care-in its different dimensions, be it care for the sick, the elderly or children-often acts as the trigger of multiple TSP arrangements. Even when access to formal care is possible, socio-cultural norms about who should provide care and how, shape the way in which resources are accessed and circulated. The informal provision of intra-familial care is more flexible, allows for covering different intertwined domains, and it binds family members together in a web of intergenerational reciprocity that expands over time and beyond the boundaries of nation states.

With a few notable exceptions (see Poeze et al., 2017), to date most studies on transnational care practices have focused on the burdens of providing care, mostly within nuclear families, especially between spouses or around the parent-child dyad (Baldassar \& Merla, 2014; Fresnoza-Flot, 2014; Hondagneu-Sotelo \& Avila, 1997; Kilkey, 2014; Parreñas, 2010; Spitzer et al., 2003; Zickgraf, 2017). In doing so, these studies have rightly pointed to the gendered nature of caregiving, in that it is often women - especially mothers - the ones carrying the burden to provide care locally and transnationally. By focusing mainly on the caregiving activities, these studies have tended to overlook the implications of what it means to receive care. Caregivers are thus depicted as the only active actors that carry the burden of delivering care to needy and passive care-receivers. This study has contributed to this body of literature by analysing the role of women as care-receivers in TSP arrangements within extended families. In doing so, this thesis has shown that, just like caregiving, carereceiving is a highly gendered process. Indeed, the findings suggest that conflict is unavoidable between caregivers and care-receivers because the definition of 'need' does not always satisfy both parties equally. In relationships with bigger differences in power (such as gender relations), agreeing on what 'need' means becomes more difficult, especially when such relationships take place across culturally and geographically distant places. This is because power relations often shape the definition of needs to suit dominant interests, and care-receivers may have little control over how their needs should be covered.

Against this backdrop, and drawing on studies of nursing and disability studies (Russell et al., 1997), this thesis has contributed to the literature of transnational caregiving, by looking at the perspective of the care-receivers and their agency in determining how to address their actual needs and navigating the unwanted consequences of care. I drew on the concept of 'protective care-receiving' defined as the efforts of the care-receiver 'to defend her/himself from problems associated with receiving care and shielding others from difficulties they could 
experience as caregivers' (Russell, 1993: 184). By taking into account the extended family relations, as well as the sending country context (see Section 10.3.1), this thesis has taken an innovative approach to transnational caring relations. By looking at the two sides of such relations, this dissertation showed how sometimes well-intended but unsolicited care becomes an additional burden for the care-recipient. This is an important gap to address if we aim to understand whether the care provided across border has met its goals and at what expense.

\subsection{Limitations of this research and avenues for further research.}

In this dissertation I have concentrated on a series of aspects that, to date, have received limited attention, such as: the semi-formal social protection mechanisms, the symbiotic relationships between welfare institutions and migrants, the processes guiding onward movements to create the broadest possible resource environment, or the gendered and burdensome process of care-receiving as an integral part of social protection. Studying these elements involved dealing with a series of methodological issues and limitations, and not all of them could be solved. In this section, I discuss some of these limitations and how they could lead to ideas for future research avenues.

This research provided rich insights on intra-family mechanisms around social protection. Yet, it could not address in depth the role of local-social networks (e.g. Sudanese associations), in the protection of its members. This was due to two main reasons: lack of time and the fact that my interviews did not reveal a strong role for Sudanese associations in the provision of social protection. In fact, both in the Netherlands and in the UK-as well as in other European countries (see Chapter 5) - the Sudanese migrant community is highly politicized, fragmented and heterogeneous, whereby divisions among the people hinder the establishment and smooth running of associations. Yet, although I did not pursue this issue, during fieldwork I observed some anecdotal evidence in which such divisions were forgotten and Sudanese from different backgrounds would gather efforts to informally support a co-national in crises. This was the case of funerals, when money was gathered across the Sudanese community (not only at the local level of the specific city where someone died, but at a national and even international level) to help the family with the funeral expenses and repatriation/travelling costs to Sudan. Although according to many of my respondents every Sudanese helped, this idea was not shared by other migrants, especially the undocumented and the newly arrived Sudanese. This raises questions on who actually helps who within the Sudanese migrant community and why. This area could be potentially fruitful for further research.

Some of the findings of this thesis relate to men and women separately, as is the case in Chapters 7 and 9, respectively, yet it is worth investigating how these findings relate to the other sex. Chapter 7 analyses the cases of male Sudanese migrants interacting with authorities in the Netherlands. Among my respondents I 
did not encounter women participating in such interactions. Yet, this does not mean that the phenomenon does not exist. In fact, while the Sudanese migration to Europe is male dominated (see Chapter 5), in recent years there has been an increase of Sudanese women arriving in Europe alone. Similarly, Chapter 9 focuses on caring practices within transnational families, highlighting how women navigate the unsolicited reception of care provided by their male relatives abroad. The ways in which men receive care in a transnational context could not be addressed in this research in a thorough manner, given my sample where I simply did not have enough male care-receivers. Yet, the ways in which men navigate the reception of care might be of relevance for understanding the guiding mechanisms of TSP arrangements. These findings should, therefore, encourage more research to investigate comparatively how and in which types of TSP arrangements the gender of the migrant and those back home plays a role. Moreover, future studies should collect more information on how single migrant women from countries traditionally characterised by sending male migrants, such as Sudan, navigate their social protection.

Rather than continuing to analyse TSP from the clear-cut division of formal and informal provisions, it is crucial for future research to acknowledge that often social protection needs are covered by a combination of formal and informal mechanisms working in symbiosis. The heuristic tool of resource environment is useful to overcome this dichotomy. Yet, rather than only looking at the resources available, it is important to bear in mind that not all resources available are equally accessible. Availability and accessibility to resources greatly depend on the migrant's capital (e.g., knowledge, skills, networks) and on the resources that migrants themselves can provide in return. The cases of countries among which there are bilateral social security agreements have the potential to bring relevant insights in this regard. Future research should address whether and how migrants make use of existing bilateral agreements between their country of origin and residence. In doing so, more attention should be focused on the interplay between formal and informal mechanisms, which might give way to new semi-formal instruments of social protection.

Finally, more research is needed to better understand the role of care-receivers in social protection arrangements within transnational families. To date, studies on transnational caregiving have mostly focused on the role of the caregiver and the burden to provide care in the distance. In Chapter 9 I have shown that care-while good intended-might actually have a negative impact on the care-receiver. Future research should question the assumption that care is per se a good thing to receive. Understanding the care-receivers' experiences is crucial to assess whether and at the expense of what/whom the care provided is actually meeting its objectives. 


\subsection{Policy recommendations}

This thesis has shown that international migration might present mobile populations-especially those moving from the Global South to the North-with particular dilemmas to cover for their own and their families' social protection needs. Although in the last years significant steps have been taken (e.g. bilateral agreements) to tackle such impasses, the findings in this dissertation have evidenced that certain aspects still need to be addressed. The findings of this research suggest that policies in sending and receiving countries could and should address some issues to improve social protection for mobile populations: 1) exploring and investing in semi-formal arrangements; 2) facilitating transnational family life and social protection arrangements.

\section{Exploring and investing in semi-formal arrangements}

Migrants' use - and misuse - of the welfare state in the receiving countries has become a major concern for policy makers. Despite the mixed results yielded by studies addressing the relationship between migration and a country's welfare system, the media, public opinion and political discourse continue to sustain the idea of 'welfare shopping'. This perception is partly due to the fact that in countries of the Global North, the welfare state is usually seen as the only and ultimate provider of social protection. It is no surprise, thus, that most research on migration and social protection has focused on issues of accessibility and portability of welfare benefits by migrants in the receiving countries (Sabates-Wheeler 2010). Indeed, the rise of formal social protection, mainly in developed countries, has generally overlooked the array of informal social protection mechanisms that have been taking place worldwide (Devereux \& Getu, 2013). This focus on the formal systems here has overlooked the ways in which social protection is devised in the sending countries, ignoring possible paths for interaction between formal and informal mechanisms across borders.

The ways in which migrants access social protection often goes beyond the formal provisions of the receiving welfare state. Therefore, in moving towards a more inclusive and fair TSP system, policy makers should identify and examine the emergence and functioning mechanisms of semi-formal institutions. In other words, in the provision of social protection across borders there is a need to look beyond the national welfare states of the receiving countries as the main source of social protection for mobile populations and activate new forms of networks, involving actors that used to act separately, namely, state-based institutions private and third sector actors, as well as with migrants themselves. The advantage of this cooperation models (e.g. transnational health insurance organisations, where migrants join forces with health insurance companies in the receiving country and healthcare providers in the origin country to cover for a number of relatives back home) is that they build on traditional community mechanisms to provide targeted social services to vulnerable groups, strengthening the links between governments and communities. 


\section{Facilitating transnational family life and social protection arrangements.}

Although access to social protection in host countries is essential for the wellbeing of migrants as individuals, migrants are often responsible for providing their families 'back home' in times of need. When some family members migrate, responsibilities and obligations remain for both: migrants and non-migrants. Nevertheless, providing for relatives abroad is often problematic.

Future development on TSP for mobile populations should go beyond what migrants can access here and also consider the migrants' responsibilities towards those 'back home'. This thesis has shown that even when the migrants' basic needs here are covered by the welfare state, their ability to provide for family members abroad continues to be limited, which leads them to seek alternative means across formal and informal provisions. Understanding how social protection is arranged in the Global South - where extended families play a crucial role in the sustenance of individuals and communities-should inform any development towards a more inclusive social protection system, where catering to a mobile population is increasingly a crucial factor. Facilitating the mobility of migrants and/or their families to address specific needs could facilitate social protection arrangements for transnational families. For example, the (health-)care needs of the migrants' elderly parents back home often becomes a major source of problems for transnational families. Even when the family has the financial resources to pay for a private operation/medical treatment in Europe, visas are frequently rejected. The intervention, thus, has to be conducted in another country, which often results in pushing other family members to relocate, which might have an impact on the wellbeing of their own lives and families. Some other times, when no other relatives are available, migrants must go and take care of their parents. In doing so, they must leave their jobs or stop their social assistance (e.g. receiving social assistance is bound to regular visits to the unemployment office). In the following paragraphs I suggest three tentative avenues to deal with these situations.

First, and most importantly, asylum seekers should be allowed to work from the very first day they arrive in their host country. As seen in different cases presented in this dissertation, people might spend years in the asylum seeking process, without being able to properly work. Although their basic needs are covered during this time, they may still be responsible for the needs of their families back home that they must support financially. Allowing them to work would be beneficial for the state (e.g. more taxes) and for the migrants themselves, in that they would be able to save money, which could be partly invested in the care of their families or in facilitating mutual visits.

Secondly, when asylum seekers obtain refugee status, they often spend several years retraining or doing volunteer jobs/internships, in order to gain experience and find a proper job. Volunteer jobs for migrants should be rewarded, for instance, in the 
form of additional time they can spend in their home country without having their social assistance benefits penalised. This would give people additional motivation to gain skills to enter the labour market.

Finally, European visa policy should facilitate border crossings of transnational families, for instance by allowing adult children, siblings or elderly parents 'back home' to visit their migrant parents, siblings and children through special visas. Currently, this is an expensive, uncertain and extremely time consuming process. In order to facilitate the circulation of people, both sending and receiving countries should join efforts and resources.

Given the increasing mobility of populations, developing a social protection system that allows for mobile lifestyles is increasingly imperative. In order to work towards a viable and comprehensive TSP system, it is necessary to understand the actual needs of the migrants and their families. Although this is by no means an easy task, both sending and receiving countries, as well as private companies, and third sector organisations must joint efforts to cater for the increasing number of people whose lives span beyond one national border. 


\section{REFERENCES}

A-Rahman, N. H. A., \& Jacquet, G. A. (2014). The state of emergency care in the Republic of the Sudan. African Journal of Emergency Medicine, 4, 55-60. http://doi.org/10.1016/j.afjem.2013.12.002

Abusabib, M. (2007). Sudanese diaspora in Sweden: challenges and prospects for contribution to democratization and reconstruction effort in Sudan. In U. J. Dahre (Ed.), The Role of Diasporas in Peace, Democracy and Development in the Horn of Africa (pp. 117-122). Lund: Media-Tryck Sociologen.

Abusharaf, R. M. (1997). Sudanese Migration to the New World: Socio-economic Characteristics. International Migration, 35(4), 513-536. http://doi.org/doi:10.1111/1468-2435.00025

Adam, E. A. M., \& Yousif, H. M. (2016). Factors that influence the changing in family function in Sudan (Khartoum case study). International Journal of Scientific Research in Science and Technology, 2(3), 77-84.

AFFORD. (2000). Globalisation and development: A diaspora dimension (Vol. 44). London.

Agrawal, R., \& Horowitz, A. W. (2002). Are international remittances altruism or insurance? Evidence from Guyana using multiple-migrant households. World Development, 30(11), 2033-2044. http://doi.org/10.1016/S0305-750X(02)00118-3

Ahrens, J., Kelly, M., \& van Liempt, I. (2016). Free Movement? The onward migration of EU citizens born in Somalia, Iran and Nigeria. Population, Space and Place, 22, 84-98. http://doi.org/10.1002/psp.1869

AIDA. (2017). Country Report: Netherlands.

Akuei, S. R. (2005a). Remittances as Unforeseen Burdens: The Livelihoods and Social Obligations of Sudanese Refugees. Global Migration Perspectives, 18(January), 1-17. Retrieved from http://www.starappeal.unhcr.org/40b1ea8a4.pdf

Akuei, S. R. (2005b). Sudan country study. Oxford. Retrieved from https://www.dfid.gov.uk/R4D/PDF/Outputs/EC-

PREP/InformalRemittanceSudanStudy.pdf

Al-Ali, N., Black, R., \& Koser, K. (2001). Refugees and transnationalism: The experience of Bosnians and Eritreans in Europe. Journal of Ethnic and Migration Studies, 27(4), 615634. http://doi.org/10.1080/13691830120090412

Al-Awad, A. E.-H., \& Sonuga-Barke, E. (1992). Childhood Problems in a Sudanese City: A Comparison of Extended and Nuclear Families. Society for Research in Child Development, 63(4), 906-914. Retrieved from file:///D:/PhD Maastricht (latest version)/Literature/Sudan/Family household from extended to nuclear.pdf

Alber, E., van Der Geest, S., \& Whyte, S. R. (2008). Generations in Africa: connections and conflicts. (E. Alber, S. van Der Geest, \& S. R. Whyte, Eds.). Münster: LIT Verlag.

Alpes, M. J. (2015). Social protection and migration control: The case of migrant care workers and Parisian welfare hotels. Transnational Social Review, 5(3), 296-311. http://doi.org/10.1080/21931674.2015.1082781

Alredaisy, S. (2011). Geography, gender and money profits in Sudanese general private education: The example of Khartoum State. Journal of Educational and Social Research, $1(2), 63-75$.

Ambrosini, M. (2012). Surviving underground: Irregular migrants, Italian families, invisible welfare. International Journal of Social Welfare, 21(4), 361-371. http://doi.org/10.1111/j.1468-2397.2011.00837.x

Ambrosini, M. (2015). NGOs and health services for irregular immigrants in italy: when the protection of human rights challenges the laws. Journal of Immigrant and Refugee Studies, 13(2), 116-134. http://doi.org/10.1080/15562948.2015.1017631

Ambrosini, M. (2017). Why irregular migrants arrive and remain: the role of intermediaries. 
Journal of Ethnic and Migration Studies, 43(11), 1813-1830. http://doi.org/10.1080/1369183X.2016.1260442

Amelina, A. (2010). Searching for an appropriate research strategy on transnational migration: The logic of multi-sited research and the advantage of the cultural interferences approach. Qualitative Social Research, 11(1), 1-15.

Amelina, A., \& Faist, T. (2012). De-naturalizing the national in research methodologies: key concepts of transnational studies in migration. Ethnic and Racial Studies, 35(10), 17071724. http://doi.org/10.1080/01419870.2012.659273

American Psychological Association. (n.d.). Education and Socioeconomic Status. http://doi.org/10.4135/9781412971959.n355

Amuedo-Dorantes, C., \& Pozo, S. (2006). Remittances as insurance: evidence from Mexican immigrants. Journal of Population Economics, 19(2), 227-254. http://doi.org/10.1007/s00148-006-0079-6

Andrew, F. A., \& Lukajo, N. M. (2005). Golden opportunities-reality or myth? Horn of Africa female migrants, refugees and asylum seekers in The Netherlands. Community Development Journal, 40(2), 224. http://doi.org/10.1093/cdj/bsi033

Antoine, P., Bry, X., \& Diouf, P. D. (1987). The "AGEVEN" record: A tool for collection of retrospective data. Survey Methodology, 13(2), 163-171.

Asian Development Bank. (2010). Grant Assistance Report Proposed Grant Assistance Regional: Social Protection of the Vulnerable in the Pacific (Cook Islands, Marshall Islands, and Tonga).

Assal, M. (2004). Sitcky Labels or Rich Ambiguities? Diaspora and challenges of homemaking for Somalis and Sudanese in Norway. University of Bergen.

Assal, M. (2006). Somalis and Sudanese in Norway-Religion, ethnicity/clan and politics in the diaspora. In M. Assal (Ed.), Diasporas within and without Africa: Dynamism, Hetereogeneity, Variation (p. 240). Uppsala: Nordiska Afrikainstitutet. Retrieved from http://staffcr.uofk.edu/Economic/dept-of-sociology/Dr.ManzoulAbdalla/downloads/Somalis and Sudanese in Norway.pdf

Assal, M. (2010). Highly-skilled Sudanese migrants: Gain or drain? (Highly-skilled Migration Series No. CARIM-AS 2010/13). San Domenico di Fiesole.

Avato, J., Koettl, J., \& Sabates-Wheeler, R. (2009). Definitions, Good Practices, and Global Estimates on the Status of Social Protection for International Migrants. (Social Protection Discussion Paper No. 0909).

Avato, J., Koettl, J., \& Sabates-Wheeler, R. (2010). Social security regimes, global estimates, and good practices: the status of social protection for international migrants. World Development, 38(4), 455-466. http://doi.org/10.1016/j.worlddev.2009.10.003

Azam, J. P., \& Gubert, F. (2006). Migrants' remittances and the household in Africa: A review of evidence. Journal of African Economies, 15(2), 426-462. http://doi.org/10.1093/jae/ej1030

Baak, M. (2015). Transnational families, remittances, cieng and obligation for Dinka women in Australia. Emotion, Space and Society, 16, 123-129. http://doi.org/10.1016/j.emospa.2014.08.001

Bähre, E. (2007). Money and violence. Financial Self-Help Groups in a South African Township. Leiden: Brill.

Baker, S. E., \& Edwards, R. (2012). How many qualitative interviews is enough? Expert voices and early career reflections on sampling and cases in qualitative research. Retrieved from http://eprints.soton.ac.uk/336913/

Bakewell, O. (2009). 'Keeping Them in Their Place': the ambivalent relationship between development and migration in Africa. Third World Quarterly, 29(7), 1341-1358. http://doi.org/10.1080/01436590802386492

Bakker, I. (2007). Social reproduction and the constitution of gendered political economy. New Political Economy, 12(4), 541-556.

Bakker, I., \& Gill, S. (2003). Power, Production and Social Reproduction. (I. Bakker \& S. Gill, Eds.). London and New York: Macmillan-Palgrave.

Bakker, I., \& Silvey, R. (Eds.). (2008). Beyond States and Markets: the Challenges of Social 
Reproduction. Abingdon and New York: Routledge.

Bakker, L., Cheung, S. Y., \& Phillimore, J. (2016). The asylum-integration paradox: comparing asylum support systems and refugee integration in the Netherlands and the UK. International Migration, 54(4), 118-132. http://doi.org/10.1111/imig.12251

Bakker, L., Dagevos, J., \& Engbersen, G. (2014). The importance of resources and security in the socio-economic integration of refugees. A study on the impact of length of stay in asylum accommodation and residence status on socio-economic integration for the four largest refugee groups in the Netherlan. Journal of International Migration and Integration, 15(3), 431-448. http://doi.org/10.1007/s12134-013-0296-2

Baldassar, L. (2007). Transnational families and aged care: The mobility of care and the migrancy of ageing. Journal of Ethnic and Migration Studies, 33(2), 275-297. http://doi.org/10.1080/13691830601154252

Baldassar, L., Baldock, C. V., \& Wilding, R. (2007). Families Caring Across Borders. New York: Palgrave Macmillan.

Baldassar, L., \& Merla, L. (2014). Transnational Families, Migration and the Circulation of Care. (L. Baldassar \& L. Merla, Eds.). New York: Routledge.

Baldwin-Edwards, M. (2004). Immigrants and the welfare state in Europe. In D. S. Massey \& J. E. Taylor (Eds.), International Migration. Prospects and Policies in a Global Market. Oxford: Oxford University Press.

Baloul, I., \& Dahlui, M. (2014). Determinants of health insurance enrolment in Sudan: evidence from Health Utilisation and Expenditure Household Survey 2009. BMC Health Services Research, 14(2). http://doi.org/http://doi.org/10.1186/1472-6963-14-S2-O17

Bang-Nielsen, K. (2004). Next stop Britain: The Influence of transnational networks on the secondary movement of Danish Somalis. (Sussex Migration Working Paper No. 22). Brighton. Retrieved from https://www.sussex.ac.uk/webteam/gateway/file.php?name=mwp22.pdf\&site=252

Barberis, E., \& Boccagni, P. (2014). Blurred rights, local practices: Social work and immigration in Italy. British Journal of Social Work, 44(SUPPL. 1), 70-87. http://doi.org/10.1093/bjsw/bcu041

Barnes, M. (2012). Care in Everyday Life. An Ethic of Care in Practice. Bristol: The Policy Press. University of Bristol.

Barrett, C. B., \& Bhattamishra, R. (2008). Community-based Risk Management Arrangements: An Overview and Implications for Social Fund Programs (No. 0830). Cornell.

Basch, L., Glick Schiller, N., \& Szanton Blanc, C. (1994). Nations Unbound: Transnational Projects, Postcolonial Predicaments, and Deterritorialized Nation-States. (L. Basch, N. Glick Schiller, \& C. Szanton Blanc, Eds.). London: Gordon and Breach.

Batnitzky, A., \& McDowell, L. (2011). Migration, nursing, institutional discrimination and emotional/affective labour: ethnicity and labour stratification in the UK National Health Service. Social \& Cultural Geography, 12(2), 181-201. http://doi.org/10.1080/14649365.2011.545142

Béland, D., Blomqvist, P., Andersen, J. G., Palme, J., \& Waddan, A. (2014). The universal decline of universality? Social policy change in Canada, Denmark, Sweden and the UK. Social Policy and Administration, 48(7), 739-756. http://doi.org/10.1111/spol.12064

Bernardi, L. (2011). A mixed-methods social networks study design for research on transnational families. Journal of Marriage and Family, 73(4), 788-803. http://doi.org/10.1111/j.

Berry, L. (Ed.). (2015). Sudan: a country study (5th ed.). n.a.: Federal Research Division, Library of Congress. Retrieved from http://countrystudies.us/germany

Betts, A. (2013). Survival Migration. Failed Governance and the Crisis of Displacement. New York: Cornell University Press.

Bhattamishra, R., \& Barrett, C. B. (2008). Community-based risk management arrangements. Cornell: Cornell University.

Bilecen, B. (2013). Analyzing Informal Social Protection Across Borders: Synthesizing Social Network Analysis with Qualitative Interviews Başak Bilecen (SFB 882 No. 19). Bielefeld. 
Bilecen, B., \& Barglowski, K. (2015). On the assemblages of informal and formal transnational social protection. Population, Space and Place, 21(3), 203-214. http://doi.org/10.1002/psp

Biswas, D., Toebes, B., Hjern, A., Ascher, H., \& Nørredam, M. (2013). Access to health care for undocumented migrants from a human rights perspective: A comparative study of Denmark, Sweden, and the Netherlands. Health and Human Rights, 14(2).

Bjeren, G. (1997). Gender and reproduction. In T. Hammar, G. Brochmann, K. Tamas, \& T. Faist (Eds.), International Migration, Immobility and Development. (pp. 219-49). Oxford: Berg.

Bloch, A. (2008). Refugees in the UK labour market: The conflict between economic integration and policy-led labour market restriction. Journal of Social Policy, 37(1), 2136. http://doi.org/10.1017/S004727940700147X

Boccagni, P. (2011). Migrants ' social protection as a transnational process : public policies and emigrant initiative in the case of Ecuador. International Journal of Social Wellfare, 20(3), 318-325. http://doi.org/10.1111/j.1468-2397.2010.00747.x

Boccagni, P. (2013). Caring about migrant care workers: from private obligations to transnational social welfare? Critical Social Policy, 32(2), 221-240. http://doi.org/10.1177/0261018313500867

Boccagni, P. (2015). Burden, blessing or both? On the mixed role of transnational ties in migrant informal social support. International Sociology, 30(3), 250-268. http://doi.org/10.1177/0268580915570508

Boddy, J. (1989). Wombs and Alien Spirits. Women, Men and the Zar Cult in Northern Sudan. Madison: The University of Wisconsin Press.

Bommes, M., \& Kolb, H. (2002). Foggy social structures in a knowledge-based society-Irregular migration, informal economy and the political system. Osnabruck: Institut für Migrationsforschung und Interkulturelle Studien.

Bondi, L. (2008). On the relational dynamics of caring: A psychotherapeutic approach to emotional and power dimensions of women's care work. Gender, Place and Culture, 15(3), 249-265. http://doi.org/10.1080/09663690801996262

Bonizzoni, P. (2012). Civic stratification, stratified reproduction and family solidarity: Strategies of Latino families in Milan. In A. Kraler, E. Kofman, M. Kohli, \& C. Schmoll (Eds.), Gender, generations and the family in international migration. (p. 404). Amsterdam: Amsterdam University Press.

Borjas, G. J. (1999). Immigration and welfare magnet. Journal of Labor Economics, 17, 60737.

Bouman, J. A. (1994). ROSCA and ASCRA : Beyond the Financial Landscape. In Financial Landscapes Reconstructed. The Fine Art of Mapping Development. Boulder: Westview.

Boyatzis, R. E. (1998). Transforming Qualitative Information: Thematic Analysis and Code Development. London: SAGE.

Broeders, D., \& Engbersen, G. (2007). The fight against illegal migration: identification policies and immigrants' counterstrategies. American Behavioral Scientist, 50. http://doi.org/10.1177/0002764207302470

Broeders, D., \& Engbersen, G. (2007). The fight against illegal migration. identification policies and immigrants' counterstrategies. American Behavioral Scientist, 50(12), 15921609. http://doi.org/10.1177/0002764207302470

Broomfield, L. (2014). Migrant Access to Social Security and Healthcare: Policies and Practices in the United Kingdom. The Home Office. Retrieved from http://www.emn.fi/files/855/Laura_Broomfield_Migrants_access_to_social_security _and_healthcare_Yhteensopivuustila_.pdf

Brown, R. (1992). Migrants' Remittances, Capital Flight, and Macroeconomic Imbalance in Sudan's Hidden Economy. Journal of African Economies, 1(1), 86-108.

Brown, R. P. C., Connell, J., \& Jimenez-Soto, E. V. (2014). Migrants' remittances, poverty and social protection in the South Pacific: Fiji and Tonga. Population, Space and Place, 20, 434-454. http://doi.org/10.1002/psp 
Brueckner, J. K. (2000). Welfare Reform and the Race to the Bottom: Theory and Evidence. Southern Economic Journal, 66, 505-525. http://doi.org/10.2307/1061423

Bruquetas-Callejo, M., Garcés-Mascareñas, B., Penninx, R., \& Scholten, P. (2007). Policymaking related to immigration and integration. The Dutch Case. (IMISCOE Country Report: Working Paper No. 15).

Bryceson, D., \& Vuorela, U. (Eds.). (2002). The Transnational Family. Oxford: Berg.

Bryman, A. (2004). Social Research Methods (Second). New York: Oxford University Press.

Caarls, K. (2015). Living Apart Together Across Borders. Maastricht University.

Carling, J. (2012). Collecting, Analysing and Presenting Migration Histories. In C. VargasSilva (Ed.), Handbook of Research Methods in Migration (pp. 137-162). Cheltenham: Edward Elgar.

Castles, S. (1986). The guest-worker in Western Europe-An obituary. Internationanl Migration Review, 20(4), 761-778.

Castles, S., de Haas, H., \& Miller, M. J. (2014). The Age of Migration. International Population Movements in the Modern World. London: Palgrave Macmillan.

Castles, S., \& Delgado-Wise, R. (2007). Migration Development : Perspectives from the South. (S. Castles \& R. Delgado-Wise, Eds.). Geneva: International Organization for Migration.

CBS. (2018). Statistics Netherlands - CBS StatLine. Retrieved February 2, 2018, from https://opendata.cbs.nl/statline/\#/CBS/nl/

Chauvin, S., \& Garcés-Mascareñas, B. (2012). Beyond informal citizenship: The new moral economy of migrant illegality. International Political Sociology, 6(3), 241-259. http://doi.org/10.1111/j.1749-5687.2012.00162.x

Chelpi-den Hamer, M., \& Mazzucato, V. (2010). The role of support networks in the initial stages of integration: the case of West African newcomers in the Netherlands. International Migration., 48(2), 31-57. http://doi.org/10.1111/j.14682435.2009.00545.x

Cindoglu, D. (1997). Virginity tests and artificial virginity in modern Turkish medicine. Women's Studies International Forum, 20(2), 253-261. http://doi.org/10.1016/S02775395(96)00096-9

Citizens Advice. (2017a). Citizens Advice. Retrieved August 10, 2017, from https://www.citizensadvice.org.uk/family/education/school-education/access-toeducation/\#compulsory_school_age

Citizens Advice. (2017b). Citizens Advice. Retrieved August 10, 2017, from https://www.citizensadvice.org.uk/benefits/coming-from-abroad-and-claimingbenefits-the-habitual-residence-test/eea-nationals-and-the-habitual-residence-test/eeanationals-claiming-benefits-as-a-jobseeker/

Citizens Advice. (2017c). Citizens Advice. Retrieved August 10, 2017, from https://www.citizensadvice.org.uk/health/help-with-health-costs/nhs-charges-forpeople-from-abroad/

Clark, I., \& Grant, A. (2015). Sexuality and danger in the field: starting an uncomfortable conversation. JASO: Special Issue on Sexual Harassment in the Field, 1-14.

COA. (2017). Living at an Asylum Seeking Centre. Retrieved October 15, 2017, from https://www.coa.nl/en/asylum-seekers/living-at-an-asylum-seekers-centre

Coe, C. (2011). What is the impact of transnational migration on family life? Women's comparisons of internal and international migration in a small town in Ghana. American Ethnologist, 38, 148-163. http://doi.org/10.1111/j.1548-1425.2010.01298.x

Collins, R. (2008). A History of Modern Sudan. Cambridge: Cambridge University Press.

Conway, D. (2007). A Nation of Immigrants? A Brief Demographic History of Britain. London.

Cooke, T. J. (2008). Migration in a family way. Population, Space and Place, 14(4), 255-265.

Crowther, N., Okamura, K., Raja, C., Rinnert, D., \& Spencer, E. (2014). Inequalities in Public Services in the Sudan. London.

Crul, M. (2009). The educational progress of children of Turkish descent in the Netherlands. International Journal on Multicultural Societies, 11(2), 195-211. Retrieved from https://pure.uva.nl/ws/files/1031768/97342_331411.pdf 
Cuadra, C. B. (2010a). Policies on health care for undocumented migrants in EU27. Country report: United Kingdom. (Healthcare in Nowhereland. Improving services for undocumented migrants in the EU. No. 6). Malmo.

Cuadra, C. B. (2010b). Policies on Health Care for Undocumented Migrants in EU27 Country Report The Netherlands. Malmo.

Cuadra, C. B. (2012). Right of access to health care for undocumented migrants in EU: a comparative study of national policies. European Journal of Public Health, 22(2), 267-71. http://doi.org/10.1093/eurpub/ckr049

Cuadra, C. B., \& Staaf, A. (2014). Public Social Services' encounters with irregular migrants in Sweden: amid values of social work and control of migration. European Journal of Social Work, 17(1), 88-103. http://doi.org/10.1080/13691457.2012.739556

Dabanga. (2017). Poor suffer as cost of living leaves Sudan's minimum wage far behind. Retrieved April 18, 2018, from https://www.dabangasudan.org/en/allnews/article/poor-suffer-as-cost-of-living-leaves-sudan-s-minimum-wage-far-behind

Dankyi, E., Mazzucato, V., \& Manuh, T. (2017). Reciprocity in global social protection: providing care for migrants' children. Oxford Development Studies, 45(1). http://doi.org/10.1080/13600818.2015.1124078

Davies, M., Commander, S., \& Zaman, C. (2011). Social Protection in EU Development Cooperation. Report on the Key Results of the Consultations with Stakeholders.

de Certeau, M. (1984). The practice of everyday life. Berkeley: University of California Press.

de Haas, H. (2006). Engaging Diasporas. How governments and development agencies can support involvement in the development of origin countries. Oxford.

De Haas, H. (2007a). Migration and Development: A Theoretical Perspective (No. 29, 2007). Bielefeld. Retrieved from http://onlinelibrary.wiley.com/doi/10.1111/j.17477379.2009.00804.x/full

De Haas, H. (2007b). Remittances, Migration and Social Development. A Conceptual Review of the Literature. Social Policy and Development. Geneva. Retrieved from https://www.tandfonline.com/doi/full/10.1080/17496535.2017.1300305

De Haas, H. (2010). Migration and Development: A Theoretical Perspective. International Migration Review, 44(1), 227-264. http://doi.org/10.1111/j.1747-7379.2009.00804.x

De Haas, H., \& Fokkema, T. (2010). Intra-household conflicts in migration decisionmaking: Return and pendulum migration in Morocco. Population and Development Review, 36(3), 541-561. http://doi.org/10.1111/j.1728-4457.2010.00345.x

de Neubourg, C. (2002). The Welfare Pentagon and the Social Management of Risks. In R. Sigg \& Behrendt (Eds.), Social Security in the Global Village (pp. 313-331). New Brunswick: Transaction Publishers.

de Neubourg, C., \& Weigand, C. (2000). Social policy as social risk management. Innovation: The European Journal of Social Science Research, 13(4), 401-412.

Dell'Olio. (2004). Immigration and immigrant policy in Italy and the UK: is housing policy a barrier to a common approach towards immigration in the EU? Journal of Ethnic and Migration Studies, (1), 107-128. http://doi.org/http://dx.doi.org/10.1080/1369183032000170196

Demireva, N. (2011). New migrants in the UK: employment patterns and occupational attainment. Journal of Ethnic and Migration Studies, 37(4), 637-655. http://doi.org/10.1080/1369183X.2011.545308

Denzin, N. K., \& Lincoln, Y. S. (2011). The Sage handbook of qualitative research. (Second). Thousand Oaks, CA: SAGE.

DESTATIS. (2018). GENESIS Online Datenbank. Retrieved July 16, 2018, from https://www.destatis.de/EN/Homepage.html

Devereux, S., \& Getu, M. (2013). Informal and formal social protection systems in Sub-Saharan Africa. Kampala: Fountain Publishers.

Devereux, S., Roelen, K., Ulrichs, M., \& Martina, U. (2015). Where Next for Social Protection? London. Retrieved from http://opendocs.ids.ac.uk/opendocs/bitstream/handle/123456789/5945/ER124_W 
hereNextforSocialProtection.pdf?sequence $=5$

Devereux, S., \& Sabates-Wheeler, R. (2004). Transformative social protection (No. 232). Brighton.

Di Bartolomeo, A., Jaulin, T., \& Perrin, D. (2012). CARIM-Migration Profile: Sudan. Migration Profile. Robert Schuman Centre for Advanced Studies. Retrieved from http://carimsouth.eu/carim/public/migrationprofiles/MP_Sudan_EN.pdf

DLIFCL. (2016). Cultural Orientation - Arabic Sudanese. Monterrey (CA). Retrieved from http://fieldsupport.dliflc.edu/products/sudanese/av_co/sudanese.pdf

Doctors of the World. (2015). Access to healthcare in the UK. Doctors of the World UK. London.

DRCMGP. (2008). Social Protection of Migrants from the Global South: Protection gaps and strategies to 'self-insure'. Development Centre on Migration, Globalisation and Poverty.

Retrieved http://www.migrationdrc.org/publications/briefing_papers/BP14.pdf

Dreby, J., \& Adkins, T. (2010). Inequalities in transnational families. Sociology Compass, 4(8), 673-689. http://doi.org/10.1111/j.1751-9020.2010.00297.x

Dwyer, P. (2004). Creeping conditionality in the UK: From welfare rights to conditional entitlements? Canadian Journal of Sociology, 29(2), 265-287. http://doi.org/10.1353/cjs.2004.0022

Eissa, G. S. (2013). Microcredit as a Strategy for Poverty Reduction: A Case Study of the Sudan., 9(4), 557-570.

Elnur, I. (2002). The second boat of Africa's new diaspora: Looking at the other side of the global divide with an emphasis on Sudan. African Issues, 30(1), 37-41. http://doi.org/10.2307/1167088

Enchautegui, M. E. (1997). Welfare Payments and Other Determinants of Female Migration. Journal of Labor Economics, 15, 529-554. http://doi.org/10.1086/209871

Engbersen, G., \& Broeders, D. (2009). The state versus the alien: immigration control and strategies of irregular immigrants. West European Politics, 32(5), 867-885. http://doi.org/10.1080/01402380903064713

Engbersen, G., \& Broeders, D. (2011). Immigration control and strategies of irregular immigrants: From light to thick fog. In M. Bommes \& G. Sciortino (Eds.), Foggy Social Structures Irregular Migration, European Labour Markets and the Welfare State. Amsterdam: Amsterdam University Press.

Entzinger, H. (2006). Changing the rules while the game is on; from multiculturalism to assimilation in the Netherlands. In M. Bodemann \& G. Yurdakul (Eds.), Migration, Citizenship, Ethnos: Incorporation Regimes in Germany, Western Europe and North America. (pp. 121-144). New York: Palgrave Macmillan.

Esping-Andersen, G. (1990). The Three Worlds of Welfare Capitalism. (P. Press, Ed.). Cambridge.

Essien, K., \& Falola, T. (2009). Culture and Customs of Sudan. Westport: Greenwood Press.

European Commission. (2017a). European Commission: Employment, social affairs and inclusion. Retrieved April 24, 2018, from http://ec.europa.eu/social/main.jsp?catId=1132\&langId=en

European Commission. (2017b). European Commission: Employment, Social Affairs and Inclusion. Retrieved August 10, 2017, from http://ec.europa.eu/social/main.jsp?catId=1122\&langId=en

European Migration Network. (2013). The Organisation of reception facilities for asylum seekers in Different Member States. The Netherlands. EMN Focused Study 2013: The Organisation of reception facilities for asylum seekers in Different Member States. Retrieved from http://static.rasset.ie/documents/news/esri-report-asylum.pdf

European Migration Network. (2014). Migrant Access to Social Security and Healthcare: Policies and Practice in the Netherlands.

Eurostat Database. (2018a). Eurostat Database. Retrieved June 3, 2018, from http://appsso.eurostat.ec.europa.eu/nui/show.do?dataset=migr_imm3ctb\&lang=en

Eurostat Database. (2018b). Eurostat Database. Retrieved July 6, 2018, from 
http://appsso.eurostat.ec.europa.eu/nui/submitViewTableAction.do

Eurostat Database. (2018c). Eurostat Database. Retrieved June 16, 2018, from http://appsso.eurostat.ec.europa.eu/nui/show.do?dataset=lfsa_urgacob\&lang=en.

Evertsson, M., England, P., Mooi-Reci, I., Hermsen, J., de Bruijn, J., \& Cotter, D. (2009). Is gender inequality greater at lower or higher educational levels?: Common patterns in the Netherlands, Sweden, and the United States. Social Politics, 16(2), 210-241. http://doi.org/10.1093/sp/jxp008

Fabos, A. (2007). Between citizenship and belonging: Transnational ethnic strategies of Muslim Arab Sudanese in the diaspora. Kvinder, Kon \& Forskning, 2(3), 49-61. Retrieved from https://tidsskrift.dk/\%0Aindex.php/KKF/article/view/44262.

Faist, T. (2000). Transnationalization in international migration: implications for the study of citizenship and culture. Ethnic and Racial Studies, 23(2), 189-222. http://doi.org/10.1080/014198700329024

Faist, T. (2013). Transnational Social Protection : An Emerging Field of Study (No. 113). Bielefeld.

Faist, T. (2014). On the transnational social question: How social inequalities are reproduced in Europe. Journal of European Social Policy, 24(3), 207-222. http://doi.org/10.1177/0958928714525814

Faist, T., Amelina, A., Bilecen, B., \& Barglowski, K. (2012). Ties That Protect? The Significance of Transnationality for the Distribution of Informal Social Protection in Migrant Networks (SFB 882 No. 6).

Faist, T., \& Bilecen, B. (2015). Social inequalities through the lens of social protection: Notes on the transnational social question. Population, Space and Place, 21(3), 282-293. http://doi.org/10.1002/psp

Faist, T., Bilecen, B., Barglowski, K., Sienkiewicz, J. J., Bilicen, B., \& Sienkiewicz, J. J. (2014). Transnational Social Protection: Migrants 'Strategies and Patterns of Inequalities. Population, Space and Place, 21(3), 193-202. http://doi.org/10.1002/psp

Falzon, M.-A. (2009). Multi-sited Ethnography. Theory, Praxis and Locality in Contemporary Research. (M.-A. Falzon, Ed.). Surrey: Ashgate Publishing, Ltd.

Fernandes, S. (2016). Access To Social Benefits For EU Mobile Citizens: "Tourism" Or Myth? (Policy Paper No. 168). Retrieved from http://institutdelors.eu/wpcontent/uploads/2018/01/socialbenefitseumobilecitizens-fernandes-jdi-june16.pdf

Finch, J., \& Mason, J. (1993). Negotiating family responsibilities. London: Routledge.

Fisher, B., \& Tronto, J. (1990). Toward a Feminist Theory of Caring. In E. K. Abel \& M. K. Nelson (Eds.), Circles of care: Work and identity in women's lives. (pp. 35-62). New York: State University of New York Press.

Fitzpatrick, S., Bramley, G., Blenkinsopp, J., Johnsen, S., Littlewood, M., Netto, G., ... Watts, B. (2015). Destitution in the UK: An interim report. York. Retrieved from http://www.jrf.org.uk/sites/files/jrf/destitution.pdf

Flegar, V., Dalli, M., \& Toebes, B. (2016). Access to preventive health care for undocumented migrants: A comparative study of Germany, The Netherlands and Spain from a Human Rights perspective. Laws, 5(9). http://doi.org/10.3390/laws5010009

Fluehr-Lobban, C. (2006). The Sudanese Family: Past Refelctions and Contemporary Realities. In Y. Oheneba-Sakyi \& B. Takyi (Eds.), African Families at the Turn of the 21st Century. (pp. 69-82). London: Praeger.

Fog-Olwig, K. (2007). Caribbean Journeys. An Ethnography of Migration and Home in Three Family Networks. Durham: Duke University Press.

Fokas, E. (2013). Welfare as a missing link in immigrant integration? Insights from a Greek case. In New Generation Research on a Changing Greece (p. 13-). Athens: KERKYRA Publications SA.

Fonchingong, C. C. (2014). Firming Up Institutional Policy for Deprived Elderly in Cameroon. Politics and Policy, 42(6), 948-980. http://doi.org/10.1111/polp.12003/abstract

Fresnoza-Flot, A. (2014). Men's caregiving practices in Filipino transnational families: A 
case-study of the left behind fathers and sons. In Transnational Families, Migration and the Circulation of Care. (pp. 170-184). New York: Routledge.

Fultz, E., \& Pieris, B. (1999). Social Security Schemes in Southern Africa. An Overview and Proposals for Future Development (No. 11). Geneva.

Gasim, G. (2010). Reflecting on Sudan's Higher Education Revolution under Al-Bashir's Regime. Comparative \& International Higher Education, 2, 50-53. Retrieved from http://higheredsig.org/cihe/Number02-

15.pdf\%5Cnhttp://www.higheredsig.org/cihe/Number02-15.pdf

Gassmann, F., Siegel, M., Vanore, M., \& Waidler, J. (2017). Does it matter where the children are? The impact of migration on elderly left behind in Moldova. Aging \& Society, 37, 607-632. http://doi.org/10.1017/S0144686X15001385

Geddes, A. (2003). Migration and the Welfare State in Europe. Political Quarterly, 74(SPEC ISS.), 150-162. http://doi.org/10.1111/j.1467-923X.2003.00587.x

Geertz, C. (1973). The Interpretation of Cultures: Selected Essays. London: Fontana Press.

Gendera, S. (2011). Gaining an insight into Central European transnational care spaces: Migrant live-in care workers in Austria. In M. Bommes \& G. Sciortino (Eds.), Foggy Social Structures. Amsterdam: Amsterdam University Press.

Ghorashi, H. (2005). Agents of change or passive victims: the impact of welfare states (the case of the Netherlands) on refugees. Journal of Refugee Studies, 18(2), 181-198. http://doi.org/10.1093/refuge/fei020

Glade, R. (2015). Social activism and transnational networks: Nafeer and Sudanese flood relief. Sudan Studies Association, 33(1).

Godshaw, D. (2014). A masculinist perspective on gendered relations of power: Rwandan migrant men in the UK (No. 72). Sussex.

Gov.UK. (2017). Gov.UK. Retrieved August 10, 2017, from https://www.gov.uk/asylumsupport/print

Grillo, R., \& Mazzucato, V. (2008). Africa < > Europe: A double engagement. Journal of Ethnic and Migration Studies, 34(2), 175-198. http://doi.org/10.1080/13691830701823830

Guarnizo, L. E., Portes, A., \& Haller, W. (2003). Assimilation and transnationalism: Determinants of transnational political action among contemporary migrants. American Journal of Sociology, 108(6), 1211-1248. http://doi.org/10.1086/375195

Guest, G., Bunce, A., \& Johnson, L. (2006). How many interviews are enough?: An experiment with data saturation and variability. Field Methods, 18(1), 59-82. http://doi.org/10.1177/1525822X05279903

Hagerstrand, T. (1970). What about people in regional science? Papers of the Regional Science Association, 24(1), 7-21.

Hamid, G. M., \& Mohamed-Elhassan, A. a. (2014). Incremental housing as an alternative housing policy: evidence from Greater Khartoum, Sudan. International Journal of Housing Policy, 14(2), 181-195. http://doi.org/10.1080/14616718.2014.908576

Hammersley, M., \& Atkinson, P. (1995). Ethnography: Principles in practice. (Second). London: Routledge.

Hannerz, U. (2003). Being there . . . and there . . . and there! Reflections on multi-site ethnography. Ethnography, 4(2), 201-216.

Hansen, R. (2017). Country Profile: United Kingdom. Osnabrück. Retrieved from http://www.heritage.org/index/country/unitedkingdom\#rule-of-law

Harding, C., Wheaton, B., \& Butler, A. (2017). Childcare survey 2017. Retrieved from file:///C:/Users/Ester/Downloads/Childcare Survey 2017_Family and Childcare Trust.pdf

Hassan, H. M. (2011). Social protection and economic growth in the Sudan: Trends, perspectives, cointegration and causality. (No. 31442). Munich: Munich Personal RePEc Archive. Retrieved from http://mpra.ub.uni-muenchen.de/31442/

Hemerijck, A. (2013). Changing Welfare States. Oxford: Oxford University Press.

Henry, L., \& Mohan, G. (2003). Making homes: the Ghanaian diaspora, institutions and 
development. Journal of International Development, 15(5), 611-622. http://doi.org/10.1002/jid.1019

Hochschild, A. R. (2000). Global care chains and emotional surplus value. In W. Hutton \& A. Giddens (Eds.), On the edge: living with global capitalism. (pp. 130-46). London: Jonathan Cape.

Holliday, A. (2007). Doing and Writing Qualitative Research (Second). London: SAGE Publications Ltd.

Holzmann, R. (2016). Do bilateral social security agreements deliver on the portability of pensions and health care benefits? A summary policy paper on four migration corridors between EU and non-EU member states. IZA Journal of European Labor Studies, 5(17). http://doi.org/10.1186/s40174-016-0067-0

Holzmann, R., \& Koettl, J. (2011). Portability of pension, health, and other social benefits: Facts, concepts, issues. (No. 5715). Bonn. Retrieved from http://nbnresolving.de/urn:nbn:de:101:1-201105306410

Holzmann, R., \& Koettl, J. (2014). Portability of pension, health, and other social benefits: Facts, concepts, and issues. CESifo Economic Studies, 61(2), 377-415.

Hondagneu-Sotelo, P. (1992). Overcoming patriarchal constrainsts: The reconstruction of Gender relations among Mexican immigrants women and men. Gender \& Society, 6(3), 393-415. Retrieved from http://www.jstor.org/stable/189994

Hondagneu-Sotelo, P. (1994). Gendered Transitions. Berkeley: University of California Press.

Hondagneu-Sotelo, P., \& Avila, E. (1997). "I'm here, but I'm there": The meanings of Latina Transnational motherhood. Gender and Society, 11, 548-571. Retrieved from http://www.jstor.org/stable/190339

Hopkins, P. E. (2007). Positionalities and knowledge: Negotiating ethics in practice. $C M E$ : An International Journal for Critical Geographies., 6(3), 386-394.

Horst, C. (2012). Expanding Sites: The Question of 'Depth' Explored. In M.-A. Falzon (Ed.), Multi-sited ethnography: Theory, praxis and locality in contemporary research (pp. 119-135). Ashgate Publishing, Ltd.

IDMC. (2007). Sudan: Outlook for IDPs remains bleak. Geneva. Retrieved from http://www.internal-displacement.org/assets/library/Africa/Sudan/pdf/sudanoverview-oct07.pdf

ILO. (2000). World Labour Report: Income Security and Social Protection in a Changing World. Geneva.

ILO. (2014). World Social Protection Report 2014/15. Building Economic Recovery, Inclusive Development and Social Justice. Geneva.

ILO. (2017). World Social Protection Report 2017-2019. Geneva. Retrieved from http://www.ilo.org/wcmsp5/groups/public/---dgreports/---dcomm/--publ/documents/publication/wcms_604882.pdf

IMF. (2014). Sudan. IMF Country Report No. 14/364.

IOM. (2006). Sudan: Mapping Exercise. London. Retrieved from http://www.iomlondon.org/doc/mapping/IOM_ETHIOPIA.pdf

IOM. (2011). Migration in Sudan. A Country Profile 2011. Khartoum.

IOM. (2015). 2015 Situation Report on International Migration Migration, Displacement and Development in a Changing Arab Region. Beirut.

Itzigsohn, J., Cabral, C. D., Medina, E. H., \& Vazquez, O. (1999). Mapping Dominican transnationalism: narrow and broad transnational practices. Ethnic and Racial Studies, 22(2), 316-339.

Jones, M., \& Lowe, R. (Eds.). (2002). From Beveridge to Blair: The First Fifty Years of Britain's Welfare State 1948-98. Manchester: Manchester University Press.

Justino, P. (2003). Social security in developing countries: Myth or necessity? Evidence from India. (Prus working paper No. 20). Brighton. Retrieved from https://core.ac.uk/download/pdf/6301572.pdf

Kandiyoti, D. (1988). Bargaining with patriarchy. Gender \& Society, 2(3), 274-290.

Kasente, D. (2006). Gender and Social Security Reform in Africa. In SADC Social Security 
Specialists Conference. Gender and Social Security in the SADC Region. Kampala: Makerere University.

Kasente, D., Asingwire, N., Banugire, F., Kyomuhendo, S., Musenge, L., Kalikiti, W., \& Musenge, D. K. (2002). Social security systems in Uganda. Journal of Social Development in Africa, 17(2), 157-183.

Kelly, M. (2013). Onward migration. The transnational trajectories of Iranians leaving Sweden. Uppsala University.

Kenyon, S. M. M. (1994). Gender and alliance in central Sudan. Journal of Cross-Cultural Gerontology, 9(2), 141-155.

Kilkey, M. (2014). Polish male migrants in London: The circulation of fatherly care. In Transnational Families, Migration and the Circulation of Care. (pp. 185-200). New York: Routledge.

Kilkey, M., \& Merla, L. (2014). Situating transnational families' care-giving arrangements : the role of institutional contexts. Global Networks, 14(2), 210-247. Retrieved from http://onlinelibrary.wiley.com/doi/10.1111/glob.12034/full

Kivisto, P. (2001). Theorizing transnational immigration: a critical review of current efforts. Ethnic and Racial Studies, 24(4), 549-577. http://doi.org/10.1080/0141987012004978

Kjellgren, A., Jones-Pauly, C., El-tayeb Alyn, H., Tadesse, E., \& Vermehren, A. (2014). Sudan Social Safety Net Assessment (Kjellgren, Annika, Christina Jones-Pauly, Hadyiat El-tayeb Alyn, Endashaw Tadesse, and Andrea Vermehren. "Sudan Social Safety Net Assessment," 2014. No. 1415).

Kloß, S. T. (2017). Sexual(ized) harassment and ethnographic fieldwork: A silenced aspect of social research. Ethnography, 18(3). http://doi.org/10.1177/1466138116641958

Kobayashi, A., \& Peake, L. (1994). Unnatural discourse: 'Race' and gender in geography. Gender, Place and Culture: A Journal of Feminist Geography, 1(2), 225-243.

Kofman, E. (2002). Contemporary European migrations, civic stratification and citizenship. Political Geography, 21(8), 1035-1054. http://doi.org/10.1016/S0962-6298(02)00085-9

Kofman, E. (2012). Rethinking Care Through Social Reproduction: Articulating Circuits of Migration. Social Politics, 19(1), 142-162. http://doi.org/10.1093/sp/jxr030

Koning, E. (2012). When and How Does Solidarity Become Selective? The Political Translation of Immigrants' Welfare Use in the Netherlands, Canada, and Sweden. Cpsa-Acsp.Ca. Retrieved from http://www.cpsa-acsp.ca/papers2012/Koning.pdf\%5Cnhttps://www.cpsa-acsp.ca/papers-2012/Koning.pdf

Krzyżowski, Ł., \& Mucha, J. (2014). Transnational caregiving in turbulent times: Polish migrants in Iceland and their elderly parents in Poland. International Sociology, 29(1), 22-37. http://doi.org/10.1177/0268580913515287

Lafleur, J. M., \& Lizin, O. (2015). Transnational Health Insurance Schemes: A New Avenue for Congolese Immigrants in Belgium to Care for Their Relatives' Health from Abroad? (Working Paper Series: From Economic to Social Remittances No. 3). Cambridge. Retrieved from https://orbi.uliege.be/bitstream/2268/172046/1/Lafleur2015_tsiworkingpaper.pdf

Laslett, B., \& Brenner, J. (1989). Gender and social reproduction: Historical perspectives. Annual Review of Sociology, 15, 381-404.

Levine, P. B., \& Zimmerman, D. J. (1999). An empirical analysis of the welfare magnet debate using the NLSY. Journal of Population Economics, 12, 391-409.

Levitt, P. (2001). The transnational villagers. Berkeley and Los Angeles: University of California Press.

Levitt, P. (2005). Social Retmittances: Culture as a Development Tool. Inter-American Development Bank.

Levitt, P., \& Glick Schiller, N. (2004). A Transnational Social Field. International Migration Review, 38(3), 1002-1039. Retrieved from http://onlinelibrary.wiley.com/doi/10.1111/j.1747-7379.2004.tb00227.x/abstract

Levitt, P., \& Jaworsky, B. N. (2007). Transnational migration studies: past developments and future trends. Annual Review of Sociology, 33(1), 129-156. 
http://doi.org/10.1146/annurev.soc.33.040406.131816

Levitt, P., Lloyd, C., Mueller, A., \& Viterna, J. (n.d.). Global Social Protections: Framing Paper. In Global Social Protections: Setting the Agenda. Harvard: Radcliffe Institute for Advanced Study.

Levitt, P., Lloyd, C., Mueller, A., \& Viterna, J. (2015). Global Social Protections: Setting the Agenda (No. RSCAS 2015/78). Badia Fiesolana.

Levitt, P., Lloyd, C., Mueller, A., \& Viterna, J. (2017). Transnational social protection: Setting the agenda. Oxford Development Studies, 45(1), 2-19. http://doi.org/10.1080/13600818.2016.1239702

Lieten, G. K., \& Nieuwenhuys, O. (1989). Introduction: Survival and Emancipation. In Women, Migrants and Tribals: Survival Strategies in Asia. New Delhi: Manohar.

Lindley, A. (2010). The Early Morning Phone Call: Somali Refugees' Remittances. New York: Berghahn Books.

Lindley, A., \& Van Hear, N. (2007). New Europeans on the Move: A preliminary review of the onward migration of refugees within the European Union, (57), 1-27. Retrieved from http://www.compas.ox.ac.uk/publications/working-papers/wp-07-57/

Litwak, E. (1959). The use of extended family groups in the achievement of social goals: Some policy implications. Social Problems, 7(3), 177-187.

Locke, C. (2017). Do male migrants 'care'? How migration is reshaping the gender ethics of care. Ethics and Social Welfare, 11(3), 277-295. http://doi.org/10.1080/17496535.2017.1300305

Long, K., \& Sabates-Wheeler, R. (2017). Migration, Forced Displacement and Social Protection. GSDRC Rapid Literature Review. Birmingham. Retrieved from http://www.gsdrc.org/wp-content/uploads/2017/06/Migration-Forced-

Displacement-and-Social-Protection-2017-06-20-BL.pdf

Lucas, R., \& Stark, O. (1985). Motivations to remit: the case of Botswana. Journal of Political Economy, 93, 901-918.

Lucassen, J., \& Penninx, R. (1997). Newcomers. Immigrants and their Descendants in the Netherlands 1550-1995. Amsterdam: Het Spinhuis.

Madianou, M., \& Miller, D. (2011). Mobile-Phone Parenting: reconfiguring relationships between Filipina mothers and their children in the Philippines. New Media \& Society, 13(3), 457-470. http://doi.org/10.1177/1461444810393903

Magnoni, B., Lovoi, A., Brown, J., \& Thornton, R. (2010). Risks across Borders. A Study of the Potential of Microinsurance Products to Help Migrants Cope with Cross Border Risks. Washington, DC.: Multilateral Investment Fund.

Mand, K. (2011). Researching Lives in Motion. In P. Coleman, Simon; von Hellermann (Ed.), Multi-sited Ethnography. Problems and Possibilities in the Translocation of Research Methods. New York: Routledge.

Marcus, G. E. (1995). Ethnography in/of the world system: The emergence of multi-sited ethnography. Annual Review of Anthropology, 24(1), 95-117. http://doi.org/10.1146/annurev.an.24.100195.000523

Mau, S. (2004). Welfare regimes and the norms of social exchange. Current Sociology, 52(1), 53-74. http://doi.org/10.1177/0011392104039314

Mayblin, L. (2014). Asylum, welfare and work: reflections on research in asylum and refugee studies. International Journal of Sociology and Social Policy, 34(5/6), 375-391. http://doi.org/10.1108/IJSSP-11-2013-0113

Mayer, M. M., Bauer, N., \& Müller, A. (2013). Social Security for Third-Country Nationals in Germany.

Mazzucato, V. (2004). Transcending the nation. Explorations of transnationalism as a concept and phenomenon. In D. Kalb, W. Pansters, \& H. Siebers (Eds.), Globalization and Development (pp. 131-162). Dordrecht: Kluwer Academic Publishers.

Mazzucato, V. (2008a). Simultaneity and networks in transnational migration: lessons learned from a simultaneous matched sample methodology. In J. DeWind \& J. Holdway (Eds.), Migration and Development within and across Borders. (pp. 69-100). 
Geneva: International Organisation for Migration.

Mazzucato, V. (2008b). The double engagement: Transnationalism and integration. Ghanaian migrants' lives between Ghana and the Netherlands. Journal of Ethnic and Migration Studies, 34(2), 199-216. http://doi.org/10.1080/13691830701823871

Mazzucato, V. (2008c). Transnational reciprocity: Ghanaian migrants and the care of their parents back home. In E. Alber, S. van der Geest, \& S. Reynolds Whyte (Eds.), Generations in Africa: connections and conflicts (pp. 91-109). Munster: LIT Verlag Münster.

Mazzucato, V. (2009a). Bridging boundaries with a transnational research approach: A simultaneous matched sample methodology. In M. A. Falzon (Ed.), Multi-sited ethnography (pp. 1-31). Farnham: Ashgate.

Mazzucato, V. (2009b). Informal insurance arrangements in Ghanaian migrants' transnational networks: The role of reverse remittances and geographic proximity. World Development, 37(6), 1105-1115. http://doi.org/10.1016/j.worlddev.2008.11.001

Mazzucato, V. (2011). Reverse remittances in the migration- development nexus: Two-way flows between Ghana and the Netherlands. Population, Space and Place, 17(October 2010), 454-468. http://doi.org/10.1002/psp

Mazzucato, V., Kabki, M., \& Smith, L. (2006). Transnational migration and the economy of funerals: Changing practices in Ghana. Development and Change, 37(5), 1047-1072. http://doi.org/10.1111/j.1467-7660.2006.00512.x

Mazzucato, V., \& Schans, D. (2011). Transnational families and the well-being of children: Conceptual and methodological challenges. Journal of Marriage and the Family, 73(4), 704-712. http://doi.org/10.1111/j.1741-3737.2011.00840.x

McDonald, J. T., \& Valenzuela, R. M. (2012). Why Filipino migrants remit? Evidence from a home-host country matched sample. (No. Discussion Papers, (9/12)).

McDowell, C., \& de Haan, A. (1997). Migration and Sustainable Livelihoods: A Critical Review of the Literature. (No. 65). Retrieved from https://opendocs.ids.ac.uk/opendocs/bitstream/handle/123456789/3369/Wp65.pdf ?sequence $=2$

McElroy, D. (2014). The Sudanese 'spies' in London Starbucks. Telegraph. London. Retrieved from https://www.telegraph.co.uk/news/worldnews/africaandindianocean/sudan/11173 595/The-Sudanese-spies-in-London-Starbucks.html

McGregor, J. (2007). 'Joining the BBC (British Bottom Cleaners)': Zimbabwean Migrants and the UK Care Industry. Journal of Ethnic and Migration Studies, 33(5), 801-824. http://doi.org/10.1080/13691830701359249

McKay, D. (2002). Negotating Positionings: Exchanging life stories in research interviews. In P. Moss (Ed.), Feminist geography in practice: Research and methods. (pp. 187-199). Oxford: Blackwell Publishers Ltd.

McKinnish, T. (2007). Welfare-Induced Migration at State Borders: New Evidence from Micro-Data. Journal of Public Economics, 91, 437-450. http://doi.org/10.1016/j.jpubeco.2006.09.002

Medora, N. P. (2007). Strengths and challenges in the Indian family. Marriage \& Family Review, 41(1-2), 165-193. Retrieved from https://doi.org/10.1300/J002v41n01_09

Mendola, M. (2010). Migration and Informal Social Protection in Rural Mozambique.

Mercer, C., Page, B. E. N., \& Evans, M. (2009). Unsettling connections: transnational networks, development and African home associations. Global Networks, 9(2), 141-161. http://doi.org/10.1111/j.1471-0374.2009.00248.x

Merla, L., \& Baldassar, L. (2010). Présentation. Les dynamiques de soin transnationales: entre émotions et considérations économiques. Recherches Sociologiques et Anthropologiques, 41, 1-14.

Merry, S. E. (2000). Crossing boundaries: ethnography in the twenty-first century. Political and Legal Anthropology Review, 23(2), 127-133.

Midgley, J. (2012). Social protection and social policy: Key issues and debates. Journal of Policy Practice, 11(1-2), 8-24. http://doi.org/10.1080/15588742.2012.624061 
Milligan, C., \& Wiles, J. (2010). Landscapes of care. Progress in Human Geography, 34(6), 736754. http://doi.org/10.1177/0309132510364556

Mills, M., Präg, P., Tsang, F., Begall, K., Derbyshire, J., Kohle, L., \& Hoorens, S. (2014). Use of childcare in the EU Member States and progress towards the Barcelona targets.

Mohamed-Ali, A. (2011). Migration to and from Sudan (CARIM Analytic and Synthetic Notes; 2011/24; Mediterranean and Sub-Saharan Migration: Recent Developments Series). San Domenico di Fiesole.

Mohammad, R. (2001). 'Insiders' and 'outsiders': Positionality, theory and praxis. In M. Limb \& C. Dwyer (Eds.), Qualitative methodologies for geographers: Issues and debates. (pp. 101-117). New York: Oxford University Press.

Mokomane, Z. (2013). Social protection as a mechanism for family protection in subSaharan Africa. International Journal of Social Welfare, 22(3), 248-259. http://doi.org/10.1111/j.1468-2397.2012.00893.x

Moret, J., Baglioni, S., \& Efionayi-Mäder, D. (2006). The Path of Somali Refugees into Exile. A Comparative Analysis of Secondary Movements and Policy Responses. Neuchatel. Retrieved from http://www.unhcr.org/4455cc6f2.pdf

Nageeb, S. A. (2004). New Spaces and Old Frontiers. Women, Social Space and Islamization in Sudan. Lanham: Lexington Books.

Nations Online Project. (2018). Political Map of Sudan and South Sudan. Retrieved June 15, 2018, from https://www.nationsonline.org/oneworld/map/sudan_map.htm

Nauck, B., \& Klaus, D. (2007). The varying value of children: Empirical results from eleven societies in Asia, Africa and Europe. Current Sociology, 55(4), 487-503. http://doi.org/10.1177/0011392107077634

Nguyen, M. T. N., Zavoretti, R., \& Tronto, J. (2017). Beyond the global care chain: Boundaries, institutions and ethics of care. Ethics and Social Welfare, 11(3), 199-212. http://doi.org/10.1080/17496535.2017.1300308

Norton, A., Conway, T., \& Foster, M. (2002). Social protection: Defining the field of action and policy. Development Policy Review, 20(5), 541-567. http://doi.org/10.1111/14677679.00189

Nyambedha, E. O. (2008). Sharing Food: Grandmothers and "The Children of Today" in Western Kenya. In E. Alber, S. Van Der Geest, \& S. R. Whyte (Eds.), Generations in Africa: connections and conflicts. Münster: LIT Verlag.

O’Donnell, C. A., Higgins, M., Chauhan, R., \& Mullen, K. (2007). "They think we're OK and we know we're not". A qualitative study of asylum seekers' access, knowledge and views to health care in the UK. BMC Health Services Research, 7(75). http://doi.org/10.1186/1472-6963-7-75

O'Reilly, K. (2012). Ethnographic Methods. Abingdon: Routledge.

Oduro, A. D. (2010). Formal and Informal Social Protection in sub-Sharan Africa. In "Promoting Resilience through Social Protection in Sub-Saharan Africa" (pp. 28-30). Dakar: European Report on Development.

OECD. (2015). Pensions at a Glance 2015: OECD and G20 indicators. Paris: OECD Publishing. http://doi.org/http://dx.doi.org/10.1787/pension_glance-2015-en

OECD. (2016). The Netherlands 2016: Foundations for the future. Paris: OECD Publishing. http://doi.org/10.1787/9789264257658-en

OECD. (2017). Pensions at a Glance 2017: OECD and G20 Indicators. Paris: OECD Publishing. Retrieved from http://dx.doi.org/10.1787/pension_glance-2017-en

Office for National Statistics. (2018). Population and Migration. Retrieved June 21, 2018, from

https://www.ons.gov.uk/peoplepopulationandcommunity/populationandmigration/ populationestimates/datasets/populationbycountryofbirthandnationality

Oldfield-Hayes, R. (1975). Female genital mutilation, fertility control, women's roles, and the patrilineage in modern Sudan: a functional analysis. American Ethnologist, 2(4), 617633.

http://doi.org/http://onlinelibrary.wiley.com/doi/10.1525/ae.1975.2.4.02a00030/p 
$\mathrm{df}$

Olivier, M., \& Govindjee, A. (2013). Labour rights and social protection of migrant workers: In search of a co- ordinated legal response workers : In search of a co- ordinated legal response by Marius Olivier * and Avinash Govindjee ** Paper pre. In Inaugural conference of the Labour Law Research Network (LLRN). Barcelona.

Opiniano, J. (2010). International migration as social protection mechanism in the Philippines: Issues and implications. In E. P. Eyébiyi, P. Herrmann, \& V. Sheen (Eds.), Global Crossroads in Social Welfare: Emergent issues, debates and innovations across the globe (pp. 63-93). BoD-Books on Demand.

Orozco, M. (2003). Hometown Associations and their Present and Future Partnerships: New Development Opportunities? Washington, DC.

Osili, U. O. (2007). Remittances and savings from international migration: Theory and evidence using a matched sample. Journal of Development Economics, 83(2), 446-465. http://doi.org/10.1016/j.jdeveco.2006.06.003

Osili, U. O. (2007). Remittances and savings from international migration: Theory and evidence using a matched sample. Journal of Development Economics, 83(2), 446-465. http://doi.org/10.1016/j.jdeveco.2006.06.003

Otieno Ong'ayo, A. (2014). How can the EU and member states foster development through diaspora organisations? The case of Ghanaian diaspora organisations in the Netherlands (No. 162).

Ouis, P. (2009). Honourable traditions - Honour violence, early marriage and sexual abuse of teenage girls in Lebanon, and Occupied Palestinian Territories and Yemen. International Journal of Children's Rights, 17, 445-474. http://doi.org/10.3366/ajicl.2011.0005

Palmer, E. (2016). A Meaningful Right to Social Security in the United Kingdom: Beyond the Policies and Politics of Austerity? In A. Egorov \& M. Wujczyk (Eds.), The Right to Social Security in the Constitutions of the World. Broadeining the Moral and Legal Space for Social Justice. (Vol. 1: Europe, pp. 296-339). Geneva: International Labour Organization.

Parreñas, R. S. (2001). Servants of globalization. Stanford, CA: Stanford University Press.

Parreñas, R. S. (2010). Transnational mothering: A source of gender conflicts in the family. North Carolina Law Review, 88(5), 291-304. http://doi.org/10.1002/(SICI)10970355(199923)20:3<291::AID-IMHJ6>3.3.CO;2-7

Pasha, T. (2012). Overview of skills transfer programmes - IOM perspecive. Geneva: IOM. Retrieved from http://www.migrantservicecentres.org/userfile/Tauhid Pasha.pdf

Pavolini, E., \& Seeleib-Kaiser, M. (2016). Comparing occupational welfare in Europe: The case of occupational pensions - PROWELFARE Analytical Report. (OSE Paper Series No. 30). Social Policy and Administration (Vol. 52). Brussels.

Phillimore, J., \& Goodson, L. (2010). Failing to Adapt: Institutional Barriers to RCOs Engagement in Transformation of Social Welfare. Social Policy and Society, 9(02), 181. http://doi.org/10.1017/S1474746409990315

PICUM. (2002). Book of Solidarity. Volume I. Belgium, Germany, the Netherlands, the UK. Antwerp: PICUM.

Pilcher, J., \& Whelehan, I. (Eds.). (2004). Fifty Key Concepts in Gender Studies. London: SAGE Publications. http://doi.org/10.1093/oxfordhb/9780199286140.013.0060

Poeze, M., Dankyi, E. K., \& Mazzucato, V. (2017). Navigating transnational childcare relationships: migrant parents and their children's caregivers in the origin country. Global Networks, 17(1), 111-129. http://doi.org/10.1111/glob.12135

Poeze, M., \& Mazzucato, V. (2014). Ghanaian Children in Transnational Families: Understanding the Experiences of Left-Behind Children Through Local Parenting Norms. In Transnational Families, Migration and the Circulation of Care. (pp. 149-169). New York: Routledge.

Poeze, M., \& Mazzucato, V. (2016). Transnational Mothers and the Law: Ghanaian Women's Pathways to Family Reunion and Consequences for Family Life. In M. Kilkey \& E. Palenga-Moellenbeck (Eds.), Family Life in an Age of Migration and Mobility. 
(pp. 187-212). London: Palgrave Macmillan.

Poinasamy, K. (2011). When Work Won't Pay. In-work poverty in the UK. (No. November 2011). Retrieved from https://policy-practice.oxfam.org.uk/publications/when-workwont-pay-in-work-poverty-in-the-uk-197010

Poptcheva, E.-M., \& Stuchlik, A. (2015). Work and social welfare for asylum-seekers and refugees. Retrieved from http://bookshop.europa.eu/en/poverty-dynamics-in-europepbKEEW15003/?CatalogCategoryID=iEKep2Ix3hEAAAEud3kBgSLq

Portes, A., Guarnizo, L. E., \& Landolt, P. (1999). The study of transnationalism: Pitfalls and promise of an emergent research field. Ethnic and Racial Studies, 22(2), 217-237.

Portes, A., \& Rumbaut, R. G. (2001). Legacies: The story of the immigrant second generation. Univ of California Press.

Rafiq, A. (2014). Child Custody in Classical Islamic Law and Laws of Contemporary Muslim World. International Journal of Humanities and Social Science., 4(5), 267-277. Retrieved from http://www.ijhssnet.com/journals/Vol_4_No_5_March_2014/29.pdf

Raithelhuber, E., Sharma, N., \& Schröer, W. (2018). The intersection of social protection and mobilities: a move towards a 'Practical Utopia'research agenda. Mobilities, 1-17. http://doi.org/10.1080/17450101.2018.1468592

Rashad, H., Magued, O., \& Roudi-Fahimi, F. (2005). Marriage in the Arab world. Washington, D.C.

Razy, E., \& Baby-Collin, V. (2011). La famille transnationale dans tous ses états. Autrepart, 1(57-58), 7-22. http://doi.org/10.3917/autr.057.0007

Reeves, M., de Wildt, G., Murshali, H., Williams, P., Gill, P., Kralj, L., \& Rushby, M. (2006). Access to health care for people seeking asylum in the UK. British Journal of General Practice, 56(525), 306-308. Retrieved from https://www.ncbi.nlm.nih.gov/pmc/articles/PMC1832248/

Russell, C. K., Bunting, S. M., \& Gregory, D. M. (1997). Protective care-receiving: the active role of care-recepients. Journal of Advanced Nursing, 25, 532-540.

Sabates-Wheeler, R. (2009). Social security for migrants: Trends, best practice and ways forward (No. 12). Geneva.

Sabates-Wheeler, R., \& Feldman, R. (2011). Social Protection and Migration: Claiming Social Rights Beyond Borders. (R. Sabates-Wheeler \& R. Feldman, Eds.). London: Palgrave Macmillan.

Sabates-Wheeler, R., \& Koettl, J. (2010). Social protection for migrants: The challenges of delivery in the context of changing migration flows. International Social Security Review, 63(3-4), 115-144. http://doi.org/10.1111/j.1468-246X.2010.01372.x

Sabates-Wheeler, R., \& Waite, M. (2003). Migration and Social Protection: A Concept Paper (No. T2). Sussex.

Sahlins, M. (1965). On the sociology of primitive exchange. In M. Banton (Ed.), The Relevance of Models for Social Anthropology (pp. 139-236). London: Routledge.

Sahlins, M. (1974). Stone Age Economics. London: Tavistock.

Sainsbury, D. (2006). Immigrants' social rights in comparative perspective: welfare regimes, forms in immigration and immigration policy regimes. Journal of European Social Policy, 16(3), 229-244. http://doi.org/10.1177/0958928706065594

Sales, R. (2002). The deserving and the undeserving? Refugees, asylum seekers and welfare in Britain. Critical Social Policy, 22(3), 456-478. http://doi.org/10.1177/0261018302022003293

Sandelowski, M. (2000). Whatever happened to qualitative description? Research in Nursing and Health, 23(4). http://doi.org/10.1002/1098-240X(200008)23:4<334::AIDNUR9 $>3.0 . C O ; 2-G$

SASPEN. (2014). The Crux of the Matter: International Migration, Rights, Social Protection \& Governance: Key challenges to our common future. In SASPEN-FES CONFERENCE SOCIAL PROTECTION FOR MIGRANTS IN SOUTHERN AFRICA. Johannesburg.

Schapendonk, J., \& Steel, G. (2014). Following Migrant Trajectories: The Im/Mobility of Sub-Saharan Africans en Route to the European Union. Annals of the Association of 
American Geographers, 104(2), 262-270. http://doi.org/10.1080/00045608.2013.862135

Schlytter, A., \& Linell, H. (2010). Girls with honour-related problems in a comparative perspective. International Journal of Social Welfare, 19(2), 152-161. http://doi.org/10.1111/j.1468-2397.2009.00651.x

Schmalzbauer, L. (2004). Searching for wages and mothering from afar: The case of Honduran transnational families. Journal of Marriage and Family, 66(5), 1317-1331. Retrieved from http://www.jstor.org/stable/3600342 Accessed:

Schneider, J. (1971). Of vigilance and virgins: Honor, shame and access to resources in Mediterranean societies. Ethnology, 10(1), 1-24. Retrieved from http://www.jstor.org/stable/3772796

Schrieder, G., \& Knerr, B. (2000). Labour Migration as a Social Security Mechanism for Smallholder Households in Sub-Saharan Africa: The Case of Cameroon. Oxford Development Studies, 28(2), 223-236.

Schultz, U., Makkawi, A., \& El-Fatih, T. (2009). Women and Finance in Rural and Urban Sudan: A Case Study in Greater Omdurman and Khartoum. (No. 87/2008). Romanian Journal of Fiscal Policy. Berlin.

Scott, J. C. (1985). Weapons of the weak: Everyday forms of resistance. New Heaven: Yale University Press.

Seesemann, R. (2002). Sufi leaders and social welfare: Two examples from contemporary Sudan. In H. Weiss (Ed.), Social Welfare in Muslim Societies in Africa. Stockholm: Nordiska Afrikainstitutet.

Seltzer, M. M., \& Li, L. W. (1996). The Transitions of Caregiving: Subjective and Objective Definitions. The Gerontologist, 36(5), 614-626. http://doi.org/10.1093/geront/36.5.614

Serra-Mingot, E., \& Mazzucato, V. (forthcoming). Moving for a better welfare? The case of transnational Sudanese families. Global Networks.

Serra-Mingot, E., \& Mazzucato, V. (2017). Mobile populations in immobile welfare systems: A typology of institutions providing social welfare and protection within a mobility framework. The European Journal of Development Research, 29(4), 787-805. http://doi.org/doi:10.1057/s41287-016-0061-4

Serra Mingot, E., \& Mazzucato, V. (2018). Providing social protection to mobile populations: symbiotic relationships between migrants and welfare institutions. Journal of Ethnic and Migration Studies, $0(0), \quad 1-17$. http://doi.org/10.1080/1369183X.2018.1429900

Sevenhuijsen, S. (1998). Citizenship and the Ethics of Care. Feminist Considerations on Justice, Morality and Politics. London and New York: Routledge.

Shakespeare, T. (2000). Help. Birmingham: Venture Press.

Shandy, D. J. (2003). Transnational linkages between refugees in Africa and in the diaspora. Forced Migration Review, 16(3), 1-2. Retrieved from internalpdf://shandy2003transnationallinkages20152222976/Shandy2003TransnationalLinkages2.pdf

Sharp, G., \& Kremer, E. (2006). The safety dance: Confronting harassment, intimidation, and violence in the field. Sociological Methodology, 36(1), 317-321. http://doi.org/10.1111/j.1467-9531.2006.00183.x

Shepherd, A., Marcus, R., \& Barrientos, A. (2004). Policy Paper on Social Protection. London. Retrieved from http://www.odi.org.uk/sites/odi.org.uk/files/odiassets/publications-opinion-files/1670.pdf

SHF. (2016). Annual Report. Retrieved from https://reliefweb.int/sites/reliefweb.int/files/resources/SHF_2016_Annual_Report.p df

Siegel, M., \& de Neubourg, C. (2011). A historical perspective on immigration and social protection in the Netherlands (2011-14). Maastricht. Retrieved from www.merit.unu.edu/publications/wppdf/2011/wp2011-014.pdf

Sienkiewicz, J., \& Bilecen, B. (2015). Informal Social Protection Networks of Migrants: Typical Patterns in Different Transnational Social Spaces. Population, Space and Place, 
21, 227-243.

Sienkiewicz, J. J., Sadovskaya, Y., \& Amelina, A. (2015). The Kazakh - German Social Space: Decreasing Transnational Ties and Symbolic Social Protection. Population, Space and Place, 21(3), 270-281.

Sigona, N. (2012). "I have too much baggage": The impacts of legal status on the social worlds of irregular migrants. Social Anthropology, 20(1), 50-65. http://doi.org/10.1111/j.1469-8676.2011.00191.x

Simich, L., Este, D., \& Hamilton, H. (2010). Meanings of home and mental well-being among Sudanese refugees in Canada. Ethnicity and Health, 15(2), 199-212.

Smith, C. E. (2016). Caring practices: the connection between logics of state and domestic violence in Cairo, Egypt. Gender, Place \& Culture, 23(9), 1227-1239. http://doi.org/10.1080/0966369X.2016.1160034

Smith, L., \& Mazzucato, V. (2009). Constructing homes, building relationships: Migrant investments in houses. Tijdschrift Voor Economische En Sociale Geografie, 100(5), 662-673. http://doi.org/10.1111/j.1467-9663.2009.00571.x

Social Security Administration. (2007). Social Security Programs Throughout the World: Africa, 2007. Washington, D.C.: Social Security Administration.

Somerville, W. Sriskandarajah, D., \& Latorre, M. (2009). United Kingdom: A reluctant country of immigration. (No. 21).

Sorensen, N. N. (2004). Migrant Remittances as Development Tool: The Case of Morocco (3). Geneva.

Spencer, J., Grove-White, R., Deakin, J., Dewhurst, E., Fox, C., \& Bragg, J. (2015). Law, order and irregularity: Undocumented migrants and UK immigration policy. Manchester: University of Manchester.

Spitzer, D., Neufeld, A., Harrison, M., Hughes, K., \& Stewart, M. (2003). Caregiving in transnational context; Where can I fly? Gender \& Society, 17(2), 267-286. http://doi.org/10.1177/0891243202250832

Spivak, G. C. (2004). Righting Wrongs. The South Atlantic Quarterly, 103(2/3 Spring/Summer), 523-581.

Stark, O., \& Levhari, D. (1982). On migration and risk in LDCs. Economic Development and Cultural Change, 31(1), 191-196.

Stark, O., \& Lucas, R. (1988). Migration, remittances and the family. Economic Development and Cultural Change, 36(3), 465-481.

Suliman, O. (2007). Current privatization policy in Sudan. (No. 52). Michigan. Retrieved from http://www.uquebec.ca/observgo/fichiers/75871_ep1.pdf

Sumption, M., \& Allen, W. (2015). Election 2015 briefing - migration and welfare benefits. Retrieved August 9, 2017, from http://www.migrationobservatory.ox.ac.uk/briefings/election-2015-briefingmigration-and-welfare-benefits

Swemmer, T. (2013). State Provision of Social Protection to International Migrants: The Relevance of Social Protection Frameworks. IDS Working Paper. (No. 009) (Vol. 2013). London.

Taha, Nurulsyahirah Messkoub, M., \& Siegmann, K. A. (2013). How portable is social security for migrant workers? A review of the literature (No. 573). The Hague.

Talleraas, C. (2018). Combining Transnational Living and National Welfare (PRIO Policy Brief No. 01). Oslo. Retrieved from https://prio.org/Publications/Publication/? $x=10832$

Taylor, E. J. (1999). The New Economics of Labour Migration and the Role of Remittances in the Migration Process. International Migration, 37(1), 63-88. http://doi.org/10.1111/1468-2435.00066

Tevera, D. (2013). International Remittances and Social Protection of Transnational Migrants and their Families: Which are the issues?

Thieme, S. (2003). Savings and Credit Associations and Remittances: The case of Far West Nepalese Labour Migrants in Delhi, India (No. 39) (Vol. 8). Geneva. Retrieved from http://pstalker.com/ilo/resources/wp39.pdf

Tognetti Bordogna, M., \& Piperno, F. (2013). Towards a transnational governance of care 
needsstemming from migration: Transnational welfare and thirdsector. In International conference: Participatory local welfare, citizenship and third sector organizations. What is at stake? (pp. 1-14). Pisa. Retrieved http://www.volontariatoepartecipazione.eu/wp-content/uploads/2012/10/PaperTognetti-Piperno-trad-finale-Bordogna-Piperno.pdf

Tronto, J. (1993). Moral Boundaries. A Political Argument for an Ethic of Care. London and New York: Routledge.

Tronto, J. (1995). Care as a basis for radical political judgments. Hypatia, 10(2), 141-149. http://doi.org/10.1111/j.1527-2001.1995.tb01376.x

UN-DESA. (2015). United Nations Department of Economic and Social Affairs. Retrieved from

http://www.un.org/en/development/desa/population/migration/data/estimates2/e stimates15.shtml

UNDP. (2009). Human Development Report 2009. Overcoming barriers: Human mobility and development. New York. Retrieved from http://hdr.undp.org/sites/default/files/reports/269/hdr_2009_en_complete.pdf

UNHCR. (2007). 2006 Global Trends: Refugees, Asylum-seekers, Returnees, Internally Displaced and Stateless Persons. Geneva. Retrieved from http://www.unhcr.org/statistics/STATISTICS/4676a71d4.pdf around 4.5

van der Leun, J. (2003). Looking for Loopholes. Processes of Incorporation of Illegal Immigrants in the Netherlands. Alternatives Journal. Amsterdam University Press.

van der Meer, M., \& Bax, J. (2016). Labour Market Integration of Asylum Seekers and Refugees. Netherlands. Brussels.

van Geel, J., \& Mazzucato, V. (2017). Conceptualising youth mobility trajectories: thinking beyond conventional categories. Journal of Ethnic and Migration Studies, on-line, 1-19. http://doi.org/10.1080/1369183X.2017.1409107

van Ginneken, W. (2013). Social protection for migrant workers: National and international policy challenges. European Journal of Social Security, 15(2), 209-221. http://doi.org/10.1177/138826271301500206

van Heelsum, A., \& Hessels, T. (2006). Afrikanen uit Angola, DR Congo, Sudan in Nederland: Een profiel. Amsterdam.

Van Heelsum, A., \& Hessels, T. (2005). Afrikanen in Nederland, een profiel. den Haag.

Van Liempt, I. (2011). "And then one day they all moved to Leicester": The relocation of Somalis from the Netherlands to the UK explained. Population, Space and Place, 17(3), 254-266. http://doi.org/10.1002/psp.605

Van Meeteren, M. (2012). Transnational activities and aspirations of irregular migrants in Belgium and the Netherlands. Global Networks, 12(3), 314-332. http://doi.org/10.1111/j.1471-0374.2012.00354.x

Van Meeteren, M. (2014). Irregular migrants in Belgium and the Netherlands: Aspirations and incorporation. Amsterdam University Press. Amsterdam: Amsterdam University Press.

van Panhuys, C., Kazi-Aoul, S., \& Binette, G. (2017). Migrant access to social protection under Bilateral Labour Agreements: A review of 120 countries and nine bilateral agreements. (No. 57). Geneva.

Vanderbeck, R. (2005). Masculinities and fieldwork: Widening the discussion. Gender, Place \& Culture, 12(4), 387-402. http://doi.org/10.1080/09663690500356537

Vasta, E. (2011). Immigrants and the paper market: borrowing, renting and buying identities. Ethnic and Racial Studies, 34(2).

Verloo, N. (2017). Learning from informality? Rethinking the mismatch between formal policy strategies and informal tactics of citizenship. Current Sociology, 65(2). http://doi.org/10.1177/0011392116657287

Verpoorten, R., \& Verschraegen, G. (2008). Formal and Informal Social Protection in SubSaharan Africa: A Complex Welfare Mix to Achieve Poverty and Inequality Reduction. University of Leuven.

Vertovec, S. (1999). Conceiving and researching transnationalism. Ethnic and Racial Studies, 
2(2), 447-462.

Vertovec, S. (2001). Transnationalism and identity. Journal of Ethnic and Migration Studies, 27(4), 573-582. http://doi.org/10.1080/13691830120090386

Vertovec, S. (2007). Super-diversity and its implications. Ethnic and Racial Studies, 30(6), 1024-1054. http://doi.org/10.1080/01419870701599465

Vivas-Romero, M. (2017). Who Cares for Those Who Cared? An Intersectional Ethnography of Global Social Protection Arrangements. University of Liege.

von Benda-Beckmann, K. (2015). Social Security in Transnational Legal Space. In S. Koengete \& W. Smith (Eds.), Transnationa Agency and Migration. Actors, Movements and Social Support. New York: Routledge.

Vonk, G. (2002a). Migration, Social Security and the Law: Some European Dilemmas. European Journal of Social Security, 3(4), 315-332. http://doi.org/10.1023/A:1015177828560

Vonk, G. (2002b). Migration, social security and the law: Observations on the impact of migration policies upon the position of migrants in social security law in Europe. Social Security in Transition, 31(0).

Vonk, G., \& Tollenaar, A. (2009). Social Security as a Public Interest. A multidisciplinary inquiry into the foundations of the regulatory welfare state. Groningen.

Vonk, G., \& van Walsum, S. (2012). Access denied. Towards a New Approach to Social Protection for Formally Excluded Migrants. Intersentia, 31, 124-150.

Waldinger, R., \& Fitzgerald, D. (2004). Transnationalism in question. American Journal of Sociology, 109(5), 1177-1195.

Watson, N., McKie, L., Hughes, B., Hopkins, D., \& Gregory, S. (2004). (Inter)dependence, needs and care: The potential for disability and feminist theorists to develop and emancipatory model. Sociology, 38(2), 331-50.

WHO. (2006). Health System Profile Sudan. Health Systems Profile. Sudan. Cairo.

Wilcock, C. (2016). Building Peace from Diaspora. UK Sudanese Opposition Activists, Peacebuilding on Hybridity. University of Manchester.

Wilcock, C. (2018). Mobilising towards and imagining homelands: diaspora formation among U.K. Sudanese. Journal of Ethnic and Migration Studies, 44(3), 363-381. http://doi.org/10.1080/1369183X.2017.1313104

Wilkinson, M., \& Craig, G. (2011). Wilful negligence: migration policy, migrants' work and the absence of social protection in the UK. In E. Carmel, A. Cerami, \& T. Papadopoulos (Eds.), Migration and Welfare in the New Europe. Social Protection and the Challenges of Integration. (pp. 177-195). Bristol: The Policy Press. University of Bristol.

Williams, L. (2006). Social networks of refugees in the United Kingdom: tradition, tactics and new community spaces. Journal of Ethnic and Migration Studies, 32(5), 865-879. http://doi.org/10.1080/13691830600704446

Wilmes, M. (2011). Irregular migration and foggy organisational structures: Implications of a German city study. In M. Bommnes \& G. Sciortino (Eds.), Foggy Social Structures. Irregular Migration, European Labour Markets and the Welfare State. Amsterdam: Amsterdam University Press.

Wimmer, A., \& Glick-Schiller, N. (2002a). Methodological nationalism and beyond: nationstate building, migration and the social sciences. Global Networks, 2(4), 301-334. http://doi.org/10.1111/1471-0374.00043

Wimmer, A., \& Glick-Schiller, N. (2002b). Methodological nationalism and the study of migration. European Journal of Sociology, 43(2), 217-240. http://doi.org/10.1017/S000397560200108X

Wimmer, A., \& Glick Schiller, N. (2003). Methodological nationalism, the social sciences, and the study of migration: An essay in historical epistemology. International Migration Review, 37(3), 576-610.

Wood, R. (1991). Care of disabled people. In G. Dalley (Ed.), Disability and Social Policy (pp. 199-202). London: Policy Studies Institute.

World Bank. (2014). World Bank Database. Retrieved April 14, 2018, from 
https://data.worldbank.org/indicator/SH.XPD.PUBL.GX.ZS?locations=SD\&year_ high_desc $=$ false

World Bank. (2016). Migration and Remittances: Factbook 2016. Library (Vol. 3). Washington, D.C.: The World Bank. http://doi.org/10.1596/978-1-4648-0319-2

YALLA Foundation. (2016). Benefits (Financial Aid). Retrieved October 24, 2017, from http://yallafoundation.nl/benefits-for-refugees-in-the-netherlands-uitkering-entoeslagen/

Yeates, N. (2005). Migration and social policy in international context: The analytical and policy uses of a global care-chains perspective. In New Frontiers of Social Policy (pp. 135). Arusha, Tanzania.

Yeates, N. (2008). Transnationalism, Social Reproduction and Social Policy: International Migration of Care Workers. In C. Moser \& A. A. Dani (Eds.), Assets, Livelihoods and Social Policy (Vol. 4th, p. 378). Washington, D.C.: The World Bank. http://doi.org/10.1596/978-0-8213-6995-1

Yeung, A. B. (2006). Churches in Europe as Agents of Welfare - Sweden, Norway and Finland. Working Paper 2 from the Project Welfare and Religion in a European Perspective. (Project Welfare and Religion in a European Perspective No. 2) (Vol. 1). Uppsala.

Young, L., \& Ansell, N. (2003). Fluid households, complex families: The impacts of children's migration as a response to HIV/AIDS in Southern Africa. Professional Geographer, 55(4), 464-476. http://doi.org/10.1111/0033-0124.5504005

Yousif, M. (2016). A Politics of Hope? Youth Charity Activism in Khartoum. University of Bergen.

Zeghnoune, M. (2016). Étude exploratoire des récents flux migratoires irréguliers de Soudanais vers la France. Université Paris.

Zickgraf, C. (2017). Transnational ageing and the 'zero generation': the role of Moroccan migrants' parents in care circulation. Journal of Ethnic and Migration Studies, 43(2), 321337. http://doi.org/10.1080/1369183X.2016.1238912

Zontini, E. (2006). Italian families and social capital. Community, Work \& Family, 9(3), 325345. http://doi.org/10.1080/13668800600743636

Zontini, E. (2010). Transnational Families, Migration and Gender: Moroccan and Filipino Women in Bologna and Barcelona. Oxon and New York: Berghahn Books.

Zorlu, A. (2011). Immigrant Participation in Welfare Benefits in the Netherlands (Discussion Paper series, Forschungsinstitut zur Zukunft der Arbeit No. 6128). Bonn. Retrieved from http://nbn-resolving.de/urn:nbn:de:101:1-201112136761

Zorlu, A. (2013). Welfare use of migrants in The Netherlands. International Journal of Manpower, 34(1), 83-95. http://doi.org/10.1108/01437721311319674 

APPENDICES 


\begin{tabular}{|c|c|c|c|c|c|c|c|c|c|}
\hline 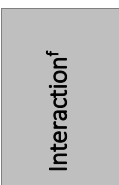 & 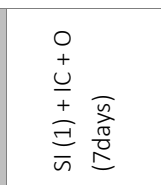 & $\begin{array}{l}\frac{\Xi}{ \pm} \\
0 \\
+ \\
\frac{a}{a} \\
\bar{n}\end{array}$ & $\begin{array}{l}\text { E } \\
0 \\
+ \\
\frac{1}{D} \\
\bar{n}\end{array}$ & $\begin{array}{ll}m & \\
0 \\
\pm \\
\pm \\
\frac{1}{1} & \bar{n} \\
\bar{n} & \frac{\pi}{0}\end{array}$ & $\begin{array}{l}\frac{E}{D} \\
0 \\
+ \\
\frac{+}{D} \\
\bar{n}\end{array}$ & $\begin{array}{l}\bar{n} \\
\frac{\pi}{\pi} \\
0 \\
0 \\
0 \\
+ \\
\bar{n}\end{array}$ & $\begin{array}{l}\bar{n} \\
\frac{\pi}{0} \\
0 \\
0 \\
0 \\
+ \\
\bar{n}\end{array}$ & $\begin{array}{l}\bar{m} \\
\bar{n}\end{array}$ & $\begin{array}{l}\frac{\Phi}{J} \\
0 \\
+ \\
\bar{n}\end{array}$ \\
\hline 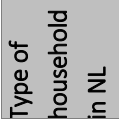 & $\begin{array}{l}\stackrel{0}{\Phi} \\
\stackrel{ \pm}{0} \\
\underline{\Phi}\end{array}$ & 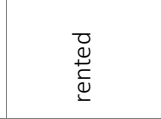 & 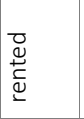 & 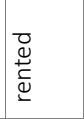 & 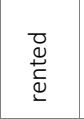 & \multicolumn{2}{|c|}{ 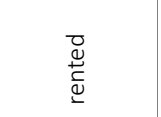 } & 胥 & 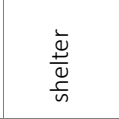 \\
\hline 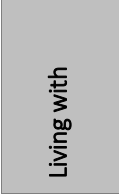 & 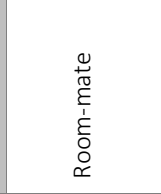 & $\begin{array}{l}\frac{0}{00} \\
\stackrel{=}{=}\end{array}$ & 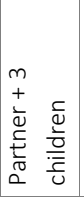 & 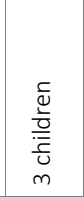 & 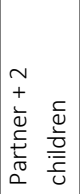 & \multicolumn{2}{|c|}{ 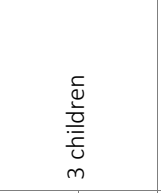 } & 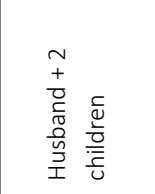 & 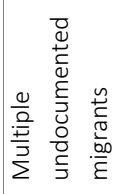 \\
\hline 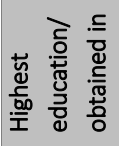 & $\sum_{\substack{c \\
\infty}}^{0}$ & 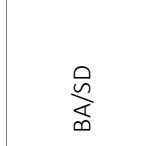 & 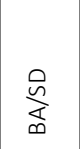 & $\stackrel{0}{\stackrel{0}{\infty}}$ & 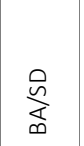 & 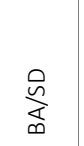 & $\begin{array}{l}\text { ㅁ } \\
\frac{0}{0} \\
\frac{0}{0} \\
\sum^{2} \\
\infty\end{array}$ & 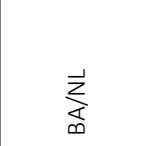 & 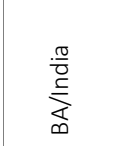 \\
\hline 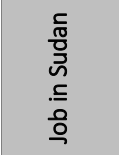 & $\begin{array}{l}\frac{\hbar \underline{n}}{\sqrt{0}} \\
\stackrel{5}{5} \\
\stackrel{0}{0}\end{array}$ & 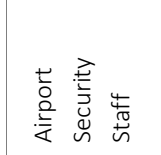 & 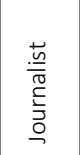 & 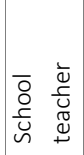 & 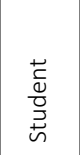 & 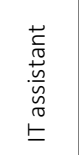 & 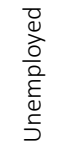 & 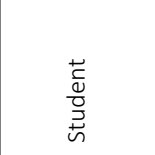 & 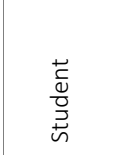 \\
\hline 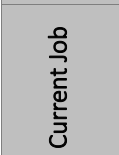 & $\begin{array}{l}\overrightarrow{0} \\
\frac{0}{\bar{d}} \\
\frac{0}{0} \\
0\end{array}$ & 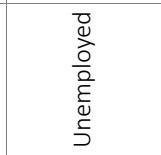 & 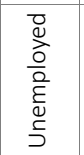 & 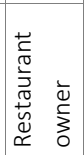 & 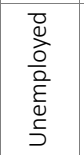 & 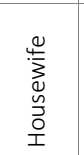 & 蒙 & 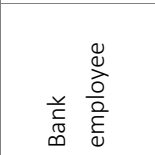 & $\begin{array}{l}\frac{\vec{c}}{0} \\
\frac{d}{0} \\
\text { 总 }\end{array}$ \\
\hline 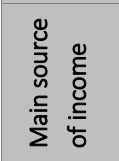 & 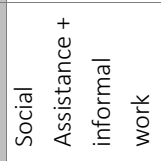 & 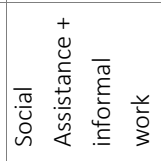 & 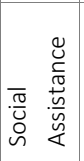 & 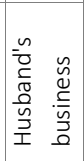 & 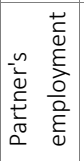 & 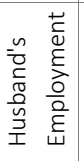 & 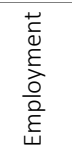 & 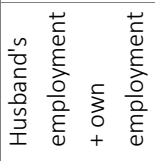 & 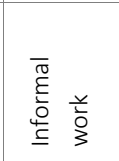 \\
\hline 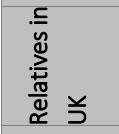 & 0 & $\circ$ & 0 & 0 & $\sim$ & $\rightarrow$ & $\rightarrow$ & 0 & 0 \\
\hline 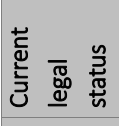 & 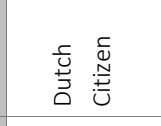 & 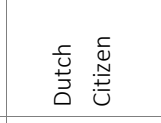 & 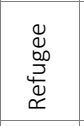 & 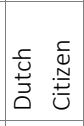 & 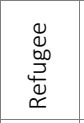 & 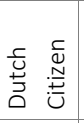 & 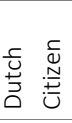 & 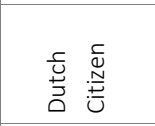 & 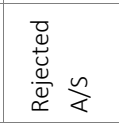 \\
\hline 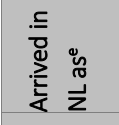 & ப் & ஸ் & ư & $\underset{\leftarrow}{\dot{c}}$ & نே & ப் & $\underset{\leftarrow}{\dot{y}}$ & ن் & ن் \\
\hline 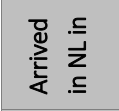 & $\stackrel{\vec{\sim}}{\stackrel{-}{\circ}}$ & 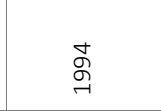 & $\underset{\sim}{\stackrel{-}{~}}$ & 命 & ¿્ర & 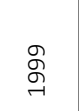 & $\begin{array}{l}\infty \\
\stackrel{\circ}{\sigma}\end{array}$ & $\begin{array}{l}\stackrel{\infty}{\circ} \\
\stackrel{్}{-}\end{array}$ & $\stackrel{m}{\stackrel{n}{\sim}}$ \\
\hline 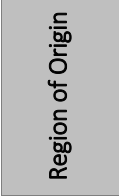 & $\underset{\substack{\frac{1}{2} \\
\frac{1}{0}}}{0}$ & 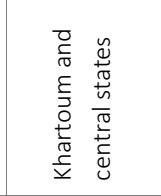 & $\underset{\frac{3}{5}}{\frac{3}{0}}$ & 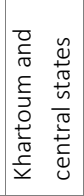 & 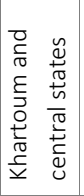 & 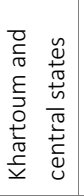 & 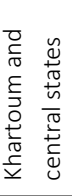 & 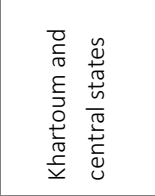 & 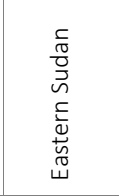 \\
\hline $\begin{array}{l}\text { ¿ } \\
\underset{<}{\alpha}\end{array}$ & बे & g & $\hat{m}$ & $\stackrel{\infty}{m}$ & 우 & 우 & F & $\stackrel{\vartheta}{\forall}$ & $\approx$ \\
\hline 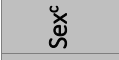 & $\Sigma$ & $\Sigma$ & $\Sigma$ & $\sqcup$ & $\Sigma$ & ч & $\Sigma$ & $\sqcup$ & $\Sigma$ \\
\hline 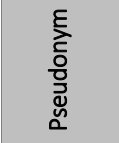 & $\frac{\frac{\pi}{\pi 0}}{\frac{2}{5}}$ & 先 & $\begin{array}{l}\overline{\overline{\bar{\pi}}} \\
\frac{\bar{\pi}}{\bar{y}}\end{array}$ & $\frac{\sqrt[\pi]{0}}{\overline{\widetilde{T}}}$ & 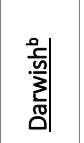 & 힌 & 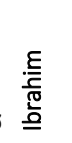 & $\begin{array}{l}\frac{\varepsilon}{\pi} \\
\stackrel{5}{\hbar}\end{array}$ & $\begin{array}{l}\text { 売 } \\
\text { 品 }\end{array}$ \\
\hline
\end{tabular}




\begin{tabular}{|c|c|c|c|c|c|c|c|c|c|c|}
\hline $\begin{array}{l}\widetilde{\pi} \\
0 \\
+ \\
\underline{u}\end{array}$ & $\begin{array}{l}\bar{\sigma} \\
0 \\
+ \\
\bar{n}\end{array}$ & $\underline{\cup}$ & $\underline{u}$ & $\frac{\bar{d}}{\bar{n}}$ & $\begin{array}{l}\bar{\Xi} \\
0 \\
+ \\
\bar{n}\end{array}$ & $\begin{array}{l}\frac{\partial}{\Xi} \\
0 \\
\pm \\
\bar{n}\end{array}$ & $\begin{array}{l}\bar{\Xi} \\
\bar{n}\end{array}$ & $\frac{\bar{m}}{\bar{n}}$ & $\begin{array}{l}\bar{m} \\
0 \\
+ \\
\bar{n}\end{array}$ & $\frac{\Phi}{\bar{\varpi}}$ \\
\hline 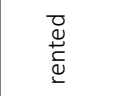 & 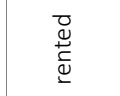 & 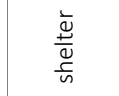 & 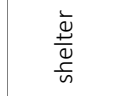 & 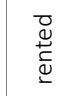 & 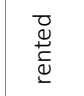 & 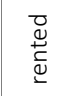 & 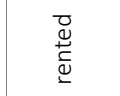 & 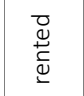 & 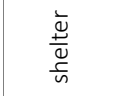 & 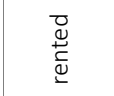 \\
\hline $\begin{array}{l}\frac{c}{d} \\
\frac{\grave{L}}{0} \\
\underline{U} \\
m \\
m\end{array}$ & $\begin{array}{l}\frac{0}{00} \\
. \frac{5}{\omega}\end{array}$ & 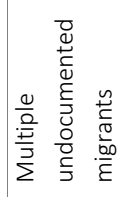 & 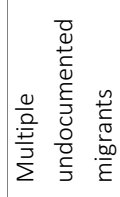 & 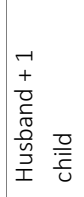 & 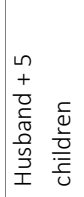 & 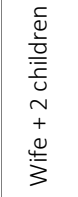 & 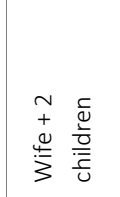 & 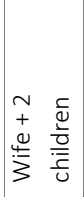 & 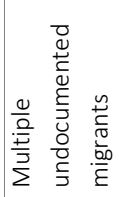 & 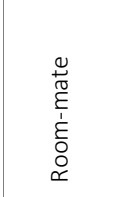 \\
\hline $\begin{array}{l}\vec{z} \\
\substack{a \\
\frac{c}{\alpha}}\end{array}$ & 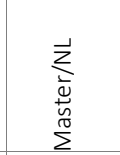 & 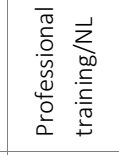 & 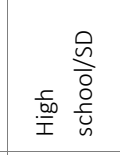 & $\underset{\infty}{\stackrel{0}{a}}$ & $\sum_{\infty}^{0}$ & 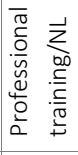 & 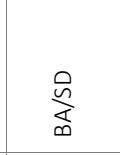 & $\begin{array}{l}\vec{z} \\
\substack{c \\
\text { c }}\end{array}$ & 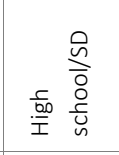 & 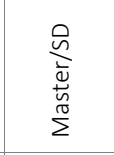 \\
\hline 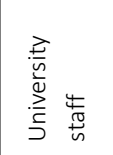 & 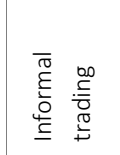 & 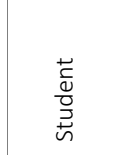 & 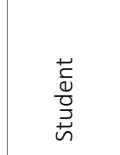 & 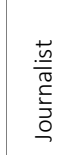 & 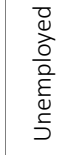 & 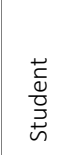 & 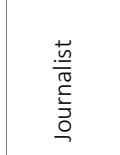 & 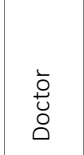 & 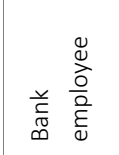 & $\sum_{-j}^{\bar{\nu}}$ \\
\hline 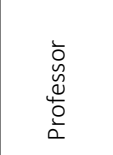 & 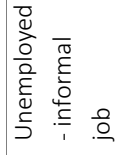 & 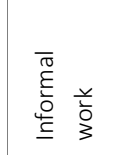 & 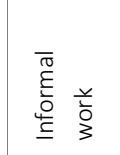 & 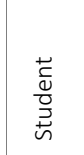 & 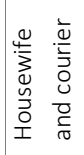 & 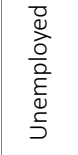 & 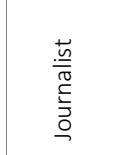 & 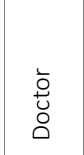 & 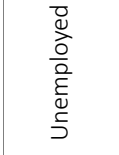 & 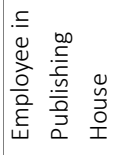 \\
\hline 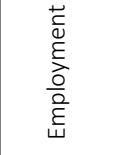 & 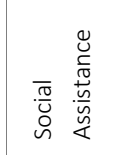 & 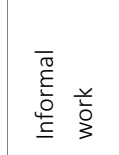 & 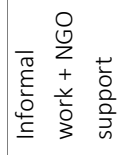 & 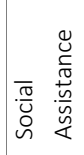 & 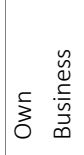 & 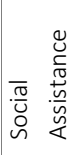 & 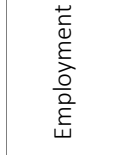 & 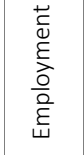 & \begin{tabular}{l} 
O \\
\} & 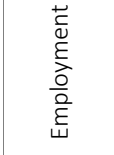 \\
\hline$m$ & $\rightarrow$ & 0 & 0 & 0 & 0 & 0 & 0 & 0 & 0 & 0 \\
\hline$\underset{\sqcup}{己}$ & 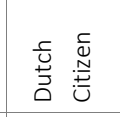 & 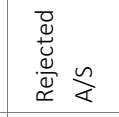 & 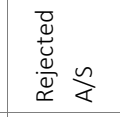 & 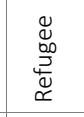 & 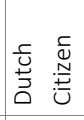 & 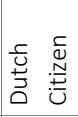 & $\underset{⺊}{己}$ & 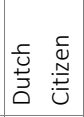 & 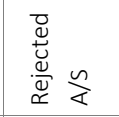 & 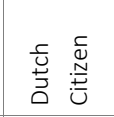 \\
\hline 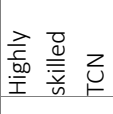 & ن্ & ن্ & ن্ & 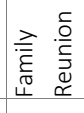 & 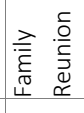 & $\stackrel{\text { i্ }}{<}$ & 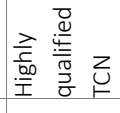 & 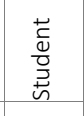 & ن্ं & ن্ \\
\hline ষ্ণ & 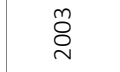 & ષ̊ & $\stackrel{m}{\stackrel{n}{0}}$ & $\underset{\sim}{\stackrel{\sim}{\sim}}$ & ષ્ઠ & 욕 & $\underset{\sim}{\stackrel{ }{\nu}}$ & $\stackrel{\infty}{\stackrel{\nu}{~}}$ & ర్రి & \\
\hline 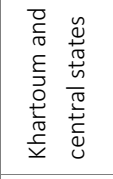 & $\underset{\frac{1}{2}}{\frac{1}{5}}$ & 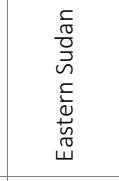 & $\underset{\frac{1}{2}}{\frac{1}{\pi}}$ & 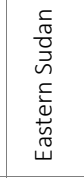 & 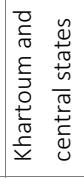 & 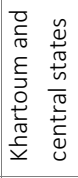 & $\underset{\substack{\frac{1}{2} \\
0}}{0}$ & 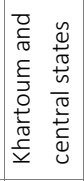 & 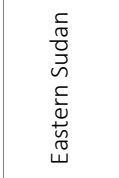 & 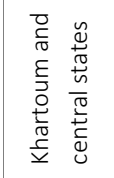 \\
\hline$\stackrel{\infty}{n}$ & ஜ & $\stackrel{m}{m}$ & $\stackrel{+}{m}$ & શి & $\tilde{m}$ & $\stackrel{\infty}{+}$ & $\stackrel{\text { น }}{f}$ & $\hat{m}$ & ஜ & ஜ \\
\hline$\sqcup$ & $\Sigma$ & $\Sigma$ & $\Sigma$ & $\sqcup$ & $\sqcup$ & $\Sigma$ & $\Sigma$ & $\Sigma$ & $\Sigma$ & $\Sigma$ \\
\hline $\begin{array}{l}\frac{\pi}{\bar{d}} \\
\frac{\bar{J}}{5} \\
\sim\end{array}$ & $\begin{array}{l}\overline{\overline{\bar{\sigma}}} \\
\underline{\underline{\varepsilon}} \\
\underline{\underline{n}}\end{array}$ & 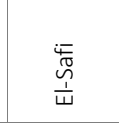 & 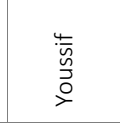 & $\underset{\stackrel{\sigma}{\xi}}{\frac{\pi}{4}}$ & 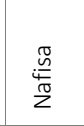 & \begin{tabular}{l}
\multicolumn{1}{c}{} \\
$\sum_{\tilde{n}}$ \\
0
\end{tabular} & 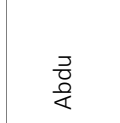 & 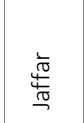 & 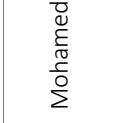 & 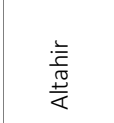 \\
\hline
\end{tabular}
\end{tabular}




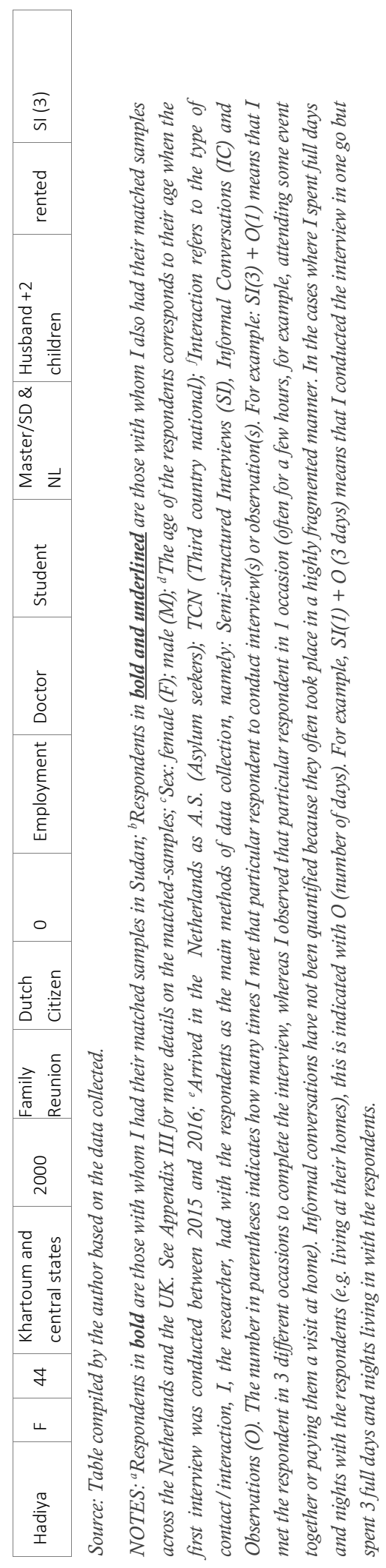




\begin{tabular}{|c|c|c|c|c|c|c|c|c|}
\hline 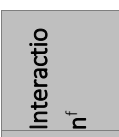 & 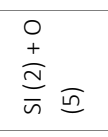 & 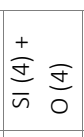 & $\begin{array}{l}\bar{\Xi} \\
\text { O } \\
\underline{+}\end{array}$ & $\begin{array}{ll}0 & \\
+ & \bar{n} \\
\vec{\Xi} & \frac{\pi}{0} \\
\bar{n} & 0\end{array}$ & $\begin{array}{l}0 \\
\stackrel{+}{\Xi} \\
\bar{n} \\
\Xi\end{array}$ & $\begin{array}{l}0 \\
\frac{+}{\sqrt{n}} \\
\bar{d}\end{array}$ & $\begin{array}{l}0 \\
\stackrel{+}{\Xi} \\
\bar{n} \bar{m}\end{array}$ & 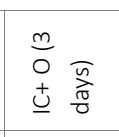 \\
\hline 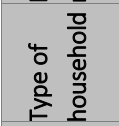 & 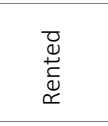 & 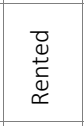 & 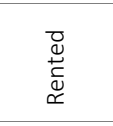 & 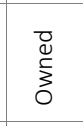 & 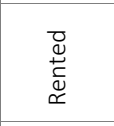 & 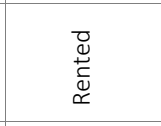 & 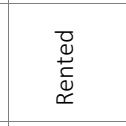 & 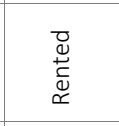 \\
\hline 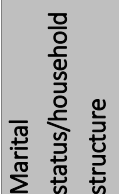 & 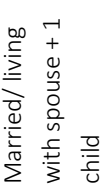 & 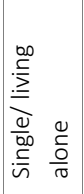 & 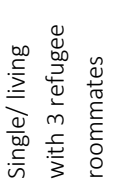 & 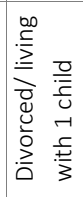 & 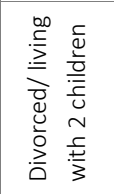 & 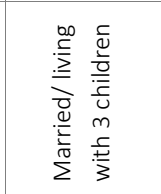 & 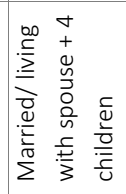 & 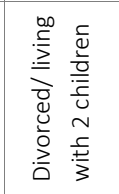 \\
\hline 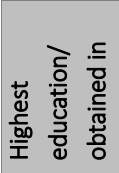 & 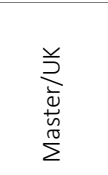 & 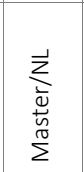 & $\stackrel{0}{\frac{0}{\infty}}$ & 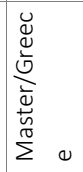 & $\stackrel{\text { 并 }}{\sum}$ & $\underset{\infty}{\grave{\infty}}$ & 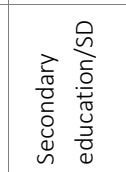 & 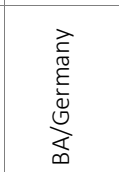 \\
\hline 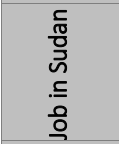 & 高紊离 & 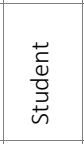 & 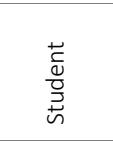 & 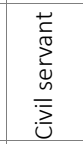 & 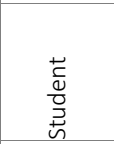 & $\begin{array}{l}\stackrel{+}{0} \\
\frac{0}{0} \\
\stackrel{\vec{D}}{n}\end{array}$ & 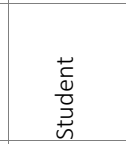 & 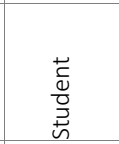 \\
\hline 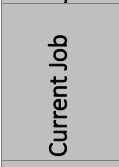 & 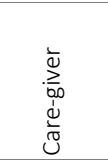 & 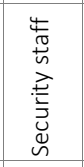 & 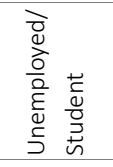 & 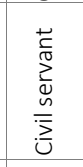 & 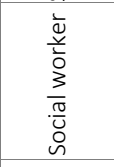 & 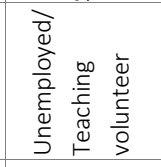 & 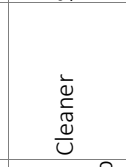 & 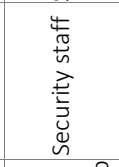 \\
\hline 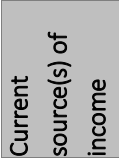 & 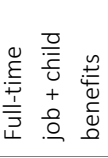 & 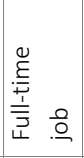 & 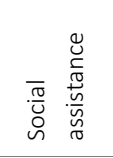 & 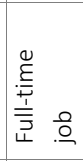 & 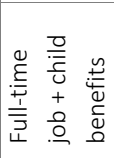 & 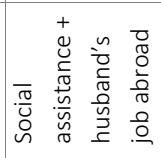 & 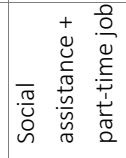 & 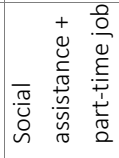 \\
\hline 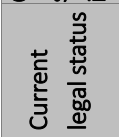 & 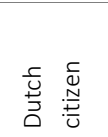 & 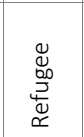 & 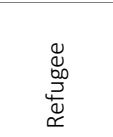 & 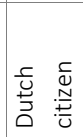 & $\begin{array}{ll}\frac{c}{D} \\
\text { D. } \\
\text { 志 }\end{array}$ & 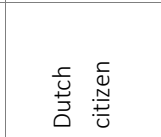 & 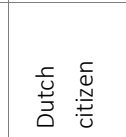 & 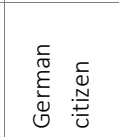 \\
\hline 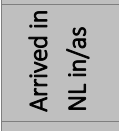 & 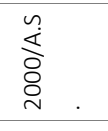 & 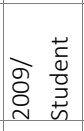 & $\stackrel{\text { ֻே }}{\check{c}}$ & 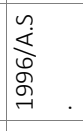 & 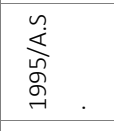 & 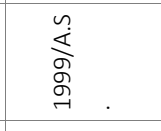 & 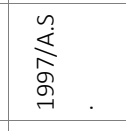 & $\begin{array}{l}\vec{c} \\
\text { ने } \\
\text { gे } \\
\text { जे }\end{array}$ \\
\hline 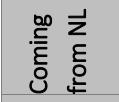 & $\stackrel{\Perp}{\nu}$ & $\stackrel{\Perp}{\nu}$ & 울 & $\stackrel{\Perp}{\nu}$ & $\stackrel{\varrho}{\nu}$ & $\stackrel{\Perp}{\nu}$ & $\stackrel{\varrho}{\nu}$ & $\stackrel{\infty}{2}$ \\
\hline 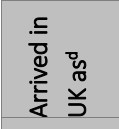 & $\mathrm{J}$ & ن্ & 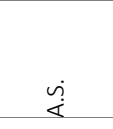 & 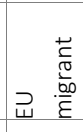 & 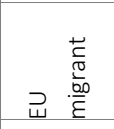 & $\mathrm{J}$ & $\mathrm{J}$ & 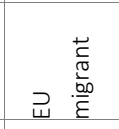 \\
\hline 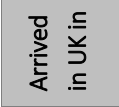 & 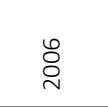 & 芩 & 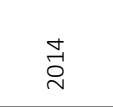 & ஜ̊̊ & 㝏 & ஜ̊ & $\stackrel{\text { ڤn }}{\circ}$ & 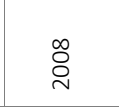 \\
\hline 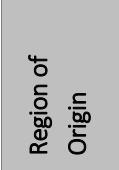 & 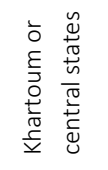 & $\begin{array}{l}\frac{1}{2} \\
\frac{1}{\pi} \\
0\end{array}$ & 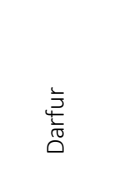 & 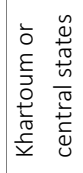 & 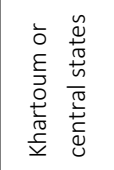 & 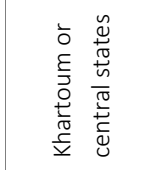 & 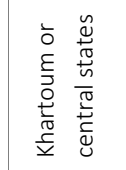 & 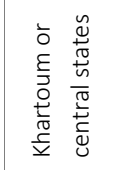 \\
\hline 品 & $\stackrel{\sim}{\sim}$ & $\tilde{m}$ & $\stackrel{\sim}{ }$ & ஜூ & $\underset{\forall}{\forall}$ & 우 & ஜ & f \\
\hline 芉 & 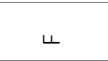 & $\Sigma$ & $\Sigma$ & ᄂ & 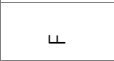 & 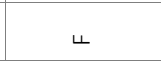 & $\Sigma$ & $\Sigma$ \\
\hline 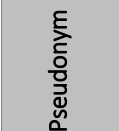 & 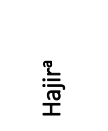 & $\begin{array}{l}\frac{5}{\overline{7}} \\
\frac{\pi}{4}\end{array}$ & $\frac{\sqrt{\bar{\pi}}}{\frac{\mathrm{T}}{<}}$ & 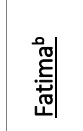 & 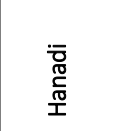 & $\begin{array}{l}\text { 뫂 } \\
\text { (n) }\end{array}$ & $\begin{array}{l}\frac{5}{\frac{\pi}{0}} \\
\frac{\overline{7}}{8} \\
\frac{0}{4}\end{array}$ & 言 \\
\hline
\end{tabular}




\begin{tabular}{|c|c|c|c|c|c|c|c|c|}
\hline$\frac{\bar{d}}{\bar{n}}$ & 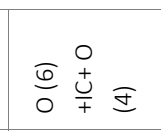 & 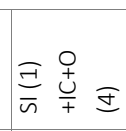 & $\begin{array}{l}0 \\
\stackrel{+}{\Xi} \\
\bar{n} \\
\Xi\end{array}$ & $\begin{array}{l}0 \\
\frac{+}{\bar{n}} \\
\bar{\Xi}\end{array}$ & $\begin{array}{l}0 \\
\frac{+}{\bar{n}} \\
\underline{n}\end{array}$ & $\begin{array}{l}0 \\
\frac{+}{\bar{n}} \\
\bar{\Xi}\end{array}$ & $\begin{array}{l}0 \\
\frac{+}{\bar{m}} \\
\Xi\end{array}$ & $\frac{\bar{m}}{\bar{n}}$ \\
\hline 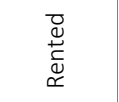 & 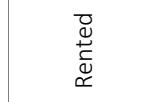 & 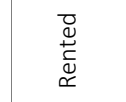 & \multicolumn{2}{|l|}{ 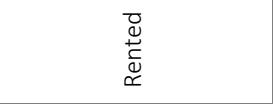 } & 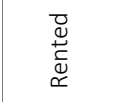 & 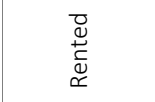 & 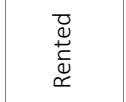 & 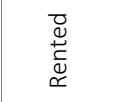 \\
\hline 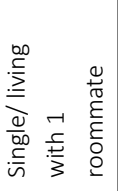 & 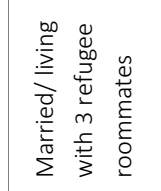 & 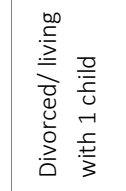 & \multicolumn{2}{|c|}{ 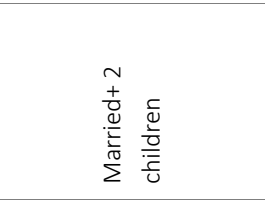 } & 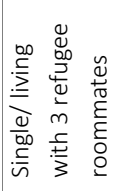 & 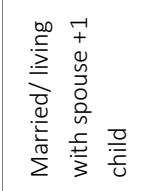 & 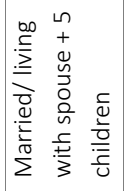 & 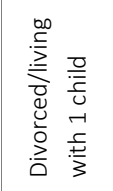 \\
\hline $\begin{array}{l}\text { 兰 } \\
\text { 方 } \\
\text { c }\end{array}$ & 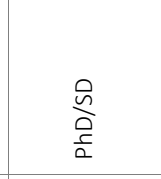 & 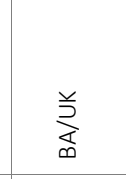 & 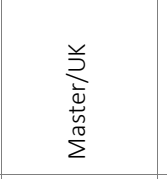 & $\underset{\infty}{0}$ & 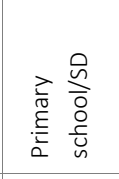 & $\stackrel{0}{\frac{0}{\infty}}$ & 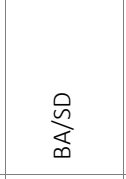 & 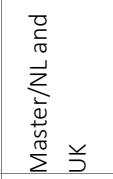 \\
\hline $\begin{array}{l}\stackrel{\vec{c}}{0} \\
\frac{0}{0} \\
\stackrel{D}{n}\end{array}$ & 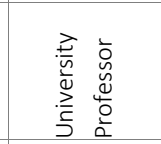 & 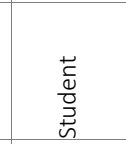 & 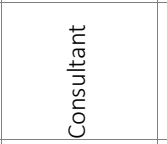 & 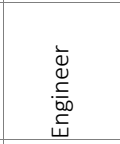 & 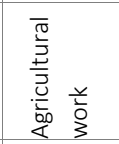 & 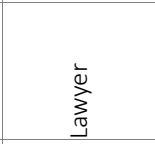 & 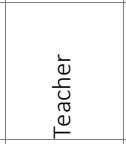 & $\begin{array}{l}\vec{v} \\
\frac{\overrightarrow{0}}{0} \\
\stackrel{\vec{D}}{n}\end{array}$ \\
\hline 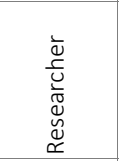 & 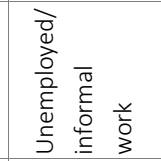 & 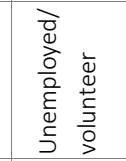 & 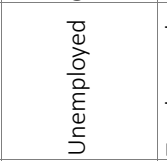 & 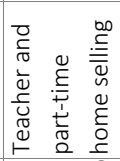 & 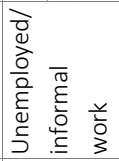 & 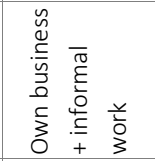 & 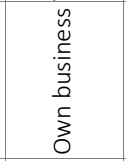 & 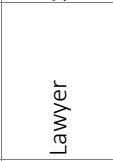 \\
\hline 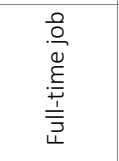 & 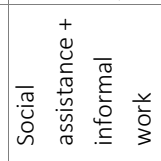 & 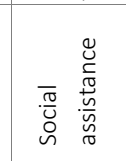 & 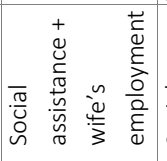 & 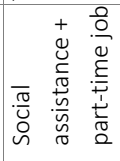 & 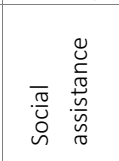 & 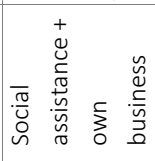 & 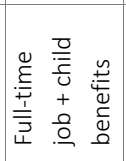 & 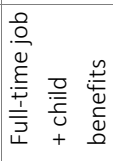 \\
\hline$\underset{⺊}{己}$ & 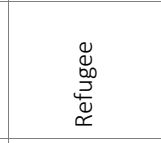 & 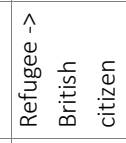 & $\underset{丶}{\circlearrowright}$ & 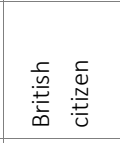 & 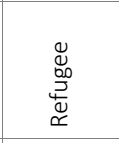 & 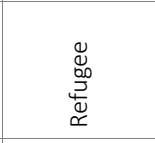 & 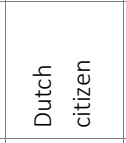 & 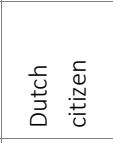 \\
\hline$\stackrel{\text { வே }}{\check{\Sigma}}$ & $\stackrel{\text { }}{\check{C}}$ & $\stackrel{\text { }}{\check{C}}$ & 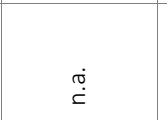 & $\stackrel{\text { }}{\check{~}}$ & 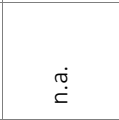 & 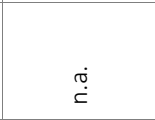 & 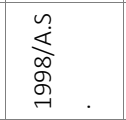 & $\begin{array}{l}\text { n } \\
\text { के } \\
\text { ने. }\end{array}$ \\
\hline 울 & ㅇ & i & $\stackrel{0}{z}$ & o & ㅇ & ㅇ & $\stackrel{\varrho}{\nu}$ & $\stackrel{\ddot{\nu}}{\nu}$ \\
\hline 己 & نे & 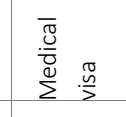 & 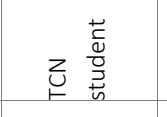 & 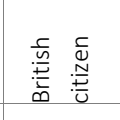 & $\underset{\leftarrow}{\text { ஸे }}$ & نे & 己 & $\mathrm{J}$ \\
\hline$\underset{\stackrel{\sim}{~}}{ت}$ & $\underset{\sim}{\stackrel{J}{~}}$ & స్ & $\underset{\sim}{\stackrel{\sim}{\sim}}$ & $\underset{\sim}{\stackrel{J}{~}}$ & $\stackrel{n}{\stackrel{n}{\sim}}$ & ت્ઞ & 吉 & ஜ̊̀ \\
\hline 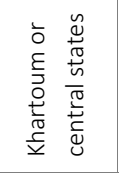 & 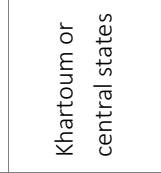 & $\begin{array}{l}\frac{\varrho}{\bar{z}} \\
\frac{\varrho}{\infty}\end{array}$ & 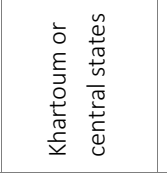 & 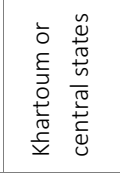 & $\underset{\frac{3}{2}}{\frac{1}{0}}$ & 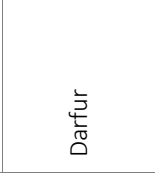 & 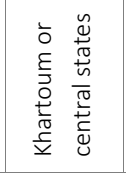 & 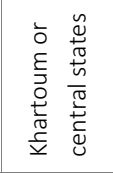 \\
\hline$\vec{m}$ & 㶽 & กิ & $\mathcal{F}$ & $\vec{\forall}$ & ન્ન & $\stackrel{m}{m}$ & $\stackrel{\infty}{+}$ & \& \\
\hline$\Sigma$ & $\Sigma$ & $\Sigma$ & $\Sigma$ & $\sqcup$ & $\Sigma$ & $\Sigma$ & $\Sigma$ & $\sqcup$ \\
\hline$\frac{\underline{E}}{\stackrel{\underline{E}}{N}}$ & 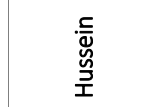 & $\begin{array}{l}\frac{i}{\pi} \\
\frac{\pi}{5} \\
\text { ల్ } \\
0\end{array}$ & 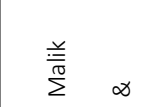 & $\frac{\widetilde{N}}{\mathscr{E}}$ & $\begin{array}{l}\stackrel{i=}{N} \\
N\end{array}$ & 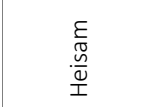 & 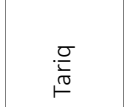 & $\begin{array}{l}E \\
\mathbb{W} \\
\stackrel{\mathscr{L}}{W}\end{array}$ \\
\hline
\end{tabular}




\begin{tabular}{|c|c|c|c|c|}
\hline 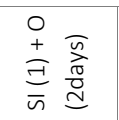 & 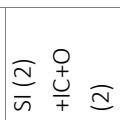 & 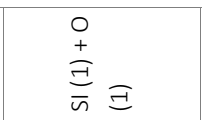 & $\frac{\bar{a}}{\bar{n}}$ & $\begin{array}{l}0 \\
\stackrel{+}{\bar{U}} \\
\frac{+}{+}\end{array}$ \\
\hline $\begin{array}{l}\stackrel{ }{\Phi} \\
\stackrel{ \pm}{ \pm} \\
\propto\end{array}$ & 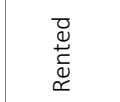 & 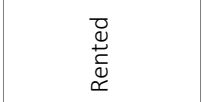 & 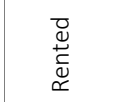 & 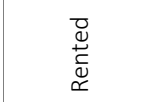 \\
\hline 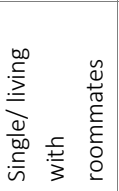 & 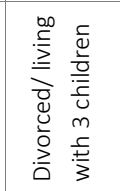 & 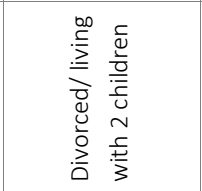 & 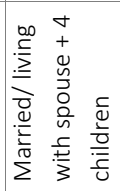 & 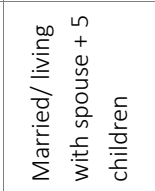 \\
\hline 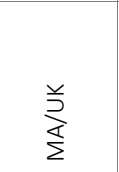 & 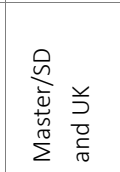 & 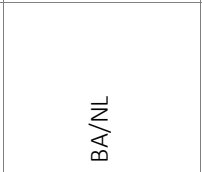 & $\underset{\infty}{\grave{\infty}}$ & 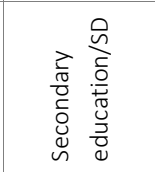 \\
\hline 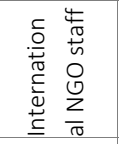 & $\begin{array}{l}\text { 苞 } \\
\text { 竞 } \\
\text { in }\end{array}$ & $\begin{array}{l}\text { 苞 } \\
\frac{0}{0} \\
\text { 总 }\end{array}$ & $\begin{array}{l}\grave{a} \\
\text { Oั } \\
\end{array}$ & 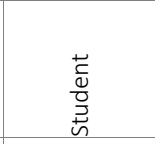 \\
\hline 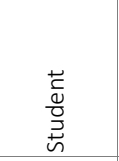 & 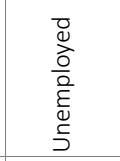 & 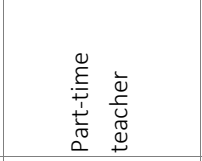 & 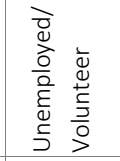 & 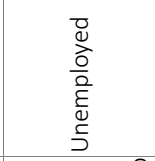 \\
\hline 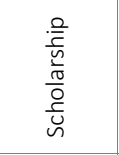 & 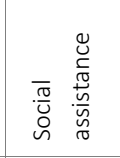 & 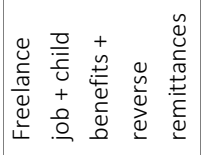 & 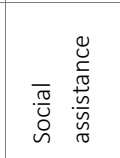 & 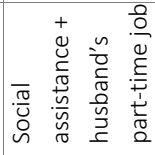 \\
\hline$\underset{\iota}{\underbrace{}_{1}}$ & 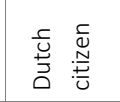 & 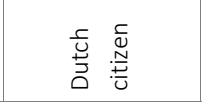 & 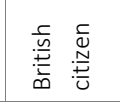 & $\underset{\sqcup}{u}$ \\
\hline ்ֻ & 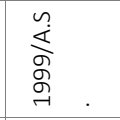 & 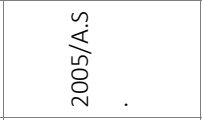 & 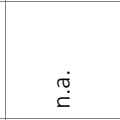 & 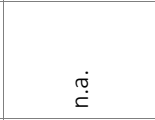 \\
\hline 2 & $\stackrel{\Perp}{\rightleftharpoons}$ & $\stackrel{\check{\Perp}}{\nsim}$ & 울 & ì \\
\hline 己 & $\mathrm{z}$ & 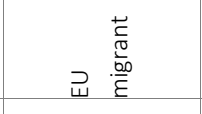 & 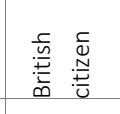 & 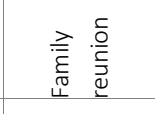 \\
\hline$\stackrel{\text { n̊ }}{\stackrel{n}{~}}$ & 옴 & $\stackrel{m}{\stackrel{n}{d}}$ & $\stackrel{\infty}{\circ}$ & 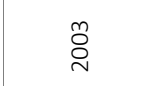 \\
\hline 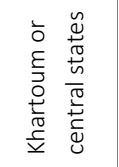 & 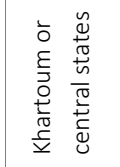 & 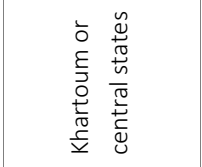 & 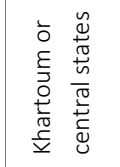 & 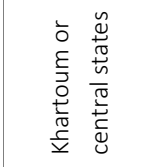 \\
\hline$\stackrel{\infty}{\sim}$ & $\stackrel{\mathscr{q}}{\sim}$ & $\stackrel{\sim}{m}$ & $\stackrel{n}{n}$ & $\hat{m}$ \\
\hline$\Sigma$ & \llcorner & $\sqcup$ & $\Sigma$ & \llcorner \\
\hline 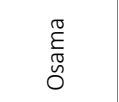 & 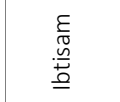 & $\frac{\frac{\pi}{\pi}}{\frac{\pi}{I}}$ & $\begin{array}{l}\frac{\varepsilon}{N} \\
3^{n}\end{array}$ & $\begin{array}{l}\underset{\pi}{\tilde{\pi}} \\
\stackrel{\pi}{\simeq}\end{array}$ \\
\hline
\end{tabular}

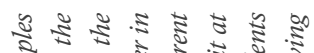

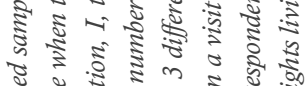

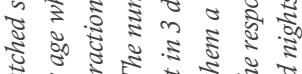

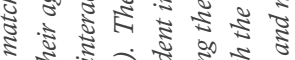

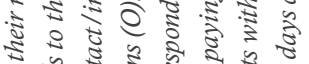
गृ ₹ कू

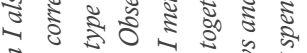
ำ ปै

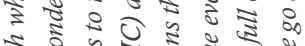

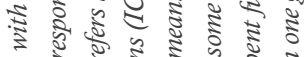

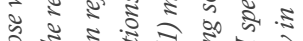

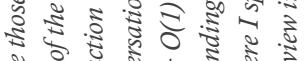

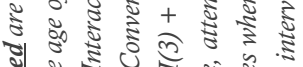
चँ

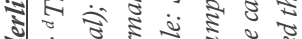
ఫ्ञ

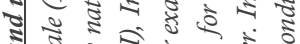

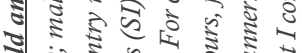
औी

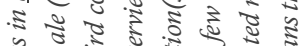

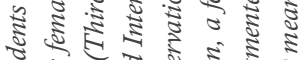
क्षे

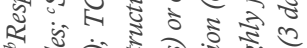
है है है है है है के क्षे के है इ ปี

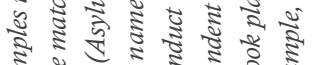

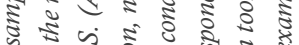

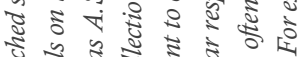

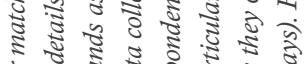

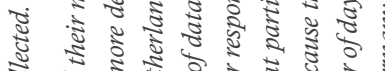
उ. ฟ

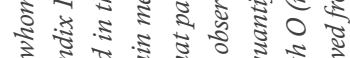
के

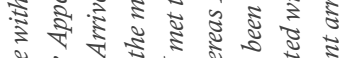
ڤัँ

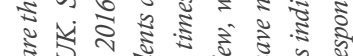

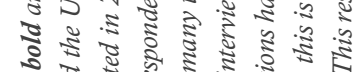

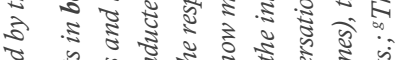

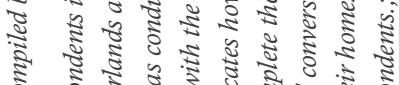
वे के

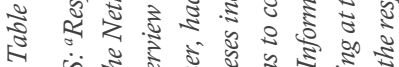

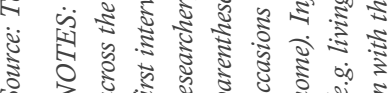




\section{Appendix III - Matched samples}

The table below provides an overview of the 19 matched samples in this research. To facilitate the interpretation of the table, in the first column there are the pseudonyms of the respondents in Europe, as shown in the Appendixes I and II.

\begin{tabular}{|c|c|c|c|}
\hline $\begin{array}{l}\text { Respondent in } \\
\text { Europe (country) }\end{array}$ & $\begin{array}{l}\text { Migrant's family member(s) } \\
\text { observed or interviewed } \\
\text { (country) }\end{array}$ & $\begin{array}{l}\text { Family member's relation to } \\
\text { the respondent in Europe }\end{array}$ & Interactiona \\
\hline Ashraf (NL) & Talia (SD) & Sister & $O(3)$ \\
\hline Atif (NL) & $\begin{array}{l}\text { Huda (SD) } \\
\text { Leem (SD) }\end{array}$ & $\begin{array}{l}\text { Mother } \\
\text { Sister }\end{array}$ & $\begin{array}{l}\mathrm{O}(1) \\
\mathrm{O}(1)\end{array}$ \\
\hline Khalil (NL) & Hamza (SD) & Cousin & IC (1) \\
\hline Laila (NL) & $\begin{array}{l}\text { Ikhlas (SD) } \\
\text { Ali (SD) }\end{array}$ & $\begin{array}{l}\text { Mother } \\
\text { Brother }\end{array}$ & $\begin{array}{l}O(1) \\
O(1)\end{array}$ \\
\hline $\begin{array}{l}\text { Darwish (NL) } \\
\widehat{\int} \text { siblings } \\
\text { Fatima (UK) }\end{array}$ & $\begin{array}{l}\text { Musa (SD) } \\
\text { Hassan (SD) } \\
\text { Sama' (SD) }\end{array}$ & $\begin{array}{l}\text { Father } \\
\text { Brother } \\
\text { Sister }\end{array}$ & $\begin{array}{l}\text { O (5 days) } \\
\text { O (5 days) } \\
\text { O ( } 5 \text { days })\end{array}$ \\
\hline $\begin{array}{l}\text { Ibrahim (NL) } \\
\text { Noor (NL) } \\
\text { Saabir (UK) }\end{array}$ & $\begin{array}{l}\text { Sumaya (SD) } \\
\text { Hafiz (NL) } \\
\text { Mustafa (UK) } \\
\text { Adil (SD) } \\
\text { Samira (SD) }\end{array}$ & $\begin{array}{l}\text { Mother } \\
\text { Brother } \\
\text { Brother } \\
\text { Brother } \\
\text { Sister }\end{array}$ & $\begin{array}{l}\text { O (6 days) } \\
\text { O (1) } \\
\text { IC } \\
\text { O ( } 6 \text { days }) \\
\text { O ( } 6 \text { days })\end{array}$ \\
\hline Siham (NL) & $\begin{array}{l}\text { Sahar (SD) } \\
\text { Sulfa (SD) }\end{array}$ & $\begin{array}{l}\text { Mother } \\
\text { Sister }\end{array}$ & $\begin{array}{l}O(5) \\
O(5)\end{array}$ \\
\hline Sharif (NL) & $\begin{array}{l}\text { Asia (SD) } \\
\text { Hakim (SD) }\end{array}$ & $\begin{array}{l}\text { Mother } \\
\text { Brother }\end{array}$ & $\begin{array}{l}O(2) \\
O(1)\end{array}$ \\
\hline Suheila (NL) & Khalifa (UK) & Brother & $O(1)+I C$ \\
\hline Hajir (UK) & $\begin{array}{l}\text { Sabrina (SD/UK) } \\
\text { Assad (SD) }\end{array}$ & $\begin{array}{l}\text { Sister } \\
\text { Father }\end{array}$ & $\begin{array}{l}\mathrm{O} \text { (3 days) } \\
\mathrm{O}(1)\end{array}$ \\
\hline Aladin (UK) & Ibtihal (SD) & Sister & $\mathrm{O}(2)$ \\
\hline
\end{tabular}




\begin{tabular}{|c|c|c|c|}
\hline & $\begin{array}{l}\text { Ibtisam (SD) } \\
\text { Butheina (SD) } \\
\text { Adara (SD) }\end{array}$ & $\begin{array}{l}\text { Sister } \\
\text { Sister } \\
\text { Mother }\end{array}$ & $\begin{array}{l}O(2) \\
O(2) \\
O(2)\end{array}$ \\
\hline Altair (UK) & $\begin{array}{l}\text { Adam (SD) } \\
\text { Bilquees (SD) }\end{array}$ & $\begin{array}{l}\text { Father } \\
\text { Mother }\end{array}$ & $\begin{array}{l}O(2) \\
O(2)\end{array}$ \\
\hline Hanadi (UK) & Samia (SD) & Niece & IC (2) +O (2 days) \\
\hline Hind (UK) & $\begin{array}{l}\text { Zanoon (SD) } \\
\text { Hakim (SD) }\end{array}$ & $\begin{array}{l}\text { Husband } \\
\text { Brother }\end{array}$ & $\begin{array}{l}\text { I (1) } \\
\text { I (2) }\end{array}$ \\
\hline Abdullah (UK) & Abu-Musa (SD) & Brother-in-law & O (3 days) \\
\hline Salim (UK) & $\begin{array}{l}\text { Youssif (SD) } \\
\text { Munira (SD) }\end{array}$ & $\begin{array}{l}\text { Father } \\
\text { Mother }\end{array}$ & $\begin{array}{l}\text { SI (1) } \\
\text { IC (2) }\end{array}$ \\
\hline Hussein (UK) & $\begin{array}{l}\text { Nafisa (SD) } \\
\text { Maida (SD) } \\
\text { Asia (SD) } \\
\text { Marwan (UK) } \\
\text { Fatima (UK/SD) } \\
\text { Muna (SD) } \\
\text { Selma (SD) } \\
\text { Sarah (SD) }\end{array}$ & $\begin{array}{l}\text { Mother } \\
\text { Wife } \\
\text { Daughter } \\
\text { Brother-in-law } \\
\text { Sister } \\
\text { Sister } \\
\text { Niece } \\
\text { Niece }\end{array}$ & $\begin{array}{l}\text { O ( } 3 \text { days) } \\
\text { O ( } 6 \text { days }) \\
\text { O ( } 6 \text { days }) \\
\text { O ( } 1 \text { ) + IC } \\
\text { O ( } 4 \text { days })+I C . \\
\text { O ( } 3 \text { days }) \\
\text { O ( } 3 \text { days }) \\
\text { O ( } 3 \text { days })\end{array}$ \\
\hline Bashar (UK) & $\begin{array}{l}\text { Dunya (SD) } \\
\text { Elham (SD) } \\
\text { Hani (SD) }\end{array}$ & $\begin{array}{l}\text { Mother } \\
\text { Sister } \\
\text { Brother }\end{array}$ & $\begin{array}{l}\mathrm{O}(1) \\
\mathrm{O}(1) \\
\mathrm{O}(1)\end{array}$ \\
\hline Selma (UK) & $\begin{array}{l}\text { Fawziya (SD) } \\
\text { Jasmin (SD) }\end{array}$ & $\begin{array}{l}\text { Sister } \\
\text { Mother }\end{array}$ & $\begin{array}{l}\text { SI (1) + O (3) } \\
O(2)\end{array}$ \\
\hline
\end{tabular}

Source: Fieldwork.

NOTES: Interaction refers to the type of contact/interaction, I, the researcher, had with the respondents as the main methods of data collection, namely: Semi-structured Interviews (SI), Informal Conversations (IC) and Observations $(O)$. The number in parentheses indicates how many times I met that particular respondent to conduct interview(s) or observation(s). For example: SI(3) $+O(1)$ means that I met the respondent in 3 different occasions to complete the interview, whereas I observed that particular respondent in 1 occasion (often, a few hours, for example, attending some event together or paying them a visit at home). Informal conversations have not been quantified because they often took place in a highly fragmented manner. In the cases where I spent full days and nights with the respondents (e.g. living at their homes), this is indicated with $O$ (number of days). For example, $S I(1)+O$ (3 days) means that I conducted the interview in one go but spent 3 full days and nights living in with the respondents; ${ }^{b}$ With this respondent I exchanged Facebook messages and informal conversations while he was living in the UK. 


\section{Appendix IV - Topic guide}

Interviews conducted with the respondents of this research were semi-structured and conducted in a conversational manner. Yet, in order to make sure I collected the relevant information from all respondents consistently, I made use of this Topic Guide. The guide is organised around four main blocks that address the following aspects: personal background and general demographic information of the respondent, personal migration history, family and socio-economic background of the respondent, and social protection events. In most cases, two or more sessions were needed to adequately cover all the points in this guide. The same Topic Guide was used and adapted accordingly to interview the migrants' relatives 'back home'.

\begin{tabular}{|l|l|}
\hline Name: \\
\hline DOB: \\
\hline Gender: \\
\hline Date of the Interview: \\
\hline Place of the Interview: \\
\hline City: \\
\hline
\end{tabular}

\section{Personal Background}

Can you tell me a bit about yourself? Like, where are you from, what do you do for a living, etc.?

1.1. Name:

1.2. Place of residence before arriving in the NL/UK:

1.3. Civil Status:

1.4. Nationality:

1.5. Legal Status:

1.6. Religion:

1.7. Highest Education acquired:

1.8. Current job/profession:

\section{Personal Migration Background}

2.1 Can you tell me about your arriving in the UK/NL?

2.1.1 When did you arrive?

2.1.2 Why did you move here and not somewhere else?

2.1.3 Did you decide to come alone or in consultation with family members?

2.1.4 Did you come alone or with someone else?

\subsection{Can you tell me about how you made your way here?}

\subsubsection{Route?}

2.2.2 Who helped you move? How?

2.2.3 Did you know someone who helped you to settle in $\mathrm{x}$ ? How did you know this person? How did you get in touch with him/her?

2.2.4 In how many cities in the NL/UK have you lived? Why? 
2.2.5 Had you lived in some other country before?

2.3 Have you incurred any costs associated with getting papers to live in the NL/UK for yourself or anyone else (e.g. lawyer, visa fees, service from someone in Sudan, etc.)?

2.4 If you had a chance, would you move somewhere else? Where? Why?

2.5 Do you reconsider going back to Sudan?

\section{Family and SES Background}

Explanation: In this study we want to find out about how families support each other, even if they live in different countries. It is important that you understand that your family members will never know anything of what you tell me in this interview. It is very important for the research to understand how family relations are affected when people leave their country. I know this can be very sensitive, but any detail, good or bad, is important for me, and will always remain confidential.

3.1 Can you tell me a bit about your family? [Can you give names, please]

3.1.1 Who are they? How many members?

3.1.2 Where are they? Are some of them living in the NL or in another EU country? Where?

3.1.3 Can you tell me briefly what they do for a living NOW?

3.2 [If applicable] Did you arrive with your wife/husband or you applied for family reunification?

3.2.1 Which family member have you reunified?

3.2.2 Can you tell me about the process?

3.2.3 Who helped you in the process?

3.2.4 Would you like to reunify other family members? Who? Why?

3.2.5 Have some of your family members/relatives here in the NL returned to SD?

3.3 Can you tell me about your life in Sudan before you left the country?

3.3.1 Where and with whom did you live?

3.3.2 What did you do (e.g. work, study, etc.)?

3.3.3 What did your parents/sibling do?

3.3.4 Who was the main provider?

3.3.5 Who is the main provider now?

3.4 How much contact do you have with them now? What sort of contact?

3.4.1 Do you call them, or do they call you?

3.4.2 Do you travel to see them? How often?

3.4.3 If they travel to see you, who does normally travel? How often?

3.5 Can you tell me about your life in the NL/UK?

3.5.1 With whom do you live here?

3.5.2 Who is the main provider in your house now?

3.5.3 Can you name 3 or more of your friends here in the NL/UK:

-Where they come from?

-Where are they based now?

-What do they do for a living?

- How often have you seen them in the last month? What for?

3.5.4 Who do you visit when you have some free time? 
3.5.5 Do you belong to some association/organisation related or not to Sudan?

- What sort of organization is that?

- Do you make some financial contribution? What's the money for?

- Have you ever received support (financial or not) from this organization?

3.5.6 Do you go to some Mosque/Religious Organisation?

- Do you make some financial contribution? What's the money for?

- Have you ever received support (financial or not) from this organization?

\subsection{How would you assess your SES in the NL/UK?}

3.6.1 Do you think it is better or worse than in SD?

3.6.2 Why?

\section{Social protection}

\section{Ground mapping questions:}

In general, can you tell me some example of how YOU SUPPORT YOUR FAMILY in SD?

○ Direct financial support...

- Indirect financial support, like paying for things for them, for example, school fees?

$\circ$ [If relevant] How?

- Are there funds/programs that you have access to that help you to support your family? For example, some Government funds, private insurance, trade unions, etc. Can you give me some example of how YOUR FAMILY in SD SUPPORTS YOU?

- E.g., by taking care of your house, or land, maybe, [if any] back in Sudan?

- Are there funds/programs that your family in Sudan has access to that help them to support themselves? For example, some Government funds, private insurance, trade unions, etc.

Thematic questions

\section{(UN) EMPLOYMENT}

\subsection{Which is your main source of income NOWADAYS?}

4.1.1. Who are you responsible for?

4.1.2. Is this money enough for you and your family?

4.1.3. Have you ever been in a situation where that money was not enough?

- What did you do? Did you ask for help to someone? Can you name some people?

4.1.4. If not, who would you ask first if you were in need of extra money for some emergency?

4.1.5. Are there other people working in your family? What do they do?

4.1.6. Have you ever applied for unemployment benefits? If yes, how did you feel about that?

4.1.7. Have you ever sought (and/or received) help from some organization (e.g. Mosque, migrant group, etc.)?

\subsection{Back in Sudan, which used to be your main source of income?}

4.2.1. Who were you responsible for?

4.2.2. Were there other people working in your family?

4.2.3. Was it enough to provide for yourself (and your family) needs? 
4.2.4. If not, what did you do? To whom did you ask for help in times of need? Can you name some people?

4.2.5. Now that you are away, how has that affected the income at a family level?

4.2.6. Have you (or the main provider) ever been unemployed in Sudan? What happened then?

- Did you ever apply for unemployment benefits? Why?

- How about the Zakat? Have you ever applied there? If yes, how did you feel about that?

\section{HEALTH and DISABILITY}

4.3. Here in the NL/UK, have you or any member of your family been seriously sick? Can you explain what happened?

4.3.1. Could you access medical services?

○

O

If yes, did you have outstanding health costs? How did you manage?

Who took care of you or the sick person?

4.3.2. If the sick person was the main provider, what happened then?

4.3.3. Do you have a private health insurance?

If yes, what and who does it cover?

4.3.4. Have you or some of your family members some disability that requires assistance from someone else?

- Who provides such assistance?

4.3.5. [If they have never been seriously sick]. Imagine you get very sick and are not able to work for a year. Who would you ask for help?

4.3.6. Have you ever been in a situation where more than one member of your family was sick and needed help?

oWhat happened? Who did you help first?

4.4. Back in Sudan, have you or any member of your family been seriously sick? Can you explain what happened?

4.4.1. Could you afford medical treatment/intervention?

$\circ \quad$ If not, what happened?

- Who took care of the sick person?

4.4.2. If the sick person was the main provider, what happened then?

4.4.3. If the care-giver was the main provider, what happened then?

4.4.4. Did you ever help someone outside your family to cover medical costs? How?

4.4.5. Do you/your family have a private health insurance in Sudan? What/who does it cover?

4.4.6. Have you or some of your family members some disability that requires assistance from someone else? Who provides such assistance?

\section{CHLDREN and DEPENDANTS}

4.5. Here in the NL/UK, do you have some children or dependents (e.g. elderly person) of whom you were responsible? Can you tell me about them?

4.5.1. Who takes care of them?

4.5.2. Do the children go to school/university? Who pays for it (e.g. fees, materials, food)? 
4.5.3. Do you receive some help from the Government or any other organisation?

4.6. Back in Sudan, did you have some children or dependents (e.g. elderly person) of whom you were responsible? Can you tell me about them?

4.6.1. What was your responsibility towards them when you were in Sudan?

4.6.2. What's your responsibility towards them now?

4.6.3. Has that affected your relationship?

4.6.4. Who takes care of them now?

4.6.5. Do the children go to school/university? Who pays for it (e.g. fees, materials, food)?

4.6.6. Do they receive some help from the Government or any other organisation?

\section{OLD-AGE}

4.7. How old are your parents?

4.8. Where are they?

4.9. Are they still working?

4.9.1. If not, what happens? How do you they manage to make ends meet?

4.9.2. Who takes care of them? How?

4.9.3. Has it always been like that? How was it before migrating?

4.9.4. Has that created conflict between you and other siblings? [If yes, who?]

4.10. When you retire/grow old, where would you like to spend your old age?

4.10.1. [If not in the NL/UK] Would you then lose any rights to receive a pension from the NL/UK Government?

4.10.2. Who do you think will take care of you?

4.10.3. Have you made specific arrangements for your old age care?

4.10.4. What would be the main challenge?

4.11. Do you have a funeral/life insurance?

4.11.1. Do you contribute to the funeral/life insurance of someone else?

4.11.2. What happens when someone dies and they don't have an insurance?

4.11.3. Have you ever contributed to pay the body-repatriation expenses for someone? Why?

\section{EDUCATION}

4.12. Where did you do your $\mathrm{X}$ studies?

4.12.1. Who paid for it?

4.12.2. Did you receive some sort of scholarship? From whom (e.g. Government, fund, etc.)?

4.13. Are you and/or any other member of your closest family studying now?

4.13.1. Who's paying for it?

4.13.2. Are you providing financial support for the education of some family member/friend?

\section{LIFE EVENTS}

4.14. Can you think of any particular event (here or in Sudan) where you or some member of your family or close friend required the investment of an important amount of money? [If they do not come up with anything, I will suggest things like: a wedding, a funeral, an urgent operation, etc.] 


\subsubsection{Who helps/ed?}

4.14.2. How?

\section{HOUSING}

4.15. Do you own the house where you're living now?

4.15.1. If yes, how did you pay for it? (e.g. loans)

4.15.2. If not, how do you pay the rent? (e.g. your own salary or housing benefits [this is important for refugees])

4.16. Do you own a house or land in Sudan?

4.16.1. Why do you keep the it?

4.16.2. Do you make any investment on it (e.g. re-building it, enlarging it, buying harvesting material in case it is a farm, etc.)?

4.16.3. Have you ever made any investment in the house of another person in Sudan?

4.16.4. Does someone make some investment in your property?

4.16.5. Who takes care of it while you're away?

4.16.6. Back in Sudan, did you live at the family house?

4.16.7. Who used to live there when you were there?

4.16.8. Who lives there now?

4.16.9. Who paid/pays for it?

\section{GENERAL IMPRESSION OF THE DUTCH SOCIAL SECURITY SYSTEM}

4.17. How do you think the NL contributes (or not) to your and your family's social wellbeing?

4.18. Do you think you would have better chances of employment/education somewhere else? Where? Why?

4.19. Do you think you would have a better living standard somewhere else? Where? Why?

\section{REMITTANCES}

As it might be your case, some migrants (especially those coming from countries with strong family ties, like many African countries, but also Spain, for instance, where I come from) maintain close contact with their families and friends. Sometimes they send money (remittances), presents, medicine, or simply they exchange telephone calls or e-mails. Sometimes they might even visit each other, or even arrange medical check-ups in the country of destination.

One of the objectives of this study is to find out how your efforts, the efforts of the migrants, are benefitting and improving the lives of those back home. Therefore, I would like to ask you a bit more about your relationship with your family and friends in Sudan. Your answers are extremely important for the development of this research, since you are the only person who can tell me about it.

\subsection{Now that you are not in Sudan, do you help your family 'back home'? How?}

\subsection{Do you send money and/or anything else?}

4.21.1. Why?

4.21.2. How much? Who decides how much money should be sent?

4.21.3. Do you always send the same amount?

4.21.4. How often?

4.21.5. Who do you send money to? 
4.21.6. Does your family expect you to send more when you earn more?

4.21.7. Do you tell your family that you earn more?

4.21.8. What do you do when you are in a difficult financial situation? Do you still send money home?

4.21.9. Has it ever happened that you didn't have enough money to send back?

- What did you do?

- How did your family react?

4.21.10. Has it ever happened to you that you had two emergency situations, one here and one there? What did you do?

4.21.11. Do you feel obliged to send this money?

4.21.12. Do you know what this money is used for?

4.21.13. Do you care about how the money is spent?

4.21.14. When did you first start to send money?

4.21.15. Will you continue sending money forever?

4.21.16. Do you help someone else besides your family in Sudan?

4.21.17. Do you contribute financially to the Zaka back home or some other organization?

4.21.18. What sort of support do you receive from your family?

- Emotional, child-caring, etc.

- $\quad$ From whom, exactly? 


\section{Appendix V - Information brochure for participants (English)}

The following information was designed by me and provided to all the participants in the shape of a three-cover brochure:

\section{Introduction}

You are invited to participate in a research project, entitled:

\section{Social Protection Across Borders. How Sudanese} migrants in the Netherlands and the United Kingdom and their families in Sudan make use of social protection, locally and transnationally.

This project is part of the TRANSMIC research programme (Transnational Migration, Citizenship and the Circulation of Rights and Responsibilities), which aims to explore the links between migration, citizenship, and development. The project runs from October 2014 until October 2017.

This study is conducted by: Ester Serra Mingot, $\mathrm{PhD}$ researcher at the Faculty of Arts and Social Sciences in Maastricht University (The Netherlands), under the supervision of Prof. Dr. Valentina Mazzucato, from the Faculty of Arts and Social Sciences, at Maastricht University.

\section{What is this research about?}

The purpose of this research project is to examine how Sudanese migrants, in the Netherlands and the United Kingdom (UK), and their families, in Sudan, provide support for each other, locally and across borders.

\section{Why are we doing this research?}

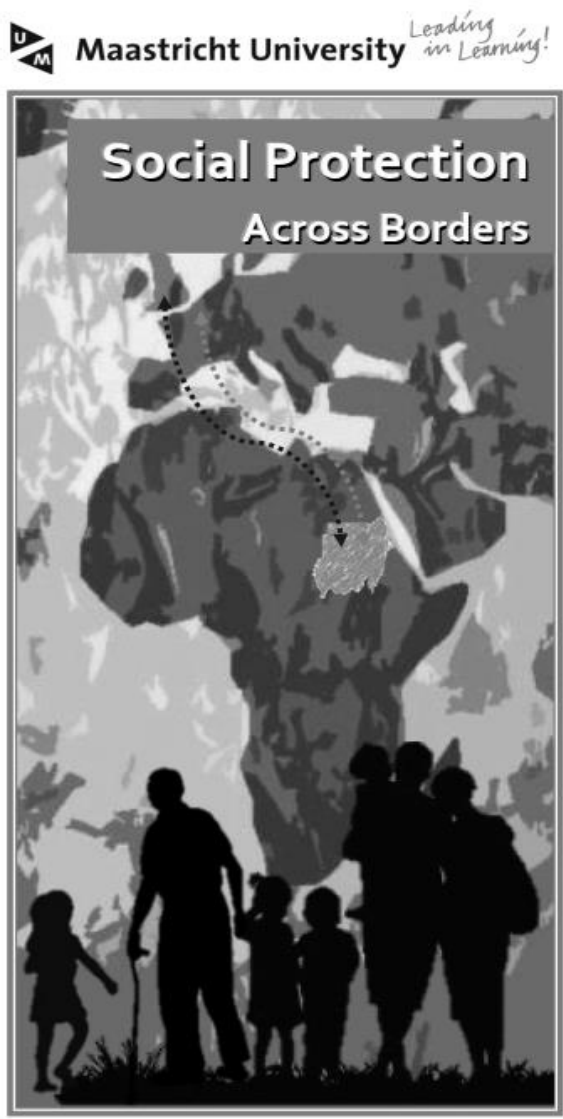

In the current globalised world, more and more people choose or are pushed to migrate internationally, whereby they develop and maintain attachments with family and friends living across different countries. Because of these attachments, migrants and their network of relations exchange support of all types, such as financial, or services that they conduct for each other.

On the one hand, in many developing countries, the remittances that migrants send often help to fund health, education, and social services that people in the origin country often cannot afford. On the other hand, the migrant's family in the country of origin might also play a role in supporting the migrant. For instance, by helping the migrant to migrate or by providing other services at home while the migrant is abroad.

This study aims to understand how migrants and their family and friends at home maintain and create new ways of supporting each other, both in destination and origin countries. Therefore, this study will research: 
- The different services and benefits that Sudanese migrants and their families receive from the state (e.g. welfare), the market (e.g. insurance companies), NGOs, religious institutions or family networks, in order to cover their basic needs, protect them against low living standards and assist them in times of socio-economic crisis, such as the lack of employment, healthcare or education, and the occurrence of other life events (e.g. funerals, weddings).

- How the different forms of social protection affect the relationships between the migrants and their families 'back home'.

\section{What will happen if you decide to take part in this research study?}

Approximately 24 Sudanese migrants and their families (12 in the UK and 12 in the Netherlands) will participate in this research.

If you agree to participate, you will be asked to take part in 2 to 4 interviews, which will be conducted by the main researcher over a period of 4 months. The length of the interviews will vary depending on the situation of each person, but they should range between 1 and 2 hours. If you live with your husband/wife or any other adult family member they might also be invited to take part in an interview, if you and they agree.

In this research, we want to explore how families provide support for each other across different countries. Therefore, the researcher will ask your permission to interview some of your family members in Sudan, with whom you have close links.

\section{What will happen to the information you provide? How will your privacy be protected?}

Your information collected for this study is completely confidential and no individual participant will ever be identified with his/her research information. Your name will be anonymised. Data from this project will be saved on a password protected computer throughout the duration of the project and up to 5 years after. Only the two main supervisors of this project will have access to the information: Prof. dr. Valentina Mazzucato Maastricht University, and Prof. Virginie Baby-Collin - Aix Marseille University. The Ethics Board at Maastricht University may review this study's records.

\section{What are the risks and benefits of taking part in this research study?}

Risks that you may experience from participating are considered minimal.

There are no costs for participating.

The participation in this research is completely voluntary. There are no benefits to you other than to further research of the wellbeing, rights and obligations of migrants and their families.

\section{Can you change your mind at any stage and withdraw from the study?}

Yes. Your participation in this project is voluntary. You may choose not to take part in this project, or if you decide to take part, you can change your mind later and withdraw from the project. You are free not to answer any specific question should you not want to.

\section{Contact}

If you have questions about the project or research procedures, you are free to contact the local project coordinator at the address and phone number below.

Ester Serra Mingot

PhD Researcher

Faculty of Arts and Social Sciences 
Maastricht University

Grote Gracht 76,

6211 Maastricht, The Netherlands

E-mail: e.serramingot@maastrichtuniversity.nl

Tel.: +31 (0)626342063 or +31433885166

Project

Web-site:

http://www.maastrichtuniversity.nl/web/Faculties/FASoS/Theme/ResearchOrganisatio

n1/ResearchProgrammes/GlobalisationTransnationalismAndDevelopment/OngoingPhD Projects.htm 


\section{Information brochure for participants (Arabic version)}

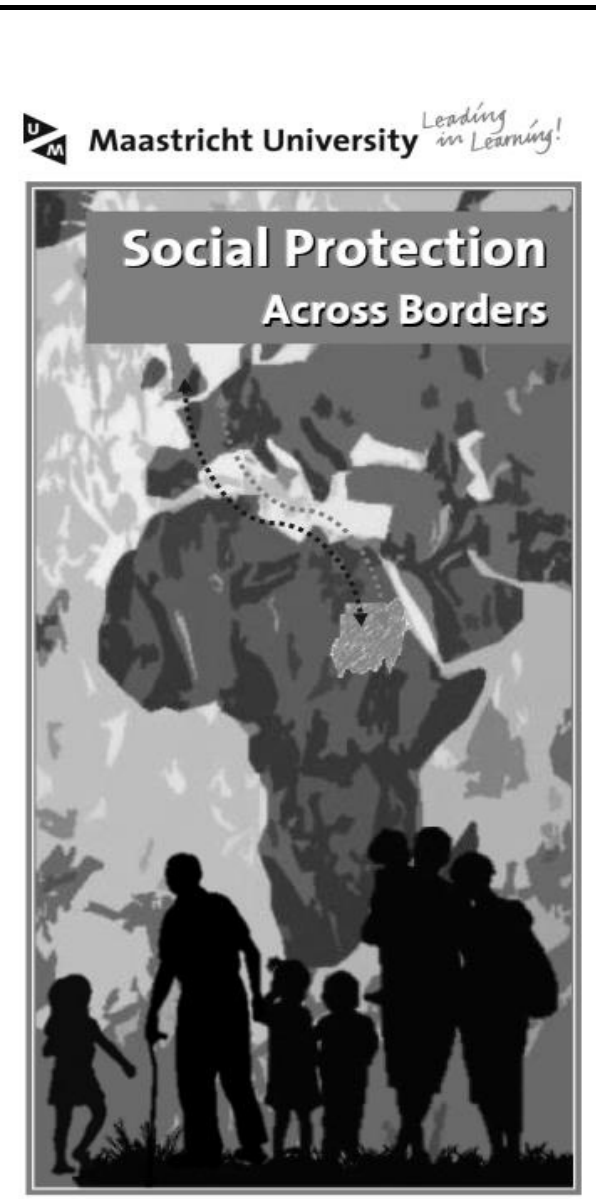

مقدمة

أنت مدعو للمشاركة في مشروع بحثي بعنوان:

الحماية الإجتماعية العابرة للحدود فئد

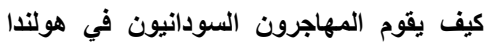

والمملكة المتحدة وأسر هم في السودان بالحماية العاية الاجتماعية،

محليا وخارج حدود أوطانهم الأصلية.

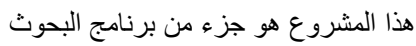

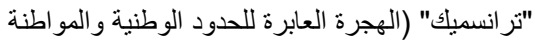

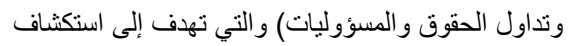

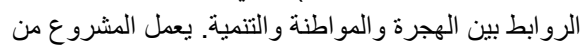

2014 حتى أكثوبر 2017.

Serra Mingot

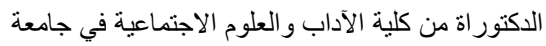
ماستريخت (هولندا)، تحت إشراف الأل الأستاذة الدكتورة Valentina Mazzucato (فالنتينا ماز كاتو )، من كلية الآداب و العلوم الاجتماعية، في جامعة ماستريخت (Maastricht).

هدف هذا المشروع البحثي هو دراسة كيف يقدم

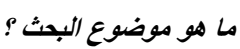

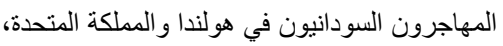

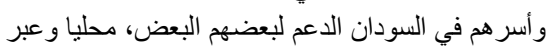

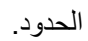

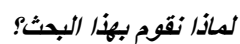

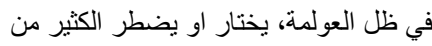

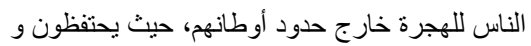

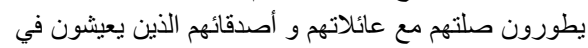
مختلف البلدان. بسبب هذه الصلات يتبادل المهاجرون وشبكات عانهات علاقتهم الإجتماعية الدعم ، مثل الدعم المالي، أو الخدمات

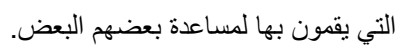

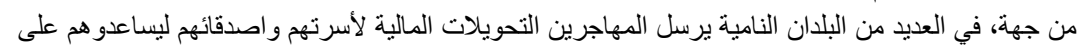

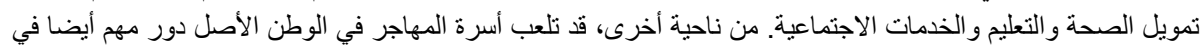

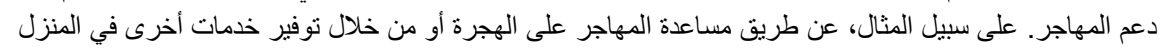
عندما يكون المهاجر في الخارج.

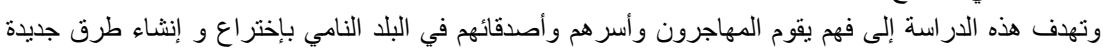

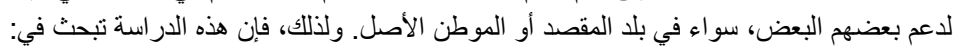

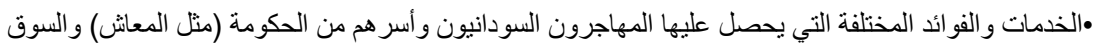

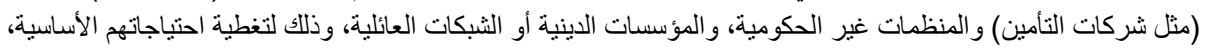

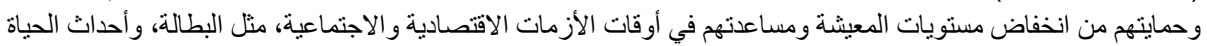
الأخرى, مثل الوفاة أو الزواج. •كيف تؤثر أثكال الحماية الاجتماعية المختلفة على العلاقات بين المهاجرين و أسر هم في السودان؟

ماذا سيحث إذا قررت المشاركة في هذا البحث؟ سيشارك في هذا البحث حوالي 24 مهاجرين سودانين وأسر هم (12 في المملكة المتحدة و 12 في هولندا). 


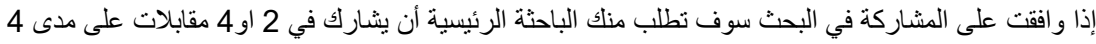

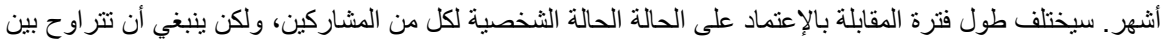

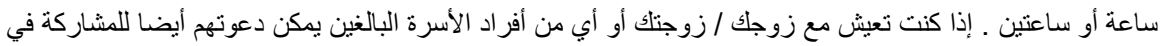

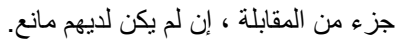
هدف هذا البحث هو در اسة كيفية دعم الأسر لأفر ادها في مختلف البلدان. ولذلك سوف تقوم الباحثة باستأنكك

$$
\text { لمقابلة بعض أفر اد أسرتلك في السودان. }
$$

ماذا سيحلث للمعلومات التي تقدمها? كيف سيتم حماية خصوصيتك؟

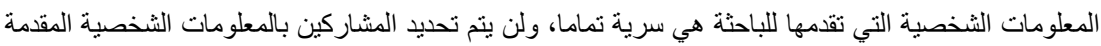

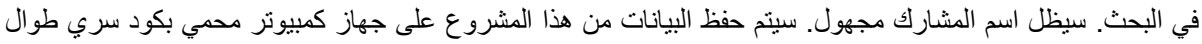

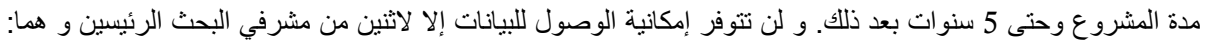

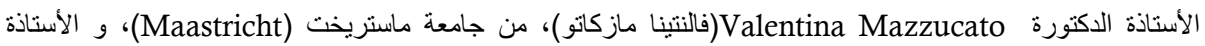

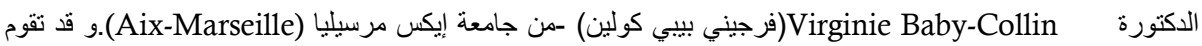
لجنة الأخلاقيات في جامعة ماستريخت بمر اجعة سجلات البحث.

$$
\text { ما هي مخاطر وفوائد المشاركتة في هذه البحث؟ }
$$

المشاركة مجانا.

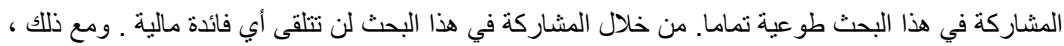

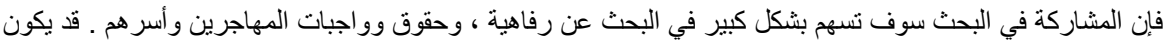
لهذا البحث تأثير على مستوى السياسات في مجال الحماية الاجتماعية العالمية.

$$
\text { يكنك تغيير رأيك في أي مرحلة والانسحاب من البحث؟ }
$$

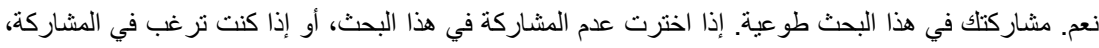

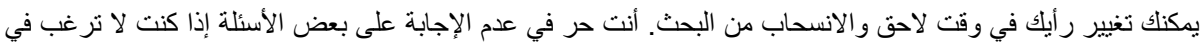
ذلك.

إذا كان لديك أسئلة حول البحث أو إجر اءات البحث أنت حر في الاتصال منسق المشروع المحلي في العنوان ورقم الهاتف أدناه: - n

\section{Ester Serra Mingot}

PhD Researcher

Faculty of Arts and Social Sciences

Maastricht University

Grote Gracht 76,

62II Maastricht, The Netherlands

E-mail: e.serramingot@maastrichtuniversity.nl

Tel.: +3। (0)626342063 or +3I 433885 I 66

Project Web-site:

http://www.maastrichtuniversity.nl/web/Faculties/FASoS/Theme/ResearchOrganisation I/Resea rchProgrammes/GlobalisationTransnationalismAndDevelopment/OngoingPhDProjects.htm 



\section{SUMMARY IN ENGLISH}

In our current globalised world, more and more people choose or are pushed to live across national borders, developing attachments and responsibilities in more than one nation-state-for example, by earning their livelihoods, making housing investments, caring for family members, or saving for their old-age in different countries. Yet, most welfare systems have been envisaged to cater for sedentary populations, tied to a particular nation-state. This becomes problematic for people with increasingly mobile lifestyles and responsibilities that span beyond a single nation-state. For example, newly arrived migrants may lack strong social networks, and they usually have to wait several years before they have access to the formal social protection system in the host country. At the same time, any contributions made to the social protection systems in their origin country might cease to exist after arriving in the new host country, and vice versa (Avato, Koettl, and Sabates-Wheeler 2009).

Even when welfare provisions in the receiving country are accessible, migrants are often responsible for providing for their families 'back home', who are often not covered by the social protection system in their origin countries. In fact, international migration does not necessarily sever the obligations and responsibilities between family members living apart (Bryceson and Vuorela 2002). On the contrary, migration is often considered a social protection strategy to guarantee the wellbeing of the different family members, now and in the future (Stark and Levhari 1982; Stark and Lucas 1988;). However, at the global level, legal provisions regarding social protection rights for international migrants and their families remain scarce. Against this backdrop, migrants must develop a series of strategies that encompass formal and informal elements from different institutions (e.g. the state, the markets, thirdsector organisations or informal social networks) to cover for their own and/or their families' needs, which are often related to the provision and reception of care.

Understanding how transnational families navigate different forms of social protection, locally and transnationally, is at the core of this dissertation. To address the main enquiry of this research, I chose to focus on the specific case of Sudanese migrants in the Netherlands and the UK, and their families back home. Although the Sudanese are not one of the most numerous migrant groups in Europe, they are a heterogeneous group in terms of legal and socio-economic statuses, which allowed for maximum variation sampling, through which I could maximize the diversity relevant to the research question by selecting a small number of cases. Moreover, the Sudanese are a relatively new migrant group in Europe, facing different migration and receiving contexts, which might impact the manner in which they engage in different transnational social protection practices. For example, new migrant groups might have fewer and less developed social networks in the receiving country, which often provide migrants with social protection, locally and transnationally. The 
selection of the UK and the Netherlands is based on three main reasons. First, many Sudanese in the Netherlands have relatives who moved from the Netherlands to the UK, which allowed me to address the social protection mechanisms across the borders of three nation-states. Second, both countries have different welfare and migration policy systems, which helps to understand the role that policies have in the social protection arrangements that migrants devise. Finally, the Sudanese community in the UK is bigger and older than in the Netherlands, which was expected to cast some light on the role of personal social networks.

Within this backdrop, this dissertation addresses the following research question: How do Sudanese migrants in the Netherlands and the UK and their families back home navigate their social protection, locally and across borders? To answer this question, I conducted 14 months of multi-sited and partly matched-sample ethnography across the three contexts where the migrants and their families lived - the Netherlands, the UK and Sudan. Multi-sited research was conducted using semi-structured interviews, informal conversations and observations with 21 respondents in the Netherlands, 22 respondents in the UK and 19 of their family members in Sudan or matched samples. By conducting research with different family members across multiple locations, I could unpack the complexities of providing social protection across diverse contexts when resources are limited.

The following sections summarize the main findings of the three empirical chapters of this dissertation (Chapters 7-9) and its main theoretical contributions.

\section{Main findings}

To answer the main research question, three sub-questions were identified and addressed in the three empirical chapters, which are based on published or submitted research articles. The reminder of this section summarises the main findings of these chapters.

Chapter 7 investigates how migrants navigate formal state-bounded social protection provisions to informally provide for themselves or their families back home. The chapter problematizes the clear-cut division between formal and informal social protection systems, which ignores how both welfare-state institutions and migrants work together at the interstices of the formal and informal to cater to national and transnational social protection needs. Based on data collected in the Netherlands and Sudan, this chapter investigates how migrants sometimes enter into symbiotic relationships with different welfare-state institutions, such as municipal offices, NGOs and other immigration institutions, which in turn rely on the support of these migrants to provide social protection to people who would otherwise escape their purview. The analysis shows that sometimes, such relations are actually initiated by the state-based institutions, which due to their geographical fixity are not prepared to cover the needs of mobile people. This finding suggests that local authorities, NGOs and immigration institutions are not only acting out of compassion or solidarity, but out of need. While these interplays allow migrants to informally participate in the 
formal social protection system, such practices are embedded within power relationships that are at times risky, especially for migrants. A transnational approach evidenced that accessing formal social protection is not only problematic for the undocumented but also for highly-skilled documented migrants with transnational aims (e.g. caring for sick relatives back home). Although documented and undocumented migrants engage in symbiotic relations with formal institutions, achieving an equally beneficial relation for both parties is marked by unbalanced power relations, which are related to the migrants' legal status.

Chapter 8 investigates what kinds of considerations underlie the decisions of migrants and their families to move to certain places for their social protection needs. The chapter draws on the life-stories of a Sudanese transnational extended family based in the Netherlands, the UK and Sudan and whose members are scattered across multiple countries, and uses a transnational approach to analyse the mechanisms guiding the access, circulation and coordination of different resources to cover for different but related social protection domains. The findings suggest that it is not the lack of formal social protection in the first host country to trigger onward movements, but the lack of possibilities for people to arrange their own and their families' social protection when such families are extended and located in multiple nation-states. People with an extensive history of mobility or with a highly geographically-scattered family network especially face insecurities when it comes to securing their social security benefits, in that, in moving to another country, such social security rights might cease to exist. Thus, people for whom mobility is part of their lives and future plans, securing their social security through geographically-fixed institutions is problematic. Therefore, it is deemed safer to invest in people (e.g. children) and other assets that can be easily accessed and circulated (e.g. education) across time and space.

The last empirical chapter (9) focuses on the concept of care as a key element in social protection arrangements within transnational family networks, based on a system of reciprocity. It investigates how female care-receivers in transnational social protection arrangements circumvent the unwanted consequences of unsolicited care provided by their male relatives abroad. This chapter examines the agency and strategies of three different migrant and non-migrant women to manoeuvre the reception of unwanted care while avoiding conflict with their relatives and gaining control of their own and their children's bodies. One of the main findings is that, in relationships with bigger differences in power (such as gender relations), agreeing on what 'need' means and how to provide for such needs becomes more difficult, especially when such relationships take place across socio-culturally and geographically distant places. Those perceived as vulnerable might have limited control over how their needs should be met and therefore suffer the consequences of unsolicited care. The multisited matched-sample methodology allowed for a better understanding of the complex power dynamics reflected in caring relationships, and revealed how wellintended but unsolicited care can be an additional burden for the care-recipient. The chapter further points out that in transnational social protection arrangements care- 
receivers are not just passive actors. On the contrary, care-receivers do play an active role in protecting themselves against the consequences of care. Different factors (e.g. geographical distance, the strength of the welfare state and the wish to avoid family conflict) shape the ways in which the female care-receivers engage in negotiations and exercise their agency to shape the reception of care in different ways.

\section{Conclusions}

This dissertation contributes to the studies of migration and transnational social protection in four different ways:

\section{1) Evidencing the importance of contextualising transnational families and social protection in both receiving and sending countries.}

Considering the role of the extended family in the sending country and the sociocultural norms on how social protection is sustained across generations is crucial to interpret the findings on the mechanisms guiding the orchestration of social protection within transnational family networks. In contrast to most Western welfare systems, with a clear-cut compartmentalisation of social protection domains (e.g. pensions, healthcare, unemployment, or family support), the weak welfare system in Sudan, leaves most people fully dependant on informal support mechanism, in which different domains are closely intertwined. In the case of transnational families, this thesis shows that elements from formal welfare systems here combine with informal systems of support and reciprocity there, resulting in a high degree of intertwinedness between the different domains. It is precisely such intertwinedness that leads people to prioritize specific needs over others (e.g. investing on the children's education as an old-age pension that formal provisions may not be able to cover if the migrants return to Sudan). By including the sending country context and taking the extended family as the main analytical unit, this thesis shows the intertwined character of different social protection needs, and the crucial role of mobility and the strategic geographical distribution of individuals in the orchestration of social protection arrangements.

\section{2) Demonstrating the importance of moving beyond welfare-state-centred approaches to better understand the mechanisms of social protection for mobile populations.}

Addressing migration and social protection with the main focus on the receiving state reinforces the idea of labelling different types of migrants, depending on the 'entry' categories-e.g. labour migrants, refugees, asylum seekers, or undocumented migrants - and the specific welfare rights attached to them (Sainsbury 2006). This thesis brings together different types of migrants, and shows that, despite the different migration statuses, the current geographically-fixed welfare systems and the restrictive migration regimes limit the ways in which all of them might engage with transnational social protection practices. In doing so, this study contributes to the body of literature addressing the interactions between welfare states and migration regimes, which has mostly focused on how, under restrictive migration and welfare 
contexts, undocumented migrants must use different tactics to cover their basic needs (Ambrosini, 2012; Broeders \& Engbersen, 2007; Vasta, 2011; Wilmes, 2011). This thesis shows that also documented migrants and refugees are pushed to restore to different tactics to cover their own and their families' needs. Finally, by investigating the role that social protection plays in shaping peoples' decisions to move to another country, this thesis contributes to the current debates on migration and welfare. As opposed to the wide-spread idea of welfare shopping, this thesis shows that migrants' decisions to move or stay in a specific location are not based on the nation-state and its welfare system per se, but on their and their families' needs and how best to fulfil them, formally or informally, now and in the future. These movements do not necessarily mean moving to a country with a more generous welfare state, but to a country with the preferred resources, such as care, education or specific medical treatments, which are deemed necessary and have priority at a particular point in time from the perspective of the needs of the extended family.

\section{3) Contributing to the understanding of the working mechanisms of the 'resource environment'.}

The findings of the different empirical chapters contribute to the theorisation of this concept in two ways. On the one hand, the findings in Chapter 7 suggest that a person's resource environment includes not only the resources they are able to receive from formal and informal institutions, but also the services they can provide to statelinked institutions, who actively use migrants to achieve their own aims. This also points to the fact that not all resources-in principle, available to everyone-are equally accessible. In other words, availability and accessibility to resources depend on the migrant's capital (e.g. knowledge, skills, networks) and on the resources they can provide in return. Moreover, while certain formal state-provided resources might be available and accessible for individual migrants, they might not be the preferred option for the social protection of the family as a whole. On the other hand, until now 'resource environment' has been used to refer to the resources available to migrants in their sending and/or receiving countries (Levitt et al. 2017). By looking at the extended family, this thesis has pointed to the multi-national character of the resource environment, whereby a range of formal and informal resources must be accessible across different locations, from where they can be carefully circulated and coordinated.

\section{4) Elucidating the role of care in transnational social protection arrangements and family relations.}

The empirical chapters showed that care often acts as the trigger of multiple transnational social protection arrangements. Even when access to formal care is possible, socio-cultural norms about who should provide care and how, shape the way in which resources are accessed and circulated. The informal provision of intrafamilial care is more flexible, allows for covering different intertwined domains, and it binds family members together in a web of intergenerational reciprocity that 
expands over time and beyond the boundaries of nation states. Moreover, rather than looking at caregiving, this study has contributed to the literature of transnational families by analysing the role of women as care-receivers in transnational social protection arrangements within extended families. In doing so, this thesis shows that, just like caregiving, care-receiving is a highly gendered process, where conflict between caregivers and care-receivers is unavoidable because the definition of 'need' does not always satisfy both parties equally. 


\section{NEDERLANDSE SAMENVATtING}

In onze huidige, geglobaliseerde wereld, kiezen steeds meer mensen ervoor om te gaan wonen in een ander land dan hun eigen land, of worden ze daartoe gedwongen. Daardoor ontwikkelen ze banden en verantwoordelijkheden in meer dan één land bijvoorbeeld door in verschillende landen in hun levensonderhoud te voorzien, te investeren in huisvesting, te zorgen voor familieleden, of te sparen voor hun pensioen. De meeste sociale systemen richten zich echter op het voorzien van sedentaire populaties die gebonden zijn aan een bepaalde natiestaat. Door internationale migratie hebben migranten dientengevolge te maken met specifieke dilemma's om de behoeften ten aanzien van sociale bescherming van henzelf en hun families te verzekeren. Nieuwkomers hebben bijvoorbeeld wellicht geen sterke sociale netwerken. Gewoonlijk dienen ze verschillende jaren te wachten, voordat ze toegang krijgen tot het formele sociale beschermingssysteem in het gastland. Tegelijkertijd kunnen bijdragen ophouden te bestaan die zijn geleverd aan de sociale beschermingssystemen in hun land van herkomst, nadat ze in het nieuwe gastland zijn aangekomen en vice versa (Avato, Koettl, and Sabates-Wheeler 2009).

Zelfs wanneer sociale voorzieningen in het ontvangende land toegankelijk zijn, zijn migranten vaak verantwoordelijk voor de zorg voor hun families 'thuis', die in hun landen van herkomst vaak niet zijn gedekt door het sociale beschermingssysteem. In feite stopt internationale migratie niet noodzakelijkerwijs de verplichtingen en verantwoordelijkheden tussen familieleden die gescheiden van elkaar wonen (Bryceson and Vuorela 2002). In tegendeel: migratie wordt vaak beschouwd als een sociale beschermingsstrategie, teneinde nu en in de toekomst het welzijn van de verschillende familieleden te garanderen (Stark and Levhari 1982; Stark and Lucas 1988;). Op mondiaal niveau blijven wettelijke voorzieningen ten aanzien van het recht op sociale bescherming voor internationale migranten en hun families echter schaars. Derhalve moeten migranten een reeks strategieën ontwikkelen die formele en informele elementen vanuit verschillende instanties omvatten (bijv. de staat, de markten, organisaties in de derde sector of informele sociale netwerken) om de behoeften van henzelf en/of hun families af te dekken, die vaak verband houden met het voorzien in en ontvangen van zorg.

De kern van deze dissertatie is om te begrijpen hoe transnationale families laveren tussen de verschillende vormen van sociale bescherming, zowel lokaal als transnationaal. Om dit inzichtelijk te maken, heb ik mij gericht op de situatie van Soedanese migranten in Nederland en het Verenigd Koninkrijk en hun families in hun thuisland. In Europa vormen de Soedanezen een relatief recente groep migranten. Terwijl er veel onderzoek is gedaan naar 'oude groepen migranten', hebben slechts enkele studies zich gericht op recente migranten uit de Sahararegio uit Afrika in Europa. Dit is een belangrijk hiaat in de literatuur, aangezien nieuwe 
groepen te maken krijgen met andere migratie- en ontvangstcontexten, die gevolgen kunnen hebben voor de wijze waarop ze deelnemen aan verschillende transnationale sociale beschermingspraktijken (Grillo and Mazzucato 2008). Voor wat betreft de juridische en sociaaleconomische status zijn de Soedanezen een zeer heterogene groep die in de steekproef kan worden gediversifieerd, om beter inzicht te kunnen krijgen in hoe migranten met een verschillende juridische en sociaaleconomische status toegang verkrijgen tot sociale beschermingsmechanismen. Er zijn drie belangrijke redenen waarom de selectie op het Verenigd Koninkrijk en Nederland is gebaseerd. Ten eerste hebben veel Soedanezen in Nederland familieleden die van Nederland naar het Verenigd Koninkrijk zijn verhuisd, waardoor ik de sociale beschermingsmechanismen van drie natiestaten grensoverschrijdend kon behandelen. Ten tweede hebben beide landen verschillende systemen voor welzijnsen migratiebeleid. Daardoor wordt de rol duidelijker die richtlijnen spelen in de sociale beschermingsregelingen die ter beschikking van migranten staan. Tot slot is de Soedanese gemeenschap in het Verenigd Koninkrijk groter en bestaat deze langer dan in Nederland wat naar verwachting enig licht kon werpen op de rol van persoonlijke sociale netwerken.

Tegen deze achtergrond behandelt deze dissertatie het volgende onderzoeksvraagstuk: Hoe navigeren Soedanese migranten in Nederland en in het Verenigd Koninkrijk en hun families in het thuisland door hun sociale bescherming; zowel lokaal als grensoverschrijdend? Om deze vraag te beantwoorden, heb ik gedurende 14 maanden een multi-sited en gedeeltelijk matched-sample etnografie uitgevoerd in de drie contexten waaronder de migranten en hun families hun bestaan leidden - Nederland, het Verenigd Koninkrijk en Soedan. Er werd multi-sited onderzoek uitgevoerd met gebruik van semigestructureerd interviews, informele gesprekken met en observaties over 21 respondenten in Nederland, 22 respondenten in het Verenigd Koninkrijk en 19 van hun familieleden in Soedan of er werd gebruik gemaakt van matched-samples. Door op meerdere locaties onderzoek te doen naar verschillende familieleden, kon ik de complexiteit van het bieden van sociale bescherming in verschillende contexten ontrafelen, wanneer de middelen beperkt zijn.

De volgende paragrafen vormen een samenvatting van de belangrijkste bevindingen van de drie empirische hoofdstukken van deze dissertatie (hoofdstukken 7 - 9) en de belangrijkste theoretische bijdragen.

\section{Belangrijkste bevindingen}

Om het belangrijkste onderzoeksvraagstuk te beantwoorden, werden drie onderliggende vraagstukken geformuleerd en behandeld in de drie empirische hoofdstukken die zijn gebaseerd op gepubliceerde of ingediende onderzoeksartikelen. Het resterende gedeelte van deze paragraaf vormt een samenvatting van de belangrijkste bevindingen van deze hoofdstukken. 
In Hoofdstuk 7 wordt onderzocht hoe migranten zich door formele staatsgebonden sociale beschermingsvoorzieningen bewegen om zichzelf of hun families in het thuisland te onderhouden. Het hoofdstuk maakt het probleem inzichtelijker van de heldere scheiding tussen formele en informele sociale beschermingssystemen, die geen rekening houdt met hoe instanties in welvaartsstaten en migranten samenwerken in de nauwe ruimten van het formele en informele om te voorzien in nationale en transnationale sociale beschermingsbehoeften. Op basis van de in Nederland en Soedan verzamelde gegevens onderzoekt dit hoofdstuk hoe migranten soms symbiotische relaties aangaan met verschillende instanties van welvaartsstaten, zoals gemeenten, NGO's en andere immigratie-instanties, die op hun beurt vertrouwen op de ondersteuning van deze migranten voor het bieden van sociale bescherming aan mensen die anders buiten hun reikwijdte zouden verdwijnen. De analyse toont aan dat dergelijke relaties in werkelijkheid soms worden geïnitieerd door de instanties van het land, die, vanwege hun geografische onveranderlijkheid, niet bereid zijn om in de behoeften van mobiele mensen te voorzien. Deze bevinding suggereert dat lokale autoriteiten, NGO's en immigratie-instanties niet alleen vanwege compassie of solidariteit optreden, maar uit noodzaak. Terwijl deze interacties migranten de mogelijkheid bieden om informeel deel te nemen aan het formele sociale beschermingssysteem, zijn dergelijke praktijken verankerd binnen machtsrelaties die in voorkomende gevallen risicovol zijn; met name voor migranten. Een transnationale aanpak bewees dat toegang verkrijgen tot formele sociale bescherming niet alleen problematisch is voor de ongedocumenteerden, maar ook voor hoogopgeleide, gedocumenteerde migranten met transnationale doelen (bijv. zorgen voor zieke familieleden in het thuisland). Hoewel gedocumenteerde en ongedocumenteerde migranten symbiotische relaties aangaan met formele instanties, wordt het bereiken van een relatie die voor beide partijen bevorderlijk is, gemarkeerd door onevenwichtige machtsrelaties die betrekking hebben op de juridische status van de migranten.

Hoofdstuk 8 onderzoekt welk type overweging aan de beslissingen van migranten en hun gezinnen ten grondslag ligt om voor hun sociale beschermingsbehoeften naar bepaalde plaatsen te verhuizen. Het hoofdstuk schetst de levensverhalen van een Soedanese, transnationaal uitgestrekte familie die is gevestigd in Nederland, het Verenigd Koninkrijk en Soedan, en waarvan de leden zijn verspreid over meerdere landen, en past een transnationale aanpak toe voor het analyseren van de mechanismen die de leidraad vormen voor toegang, circulatie en coördinatie van verschillende resources voor het voorzien in verschillende, echter gerelateerde sociale beschermingsdomeinen. De bevindingen suggereren dat er in het eerste gastland geen gebrek aan formele sociale bescherming bestaat om de drang om verder te trekken te triggeren, maar het gebrek aan mogelijkheden voor mensen om hun eigen sociale bescherming en die van hun families te organiseren, wanneer dergelijke families verspreid zijn over en gevestigd zijn in meerdere natiestaten. Met name mensen die een uitgebreide historie van verspreide mobiliteit hebben, of die zich in een zeer 
verspreid geografisch familienetwerk bevinden, hebben te maken met onzekerheden, wanneer het gaat om het veiligstellen van hun sociale zekerheidsvoorzieningen in de zin dat door verhuizing naar een ander land, dergelijke sociale zekerheidsrechten mogelijk niet meer zullen bestaan. Dientengevolge is het problematisch voor mensen bij wie mobiliteit een deel van hun leven en toekomstplannen vormt, om hun sociale zekerheid door middel van geografisch onveranderlijke instanties veilig te stellen. Om die reden wordt verondersteld dat het beter is om gedurende langere tijd en op meerdere gebieden in mensen (bijv. kinderen) te investeren en in andere kwaliteiten die gemakkelijk toegankelijk zijn en gemakkelijk kunnen worden verspreid (bijv. onderwijs).

Het laatste empirische hoofdstuk (9) focust op het zorgconcept als kernelement in sociale beschermingsregelingen binnen transnationale familienetwerken, gebaseerd op een systeem van reciprociteit. Het onderzoekt hoe vrouwen die zorg ontvangen in transnationale sociale beschermingsregelingen, de ongewenste gevolgen van ongevraagde zorg omzeilen die wordt geboden door hun mannelijke familieleden in het buitenland. Dit hoofdstuk onderzoekt de macht en strategieën van drie verschillende migranten- en niet-migranten vrouwen om de ontvangst van ongewenste zorg te hanteren, terwijl een conflict met hun familieleden wordt vermeden en de zeggenschap over zichzelf en hun kinderen wordt verkregen. Eén van de belangrijkste bevindingen is dat in relaties met grotere machtsverschillen (zoals relaties tussen geslachten), het overeenkomen van wat 'behoefte' betekent en hoe er in dergelijke behoeften wordt voorzien, steeds moeilijker wordt; met name wanneer dergelijke relaties plaatshebben, verspreid over ver van elkaar verwijderde sociaal-culturele en geografische locaties. Degenen die als kwetsbaar worden aangemerkt, hebben mogelijk beperkte zeggenschap over hoe er in hun behoeften dient te worden voorzien en hebben daarom te lijden onder de gevolgen van ongevraagde zorg. De multi-sited matched-sample methodologie bood meer inzicht in de complexe machtsdynamiek die in zorgrelaties wordt weerspiegeld, en onthulde hoe goed bedoelde echter ongevraagde zorg een extra belasting voor de zorgontvanger kan zijn. In het hoofdstuk wordt er verder op gewezen dat in transnationale sociale beschermingsregelingen zorgontvangers niet alleen slechts passieve spelers zijn. Zorgontvangers spelen in tegendeel een actieve rol in de bescherming van henzelf tegen de gevolgen van zorg. Verschillende factoren (bijv. geografische afstand, de kracht van de welzijnsstaat en de wens om een familieconflict te vermijden) vormen de manier waarop de vrouwelijke zorgontvangers zich opstellen in onderhandelingen en hun macht uitoefenen om de ontvangst van zorg op verschillende wijzen vorm te geven.

\section{Conclusie}

Deze dissertatie draagt op 4 manieren bij aan migratiestudies en onderzoek naar transnationale sociale zekerheid: 
1) Het laat zien dat het noodzakelijk is om transnationale families en sociale zekerheid te contextualiseren in zowel thuis- als gastland.

Als men kijkt naar het mechanisme dat sociaal welzijn binnen transnationale families orkestreert is het cruciaal de rol van de grootfamilie in het thuisland en de sociaal-culturele normen met betrekking tot hoe sociale zekerheid over generaties wordt behouden in acht te nemen. In tegenstelling tot de meeste Westerse formele sociale beschermingsvoorzieningen, die verschillende domeinen binnen sociale zekerheid duidelijk categoriseren (pensioen, zorg, werkloosheid of familiesteun), maken de zwakke staatsgebonden sociale beschermingsvoorzieningen in Soedan mensen volledig afhankelijk van informele steunmechanismen, waarbinnen verschillende domeinen verstrengeld zijn. Als we kijken naar transnationale families, toont deze dissertatie aan dat welvaartssystemen hier worden gecombineerd met informele systemen van ondersteuning en reciprociteit daar, resulterend in een hoge mate van verstrengeling van de verschillende domeinen. Het is precies deze verstrengeling die mensen ertoe leidt om bepaalde behoeftes boven andere te stellen (b.v. investeren in onderwijs van de kinderen met pensioengeld, iets wat formele voorzieningen mogelijk niet kunnen dekken als de migranten terugkeren naar Soedan). Door het thuisland in de analyse op te nemen en de grootfamilie te behandelen als de analytische eenheid laat deze dissertatie het ineengestrengelde karakter zien van de verschillende benodigdheden aan sociale zekerheid. Bovendien laat het de cruciale rol van mobiliteit zien en de strategische geografische distributie van individuen binnen de orkestratie van voorzieningen van sociale zekerheid.

\section{2) Demonstreert het belang verder te kijken dan de hoe de staat sociale zekerheid} benaderd, zodat we het belang van mechanismen van sociale zekerheid beter kunnen begrijpen voor mobiele groepen.

Door enkel naar migratie en sociale zekerheid te kijken door de lens van het gastland, wordt het gebruik van labels bemoedigd die op verschillende typen migranten worden geplakt overeenkomstig hun reden tot immigratie - bijvoorbeeld arbeidsmigranten, vluchtelingen, asielzoekers of ongedocumenteerden - inclusief de verschillende rechten van sociale zekerheid die daarbij horen. Deze dissertatie brengt deze verschillende typen migranten samen en toont aan dat, ondanks de verschillende status die zij hebben, hedendaagse geografisch bepaalde welvaartssystemen en restrictief migratiebeleid de manier waarop deze migranten deelnemen in praktijken van transnationale sociale bescherming beperken. Dientengevolge, draagt deze studie bij aan de literatuur omtrent de interactie tussen welzijns- en migratiebeleid, die zich vooral gericht heeft op hoe onder streng migratie- en welzijnsbeleid ongedocumenteerde migranten verschillende strategieën moeten gebruiken om in hun basisbehoeften te kunnen voorzien. Bovendien toont deze dissertatie dat gedocumenteerde migranten en vluchtelingen ook verschillende strategieën gebruiken om in hun eigen en hun familie zijn behoeften te voorzien. Ten slotte, door de rol te onderzoeken die sociale bescherming speelt in besluitvorming 
omtrent internationale migratie, draagt deze dissertatie bij aan het huidige debat over migratie en sociale zekerheid. In tegenstelling tot het idee dat verschillende sociale zekerheid geshopt kan worden, laat deze dissertatie zien dan migranten hun besluit om te blijven of verhuizen niet per sé op de natiestaat en het welzijnsbeleid stoelen, maar op de familiebenodigdheden en hoe deze het best tegemoet te komen. Dit zowel formeel als informeel, zowel nu als in de toekomst. Deze migraties betekenen ook niet noodzakelijk dat naar een royale welvaartsstaat wordt verhuisd, maar naar een staat met de hulpbronnen die de voorkeur hebben, zoals zorg, onderwijs of bepaalde medische behandelingen, die nodig zijn en de prioriteit hebben gezien vanuit de behoeftes van de grootfamilie.

\section{3) Bijgedragen aan een beter begrip van hoe de mechanismen van de 'resource environment' werken.}

De bevindingen in de verscheidene empirische hoofdstukken dragen op 2 manieren bij aan theorievorming omtrent de 'resource environment'. Aan de ene kant laten de bevindingen gepresenteerd in hoofdstuk 7 zien dat de 'resource environment' van een individu niet alleen de hulpbronnen bevatten die zij ontvangen van formele en informele instituties, maar ook de diensten die zij kunnen leveren aan instituties die verbonden zijn aan de staat die migranten actief gebruiken om hun eigen doelen te bereiken. Dit toont ook aan dat niet alle hulpbronnen - die in principe voor iedereen beschikbaar zijn - even toegankelijk zijn. Met andere woorden, de beschikbaarheid en toegankelijkheid van die hulpbronnen is afhankelijk van het kapitaal van de migrant (b.v. kennis, vaardigheden en netwerken) en de hulpbronnen die zij terug kunnen geven. Bovendien, terwijl sommige formele hulpbronnen die door de staat worden geleverd beschikbaar en toegankelijk zijn voor individuele migranten, hebben zij mogelijk niet de voorkeur van de gehele familie als sociale voorziening. Aan de andere kant is de 'resource environment' tot heden gebruikt om de hulpbronnen aan te duiden die beschikbaar zijn voor migranten in thuis- en gastland. Door naar de grootfamilie te kijken heeft deze dissertatie het multinationale karakter van de 'resource environment' aangeduid, waarbij verschillende informele en formele hulpbronnen toegankelijk moeten zijn in verschillende locaties waarvan zij zorgvuldig gecirculeerd en gecoördineerd kunnen worden.

\section{4) Verhelderen van de rol die zorg speelt in transnationale sociale zekerheid en familierelaties.}

De empirische hoofdstukken laten zien dat zorg vaak als trigger fungeert van verschillende transnationale sociale beschermingsregelingen. Zelfs wanneer toegang tot formele zorg mogelijk is bepalen sociaal-culturele normen over wie zorg moet bieden en hoe deze zorg geboden moet worden de manier waarop hulpbronnen worden aangezocht en gecirculeerd. De informele voorziening van zorg binnen families is flexibeler, beslaat verschillende domeinen en verbind familieleden in een web van intergenerationele reciprociteit ongebonden aan tijd en ruimte. Bovendien, 
in tegenstelling tot te kijken naar zorgverlening, draagt deze studie bij aan de literatuur omtrent transnationale families door de rol van vrouwen als ontvangers van zorg en transnationale sociale zekerheid binnen de grootfamilie te bestuderen. Ten gevolge laat deze studie zien dat, net zoals zorgverlening, ontvangen van zorg een proces is dat in hoge mate gestuurd wordt door gender. Conflict tussen zorgverleners en ontvangers is onvermijdelijk omdat 'behoeftes' niet altijd hetzelfde geduid worden en niet altijd beiden partijen tevreden stelt. 



\section{RESUME DE LA THESE DE DOCTORAT EN FRANÇAIS}

Dans notre monde globalisé actuel, de plus en plus de personnes vivent au-delà des frontières nationales, développant des attaches et des responsabilités dans plus d'un État-nation, pour, par exemple, y gagner leur vie, investir dans la pierre, ou prendre soin de membres de leur famille dans leur pays d'origine. Toutefois, la plupart des systèmes de protection sociale formels traditionnels ont été conçus pour répondre aux besoins de populations sédentaires résidentes dans un seul pays. Cela pose un problème pour ceux dont le mode de vie et les responsabilités sont de plus en plus mobiles et dépassent les frontières nationales. Par exemple, les migrants récemment arrivés peuvent ne pas disposer de réseaux sociaux solides ; ils doivent souvent attendre plusieurs années avant d'avoir accès au système de protection sociale formel du pays d'accueil, alors que les contributions versées aux systèmes de protection sociale de leur pays d'origine sont susceptibles d'être interrompues après leur arrivée dans le pays d'accueil (Avato, Koettl, and Sabates-Wheeler 2009).

Même lorsque les services de protection sociale du pays d'accueil sont accessibles, les migrants sont souvent responsables de subvenir aux besoins de leurs familles restées en " origine », qui ne sont généralement pas couverts par les systèmes de protection sociale qui y ont cours. La migration internationale ne sépare pas nécessairement les obligations et les responsabilités des membres de familles vivant séparés (Bryceson and Vuorela 2002). Au contraire, plutôt qu'un projet individuel de maximisation des revenus en réponse à des situations d'urgence, la migration est souvent considérée comme une stratégie de subsistance familiale ou un mécanisme de protection sociale permettant de diversifier les sources de revenus, de faire face aux contraintes socio-économiques et de garantir le bien-être présent et futur des différents membres de la famille (Stark and Levhari 1982; Stark and Lucas 1988). Dans ce contexte, les migrants doivent élaborer une série de stratégies englobant des éléments formels et informels provenant de différentes institutions (États, marchés, organisations du tiers secteur ou réseaux sociaux informels) afin de couvrir leurs propres besoins de protection sociale et / ou ceux de leur famille, qui sont souvent liés à la provision et à la réception de soins.

Cette thèse examine la façon dont les migrants organisent leur propre protection sociale et celle de leurs familles restées dans le pays d'origine, localement et au-delà des frontières. Pour ce faire, j'ai choisi de me concentrer sur le cas spécifique des migrants soudanais aux Pays-Bas et au Royaume-Uni et de leurs familles au Soudan. Le cas soudanais est pertinent pour l'étude de la protection sociale transnationale pour deux raisons principales. Premièrement, les Soudanais constituent un groupe de migrants relativement nouveau en Europe. Aux Pays-Bas, par exemple, de nombreuses recherches ont été menées sur les « anciens groupes de 
migrants ", tels que les Marocains. Cependant, seules quelques études se sont concentrées sur les nouveaux migrants en provenance d'Afrique subsaharienne s'installant en Europe. Il s'agit d'une lacune importante dans la littérature, car ces nouveaux groupes sont confrontés à des contextes de migration et d'accueil différents, ce qui pourrait avoir une incidence sur la manière dont ils s'engagent dans différentes pratiques transnationales de protection sociale. Deuxièmement, en termes de statut juridique et socio-économique, les Soudanais forment un groupe très hétérogène. Cela permet de diversifier l'échantillon et de mieux comprendre comment les migrants de statuts juridiques et socio-économiques différents ont accès aux mécanismes de protection sociale. Le choix du Royaume-Uni et des Pays-Bas repose sur trois raisons principales. Premièrement, de nombreux Soudanais aux Pays-Bas ont des parents vivant au Royaume-Uni, dont certains sont partis au Royaume-Uni après avoir vécu aux Pays-Bas. Cela m'a permis d'aborder les mécanismes de protection sociale mis en place au-delà des frontières dans trois États (le Soudan, les Pays-Bas et le Royaume-Uni). Deuxièmement, les politiques migratoires et de protection sociale y sont distinctes, ce qui permet d'interroger leur rôle dans les arrangements de protection sociale élaborés par les migrants. Enfin, la communauté soudanaise au Royaume-Uni est plus grande et plus ancienne qu'aux Pays-Bas, ce qui devrait éclairer le rôle des réseaux sociaux personnels.

Dans ce contexte, cette thèse aborde la question de recherche suivante : Comment les migrants soudanais aux Pays-Bas et au Royaume-Uni et leurs familles au Soudan organisent-ils leur protection sociale, localement et au-delà des frontières? Cette thèse est basée sur des données collectées lors de 14 mois d'ethnographie multi-située conduite avec des migrants aux Pays-Bas et au Royaume-Uni, et leurs familles au Soudan. Cette recherche multi-sites a été menée à l'aide d'entretiens semi-structurés, de conversations et d'observations informelles auprès de 21 personnes aux Pays-Bas, 22 au Royaume-Uni et 19 membres de leur famille au Soudan.

Les sections suivantes résument les principaux résultats des trois chapitres empiriques de cette thèse (chapitres 7 à 9) et leurs contributions théoriques.

\section{Principales conclusions}

Pour répondre à la question de recherche principale, trois sous-questions ont été identifiées et abordées dans les trois chapitres empiriques, qui sont basés sur des articles de recherche publiés ou soumis. Cette section résume le contenu principal des chapitres empiriques de cette thèse et présente leurs principaux résultats.

Le chapitre 7 examine comment les migrants naviguent dans les dispositifs officiels de protection sociale liés à l'État pour subvenir de manière informelle à leurs besoins ou à ceux de leur famille dans leur pays d'origine. Le chapitre problématise la distinction entre les systèmes de protection sociale formels et informels, qui ignore les manières dont les institutions d'État providence et les migrants travaillent ensemble aux confins des dispositifs de protection sociale formels et informels pour répondre aux besoins nationaux et transnationaux en matière de protection sociale. Sur la base de données 
recueillies aux Pays-Bas et au Soudan, ce chapitre examine comment des migrants établissent parfois des relations symbiotiques avec différentes institutions de l'État providence, telles que les bureaux municipaux, des organisations non gouvernementales et d'autres institutions d'immigration, qui comptent sur le soutien de ces migrants pour fournir une protection sociale aux personnes qui autrement n'en bénéficieraient pas. L'analyse souligne le fait que parfois, de telles relations sont initiées par des institutions d'État qui, en raison de leur fixité géographique, ne sont pas prêtes à couvrir les besoins des personnes mobiles. Cette constatation suggère que les autorités locales, les ONG et les institutions d'immigration agissent non seulement par compassion ou par solidarité, mais aussi par nécessité. Si ces échanges permettent aux migrants, parfois sans papiers, de participer de manière informelle au système formel de protection sociale, de telles pratiques sont enchâssées dans des relations de pouvoir parfois risquées, en particulier pour les migrants. Une approche transnationale nous a permis de découvrir que l'accès à la protection sociale formelle n'était pas seulement problématique pour les sans-papiers, mais également pour tout migrant ayant des objectifs transnationaux (par exemple, s'occuper de parents malades chez eux). L'analyse montre en outre que, bien que les migrants de statut juridique différent semblent entretenir des relations symbiotiques avec les institutions officielles, la création d'une relation tout aussi bénéfique pour les deux parties est caractérisée par des relations de pouvoir déséquilibrées, liées au statut juridique des migrants.

Le chapitre 8 examine en particulier quels types de considérations sous-tendent les choix des migrants et de leurs familles de s'installer dans certains lieux pour leurs besoins de protection sociale. Pour ce faire, le chapitre s'inspire du récit de la vie d'une famille élargie transnationale soudanaise basée aux Pays-Bas, au Royaume-Uni et au Soudan et dont les membres sont dispersés dans plusieurs pays. Le chapitre utilise une approche transnationale pour analyser les mécanismes qui régissent l'accès, la circulation et la coordination de différentes ressources pour couvrir des domaines de protection sociale différents mais connexes. Contrairement à l'idée largement répandue que les migrants s'installent dans des pays dotés d'États de protection sociale plus généreux, le chapitre suggère que ce n'est pas le manque de protection sociale formelle dans le premier pays d'accueil qui déclenche de nouvelles mobilités, mais le manque de possibilités d'organiser sa propre protection sociale et celle de sa famille lorsque qu'elle est étendue et située dans plusieurs États-nations. Le chapitre montre que les personnes ayant de nombreux antécédents de mobilité ou un réseau familial très dispersé géographiquement sont confrontées à des difficultés quant à la sécurisation de leurs prestations de sécurité sociale, dans la mesure où, lors de leur déménagement dans un autre pays, ces droits sont susceptibles de cesser de s'appliquer. Pour les personnes dont la mobilité fait partie de la vie et de projets futurs, sécuriser une protection sociale par le biais d'institutions géographiquement fixes, est problématique. Par conséquent, il est jugé plus sûr d'investir dans les personnes (par 
exemple, les enfants) et dans d'autres actifs facilement accessibles et plus facilement mobiles (par exemple dans l'éducation) dans le temps et dans l'espace.

Le dernier chapitre empirique (9) aborde la notion de soin en tant qu'élément clé des dispositifs de protection sociale au sein des réseaux familiaux, reposant sur un système de réciprocité entre les migrants et leurs familles. Il examine comment les prestataires de soins de sexe féminin bénéficiant d'accords de protection sociale transnationaux contournent les conséquences non désirées des soins non sollicités fournis par leurs parents de sexe masculin à l'étranger. Ce chapitre examine l'agency et les stratégies de trois femmes migrantes et non migrantes pour gérer la réception de soins non désirés tout en évitant les conflits avec leurs proches et en prenant le contrôle de leur corps et de celui de leurs enfants. L'une des principales conclusions est que les soins ne sont pas toujours une bonne chose à recevoir. En particulier dans des relations avec des différences de pouvoir importantes, telles que le genre, il peut devenir plus difficile de s'entendre sur la signification du besoin, en particulier lorsque ces relations se déroulent dans des lieux culturellement et géographiquement éloignés. Les personnes perçues comme vulnérables peuvent avoir un contrôle limité sur la manière dont leurs besoins doivent être satisfaits et donc subir les conséquences de soins non sollicités. La méthodologie multi-située avec les migrants et leurs familles a permis de mieux comprendre les deux côtés de la dynamique de pouvoir complexe incarnée dans les différentes relations de soins, et a révélé comment des soins bien intentionnés mais non sollicités peuvent constituer un fardeau supplémentaire pour le bénéficiaire. Le chapitre souligne en outre que, dans les dispositifs transnationaux de protection sociale, les bénéficiaires de soins ne sont pas simplement des acteurs passifs. Au contraire, les femmes prestataires de soins jouent un rôle actif dans la protection contre les conséquences des soins. Le chapitre souligne différents facteurs (par exemple, la distance géographique, la force de l'État providence et le souhait d'éviter les conflits familiaux) qui déterminent la manière dont les femmes bénéficiaires des soins engagent des négociations et exercent leur agency pour influer sur la réception des soins par différents moyens.

\section{Conclusions}

Cette thèse a contribué - théoriquement et méthodologiquement - aux études sur la migration et la protection sociale transnationale de quatre manières différentes :

\section{1) Démontrer l'importance de la contextualisation des familles transnationales et de la protection sociale dans les pays d'origine et de destination.}

Examiner le rôle de la famille élargie dans le pays d'origine et les normes socioculturelles, dans la manière dont la protection sociale est maintenue d'une génération à l'autre a été crucial pour interpréter les résultats relatifs aux mécanismes guidant l'orchestration de la protection sociale au sein de réseaux familiaux transnationaux. Contrairement à la plupart des systèmes de protection sociale occidentaux, où les domaines de la protection sociale sont clairement 
compartimentés (comme les retraites, les soins de santé, le chômage ou l'aide à la famille), la faiblesse du système de protection sociale formel au Soudan laisse la plupart des personnes entièrement dépendantes du mécanisme de soutien informel, dans lequel différents domaines sont étroitement liés. Dans le cas des familles transnationales, cette thèse a montré que des éléments des systèmes de protection sociale formels des pays d'accueil se combinent avec des systèmes informels de soutien et de réciprocité des pays d'origine et produisent une grande interdépendance entre les différents domaines. C'est précisément cette interdépendance qui conduit les gens à donner la priorité à des besoins spécifiques (par exemple, investir dans l'éducation des enfants en guise de retraite future, que les dispositifs officiels de cotisation ne pourront peut-être pas couvrir si les migrants retournent au Soudan). En prenant en compte le contexte du pays d'origine et en élargissant notre unité d'analyse du migrant individuel à un réseau de familles élargies dispersées dans différents pays, cette thèse met en évidence le caractère inextricable de différents besoins de protection sociale, ainsi que le rôle crucial de la mobilité et du rôle de la distribution géographique stratégique des individus dans l'orchestration d'arrangements complexes de protection sociale.

\section{2) Démontrer l'importance de dépasser les approches centrées sur l'État providence pour mieux comprendre les mécanismes de protection sociale des populations mobiles.}

Traiter de la migration et de la protection sociale en mettant l'accent sur l'Etat-Nation de destination implique d' étiqueter différents types de migrants (migrants économiques, réfugiés et demandeurs d'asile, ou sans - papiers) et de sérier les droits et obligations qui leur sont rattachés (Sainsbury 2006). Dans cette thèse, j'ai réuni différents types de migrants et montré que, malgré des statuts différents, les systèmes de protection sociale actuellement fixés géographiquement et les régimes de migration restrictifs limitent les possibilités pour tous de s'engager dans des pratiques de protection sociale transnationale. Ce faisant, cette étude a contribué aux études traitant des interactions entre États providence et régimes de migration, principalement axés sur la manière dont, dans le contexte restrictif actuel en matière de migration et de protection sociale, les migrants sans-papiers doivent utiliser différentes tactiques pour couvrir leurs besoins fondamentaux (Ambrosini, 2012; Broeders \& Engbersen, 2007; Vasta, 2011; Wilmes, 2011). En adoptant une approche transnationale et en incluant les migrants avec des statuts juridiques différents, cette thèse a contribué à la recherche en montrant que les migrants réguliers et les réfugiés sont également incités à établir des tactiques différentes afin de couvrir leurs propres besoins et ceux de leurs familles. Enfin, en enquêtant sur le rôle que joue la protection sociale dans l'élaboration des prises de décision des gens pour se déplacer dans un autre pays, cette thèse a contribué aux débats actuels sur la migration et le bien être. En mettant l'accent sur l'accès des familles élargies à la protection sociale, cette thèse a montré que les décisions des migrants pour se déplacer ou rester dans un endroit précis ne sont pas basées sur l'État-nation et son système de protection 
sociale en soi, mais sur leurs besoins et ceux de leurs familles et sur la meilleure façon de les satisfaire, officiellement ou officieusement, maintenant et à l'avenir. Ces mouvements ne signifient pas nécessairement aller dans un pays doté d'un État social plus généreux, mais dans un pays disposant des ressources à privilégier, telles que les soins, l'éducation ou des traitements médicaux spécifiques, qui sont jugés nécessaires et prioritaires à un moment donné dans la perspective des besoins de la famille élargie.

\section{3) Contribuer à la compréhension du concept de 'resource environment' (environnement de ressources).}

Les résultats des différents chapitres empiriques contribuent à la théorisation du concept de 'resource environment' (environnement de ressources) de deux manières. D'un côté, les conclusions du chapitre 7 suggèrent que l'environnement des ressources d'une personne comprend non seulement les ressources qu'elle est en mesure de recevoir d'institutions formelles et informelles, mais également les services qu'elle peut fournir aux institutions liées à l'État, qui utilisent activement les migrants pour atteindre leurs propres objectifs. Cela indique que toutes les ressources - en principe, disponibles pour tous - ne sont pas également accessibles. En d'autres termes, la disponibilité et l'accessibilité des ressources dépendent du capital du migrant (par exemple connaissances, compétences, réseaux) et des ressources que les migrants eux-mêmes peuvent fournir en retour. En outre, bien que certaines ressources officielles fournies par l'État puissent être disponibles et accessibles pour des migrants individuels, elles pourraient ne pas être l'option privilégiée pour la protection sociale de la famille dans son ensemble. Cette thèse a mis en évidence que la disponibilité et l'accessibilité des ressources doit être analysée du point de vue de la famille, pas seulement du migrant. D'autre part, jusqu'à présent, le terme « resource environment » a été utilisé pour désigner les ressources disponibles pour les migrants dans leurs pays d'origine et / ou d'accueil (Levitt et al. 2017). En regardant la famille élargie plutôt que le migrant, cette thèse a souligné le caractère multi-national de l'environnement des ressources, dans lequel une gamme de ressources formelles et informelles doit être accessible dans différents endroits, d'où elles peuvent être distribuées et coordonnées avec soin.

\section{4) Élucider le rôle des prestataires de soin dans les dispositifs transnationaux de protection sociale et les relations familiales.}

Les chapitres empiriques de cette thèse ont montré que les soins sont souvent le déclencheur de multiples dispositifs de protection sociale transnationaux. Même lorsque l'accès aux soins formels est possible, les normes socioculturelles concernant les personnes qui doivent fournir les soins et comment, déterminent la manière dont les ressources sont accessibles et distribuées. La prestation informelle de soins intrafamiliaux est plus flexible, permet de couvrir différents domaines imbriqués et rassemble les membres de la famille dans un réseau de réciprocité 
intergénérationnelle qui s'étend au fil du temps et au-delà des frontières des Étatsnations. De plus, plutôt que de s'intéresser aux soignants, qui ont retenu l'attention dans la littérature des familles transnationales, cette étude a contribué à ce corpus de littérature en analysant le rôle de la femme en tant que bénéficiaire de soins dans les dispositifs transnationaux de protection sociale au sein des familles élargies. Ce faisant, cette thèse a montré que, tout comme la prestation de soins, recevoir des soins est un processus hautement sexospécifique, dans lequel un conflit entre soignants et bénéficiaires de soins est inévitable, car la définition du «besoin» ne satisfait pas toujours les deux parties de manière égale. 



\section{VALORISATION ADDENDUM}

This dissertation investigated how Sudanese migrants in the Netherlands and the UK and their families back home navigate different forms of social protection to cover for their needs locally and across borders. Nowadays more and more people live or are pushed to live away from their country of birth. In doing so, they develop attachments and responsibilities in more than one nation-state-for example, earning their livelihoods, making housing investments, caring for family members, or saving for their old-age in different countries. Yet, the traditional formal social protection systems have been envisaged to cater for sedentary populations, tied to a particular nation-state. Thus, even though migration has often been considered a social protection strategy for migrants and their families, this dissertation showed that, in fact, international migration might present mobile populations-especially those moving from the Global South to the North-with particular dilemmas for how to cover for their own and their families' social protection needs.

On the one hand, migrants move not only between countries, but also between differently regulated labour markets and social protection systems, with different institutionalised levels of formality and informality. Newly arrived migrants may lack strong social networks, and they usually have to wait several years before they have access, if at all, to the formal social protection system in the host country. At the same time, any contributions made to the social protection systems in their country of origin might cease to exist after arriving in the new host country, and vice versa.

On the other hand, migrants are often responsible for providing their families 'back home' in times of need - such as, the illness of a relative or the incapacity of an elderly person to provide for themselves. Supporting family members abroad, however, might become problematic. In this context, migrants and their families develop sophisticated strategies to cover for the social protection needs, through a combination of resources -provided by the state, the market, third-sector organisations and the family and other social networks - that are circulated in a coordinated fashion across two or more nation-states. It is within this backdrop that this thesis addresses how migrants and their families 'back home' make use of different forms of social protection to provide for each other's needs, both locally and transnationally.

This thesis addressed a highly pressing issue in the current context of increasingly restrictive migration regimes and shrinking welfare systems. The findings of this research suggest that two main aspects should be considered in the development of future policies on social protection for mobile populations, both in sending and receiving countries. These are explained below. 


\section{Exploring and investing in semi-formal arrangements.}

Despite the mixed results yielded by studies addressing the relationship between migration and a country's welfare system, the media, public opinion and political discourse continue to sustain the idea of 'welfare shopping'. In fact, migrants' useand misuse - of the welfare state in receiving countries has become a major concern for policy makers. This perception is partly due to the fact that in countries of the Global North, the welfare state is usually seen as the main (if not the only) provider of social protection. Therefore, most research and policies on migration and social protection have focused on addressing issues around the accessibility and portability of welfare benefits by migrants in the receiving countries, frequently overlooking other ways through which migrants navigate their social protection.

This thesis shows that the ways in which migrants access social protection often goes beyond the formal provisions of the receiving welfare state. Therefore, in moving towards a more inclusive and fair transnational social protection system, policy makers should consider the emergence and functioning mechanisms of semiformal institutions. In other words, in the provision of social protection across borders there is a need to look beyond the national welfare states of the receiving countries as the main source of social protection for mobile populations and activate new forms of network, involving actors that used to act separately, namely, statebased institutions, private and third sector actors, as well as with migrants themselves. The advantage of different formal and informal social protection actors working together (e.g. transnational healthcare organisations, where migrants join forces with NGOs, health insurance companies in the receiving country and healthcare providers in the origin country to cover for a number of relatives back home) is that they build on traditional community mechanisms to provide targeted social services to vulnerable groups, strengthening the links between governments and communities.

\section{Facilitating transnational family life and social protection arrangements.}

International migration does not necessarily sever the obligations and responsibilities between family members living apart (Baldassar, Baldock, and Wilding 2007; Bryceson and Vuorela 2002). On the contrary, rather than an individual project of income maximization in response to emergencies, migration is a family livelihood strategy or social protection mechanism to diversify income sources, face socioeconomic constraints, and guarantee the wellbeing of the different family members, now and in the future (Stark and Levhari 1982; Sabates-Wheeler and Waite 2003; Mazzucato and Schans 2011). Nevertheless, migrants who want to ensure their own and their families' social protection might face different challenges. Even when migrants enjoy full access to formal social protection provisions in the receiving country, migrants are often responsible for providing for the needs of their families 'back home', who might not be covered by the social protection system (if 
any) in their origin countries. At the global level, legal provisions regarding social protection rights for international migrants and their families remain scarce. In the past decades, bilateral social-security agreements between migrant-sending and migrant-receiving countries have become an important instrument to guarantee the portability of social security benefits for internationally mobile workers. Yet, very few developing countries are part of these agreements and only about $23 \%$ of international migrants profit from them (Holzmann, 2016). Moreover, supporting family members abroad becomes not only problematic but at times is even penalised. In the case of Sudan, which is the focus of this thesis, sending money through bank transfers is not allowed from the US and many European countries since the US introduced sanctions in 1997. Therefore, the current context of restrictive migration regimes and geographically-fixed national welfare systems often hinders the transnational character of migrants' lives.

Future development on transnational social protection for mobile populations should go beyond what migrants can access here and also consider the migrants' responsibilities towards those 'back home'. This thesis showed that even when the migrants' basic needs here are covered by the welfare state, their ability to provide for family members abroad continues to be limited, which has an impact on the migrants' wellbeing and often leads them to seek alternative means across formal and informal provisions beyond a single receiving state. For example, the (health-)care needs of the migrants' elderly parents back home often becomes a major source of problems for transnational families. Even when the family has the financial resources to pay for a private operation/medical treatment in Europe, visas are frequently rejected. The intervention, thus, has to be conducted in another country, which often results in pushing other family members to relocate. This might have an impact on the wellbeing of the migrants and their families. Some other times, when no other relatives are available, migrants must go and take care of their parents. In doing so, they must leave their jobs or stop their social assistance (e.g. receiving social assistance is bound to regular visits to the unemployment office). Policy developments towards a more inclusive social protection system that caters for the needs of increasingly mobile populations should acknowledge the important role of the migrants' families 'back home'. Understanding how social protection is arranged in the Global South - where extended families play a crucial role in the sustenance of individuals and communities - should inform any development towards a more inclusive social protection system, where the migrants' needs are linked to the needs of their families 'back home'. This does not mean that welfare states in the receiving countries should provide for the needs of the migrants' family members 'back home'. In fact, this would most likely proof to be unsustainable and could increase inequalities in the sending countries between those who have migrant relatives and those who do not. Yet, 'simple' measures, such as facilitating border crossings of transnational families (e.g. allowing adult children, siblings or elderly parents 'back home' to visit their migrant parents, siblings and children through special visas) could 
considerably improve the ways in which these families cover for their needs, especially those related to care.

\section{Dissemination activities}

During my fieldwork in Sudan, the Centre d'études et de documentation économiques, juridiques et sociales (CEDEJ) showed interest in my research and facilitated my fieldwork there. During this time I published a research post in their blog and participated in a seminar where local academics, journalists and other interested people took part. Through the CEDEJ, I was contacted by staff members of the EU External Action, with whom I met and explained the goal of the research. They were interested in my findings, and requested to be informed of any publication based on my data. Based on their interest and the relevance of my research for the current migration projects at the EU External Action in Sudan, I expect to produce a policy brief with the main findings and specific policy recommendations.

Upon my return from Sudan I was also contacted by the GSDRC, a UK-based think tank, with whom I collaborated in their report on Sudan (on-line publication). In September 2017 I was selected, among 25 other $\mathrm{PhD}$ to be part of a policy workshop at the METROPOLIS conference in The Hague, where I had the opportunity to present my research to different policy makers and NGO staff. Finally, in November 2017, I applied and obtained a valorisation grant by Maastricht University, whereby I intend to travel to Sudan to conduct three main follow-up activities. First, I will organise a seminar/colloquium at the CEDEJ where I can present my findings and contribute to the knowledge of this institute in the field of Sudanese studies, who supported and facilitated my fieldwork in Sudan. In discussion with the CEDEJ, I would like to extend the invitation to such event to researchers from Ahfad University for Women and Khartoum University, as well as to members of the EU External Action and the Sudanese-Dutch Association. The CEDEJ works closely with several Sudanese scholars, so this would be an excellent way to bring my findings to Sudan and interact with local experts in this regards. The Sudanese context, and in particular the transnational practices between Sudanese migrants in Europe and their families back home, has been largely under-researched, so this research contributes to partly filling in this gap. Second, with the support of the CEDEJ, I intend to organise a workshop on multi-sited methods for interested students. Finally, I will use part of my stay there to conduct preliminary research in preparation for a post-doc application. Based on the feedback I receive from these events I intend to write a policy brief, of interest to EU and Sudanese diaspora audiences, whereby the proposed activities will not only result in knowledge transfer but also knowledge creation. 


\section{ABOUT THE AUTHOR}

Ester Serra Mingot was born in January $10^{\text {th }}, 1984$ in Alcoi (Spain). In 2007 she graduated in Translation and Interpreting at the University of Alicante (Spain), with English, German and Arabic as her main foreign languages. In the following three years, she worked as a Spanish teacher in London, a conference interpreter in Barcelona, and a tour guide in Egypt and Jordan. In 2011 she obtained a Master in International Relations, Security and Development at the Universitat Autonoma de Barcelona (Spain), which led her to enrol in an Erasmus Mundus funded Master at Oldenburg University (Germany), Stavanger University (Norway) and Ahfad University for Women (Sudan). During this Master she travelled, studied, worked and conducted fieldwork in Sudan, on the challenges faced by Southern Sudanese women living in Khartoum after the secession of South Sudan. This time in Sudan gave her the opportunity to make use of and improve her Arabic skills, and learn Sudanese Arabic. She also conducted an internship at the UNHCR-Khartoum, were she worked with Congolese cases of asylum seekers and refugees.

After this Master, Ester worked in a consulting company for development, based in the UK and Kenya, and it was in October 2014 when she started her PhD at Maastricht University within the TRANSMIC project. 